\title{
PATIENT-SPECIFIC COMPUTATIONAL \\ MODELING FOR SPINAL CORD \\ STIMULATION THERAPY OPTIMIZATION
}

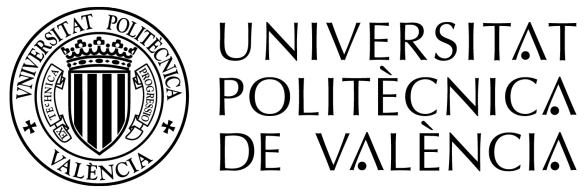

Ph.D. Thesis

Author:

Carmen Solanes Galbis

Supervisor:

Dr Francisco Javier Saiz Rodríguez

Center of Research and Innovation in Bioengineering

Departamento de Electrónica

Universitat Politècnica de València

September, 2021 



\section{PATIENT-SPECIFIC COMPUTATIONAL MODELING FOR SPINAL CORD STIMULATION THERAPY OPTIMIZATION}

Ph.D. in Technologies for Health and Well-Being

Author:

Carmen Solanes Galbis

Supervised by:

Dr Francisco Javier Saiz Rodríguez

Center of Research and Innovation in Bioengineering

Departamento de Electrónica

Universitat Politècnica de València

September, 2021 

This research work has been carried out under the Industrial Doctorate modality in the Universitat Politècnica de València (UPV), in collaboration with the company Biotecnología y Salud, S.L. for the realization of the following industrial project: Desarrollo y validación de modelos computacionales para el estudio de la neuroestimulación en el tratamiento del dolor crónico. 

"What would life be if we had no courage to attempt anything?" “QQué sería de la vida si no tuviéramos el valor de intentar hacer algo nuevo?”

Vincent Van Gogh 



\section{Acknowledgement}

When you drink water, remember the source

(Chinese proverb)

When you decide to do a $\mathrm{PhD}$, you have no idea what you are going to face. I'm not just saying this because of the academic learning it entails, but also for the personal growth you experience. Fortunately, when you enter this adventure, some people accompany you and smooth you the way; people you should never forget. That is why I want to take advantage of this moment to thank all of you for all your support because, besides helped me to carry out research work of which I am very proud, you turned me into a stronger person, in every way.

First of all, I want to thank two people who have been my pillars during these four years: Javier (my thesis supervisor) and José Luis (my boss and research teammate). To you, Javier, for agreeing to direct a doctoral thesis in a research field that was unknown to us, and also throughout the time you have invested in solving doubts, in correcting drafts, in helping me to publish articles and to give me moral support at key moments. But above all, I will always be very grateful to you for connecting me with José Luis from the beginning, because without that connection, neither this thesis would have existed, nor would I be the professional that I am now. And to you, José Luis, I have to thank you twice. On the one hand, for having allowed me to do this thesis in your company. Being first-hand in the operating room together with doctors and patients has been fundamental to understand clinical problems and address them from research, and it is what has 
given meaning to this research work. Besides, you have provided me with everything I have needed, whether it was congresses, ideas, material or your time and knowledge of the subject to design and review research articles. And, on the other hand, for joining me in the company. Thanks to this I have learned to be in contact with patients, to have great responsibilities, to be team-working, to know how to handle complicated situations, to make decisions intelligently and knowing how to work with all kinds of professionals (doctors, nurses, technicians, clerks, engineers, etc.). I honestly think I had tremendous luck to crossed paths with you, and I hope we continue to be a great team for a long time.

Secondly, to thank everyone who, in one way or another, has collaborated for this thesis to go forward. To Dr Jose De Andrés (head of the Anesthesia, Critical Care, and Multidisciplinary Pain Management Department of the Consorci Hospital General Universitari de València), for intervening in difficult moments, for all the messages of encouragement received and for collaborating in all the publications of this research work. To Dr $\mathrm{M}^{a}$ Ángeles Canós (head of the Pain Unit of the Hospital Universitari i Politècnic La Fe), for agreeing to carry out the research study with us with patients in your unit, facilitating the processing of the ethical consent, requests for MRIs, acquisition of intraoperative fluoroscopy images, and for all the confidence, encouragement and congratulations that I have received from you. To Dr Luis Martí-Bonmatí (head of Radiology Service of the Hospital Universitari i Politècnic La Fe), for accepting collaborate with us for the acquisition of resonance images; and to Joaquín Bosque Hernández (nurse of the Resonance Unit Magnetic), for readjusting with me the protocol for the images of resonance acquisition and for looking for a space to do the resonances before the implants. I also take the opportunity to thank Bea Trénor (program coordinator $\mathrm{PhD}$ in Health and Well-being Technologies of the Universitat Politècnica de València), for explaining to me what the Industrial Doctorate mention was, for allowing me to teach in the University Master's Degree in Biomedical Engineering and for all the encouragement. And, of course, to the entire team of the Pain Unit of the Hospital Universitari i Politècnic La Fe, thank you for all your support: to Dr Ruth Robledo, for being so close and affectionate, and for the encouragement that you have given me since we know each other, especially during confinement 
because you managed to excite me, raise my morale and give me even more desire to continue with the thesis; to Dr Ros Izquierdo, for being so honest with me and for teaching me to be more direct and clear, but always doing things from the heart and without losing the sense of humour; to Dr Ara Bermejo, for listening to me and explaining in detail what to do with complicated patients; to Pilar (secretary) and to the team of nurses and nursing assitants: Rebeca, Fuencis, Esther, Sonia, and Pilar, for all your honey and for facilitating the programming sessions with the patients, and specially to $\mathrm{M}^{a}$ José, for helping me to select and contact the patients of the study, notifying me any schedule change to adapt it with the resonance day; to Elisa (psychologist), for your support and for teaching me to speak with patients without frightening or alarming them; and also to scrub nurses: to Jovi, for brightening up the days in the operating room, for all the encouragement and for having such a big and humble heart; to Merche, for all the long talks in the operating room and for continuing to remember me even though you have retired; and to Mati, for be the joy of the operating room, necessary to work with enthusiasm and well at ease.

I would also like to give a special thanks to Gabi, my coworker and friend. You are a person with a lot of light (inadvertently, you leave a mark on others) and a great professional. Since I know you, you have taught me so many things: to program patients, to know how to talk to them, to know how to prevent, to be selfsufficient, to communicate more and, best of all, to learn from mistakes. Also, you always trusted me a lot and integrated me very well into all the hospitals. And, of course, you always encouraged me and supported me at all times. I feel very lucky to meet you and I hope to be able to continue learning much more from you.

To my best friend Rocio, and to her entire family (Rebeca, Chari, and Pepe), thank you for all the love and support you have given me, and continue to give me, since I was born. And, especially to you, Rocio, thank you for always counting on me, for helping me clear my mind and for understanding me when I said no to so many plans. Undoubtedly, I am extremely lucky to have you.

Fortunately, I have also had a person by my side who has been responsible that 
this thesis flowed constantly: my brother Juan Ernesto. I have to thank you for all the advice and experiences you told me, because that is what made me understand how the research world works to go, little by little, moving forward. Also, you were the person I talked to the most about the thesis and with whom I have shared more moments of nervousness, which has helped me to calm down and, again, to keep moving forward. You are a great example of resilience and honesty, values you convey to me. With all my heart, thank you for always being at my side.

Finally, thank my parents, Juan Ernesto and Angelita, for all their support and honey, but not only in these four years but throughout my life. To you, dad, because you are the one who teaches me to be mentally strong, to be humble, to fight for my dreams and the most important thing in life: to be happy, simply being what you are. To you, mom, for being my best friend, for not getting tired to listen to me and to worry about me not missing anything. Also give thanks to my sister, $\mathbf{M}^{a}$ Ángeles, for encouraging me in everything I do but, above all, for being another great example for me. You are a clear example of professionalism, responsibility, nerve and dedication at work and when you tell me what you see and what happens to you, I learn a lot from you. And I leave for the end to the one who always looks for me, waits for me, asks me questions, tells me how she feels and teaches me the most to live the moment; my great weakness: my niece Laura. I love the transparency you have to express everything. You are so sincere that, sometimes, I do not even know what to answer you. As an example, I stick with this dialogue: "Aunt, what letter are you going to school for?" "Me? I'm already going for the $z$ ! And you?" "For the $z$ yet? How easy! I'm going for the $y$ !" You know? You are right, I still have a lot to learn! But I do not lack desire and enthusiasm!

And you, Carmen, never forget what you learned from this experience:

\section{"Try again, fail again, fail better; for victory is always possible for one who refuses to surrender.”}




\section{Agradecimientos}

Cuando bebas agua, recuerda la fuente.

(Proverbio chino)

Cuando decides hacer un doctorado, no tienes ni la más remota idea de a qué te vas a enfrentar. No solo lo digo por el aprendizaje académico que conlleva, sino también por el crecimiento personal que experimentas. Por suerte, cuando te adentras en esta aventura, hay personas que te acompañan y te allanan el camino; personas que nunca debes olvidar. Es por ello que quiero aprovechar este momento para agradecerles todo su apoyo porque, además de haberme ayudado a realizar un trabajo de investigación del cual me siento muy orgullosa, me han convertido en una persona mucho más fortalecida, en todos los sentidos.

En primer lugar, quiero dar las gracias a dos personas que han sido mis pilares durante estos cuatro años: Javier (mi director de tesis) y José Luis (mi jefe y compañero de equipo de investigación). A ti, Javier, por aceptar dirigir una tesis doctoral en un campo de investigación que nos era desconocido, y también por todo el tiempo que has invertido en resolver dudas, en corregir borradores, en ayudarme a publicar artículos y en darme apoyo moral en momentos clave. Pero sobre todo, siempre te estaré muy agradecida por conectarme desde el principio con José Luis, porque sin esa conexión, ni esta tesis hubiera existido, ni yo sería la profesional que soy ahora. Y a ti, José Luis, te tengo que dar las gracias por partida doble. Por una parte, por haberme dado la oportunidad de realizar este trabajo de investigación en tu empresa. El estar de primera mano en quirófano junto con médicos y 
pacientes ha sido fundamental para entender los problemas clínicos y abordarlos desde la investigación, y es lo que le ha dado sentido a esta tesis. Además, me has facilitado cualquier cosa que he necesitado, ya fuera congresos, ideas, material o tu tiempo y conocimiento del tema para diseñar y revisar los artículos de investigación. Y por otra parte, por incorporarme en la empresa. Gracias a ello he aprendido a estar en contacto con pacientes, a tener grandes responsabilidades, a trabajar en equipo, a saber manejar situaciones complicadas, a tomar decisiones de forma inteligente y a saber trabajar con todo tipo de profesionales (médicos, enfermeros, técnicos, administrativos, ingenieros, etc.). Sinceramente, creo que he tenido una tremendísima suerte al haberme cruzado contigo, y espero que sigamos siendo un gran equipo por mucho tiempo.

En segundo lugar, agradecer a todos los que, de una forma u otra, han colaborado para que esta tesis saliera adelante. Al Dr. Jose De Andrés (jefe del Servicio de Anestesia y Reanimación del Consorci Hospital General Universitari de València), por intervenir en momentos complicados, por todos los mensajes de ánimos recibidos y por colaborar en todas las publicaciones de este trabajo de investigación. A la Dra. $\mathbf{M}^{a}$ Ángeles Canós (jefa de la Unidad del Dolor del Hospital Universitari i Politècnic La Fe), por aceptar realizar con nosotros el estudio de investigación con pacientes en tu unidad, facilitándome el trámite del consentimiento ético, las peticiones de las resonancias magnéticas, la adquisición de imágenes de fluoroscopía intraoperatorias, y por toda la confianza, ánimos y felicitaciones que he recibido por tu parte. Al Dr. Luis Martí-Bonmatí (jefe de Servicio de Radiología del Hospital Universitari i Politècnic La Fe), por aceptar colaborar con nosotros para la adquisición de las imágenes de resonancia; y en especial, a Joaquín Bosque Hernández (enfermero de la Unidad de Resonancia Magnética), por reajustar conmigo el protocolo de adquisición de las imágenes de resonancia y por buscar hueco para hacer las resonancias antes de los implantes. También aprovecho para darle las gracias a Bea Trénor (coordinadora del programa de Doctorado de Tecnologías de la Salud y el Bienestar de la UPV), por explicarme lo que era la mención de Doctorado Industrial, por darme la oportunidad de dar clase en el Máster Universitario de Ingeniería Biomédica y por todos los ánimos. Y, por supuesto, a todo el equipo de la Unidad del Dolor del Hospi- 
tal Universitari i Politècnic La Fe, daros las gracias por todo vuestro apoyo: a la Dra. Ruth Robledo, por ser tan cercana y cariñosa, y por los ánimos que me has dado desde que nos conocemos, especialmente durante el confinamiento, porque conseguiste emocionarme, subirme la moral y darme más ganas aún de seguir con la tesis; a la Dra. Ros Izquierdo, por ser tan sincera conmigo y por enseñarme a ser más directa y clara, pero siempre haciendo las cosas de corazón y sin perder el sentido del humor; a la Dra. Ara Bermejo, por escuharme y explicarme con detalle lo que hacer con los pacientes complicados; a Pilar (secretaria) y al equipo de enfermeras y auxiliares: Rebeca, Fuencis, Esther, Sonia y Pilar, por todo vuestro cariño y por facilitarme las sesiones de programación con los pacientes, y en especial a $\mathrm{M}^{a}$ José, por ayudarme a seleccionar y contactar con los pacientes del estudio, avisándome además de cualquier cambio de horario para cuadrarlo con el día de la resonancia; a Elisa (psicóloga), por tu apoyo y por enseñarme a hablar con los pacientes sin asustarles ni alarmarles; y también a los enfermeros instrumentistas: a Jovi, por amenizar los días de quirófano, por todos los ánimos y por tener un corazón tan grande y humilde; a Merche, por todas las largas charlas en quirófano y por seguir acordándote de mí aunque te hayas jubilado; y a Mati, por ser la alegría del quirófano, necesario para trabajar con ganas y bien a gusto.

Me gustaría también dar un especial agradecimiento a Gabi, mi compañero de trabajo y amigo. Eres una persona con mucha luz (sin querer, dejas huella en los demás) y un gran profesional. Desde que te conozco, me has enseñado muchísimas cosas: a programar a pacientes, a saber cómo hablarles, a saber prevenir, a ser autosuficiente, a comunicarme más y, lo mejor de todo, a aprender de los errores. Además, siempre has confiado mucho en mí y me has integrado muy bien en todos los hospitales. Y, por supuesto, siempre me has dado muchos ánimos y me has apoyado en todo momento. Me siento muy afortunada de conocerte y espero poder seguir aprendiendo mucho más de ti.

A mi mejor amiga Rocio, y a toda su familia (Rebeca, Chari y Pepe), agradecerles todo el cariño y apoyo que me han dado, y me siguen dando, desde que he nacido. Y, especialmente a ti, Rocio, gracias por contar siempre conmigo, por ayudarme a despejar la mente y por entenderme cuando te he dicho que no a tan- 
tos planes. Sin duda, tengo muchísima suerte de tenerte.

Afortunadamente, también he tenido a mi lado una persona que ha sido la responsable de que esta tesis fluyera constantemente: mi hermano Juan Ernesto. A tu he d'agrair-te tots els consells i experiències que m'has contat, ja que és el que $m$ 'ha fet entendre com funciona el món de la investigació per a anar, poc a poc, avançant. A més, eres la persona amb la que més he parlat de la tesi i amb el que més he compartit moments de nerviosisme, $i$ això $m$ 'ha ajudat a calmar-me $i$, de nou, a seguir avançant cap endavant. Eres un gran exemple de resiliència $i$ honestitat, valors que em transmets. De tot cor, gràcies per estar sempre al meu costat.

Por último, agradecer a mis padres, Juan Ernesto y Angelita, todo su apoyo y cariño, pero no solo en estos cuatro años, sino durante toda mi vida. A $t u$, papà, perquè eres el que m'ha ensenyat a ser forta mentalment, a ser humil, a lluitar pels meus somnis $i$, el més important de la vida: a ser feliç, simplement, sent el que eres. A tu, mamà, per ser la meua millor amiga, per no cansar-te d'escoltarme i per preocupar-te perquè no em falte de res. También darle las gracias a mi hermana, $\mathrm{M}^{a}$ Ángeles, por darme ánimos en todo lo que hago pero, sobre todo, por ser otro gran ejemplo para mí. Tu eres un clar exemple de profesionalitat, responsabilitat, nervi i dedicació en el treball $i$, quan em contes el que veus $i$ el que et passa, aprenc molt de tu. Y dejo para el final a la que siempre me busca, me espera, me pregunta, me cuenta lo que siente y la que más me enseña a vivir el momento; mi gran debilidad: mi sobrina Laura. De tu em quede amb la transparència que tens per a expressar-ho tot. De fet, eres tan sincera que, de vegades, no sé ni què contestar-te. Com a exemple, em quede amb aquest diàleg. "Tia, per quina lletra vas tu en el cole?" "Jo? Ja vaig per la z! I tu?" "Per la z de zapato encara? Què fàcil! Jo vaig per la y de yegua!”. Saps? Tens tota la raó, encara em queda molt per a aprendre! Però ganes i il.lusió no em falten!

I tú, Carmen, nunca olvides lo que has aprendido de esta experiencia:

"Vuelve a intentarlo, fracasa de nuevo, fracasa mejor; pues la victoria siem- 
pre es posible para quien se niega a rendirse." 



\section{Abstract}

Chronic pain disease has $35-50 \%$ of prevalence worldwide. In addition to the physical and emotional problems that the patients (and their social circle) have, the financial cost to society is huge. When drugs stop working, spinal cord stimulation (SCS) therapy is a non-drug alternative treatment for several conditions of chronic pain, such as neuropathic pain. In the last 40 years, SCS computational modeling has been the key tool to analyze and understand the effect of the stimulation parameters on neural response. However, the lack of realistic models limits the model-based predictions accuracy for SCS therapy optimization concerning the stimulation parameters management and the development of clinical applications.

This thesis presents three improvements in SCS modeling from cellular to organic levels:

- Cellular level: a human $\mathrm{A} \beta$ sensory myelinated nerve fiber model is shown. The model simulates the action potential creation and propagation of human sensory fibers produced by electrical stimulation. Moreover, to consider the current losses produced at the internodal compartments, a realistic myelin model is included.

- Organic level: two spinal cord volume conductor models are presented. The first one is a generalized SCS model, which is based on in vivo $3 \mathrm{~T}$ highresolution magnetic resonance images from the human spinal cord, solving then one of the main limitations of previous SCS models, which is the in- 
clusion of cadaveric measurements. The second one is a 3D patient-specific SCS model, which includes the entire spinal cord geometry variation of three different vertebral levels (T8, T9, and T10) from patients undergoing SCS treatment. This novel approach is validated clinically, showing that patient-specific modeling improves model-based predictions accuracy compared to generalized SCS models.

In addition to this, this thesis presents three studies related to SCS therapy by using the three computational models developed previously:

- Role of stimulation frequency: the investigation of the role of the stimulation frequency on sensory neural response is performed using the human $\mathrm{A} \beta$ sensory myelinated nerve fiber model. The outcome of this study showed that frequency could have a significant influence on the reduction or increase of the neuron activity, participating thus in the selection of the targeted neural elements in SCS therapy, in tonic stimulation.

- Effect of electrode polarity: using the 3D generalized SCS model, the effect of the most used and known polarities (bipolar, guarded cathode, and dual-guarded cathode) is shown. The results showed that, unlike guarded cathode, dual-guarded cathode maximized the activating area and depth in dorsal columns, also increasing the probability of activating dorsal roots fibers.

- Clinical applications: the pre-implantation selection of the electrode polarity was performed with the 3D patient-specific model. The findings showed that this clinical application could determine the electrode configurations that best overlapped paresthesia coverage to the painful dermatomes of the patient before the SCS device implant. On the other hand, the effect of offset electrodes was also investigated. In this case, the results revealed that staggered offset placement canceled the left- or right-activation displacement in the dorsal columns, suggesting that offset electrodes placement should be avoided in tonic stimulation. 


\section{Resum}

El dolor crònic es una enfermetat amb una prevalència d'entre el 35\% i el 50\% de la població mundial. A més dels problemas físics i emocionals que comporta en els pacients (i la gent del seu voltant), el cost financer que suposa per a la societat és enorme. Quan els fàrmacs deixen de fer efecte, la teràpia d'estimulació de mèdul-la espinal (EME) és una alternativa no farmacològica que s'usa per al tractament de diverses condicions de dolor crònic, com el dolor neuropàtic. En els últims 40 anys, el modelatge computacional de l'EME ha sigut la ferramenta clau per a analitzar i entendre l'efecte dels paràmetres d'estimulació elèctrica en la resposta neuronal. No obstant això, la falta de models realistes limita la precisió de les prediccions dels models per a l'optimizació de la teràpia d'EME, en referència a la programació dels paràmetres d'estimulació i el desenvolupament d'aplicacions clíniques.

Esta tesi presenta tres millores en el modelatge computacional de la teràpia d'EME, des del nivell cel-lular fins al nivell orgànic:

- Nivell cel-lular: es presenta un model de fibra mielínica $\mathrm{A} \beta$ sensitiva humana. El model simula la creació i propagació del potencial d'acció de fibres humanes sensitives que es produeix baix l'efecte d'un estímul elèctric. A més a més, amb la finalitat de considerar les pèrdues de corrent produïdes als compartiments internodals, la mielina es modela de forma realista.

- Nivell orgànic: es presenten dos models de conductor volumètric de mèdul-la espinal. El primer es tracta d'un model d'EME generalitzat, el qual es basa 
en imatges de ressonància magnètica de $3 \mathrm{~T}$ d'alta resolució de mèdul·la espinal humana obtingudes in vivo. Esta proposta resol una de les principals limitacions present en models d'EME anteriors, que és la inclusió de mesures geomètriques obtingudes de cadàvers. El segon model és un model tridimensional personalitzat al pacient, el qual inclou la variació de la geometria de la mèdul.la espinal en tres nivells vertebrals diferentes (T8, T9 i T10) a partir de pacients sotmesos al tractament d'EME. Aquesta innovadora proposta és validada clínicament, demostrant també que el modelatge computacional personalitzat millora la precisió de les prediccions del model en comparació a un model generalitzat.

A més, esta tesi presenta tres estudis relacionats amb la teràpia d'EME utilitzant els tres models desenvolupats prèviament:

- El paper de la frequiència d'estimulació: la investigació del paper de la freqüència d'estimulació en la resposta neuronal sensorial es realitza mitjançant l'ús del model de fibra mielínica $\mathrm{A} \beta$ sensitiva humana. Els resultats d'este estudi mostren que la frequiència podria tindre una influència significant en la reducció o augment de l'activitat de la neurona, participant així en la selecció dels elements neurals objectiu en la teràpia d'EME, en estimulació tònica.

- Efecte de la polaritat de l'elèctrode: usant el model 3D generalitzat d'EME, es mostra l'efecte de les polaritats més conegudes i utilitzades: bipolar, càtode guardat i doble-càtode guardat. Els resultats mostren que, a diferència del càtode guardat, la polaritat de doble-càtode guardat maximitza l'àrea $i$ profunditat d'activació en els cordons posteriors, augmentant també la probabilitat d'activar les fibres de les arrels dorsals.

- Aplicacions clíniques: usant el model 3D personalitzat al pacient, s'ha realitzat la selecció pre-implant de la polaritat de l'elèctrode. Els resultats mostren que esta aplicació clínica podria determinar les configuracions d'elèctrodes que millor solapen la cobertura de parestèsia amb els dermatomes dolorosos del pacient abans de l'implant del dispositiu d'EME. 
D'altra banda, també s'ha estudiat l'efecte de la posició esglaonada dels elèctrodes en el pacient. En este cas, els resultats revelen que el posicionament esglaonat cancel-la el desplaçament esquerre o dret de l'activació neuronal en els cordons posteriors, sugerint així que el posicionament esglaonat deuria evitar-se quan s'aplica l'estimulació tònica. 



\section{Resumen}

El dolor crónico es una enfermedad que tiene una prevalencia de entre el $35 \%$ y el 50\% de la población mundial. Además de los problemas físicos y emocionales que conlleva en los pacientes (y la gente de su alrededor), el coste financiero que supone para la sociedad es enorme. Cuando los fármacos dejan de hacer efecto, la terapia de estimulación de médula espinal (EME) es una alternativa no farmacológica que se usa para el tratamiento de diversas condiciones de dolor crónico, como el dolor neuropático. En los últimos 40 años, el modelado computacional de la EME ha sido la herramienta clave para analizar y entender el efecto de los parámetros de estimulación eléctrica en la respuesta neuronal. Sin embargo, la falta de modelos realistas limita la precisión de las predicciones de los modelos para la optimización de la terapia de EME, en referencia a la programación de los parámetros de estimulación y el desarrollo de aplicaciones clínicas.

Esta tesis presenta tres mejoras en el modelado computacional de la terapia de EME, desde el nivel celular hasta el nivel orgánico:

- Nivel celular: se presenta un modelo de fibra mielínica $\mathrm{A} \beta$ sensitiva humana. El modelo simula la creación y propagación del potencial de acción de fibras humanas sensitivas que se produce bajo el efecto de un estímulo eléctrico. Además, con el fin de considerar las pérdidas de corriente producidas en los compartimentos internodales, la mielina se modeliza de forma realista.

- Nivel orgánico: se presentan dos modelos de conductor volumétrico de 
médula espinal. El primero se trata de un modelo de EME generalizado, el cual está basado en imágenes de resonancia magnética de 3T de alta resolución de médula espinal humana obtenidas in vivo. Esta propuesta resuelve una de las principales limitaciones presente en modelos de EME anteriores, que es la inclusión de medidas geométricas obtenidas de cadáveres. El segundo modelo es un modelo tridimensional personalizado al paciente, el cual incluye la variación de la geometría de la médula espinal en tres niveles vertebrales diferentes (T8, T9 y T10) a partir de pacientes sometidos al tratamiento de EME. Esta novedosa propuesta es validada clínicamente, mostrando además que el modelado computacional personalizado mejora la precisión de las predicciones del modelo en comparación a un modelo generalizado.

Además de esto, esta tesis presenta tres estudios relacionados con la terapia de EME usando los tres modelos desarrollados previamente:

- El papel de la frecuencia de estimulación: la investigación del papel de la frecuencia de estimulación en la respuesta neural sensorial se realiza mediante el uso del modelo de fibra mielínica $\mathrm{A} \beta$ sensitiva humana. Los resultados de este estudio muestran que la frecuencia podría tener una influencia significante en la reducción o aumento de la actividad de la neurona, participando de este modo en la selección de los elementos neurales objetivo en la terapia de EME, en estimulación tónica.

- Efecto de la polaridad del electrodo: usando el modelo 3D generalizado de EME, se muestra el efecto de las polaridades más conocidas y usadas: bipolar, cátodo guardado y doble-cátodo guardado. Los resultados muestran que, a diferencia del cátodo guardado, la polaridad de doble-cátodo guardado maximiza el área y profundidad de activación en los cordones posteriores, aumentando también la probabilidad de activar las fibras de las raíces dorsales.

- Aplicaciones clínicas: usando el modelo 3D personalizado al paciente, se ha realizado la selección pre-implante de la polaridad del electrodo. Los 
resultados muestran que esta aplicación clínica podría determinar las configuraciones de electrodos que mejor solapan la cobertura de parestesia con los dermatomas dolorosos del paciente antes del implante del dispositivo de EME. Por otro lado, también se ha estudiado el efecto de la posición escalonada de los electrodos en el paciente. En este caso, los resultados revelan que el posicionamiento escalonado cancela el desplazamiento izquierdo o derecho de la activación neuronal en los cordones posteriores, sugiriendo así que el posicionamiento escalonado debería evitarse cuando se aplica la estimulación tónica. 



\section{Contents}

Acknowledgement $\quad$ ix

Agradecimientos xiii

Abstract

$\begin{array}{ll}\text { Resum } & \text { xxi }\end{array}$

$\begin{array}{lll}\text { Resumen } & \mathbf{X x v}\end{array}$

1 Introduction $\quad 1$

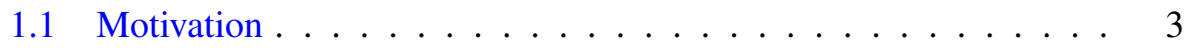

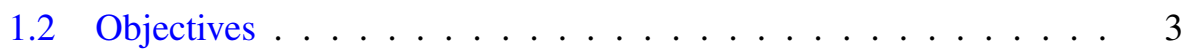

1.2.1 General objective .............. . . . . . . . . . . . 3

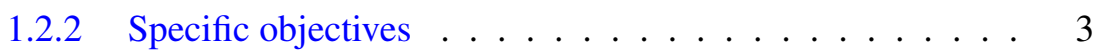

1.3 Manuscript Outline ................. 4

2 State of the art $\quad 7$

2.1 Chronic pain. Description, classification and treatments . . . . . 7

2.2 Spinal Cord Stimulation (SCS) therapy . . . . . . . . . . . . . 10

2.3 Stimulation parameters and SCS therapy concepts . . . . . . . . . 19

2.4 Myelinated nerve fiber models . . . . . . . . . . . . . 20

2.5 SCS computational models .............. 24

xxix 
3 SCS computational modeling. General methodology

4 Development of a human $A \beta$ sensory nerve fiber model 33

4.1 Motivation .................. 34

4.2 Nerve fiber model description . . . . . . . . . . . 35

4.2.1 Shape of the AP . . . . . . . . . . . . 37

4.2.2 Electrical behavior of the model . . . . . . . . . . . 44

4.2 .3 Sensitivity analysis . . . . . . . . . . . . . 47

4.3 The role of frequency on $\mathrm{A} \beta$ sensory nerve fibers activation in tonic stimulation. . . . . . . . . . . . . . . 52

4.3.1 Effect on nerve fiber activation . . . . . . . . . . 53

4.3.2 Patterns of activity and nerve fiber diameter . . . . . . . 58

4.4 Discussion .................... 60

4.4.1 New nerve fiber model . . . . . . . . . . . . . 60

4.4.2 Effect of frequency on nerve fiber activation . . . . . . . 64

4.4 .3 Limitations . . . . . . . . . . . . . . . 67

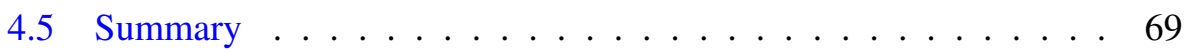

5 Development of a realistic generalized spinal cord volume conductor $\begin{array}{ll}\text { model } & \mathbf{7 1}\end{array}$

5.1 Motivation ................... 72

5.2 Generalized SCS model description . . . . . . . . . . 73

5.2.1 Myelinated nerve fiber model . . . . . . . . . . . 79

5.2.2 Model behavior . . . . . . . . . . . . . 81

5.3 Sensitivity analysis ................ 83

5.3.1 Geometric parameters of the spinal cord . . . . . . . . 83

5.3.2 Electrical conductivities of the spinal cord tissues . . . . . 87

5.3.3 Geometry and electrical conductivity of the stimulation electrode ................... 91

5.4 Effect of electrode polarity on neural activation in single-lead stim-

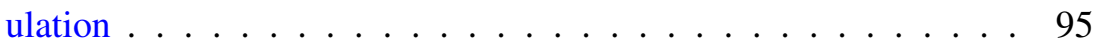

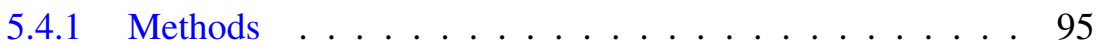


5.4.2 Simulation results ............... . . 97

5.5 Discussion ..................... 100

5.5.1 Limitations . . . . . . . . . . . . . . 103

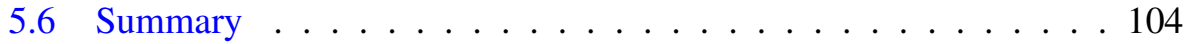

6 Development of a patient-specific spinal cord volume conductor model107

6.1 Motivation . . . . . . . . . . . . . . . . . . . . . 108

6.2 Workflow . . . . . . . . . . . . . . . 109

6.3 Patient-specific SCS model . . . . . . . . . . . . 110

6.4 Clinical restrospective proof-of-concept . . . . . . . . . . . 118

6.4.1 Methods ................. 118

6.4.2 Patient $1 \ldots \ldots . \ldots . \ldots . \ldots 119$

6.4 .3 Patient $2 \ldots \ldots \ldots \ldots \ldots$

6.5 Pre-implantation selection of the electrode polarity. Clinical application . . . . . . . . . . . . . . . . . 128

6.6 Effect of electrode offset . . . . . . . . . . . . . . 131

6.7 Discussion . . . . . . . . . . . . . . 132

6.7 .1 Limitations . . . . . . . . . . . . . 136

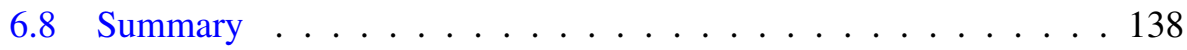

7 Conclusions and perspectives $\quad 139$

7.1 Contributions ..................... 139

7.1.1 On the development of a realistic human $\mathrm{A} \beta$ myelinated sensory nerve fiber computational model . . . . . . . 140

7.1.2 On the development of a realistic generalized spinal cord volume conductor computational model . . . . . . . . . 140

7.1.3 On the developement of a patient-specific spinal cord volume conductor model . . . . . . . . . . . . . . . . . . 141

7.2 Perspectives ...................... 142

7.2.1 Future research lines . . . . . . . . . . . . . . . 142

7.2.2 Future clinical applications . . . . . . . . . . 143 
8 Contributions $\quad 145$

A

A.1 Equations, geometric and electrical parameters of the $\mathrm{A} \beta$ human sensory myelinated nerve fiber model developed . . . . . . . . 151

B

B.1 Equations, geometric and electrical parameters of the Richardson, McIntyre and Grill (RMG) model B. . . . . . . . . . . . . . . . . 155

C

C.1 Dimensions of the generalized and patient-specific spinal cord models ..................... . . 159 


\section{List of Figures}

1.1 Limitations of SCS modeling and model-based predictions accuracy affectation. . . . . . . . . . . . . .

2.1 Gate-control theory of pain diagram [103]. Activation of small nerve fibers (unmyelinated C-fibers and myelinated $\mathrm{A} \delta$ fibers) produces gate opening and painful sensation is transmitted to the brain. On the contrary, activation of large nerve fibers (myelinated $\mathrm{A} \beta$-fibers) produces gate closing and pain signal is inhibited [137]. 11

2.2 Spinal cord anatomy. DC: dorsal column. . . . . . . . . . . 12

2.3 SCS therapy system. (a) Percutaneous electrodes of four and eight contacts connected to a non-rechargeable IPG (Prime, Medtronic). (b) Paddle electrodes (Medtronic). Image courtesy of Medtronic, Inc. (c) Rechargeable IPG (Intellis, Medtronic) and patient's controller. Image courtesy of Medtronic, Inc. IPG: implantable pulse generator. . . . . . . . . . . . . . . . 14

2.4 Surgical procedure of the SCS system. . . . . . . . . . 16

2.5 Nerve fiber models developed during the last 50 years. The blue colored nerve fiber models are based on the cable model. The yellow colored nerve fiber models are based on the double-cable model. . . . . . . . . . . . . . . . . . . 22 
2.6 Myelin models included in the nerve fiber models. Model A: perfect insulator. Model B: cable model, imperfect insulator. Model C: double-cable model, imperfect insulator. Figure modified from Gaines et al. [46] . . . . . . . . . . . . . . . . . . 23

2.7 SCS models from 1980 to 2021. Blue bubbles are models developed and used for studies about stimulation parameters effect on neural response. Red bubbles are models developed and used for studies about the effect of different stimulation types. Green squares are models developed with innovative features. Yellow squares are models developed by our research group. . . . . . . . 25

3.1 SCS computational model submodels and workflow. DC: dorsal column; PT: perception threshold; DT: discomfort threshold; AA: activating area; AD: activating depth; AP: action potential. . . . . 31

3.2 Evaluation parameters obtained from the SCS model. DC: dorsal columns; DR: dorsal roots; $\mathrm{PT}_{\mathrm{DC}}$ : perception threshold in $\mathrm{DC}$; $\mathrm{PT}_{\mathrm{DR}}$ : perception threshold in DR; DT: discomfort threshold; $\mathrm{AA}$ : activating area; AD: activating depth. . . . . . . . . . . 32

4.1 Electrical diagram of the developed sensitive nerve fiber model.

4.2 Methodology for rheobase (left) and chronaxie (right) values calculation. Electrode-to-axon distance: $500 \mu \mathrm{m}$; nerve fiber diame-

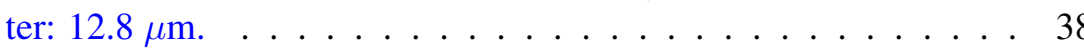

4.3 Methodology for RRP (left) and ARP (right) values calculation. ARP: absolute refractory period; RRP: relative refractory period. Electrode-to-axon distance: $500 \mu \mathrm{m}$; nerve fiber diameter: $12.8 \mu \mathrm{m} .40$ 
4.4 Simulated action potentials at $37^{\circ} \mathrm{C}$ obtained with the developed model (left). The horizontal line represents the rest potential considered $(-84 \mathrm{mV})$; and action potential propagation through two nodes of Ranvier and one internode located between them (right). A nerve fiber of $12.8 \mu \mathrm{m}$ in diameter was stimulated with a stimulus of $300 \mu$ s of pulse width and an amplitude of $1.2 \mathrm{~V}_{\text {th }}$. A separation of 6 nodes of Ranvier between the two nodes was selected to clearly see the action potential propagation. The internode that was just in the middle of the two selected nodes was the one whose action potential is represented in the graph. . . . . . .

4.5 Hyperpolarizing afterpotentials obtained with the Wesselink-HolsheimerBoom nerve fiber model (left), and the new nerve fiber developed (right). The curves of the models' response shown are semilog plot of the action potential. The electric response corresponds to a $12.8 \mu \mathrm{m}$-diameter nerve fiber stimulated with a $100 \mu \mathrm{s}$-duration monophasic rectangular pulse. Electrode is located $0.5 \mathrm{~mm}$ from the middle of the axon. . . . . . . . . . . . . . . . . . . 43

4.6 Conduction velocity for different fiber diameters (5.7-16 $\mu \mathrm{m})$ of the developed model, WHB model [159], MRG model [96], Gaines et al. model [46], and experimental data from Van Veen et al. [153] and Schalow et al. [126]. . . . . . . . . . . . . . . 45

4.7 Strength-duration curve of the developed model compared to WHB model [159], MRG model [96], Gaines et al. model [46], experimental data (Mogyoros et al. [105]) and clinical (Abejón et al.

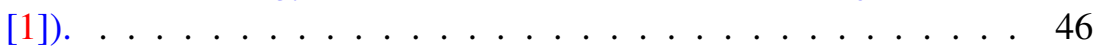


4.8 Current-distance (left) and current-diameter (right) relationships. Stimulus applied for the current-distance curve: cathodical rectangular monophasic pulse of $100 \mu \mathrm{m}$-duration. Nerve fiber diameter: $12.8 \mu \mathrm{m} ; \rho_{\text {ext }}: 300 \Omega \cdot \mathrm{cm}$. Stimulus applied for MRG motor nerve fiber model results [96]: cathodical rectangular monophasic pulse. Nerve fiber diameter: $10 \mu \mathrm{m} ; \rho_{\text {ext }}: 300 \Omega \cdot \mathrm{cm}$ (longitudinal) and $1200 \Omega \cdot \mathrm{cm}$ (transversal)). Stimulus applied for the currentdiameter curve: cathodical rectangular monophasic pulse of 100 $\mu$ m-duration. Electrode-to-axon distance: $500 \mu \mathrm{m}$. . . . . . . . .

4.9 Sensitivity analysis of AP (action potential) amplitude (left) and $\mathrm{CV}$ (conduction velocity) (right). All parameter values are expressed as multiples of default parameter value. All AP amplitude and $\mathrm{CV}$ values are normalized to their respective values obtained with default parameters. Default values: $\mathrm{g}_{\mathrm{m}}: 1 \mathrm{mS} \cdot \mathrm{cm}^{-2} ; \mathrm{c}_{\mathrm{m}}: 0.1$ $\mu \mathrm{F} \cdot \mathrm{cm}^{-2} ; \rho_{\text {ax }}: 70 \Omega \cdot \mathrm{cm} ; \rho_{\text {ext }}: 300 \Omega \cdot \mathrm{cm} ;$ AP amplitude: 108.5 $\mathrm{mV} ; \mathrm{CV}: 49.25 \mathrm{~m} / \mathrm{s} \ldots \ldots \ldots . \ldots . \ldots 48$

4.10 Sensitivity analysis of ARP (absolute refractory period) (left) and RRP (relative refractory period) (right). All parameter values are expressed as multiples of default parameter value. All AP amplitude and $\mathrm{CV}$ values are normalized to their respective values obtained with default parameters. Default values: $\mathrm{g}_{\mathrm{m}}: 1 \mathrm{mS} \cdot \mathrm{cm}^{-2}$; $\mathrm{c}_{\mathrm{m}}: 0.1 \mu \mathrm{F} \cdot \mathrm{cm}^{-2} ; \rho_{\mathrm{ax}}: 70 \Omega \cdot \mathrm{cm} ; \rho_{\mathrm{ext}}: 300 \Omega \cdot \mathrm{cm}$; ARP: $1.23 \mathrm{~ms}$; RRP: $2.42 \mathrm{~ms} \ldots \ldots \ldots \ldots \ldots$

4.11 Sensitivity analysis of chronaxie (left) and activation threshold (right). All parameter values are expressed as multiples of default parameter value. All AP amplitude and CV values are normalized to their respective values obtained with default parameters. Default values: $\mathrm{g}_{\mathrm{m}}: 1 \mathrm{mS} \cdot \mathrm{cm}^{-2} ; \mathrm{c}_{\mathrm{m}}: 0.1 \mu \mathrm{F} \cdot \mathrm{cm}^{-2} ; \rho_{\mathrm{ax}}: 70 \Omega \cdot \mathrm{cm}$; $\rho_{\text {ext }}: 300 \Omega \cdot \mathrm{cm}$; chronaxie: $103 \mathrm{~ms}$; activation threshold: $66.4 \mu \mathrm{A}$. 
4.12 Summary of the sensitivity analysis results at a) maximum, and b) minimum values of $\mathrm{g}_{\mathrm{m}}, \mathrm{c}_{\mathrm{m}}, \rho_{\mathrm{ax}}$, and $\rho_{\mathrm{ext}}$ values. The colormap represents the percentage of change in AP (action potential) amplitude, CV (comduction velocity), ARP (absolute refractory period), RRP (refractory relative period), chronaxie, and $\mathrm{V}_{\text {th }}$ (threshold stimulation). . . . . . . . . . . . . . . .

4.13 Electric response of a $12.8 \mu \mathrm{m}$ nerve fiber during a stimulus with a frequency of $50 \mathrm{~Hz}$ (left) and $350 \mathrm{~Hz}$ (right), and pulse width of $300 \mu \mathrm{s}$. The figures above show the stimulus pattern applied. The figures below show the action potential and the evolution of the gates' probabilities in the node 75 of the nerve fiber at each pulse stimulus. The amplitude applied is $1.2 \mathrm{~V}_{\text {th }}$ (threshold stimulus). Electrode is located at $0.5 \mathrm{~mm}$ from the middle of the axon. . . . .

4.14 Electric response of a $12.8 \mu \mathrm{m}$ nerve fiber during a stimulus with a frequency of $600 \mathrm{~Hz}$ (left) and $800 \mathrm{~Hz}$ (right), and pulse width of $300 \mu \mathrm{s}$. The figures above show the stimulus pattern applied. The figures below show the action potential and the evolution of the gates' probabilities in the node 75 of the nerve fiber at each pulse stimulus. The amplitude applied is $1.2 \mathrm{~V}_{\text {th }}$ (threshold stimulus). Electrode is located at $0.5 \mathrm{~mm}$ from the middle of the axon. . . .

4.15 Electric response of a $12.8 \mu \mathrm{m}$ nerve fiber during a stimulus with a frequency of $1000 \mathrm{~Hz}$ and pulse width of $300 \mu \mathrm{s}$. The figure above show the stimulus pattern applied. The figure below show the action potential and the evolution of the gates' probabilities in the node 75 of the nerve fiber at each pulse stimulus. The amplitude applied is $1.2 \mathrm{~V}_{\text {th }}$ (threshold stimulus). Electrode is located at 0.5 $\mathrm{mm}$ from the middle of the axon. . . . . . . . . . . . . .

4.16 Firing rate in function of stimulation frequency for 5.7 and 12.8 $\mu$ m-diameter nerve fiber when applying a pulse width stimuli of: a) $100 \mu \mathrm{s}$; b) $300 \mu \mathrm{s}$; and c) $500 \mu \mathrm{s}$. The nerve fibers are stimulated with a rectangular monophasic pulse, and an amplitude of $1.2 \mathrm{~V}_{\text {th }}$ (threshold stimulus). Electrode is located at $0.5 \mathrm{~mm}$ from the middle of the axon. . . . . . . . . . . . . . 
4.17 Electric response of a $12.8 \mu \mathrm{m}$ nerve fiber (left) and $5.78 \mu \mathrm{m}$ nerve fiber (right) during a stimulus with a frequency of $350 \mathrm{~Hz}$ and pulse width of $300 \mu \mathrm{s}$. The figures above show the stimulus pattern applied to $12.8 \mu \mathrm{m}$ nerve fiber (left) and $5.7 \mu \mathrm{m}$ nerve fiber (right). The figures of the right column show the action potential and the evolution of the gates' probabilities in the node 75 of the nerve fiber at each pulse stimulus. The amplitude applied is 1.2 $\mathrm{V}_{\text {th }}$ (threshold stimulus). Electrode is located at $0.5 \mathrm{~mm}$ from the

5.1 Measurements from a MRI of the human spinal cord. Image modified from Fradet et al. [42]. . . . . . . . . . . . . . . . . . . . . . 74

5.2 Generalized volume conductor model of the spinal cord. . . . . . 75

5.3 Tetrahedral adaptive mesh of the generalized spinal cord volume conductor model. Smaller edge length is used in the region of interest (grey matter, white matter, CSF) and small structures (dura mater, electrode). A larger edge length is used in the rest of the tissues (fat, bone). . . . . . . . . . . . . . 76

5.4 Nerve fiber distribution in the dorsal columns (DC) in the generalized volume conductor model. In the axial view, each blue point represents a nerve fiber in that position. . . . . . . . . . . 78

5.5 Nerve fiber distribution in the dorsal roots (DR) in the generalized volume conductor model. The figure above shows the definition of the $\mathrm{x}, \mathrm{y}$ and $\mathrm{z}$ axes in the model. The figures below show the spatial location of the surfaces of points (shown in red) where the 168 DR fibers are included in transverse (left), coronal (center) and sagittal (right) views. . . . . . . . . . . . . . .

5.6 a) Schematic diagram of myelinated nerve fiber and equivalent electric circuit. b. Action potential when the nerve fiber is stimulated at threshold stimulus (blue line) and at subthreshold stimulus (red line). . . . . . . . . . . . . . . . . . . 80 
5.7 a) Threshold stimulation as a function of dCSF thickness. Solid line: results obtained using our model. Dotted line: results from Holsheimer's group [56]. b) Threshold stimulation as a function of nerve fiber diameter. Solid line: results obtained using our model. Dotted line: results from Holsheimer's group [55]. . . . .

5.8 Sensitivity of perception threshold on $\mathrm{DC}\left(\mathrm{PT}_{\mathrm{DC}}\right)$, perception threshold on $\mathrm{DR}\left(\mathrm{PT}_{\mathrm{DR}}\right)$, activating area (AA), and activating depth (AD) to variations in antero-posterior (AP) diameter (left) and transversal (T) diameter (right) of the spinal cord. All parameter values are expressed as multiples of default parameter value. All $\mathrm{PT}_{\mathrm{DC}}, \mathrm{PT}_{\mathrm{DR}}, \mathrm{AA}$, and $\mathrm{AD}$ are normalized to their respective values obtained with default parameters. Default parameters: AP diameter: $6.5 \mathrm{~mm}$; T diameter: $9 \mathrm{~mm}$. Vertebral level: T9. Stimulation parameters applied: rectangular monophasic pulse; guarded cathode configuration; pulse width: $300 \mu \mathrm{s}$. . . . . . . . . . . 84

5.9 Sensitivity of perception threshold on $\mathrm{DC}\left(\mathrm{PT}_{\mathrm{DC}}\right)$, perception threshold on $\mathrm{DR}\left(\mathrm{PT}_{\mathrm{DR}}\right)$, activating area $(\mathrm{AA})$, and activating depth $(\mathrm{AD})$ to variations in cerebrospinal fluid (CSF) diameter, dorsal CSF (dCSF) thickness, and dura mater thickness. All parameter values are expressed as multiples of default parameter value. All $\mathrm{PT}_{\mathrm{DC}}, \mathrm{PT}_{\mathrm{DR}}, \mathrm{AA}$, and $\mathrm{AD}$ are normalized to their respective values obtained with default parameters. Default parameters: CSF diameter: $13.6 \mathrm{~mm}$; dCSF: $4.25 \mathrm{~mm}$; dura mater thickness: 0.3 $\mathrm{mm}$. Vertebral level: T9. Stimulation parameters applied: rectangular monophasic pulse; guarded cathode configuration; pulse width: $300 \mu$ s. . . . . . . . . . . . . . . . . . .

5.10 Summary of the sensitivity analysis results at a) maximum, and b) minimum values of $\varnothing \mathrm{AP}, \varnothing \mathrm{T}, \varnothing \mathrm{CSF}, \mathrm{dCSF}$ thickness, and dura mater thicknes. The colormap represents the percentage of change in $\mathrm{PT}_{\mathrm{DC}}$ (perception threshold in dorsal columns), $\mathrm{PT}_{\mathrm{DR}}$ (perception threshold in dorsal roots), AA (activating area), and AD (activating depth) $\ldots \ldots \ldots \ldots \ldots \ldots$. . . . . . . . 86 
5.11 Sensitivity of perception threshold on DC ( $\left.\mathrm{PT}_{\mathrm{DC}}\right)$, perception threshold on DR ( $\left.\mathrm{PT}_{\mathrm{DR}}\right)$, activating area (AA), and activating depth (AD) to variations in electrical conductivity of bone, fat, dura mater, and grey matter tissue. All parameter values are expressed as multiples of default parameter value. All $\mathrm{PT}_{\mathrm{DC}}, \mathrm{PT}_{\mathrm{DR}}, \mathrm{AA}$, and $\mathrm{AD}$ are normalized to their respective values obtained with default parameters. Default parameters: $\sigma_{\text {bone }}: 0.02 \mathrm{~S} / \mathrm{m} ; \sigma_{\text {fat }}: 0.04 \mathrm{~S} / \mathrm{m}$; $\sigma_{\text {dura mater }}: 0.03 \mathrm{~S} / \mathrm{m}$; $\sigma_{\text {grey matter: }} 0.23 \mathrm{~S} / \mathrm{m}$. Vertebral level: T9. Stimulation parameters applied: rectangular monophasic pulse; guarded cathode configuration; pulse width: $300 \mu$ s. . . . . . . . .

5.12 Sensitivity of perception threshold on $\mathrm{DC}\left(\mathrm{PT}_{\mathrm{DC}}\right)$, perception threshold on DR ( $\left.\mathrm{PT}_{\mathrm{DR}}\right)$, activating area (AA), and activating depth (AD) to variations in electrical conductivity of transversal white matter $\left(\mathrm{WM}_{\text {trans }}\right)$, longitudinal white matter $\left(\mathrm{WM}_{\text {long }}\right)$, and cerebrospinal fluid (CSF) tissue. All parameter values are expressed as multiples of default parameter value. $\mathrm{All}_{\mathrm{PT}} \mathrm{DC}_{\mathrm{DR}}, \mathrm{PT}_{\mathrm{DR}} \mathrm{AA}$, and $\mathrm{AD}$ are normalized to their respective values obtained with default parameters. Default parameters: $\sigma_{\mathrm{WM}_{\text {trans }}}: 0.083 \mathrm{~S} / \mathrm{m} ; \sigma_{\mathrm{WM}_{\text {long }}}: 0.6$ $\mathrm{S} / \mathrm{m} ; \sigma_{\mathrm{CSF}}: 1.7 \mathrm{~S} / \mathrm{m}$. Vertebral level: T9. Stimulation parameters applied: rectangular monophasic pulse; guarded cathode configuration; pulse width: $300 \mu \mathrm{s}$. . . . . . . . . . . . . . .

5.13 Summary of the sensitivity analysis results at a) maximum and b) minimum values of bone, fat, dura mater, CSF (cerebrospinal fluid), WM (transversal and longitudinal) (white matter), and GM (gray matter). The colormap represents the percentage of change in $\mathrm{PT}_{\mathrm{DC}}$ (perception threshold in dorsal columns), $\mathrm{PT}_{\mathrm{DR}}$ (perception threshold in dorsal roots), AA (activating area), and AD (activating depth). . . . . . . . . . . . . . 90 
5.14 Sensitivity of perception threshold on $\mathrm{DC}\left(\mathrm{PT}_{\mathrm{DC}}\right)$, perception threshold on $\mathrm{DR}\left(\mathrm{PT}_{\mathrm{DR}}\right)$, activating area $(\mathrm{AA})$, and activating depth (AD) to variations in electrical conductivity of poles, insulation, and electrode-tissue interface of the electrode. All parameter values are expressed as multiples of default parameter value. All $\mathrm{PT}_{\mathrm{DC}}, \mathrm{PT}_{\mathrm{DR}}, \mathrm{AA}$, and $\mathrm{AD}$ are normalized to their respective values obtained with default parameters. Default parameters: $\sigma_{\text {pole }}$ : $5.278 \cdot 10^{6} \mathrm{~S} / \mathrm{m}$; $\sigma_{\text {insulation }}: 0.002 \mathrm{~S} / \mathrm{m}$; $\sigma_{\text {interface }}: 0.15 \mathrm{~S} / \mathrm{m}$. Vertebral level: T9. Stimulation parameters applied: rectangular monophasic pulse; guarded cathode configuration; pulse width: $300 \mu \mathrm{s} . \ldots \ldots \ldots \ldots$. . . . . . . . . . . 92

5.15 Sensitivity of perception threshold on $\mathrm{DC}\left(\mathrm{PT}_{\mathrm{DC}}\right)$, perception threshold on $\mathrm{DR}\left(\mathrm{PT}_{\mathrm{DR}}\right)$, activating area (AA), and activating depth $(\mathrm{AD})$ to variations in electrode-tissue interface thickness and distance electrode-dura mater $\left(\mathrm{D}_{\mathrm{e}-\mathrm{d}}\right)$. All parameter values are expressed as multiples of default parameter value. All $\mathrm{PT}_{\mathrm{DC}}, \mathrm{PT}_{\mathrm{DR}}$, $\mathrm{AA}$, and $\mathrm{AD}$ are normalized to their respective values obtained with default parameters. Default parameters: electrode-tissue interface thickness: $0.1 \mathrm{~mm} ; \mathrm{D}_{\mathrm{e}-\mathrm{d}}: 0.1 \mathrm{~mm}$. Stimulation parameters applied: rectangular monophasic pulse; guarded cathode configu-

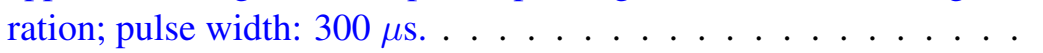

5.16 Summary of the sensitivity analysis results at a) maximum and b) minimum values of poles, insulators, and $\mathrm{I}_{\mathrm{e}-\mathrm{t}}$ (electrode-tissue interface) electrical conductivities, and $\mathrm{I}_{\mathrm{e}-\mathrm{t}}$ and $\mathrm{D}_{\mathrm{e}-\mathrm{d}}$ (electro-dura mater distance) thickness. The colormap represents the percentage of change in $\mathrm{PT}_{\mathrm{DC}}$ (perception threshold in dorsal columns), $\mathrm{PT}_{\mathrm{DR}}$ (perception threshold in dorsal roots), AA (activating area), and $\mathrm{AD}$ (activating depth). . . . . . . . . . . . . .

5.17 a) Dorsal roots and electrode modeling. Model dimensions: x: 45 $\mathrm{mm}, \mathrm{y}: 42 \mathrm{~mm}$, and z: $44 \mathrm{~mm}$. b) Geometric parameters of the lead size: contact length (a) is $3 \mathrm{~mm}$; insulator length (b) is $4 \mathrm{~mm}$; insulator length in the extremes (c) is $1.5 \mathrm{~mm}$ and lead diameter (d) is $1.3 \mathrm{~mm} \ldots \ldots \ldots \ldots \ldots$. . . . . . . . . . . . . . 96 
5.18 Single-lead polarities considered in this study. Positive symbols represent the anodes (positive voltage) and negative symbols represent the cathodes (negative voltage). Only four electrode contacts are represented because no more than four contacts are programmed. a) Bipolar 1 (B1). b) Bipolar 2 (B2). c) Guarded cathode (GC). d) Dual-guarded cathode (DGC). . . . . . . . . . . . . 98

5.19 Activating area and depth obtained in different single-lead polarities in the DC at different DTs (1.2PT $\mathrm{PC}_{\mathrm{DC}}, 1.4 \mathrm{PT}_{\mathrm{DC}}$, and $\left.1.8 \mathrm{PT}_{\mathrm{DC}}\right)$. Blue zones represent the nerve fibers that are not activated and red zones represent the activated nerve fibers. . . . . . . . . . .

6.1 Workflow for the developement of the patient-specific volume conductor model. . . . . . . . . . . . . . . . . . . . . 110

6.2 High-resolution MRI modalities of the spinal cord from T4 to L1 vertebral levels of a patient. CSF: cerebrospinal fluid. . . . . . . 111

6.3 Grey mater, white matter, CSF layer, and vertebral levels automatic segmentation results from SCS toolbox software in axial and sagittal views. MR images used: T2- and T1-weighted. GM: grey matter; PW: posterior width; WM: white matter; CSF: cerebrospinal fluid. . . . . . . . . . . . . . . . . 112

6.4 Vertebral bone segmentation process. . . . . . . . . . . 113

6.5 Patient-specific model in COMSOL Multiphysics ${ }^{\circledR}$. . . . . . . . . 114

6.6 Definition of the middle line in DC of the patient-specific model. Middle line is defined for the three vertebral level (T8 (red), T9 (green)and T10 (yellow)) manually in COMSOL Multiphysics ${ }^{\circledR}$. After assigning the points (in positions $\mathrm{x}, \mathrm{y}$ and $\mathrm{z}$ ) on the surface of the white matter of the previously defined middle line the rest of the nerve fibers are selected applying a lateral separation of 66$79 \mu \mathrm{m}$ (in x-axis) and a depth separation of $50 \mu \mathrm{m}$ (in y-axis). Each blue point of the DC represents a node of Ranvier of a nerve fiber in that position. . . . . . . . . . . . . 116 
6.7 DR nerve fibers distribution in the patient-specific model. The surfaces of the (red) points defined to include the DRs in a specific zone of the spinal cord (between T9-T10) is shown for transverse (left), coronal (center) and sagittal (right) views. DR: dorsal root. . 117

6.8 Left: intraoperative radiographies of the electrodes location after the second time surgery in AP (above) and lateral (below) views. Center: electrodes location in the generalized SCS model in AP (above) and lateral (below) views. Right: electrodes location in the patient-specific SCS model in AP (above, with bone and fat tissue hidden (left), and with dura mater and CSF also hidden (right) and lateral (below) views). AP: antero-posterior; SCS: Spinal Cord Stimulation. . . . . . . . . . . . . . . . . 120

6.9 Paresthesia coverage of patient 1. GC: guarded cathode; TGC: transverse guarded cathode. The striped green zones represent the zones where the patient feels a pleasant tingling sensation during stimulation. Left electrode: from pole 0 to pole 7 ; right electrode: from pole 8 to pole 15 . Vertebral level stimulated in both programs: T9. R: right; L: left. . . . . . . . . . . . . . . . . . . . 121

6.10 Evaluation parameter prediction in TGC and GC polarities. Red points represent activated nerve fibers. Blue points are not activated nerve fibers. White areas are zones with no nerve fibers considered. Stimulus applied: a rectangular pulse of $300 \mu \mathrm{s} \mathrm{du}-$ ration with an electrical strength of $1.357 \mathrm{PT}$ for GC polarity and 1.375 PT for TGC in V. Dashed line represents the central line of the spinal cord. TGC: transverse guarded cathode; GC: guarded cathode; PT: perception threshold. . . . . . . . . . . . . . . 123 
6.11 Paresthesia coverage of patient 2. The striped zones represent the anatomic location where the patient feels a tingling sensation during stimulation. Soft tingling (yellow): a slight tingling that is felt like the initial sensation that is produced when the perception threshold is achieved. Pleasant tingling (green): strong and comfortable sensation produced at a stimulus amplitude that is just below the discomfort threshold. Unpleasant tingling (red): discomfortable and painful sensation that is produced at (or above) the discomfort threshold. Left electrode: from pole 0 to pole 7 ; right electrode: from pole 8 to pole 15 . R: right; L: left. . . . . . . 125

6.12 Evaluation parameter prediction for patient 2. Red points represent activated nerve fibers. Blue points are not activated nerve fibers. White areas are zones with no nerve fibers considered. Stimulus applied: a rectangular monophasic pulse of $300 \mu \mathrm{s} \mathrm{du}-$ ration with an electrical strength of $1.13 \mathrm{PT}$ for program 1 in V; 1.24 PT for program 2; and 1.22 PT for program 3. Dashed line represents the central line of the spinal cord. . . . . . . . . .

6.13 Activation area and depth at ideal electrode position in the $3 \mathrm{D}$ patient-specific model of patient 1. TGC polarity. Red points represent activated nerve fibers, blue points not activated nerve fibers. White area represents zones with no nerve fibers considered. Stimulus applied: a rectangular monophasic pulse of 300 $\mu$ s duration with an electrical strength of $1.4 \mathrm{PT}$ in V. Vertebral bodies and fat tissues are hidden to highlight electrode polarity. Red poles are anodes and blue poles cathodes. Dashed line is the central line of the spinal cord. PT: perception threshold. Programmed poles for each case: Case 1: $5(+) 6(-) 7(+)$ and $14(+)$; Case 2: $4(+) 5(-) 6(+)$ and $13(+)$; Case 3: $3(+) 4(-) 5(+)$ and 12(+); Case 4: $2(+) 3(-) 4(+)$ and $11(+)$; Case 5: $1(+) 2(-) 3(+)$ and $10(+)$; Case 6: $0(+) 1(-) 2(+)$ and $9(+) \ldots . . . . . . . .129$ 
6.14 Electrode offset effect on activation area and depth. TGC polarity. Red points represent activated and blue not activated nerve fibers. White area represents zones with no nerve fibers considered. Stimulus applied: a rectangular monophasic pulse $300 \mu \mathrm{s}$ duration with an electrical strength of 1.4 PT in V. Programmed poles: $4(+), 5(-), 6(+)$ and $14(+)$. Red poles are anodes and blue poles cathodes. Vertebral bodies and fat tissues are hidden to highlight electrode polarity. Offset is generated by raising the right electrode position on the y axis by $3.5 \mathrm{~mm}$. Dashed line is the central line of the spinal cord. PT: perception threshold. . . . . . . 132

A.1 Squeme of the geometric parameters considered in the new sesory nerve fiber model. $D$ : axon diameter; $F_{d}$ : fiber diameter; $L$ : internodal length; $l$ : nodal length; $d$ : nodal diameter. . . . . . . . 152

C.1 Geometrical parameters of the spinal cord. $\varnothing \mathrm{T}$ : transversal diameter, $\varnothing \mathrm{AP}$ : anteroposterior diameter, $\varnothing \mathrm{T}$ : cerebrospinal fluid diameter, L: left, R: right, A: anterior; P: posterior and PW: posterior width. . . . . . . . . . . . . . . . . 160 



\section{List of Tables}

4.1 Electrical parameters of the developed sensory nerve fiber model. . 35

4.2 Characteristics of the Wesselink sensory nerve fiber model and experimentally determined characteristics of myelinated nerve fibers. Calculated values with monopolar stimulus of $100 \mu$ s of pulse width; $12.8 \mu \mathrm{m}$ nerve fiber diameter and $0.5 \mathrm{~mm}$ of distance between the electrode and the nerve fiber. DC: dorsal column; WM: white matter.

5.1 Tissue electrical conductivities considered in the conductor volume model of the spinal cord. . . . . . . . . . . . . . . 74

5.2 Boundary conditions and mesh resolution data of the generalized SCS model. . . . . . . . . . . . . . . . . . . . 77

5.3 Geometric parameters considered in the sensitivity analysis. Minimum and maximum values are taken from in vivo MRI measurements of the human spinal cord, T9 vertebral level [42]. . . . . . . 83

5.4 Tissue electrical conductivities considered for the sensitivity analysis. . . . . . . . . . . . . . . . . 87

5.5 Lead parameters considered for the sensitivity analysis. . . . . . . 91

5.6 Evaluation parameters values of single-lead stimulation with different polarities: B1 (bipolar 1), B2 (bipolar 2), GC (guarded cathode) and DGC (dual-guarded cathode). . . . . . . . . . . . . 97

6.1 Boundary conditions and mesh resolution data. . . . . . . 115 
6.2 Evaluation parameters obtained from the real patient 1, the generalized spinal cord model and the patient-specific spinal cord model. $\mathrm{PT}_{\mathrm{DC}}$ : perception threshold in $\mathrm{DC} ; \mathrm{PT}_{\mathrm{DR}}$ : perception threshold in DR; DT: discomfort threshold; $\mathrm{R}_{\mathrm{DC} / \mathrm{DR}}$ : recruitment ratio; AA: activating area; AD: activating depth. . . . . . . . . . . 122

6.3 Evaluation parameters obtained from the real patient 2, the generalized spinal cord model and the patient-specific spinal cord model. $\mathrm{PT}_{\mathrm{DC}}$ : perception threshold in $\mathrm{DC} ; \mathrm{PT}_{\mathrm{DR}}$ : perception threshold in DR; DT: discomfort threshold; $\mathrm{R}_{\mathrm{DC} / \mathrm{DR}}$ : recruitment ratio; AA: activating area; AD: activating depth. . . . . . . . . 126

6.4 Evaluation parameters obtained from the patient-specific spinal cord model. $\mathrm{PT}_{\mathrm{DC}}$ : perception threshold in $\mathrm{DC} ; \mathrm{PT}_{\mathrm{DR}}$ : perception threshold in DR; DT: discomfort threshold; $\mathrm{R}_{\mathrm{DC} / \mathrm{DR}}$ : recruitment ratio; AA: activating area; AD: activating depth. . . . . . . . 130

B.1 Geometric parameters of the nerve fibers. . . . . . . . 155

B.2 Electrical parameters of the RMG nerve fiber model B. . . . . . 156

C.1 Geometrical parameters of the generalized and patient-specific spinal cord model. The values used for the generalized models are extracted from Fradet et al. [42] . . . . . . . . . . . . . . . 159

C.2 Sensitivity analysis of excluding grey matter in the generalized volume conductor model. $\mathrm{PT}_{\mathrm{DC}}$ : perception threshold in $\mathrm{DC}$; $\mathrm{PT}_{\mathrm{DR}}$ : perception threshold in DR; DT: discomfort threshold (1.4 $\left.\mathrm{PT}_{\mathrm{DC}}\right) ; \mathrm{R}_{\mathrm{DC} / \mathrm{DR}}$ : recruitment ratio; $\mathrm{AA}$ : activating area; $\mathrm{AD}$ : activating depth. Stimulation parameters: guarded cathode $(5(+), 6(-), 7(+))$ and a rectangular monophasic pulse $300 \mu$ s duration. . . . . . . 160 


\section{Chapter 1}

\section{Introduction}

During the last four decades, several Spinal Cord Stimulation (SCS) computational models have been developed by many researchers. Generally, these models are aimed to understand the effect of the stimulation parameters on neural activation by computational simulation [23, 58, 60, 78, 93], to study the effect of the electrode design [54, 92], and even to make the hypothesis of the mechanisms of action that could be behind electrical stimulation for chronic pain treatment $[8,55$, 79]. However, although SCS computational modeling has been demonstrated to be an indispensable tool to improve the SCS device design and the programming parameters management in clinical practice, the model-based predictions accuracy are highly dependent on chronic pain neurophysiological knowledge and the available computational capability.

As shown in Fig. 1.1, SCS modeling is a combination of a nerve fiber model with a volume conductor model of the spinal cord.

First, the knowledge of the neurophysiological mechanisms of action involved in SCS therapy determines the neural structure to be stimulated, and therefore, the nerve fiber model to be used. At the same time, the nerve fiber model is developed according to the type of neuron to be modeled, thus the model accuracy depends on the available experimental data to compare the model results, the considered ionic channels that participate in the creation of the action potential, and the in- 


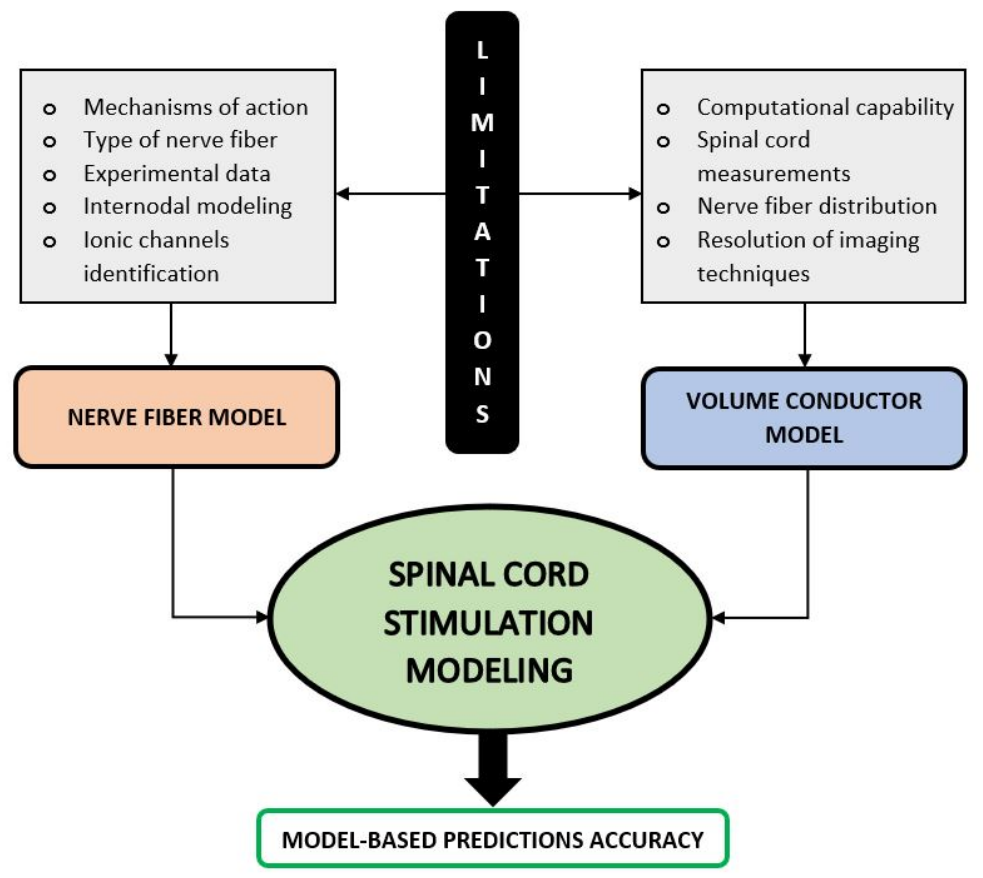

Figure 1.1: Limitations of SCS modeling and model-based predictions accuracy affectation.

ternodal model included.

On the other hand, the spinal cord volume conductor model is developed from spinal cord measurements, then the model realism depends on the resolution of the magnetic resonances images. Moreover, the accuracy of the electric field distribution prediction accuracy strongly depends on the computational capability. Lastly, this model also depends on the available histological data of the nerve fiber distribution in human dorsal columns, since it determines the size and locations of the nerve fibers in the dorsal columns of the spinal cord volume conductor model.

Therefore, SCS modeling evolves as science progresses and technology im- 
proves, leading to more accurate model-based predictions to enhance SCS therapy for chronic pain treatment. This demonstrates the interest this field of research awakes not only in the academic community but also in society in general.

\subsection{Motivation}

Current SCS models are still based on cadaveric measurements of the spinal cord, and most of them also use nerve fiber models that are too complex, include unrealistic internodal model or do not represent the electrical behavior of human sensory nerve fibers, which limit the model-based predictions accuracy. However, the increase of available experimental data for both nerve fiber characterization and spinal cord measurements as well as the increase of the computational capability allow to develop more realistic and sophisticated SCS models. This opportunity has motivated us to accomplish the present work.

\subsection{Objectives}

\subsubsection{General objective}

This thesis aims to develop a realistic three-dimensional SCS computational model to study the effect of the stimulation parameters on neural activation and perform clinical applications that help to improve and optimize SCS therapy.

\subsubsection{Specific objectives}

To achieve the main goal of this work, this thesis focuses on:

- The developement of a realistic human $\mathrm{A} \beta$ myelinated sensory nerve fiber computational model.

- The development of a realistic generalized spinal cord volume conductor computational model. 
- The development of a patient-specific spinal cord volume conductor model.

\subsection{Manuscript Outline}

This manuscript is compound of 8 chapters, including the introductory, the conclusions, and the contributions list chapters. After the introductory chapter, it starts by describying chronic pain disease and spinal cord stimulation therapy concepts, and reviewing the state of the art in nerve fiber models and spinal cord volume conductor models for SCS computational modeling. Then, the new approaches to improve model-based predictions in SCS therapy are proposed from cellular level (nerve fiber model) to organic (spinal cord volume conductor model), performing computational studies that present new strategies to optimize SCS therapy in clinical scenario.

- Chapter 2. State of the art: in this chapter, a brief introduction of chronic pain disease opens to a broad spinal cord stimulation therapy description, from the different types of the system components to the detailed description of the surgery procedure and the associated complications. Then, state of the art focused on spinal cord stimulation computational modeling, including both nerve fiber models and spinal cord volume conductor models evolution, is presented.

- Chapter 3. SCS computational modeling. General methodology: in this chapter, the general methodology applied in the computational studies performed in this work for the evaluation parameters calculation, using a nerve fiber model in combination with a spinal cord volume conductor model, is described.

- Chapter 4. Developement of a human A $\beta$ sensory nerve fiber model: in this chapter, a new human sensory nerve fiber model is shown, Solanes et al. [133], which solves the problem of the unrealistic myelin representation that previous sensory nerve fiber models present, and reduces the computational complexity. The model-based action potential characteristics measurements and the generation of the strength-duration, conduction velocity-diameter, 
current-distance, and current-diameter relationships are performed to analize the electrical behavior matching to human sensory fibers experimental data. Then, the sensitivity analysis showed the parameters that are most sensitive to changes in myelin model paramaters and axonal and external resistivities. A computational study is then performed to investigate the role of frequency in tonic stimulation in SCS therapy, using the new sensory nerve fiber model described within this chapter.

- Chapter 5. Development of a realistic generalized spinal cord volume conductor model: in this chapter, a new realistic generalized spinal cord volume conductor model is proposed, Durá et al. [36], whose geometric parameters are based on in vivo spinal cord measurements from highresolution magnetic resonance images. A sensitivity analysis is also conducted to show the geometric and electrical parameters that most affect the model-based predictions. A comutational study is then performed to study the effect of the most used and known electrode polarities (bipolar, guarded cathode, and dual-guarded cathode) on neural activation in the dorsal columns of the spinal cord, Durá et al. [36], Solanes et al. [135] and Solanes et al. [134]. From the results, a new programming strategy is presented to control paresthesia coverage in clinical practice, Durá et al. [36].

The results shown in this chapter come from a work shared with other Ph.D. student: José Luis Durá Cantero. In Durá et al. publication [36], it is clearly stated that José Luis Durá and Carmen Solanes contributed equally to this work.

- Chapter 6. Development of a patient-specific spinal cord volume conductor model: in this chapter, a new detailed 3D patient-specific spinal cord volume conductor model is proposed to enhance model-based predictions accuracy and to perform future clinical applications. After the model description, two 3D patient-specific SCS models are developed from two patients undergoing SCS therapy. In addition to this, the model-based predictions are compared to both the clinical data from the two patients and the generalized SCS model-based predictions, showing the significant accuracy 
obtained with the 3D patient-specific SCS models. A clinical application is then proposed to perform a pre-implantation selection of the electrode polarity, which show the potential usefulness of the 3D patient-specific SCS model. Finally, the investigation of the effect of electrode offset on the displacement of neural activation and paresthesia coverage prediction is provided, Solanes et al. [136] and Solanes et al. [132].

- Chapter 7. Conclusions and perspectives: in this chapter, the degree of accomplishment of the objectives of this thesis is stated. Moreover, the perspectives, including the future research lines and clinical applications, are also disclosed.

- Chapter 8. Contributions: in this chapter, the publications achieved, the research awards obtained, and the projects guided during this doctoral period are listed. 


\section{Chapter 2}

\section{State of the art}

\subsection{Chronic pain. Description, classification and treat- ments}

Chronic pain (CP) is defined, according to pain duration, as persistent or recurrent pain that lasts or recurs for more than 3 or 6 months [150]. However, CP not only affects the patient's daily activity and quality of life (both as sensory and emotional problem), but it also affects his family and social circle [35].

The estimate prevalence of $\mathrm{CP}$ is between $35 \%$ and $50 \%$ worldwide [5]. In Europe, some studies have demonstrated that CP affects between $10 \%$ and $30 \%$ of the adult population $[35,152]$. Indeed, this condition has a prevalence of $16.6 \%$ among the general population in Spain [35]. So, in addition to the physical and emotional burden CP brings, in Europe the financial cost to society is huge, estimated at about $€ 570$ billion per annum (approximately 3\% of their gross domestic product (GDP)) [152].

There is a huge number of disorders that belong to the $\mathrm{CP}$ category. Therefore, a recent study has proposed a new $\mathrm{CP}$ classification in the International Classification of Diseases (ICD). This classification comprises the most common clinically 
relevant disorders, divided into the following 7 groups [150]:

\section{1. - Chronic primary pain:}

Chronic primary pain is pain in one or more anatomic regions associated with significant emotional distress or functional disability that cannot be better explained by another CP condition.

\section{2. - Chronic cancer pain:}

Pain is a frequent and debilitating accompaniment of cancer. Chronic cancer pain includes pain caused by the cancer itself (the primary tumor or metastases) and pain that is caused by the cancer treatment (surgical, chemotherapy, radiotherapy, and others).

\section{3. - Chronic postsurgical and posttraumatic pain:}

This is pain that develops after a surgical procedure or a tissue injury (trauma, burns) and persists at least 3 months after surgery or tissue trauma. The diagnosis of neuropathic pain requires a history of nervous system injury (nerve trauma, stroke or diabetic neuropathy) and a neuroanatomically plausible distribution of the pain.

\section{4. - Chronic neuropathic pain:}

Chronic neuropathic pain is caused by a lesion or disease of the somatosensory nervous system. The somatosensory nervous system provides information about the body including skin, musculoskeletal and visceral organs.

\section{5. - Chronic headache and orofacial pain:}

Chronic headache and orofacial pain is defined as headaches or orofacial pains that occur at least $50 \%$ of the days during at least 3 months. The most common chronic orofacial pains are temporomandibular disorders.

\section{6. - Chronic visceral pain:}

Chronic visceral pain is persistent or recurrent pain that originates from the internal organs of the head and neck region and the thoracic, abdominal and 
pelvic cavities. The pain is usually perceived in the somatic tissues of the body wall (skin, subcutis and muscle) in areas that receive the same sensory innervation as the internal organ at the origin of the symptom (referred visceral pain).

\section{7. - Chronic musculoskeletical pain:}

Chronic musculoeskeletical pain is defined as persistent or recurrent pain that arises as part of a disease process directly affecting bone(s), joint(s), muscle(s) or related soft tissue(s). The entities subsumed in this approach include those characterized by persistent inflammation of infectious, autoimmune or methabolic etiology, such as rheumatoid arthritis, and by structural changes affecting bones, joints, tendons or muscles, such as symptomatic osteoarthrosis.

According to Pain Proposal, the mean european time to get the right treatment to a specific CP disorder is 1.9 years [149]. Nowadays, there are different drug treatments and therapies to $\mathrm{CP}$ management. The most frequent World Health Organization (WHO) class drug treatments prescribed to patients with chronic pain in Europe are NSAIDs (nonsteroidal anti-inflammatory drugs) (43-44\%) and opioids (22.4-23\%). Those with any general chronic neuropathic pain also are frequently prescribed anti-epileptics (50.7\%) and anti-depressants $(28.7 \%)$ among other non-standard pain medication. On the other hand, the most frequent nondrug pain treatment tried by those with moderate-to-severe general chronic pain was massage (30\%) followed by physical therapy $(21 \%)$ and acupuncture $(13 \%)$ [118]. However, most of these available treatments only produce slight improvements and it is rare that a total recovery is achieved. One of the main problems of $\mathrm{CP}$ management is that, although $\mathrm{CP}$ is recognized as a major public health problem, fewer than $2 \%$ of patients ever attend a pain clinic with the remainder managed mainly in primary care, if anywhere [152]. So, management of CP is generally unsatisfactory, since two-thirds of sufferers, report dissatisfaction with current treatment and most CP persist for many years [152].

Fortunately, there is a non-drug treatment modality that could be the last alternative to the patient to recover his quality of life: Spinal Cord Stimulation (SCS) 
therapy.

\subsection{Spinal Cord Stimulation (SCS) therapy}

SCS therapy is a reversible and minimally invasive pain treatment modality predicated on reducing the intensity, duration and frequency with which pain is felt [77]. This electrical neurostimulation technique has been used for more than 50 years, since Shealy et al. reported the first clinical case of the SCS effectiveness in a patient in 1967 [128]. During all these years, SCS has been clinically proven to be effective for treating a variety of chronic pain conditions that are refractory to current pharmacotherapies [50]. The most common indications for SCS therapy include complex regional pain syndrome (CRPS), failed back surgery syndrome (FBSS) with radicular pain, peripheral neuropathy, phantom limb pain, angina, ischaemic limb pain, postherpetic neuralgia, postamputation pain, multiple sclerosis, spinal cord injury or lesion and diabetic neuropathy [39, 66].

The neurophysiological mechanisms involved in SCS therapy are still not well-known. However, Melzack and Wall developed the gate-control theory in 1965 [100], which has been the basis for understanding the mechanisms of action of SCS for many years. The gate-control theory states that painful nociceptive information in the periphery is transmitted to the spinal cord in small-diameter (unmyelinated C-fibers) and lightly myelinated $\mathrm{A} \delta$ fibers. On the other hand, other sensory information, such as touch or vibration, are carried in large myelinated sensory $\mathrm{A} \beta$-fibers. The theory explains that, if there is more activity of small nerve fibers (C-fibers and A $\delta$ fibers), a "gate" would be opened and a painful feeling would be transmitted to the brain. On the contrary, if there is more activity of large $\mathrm{A} \beta$ nerve fibers, the transmission of large-fiber information would close the "gate" and a tingling sensation would be produced, known as paresthesia (see Fig 2.1). As a result, the clinical effect of this gate closure would be analgesia.

Although SCS therapy evolved as a consequence of this gate-control theory, it does not explain the mechanism of action of SCS accurately [12]. Thus, there is a great and common interest of studying the SCS mechanisms of action and its 


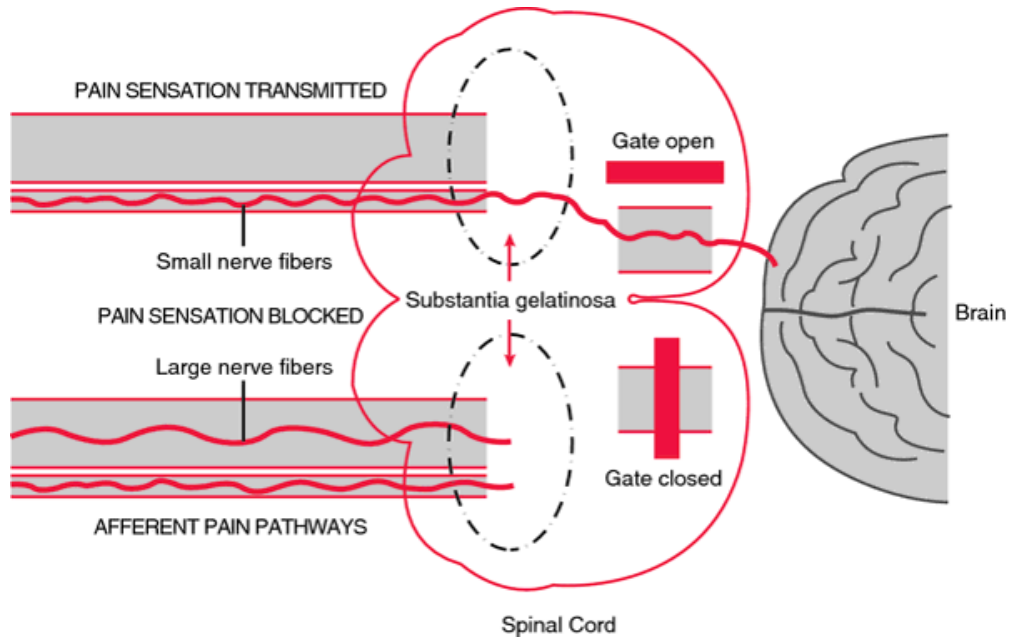

Figure 2.1: Gate-control theory of pain diagram [103]. Activation of small nerve fibers (unmyelinated $\mathrm{C}$-fibers and myelinated $\mathrm{A} \delta$ fibers) produces gate opening and painful sensation is transmitted to the brain. On the contrary, activation of large nerve fibers (myelinated $\mathrm{A} \beta$-fibers) produces gate closing and pain signal is inhibited [137].

exact electrical target. As an example, according to Guan [50], recent studies have identified some gate-keepers, such as $\gamma$-aminobutyric acid (GABA), which can be activated by convergent $\mathrm{A} \beta$-fiber inputs. These GABAergic neurons may play a role of inhibitory gates in dorsal horn. So, they may suppress nociceptive inputs mediated by thinly myelinated $\mathrm{A} \delta$ - or unmyelinated C-fibers.

According to the gate-control theory, the goal of SCS therapy seems to be to activate the large $\mathrm{A} \beta$ nerve fibers of the spinal cord. Thus, the knowledge of where these nerve fibers are located in the spinal cord is pivotal to determine the stimulation target.

Fig. 2.2 shows the anatomy of the spinal cord. The spinal cord is a soft bundle of nerves which extends from the base of the brain to the low back. It runs through the spinal canal and it is protected by the bones of the vertebral column 


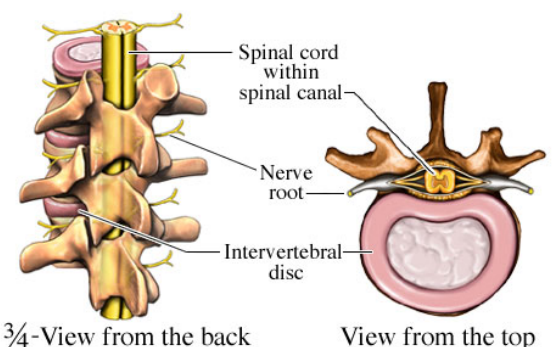

(a) Spinal cord localization in the vertebral column.

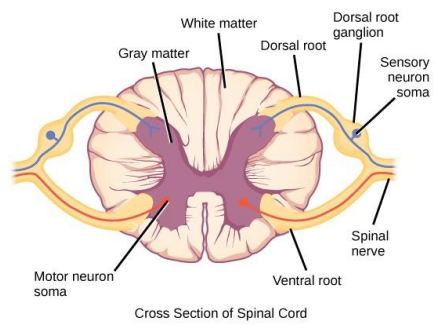

(c) Parts of the spinal cord.

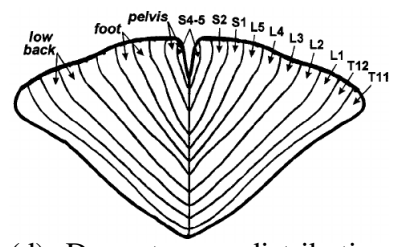

(d) Dermatomes distribution in the DCs of the spinal cord at $\mathrm{T} 11$ vertebral level

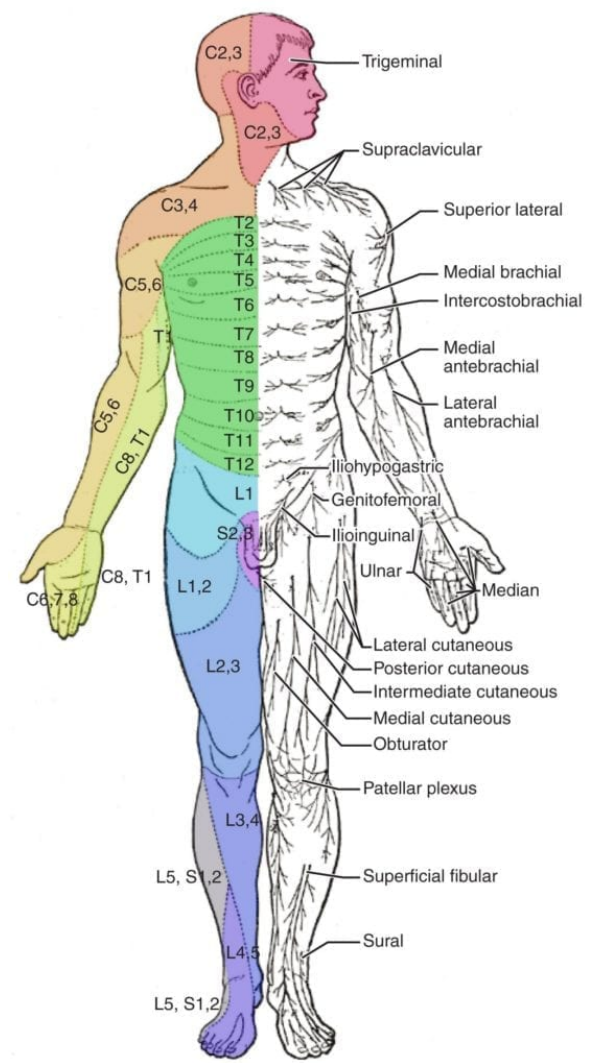

(b) Dermatomes distribution in body human skin.

Figure 2.2: Spinal cord anatomy. DC: dorsal column.

(vertebrae) (see Fig. 2.2(a)) [101]. The spinal cord is composed of grey matter and white matter (see Fig. 2.2(c)). The grey matter is a symmetrical butterfly-shaped structure in the middle of the spinal cord. The dorsal horn is in the posterolateral position and contains mainly sensory neurons [108]. The white matter is orga- 
nized in three columns: dorsal, lateral and ventral. The dorsal columns (DCs) are involved in touch, proprioception and vibration sensation [108]. As it is shown in Fig. 2.2(d), in the DCs, there is a lamination of fibers that are somatotopically organized. So, each segment of the spinal cord innervates a certain sensory area of the body, known as dermatome (see Fig. 2.2(b)). On the other hand, the dorsal roots (DRs) are a set of sensory nerves of a spinal nerve (a nerve associated with a specific segment of the spinal cord) which carry sensory information to the spinal cord and enters the posterior side of the cord (see Fig. 2.2(c)), known as the dorsal root entry zone (DREZ), which is near the dorsal horn of the grey matter [34]. The large myelinated $\mathrm{A} \beta$-fibers are distributed in the DCs and in the DRs. The main difference between these two structures is that DCs carry sensory information of all body dermatomes of a specific vertebral level while DRs carry information of a specific segment of the spinal cord, i.e. one or two dermatomes [55, 92, 106].

Then, in order to ensure the success of SCS, the objective of the therapy seems to be focused on activating the maximum myelinated $\mathrm{A} \beta$ nerve fibers of the DCs of the spinal cord to produce the maximum overlap paresthesia coverage to the painful dermatomes of the patients [55].

The SCS therapy system consists of electrodes, implantable pulse generator (IPG) and patient's controller (see Fig. 2.3) [12]. The electrodes are placed in the epidural space, just over dura mater. There is a wide variety of electrode sizes and shapes, with more or less contacts than others. They can be divided in two main groups [112]:

- Percutaneous electrodes: Percutaneous electrodes are shaped like a straight wire (see Fig. 2.3(a)). This shape allows physicians to introduce these electrodes into the spine through a large hollow needle, which is a minimally invasive surgical procedure. Typically, two electrodes are implanted and placed parallel to each other on either side of the midline of the spinal cord to produce concordant paresthesia to the patient $[39,74]$.

- Surgical or paddle electrodes: Surgical electrodes are shaped like a paddle, so they are wider and flatter than percutaneous electrodes (see Fig. 


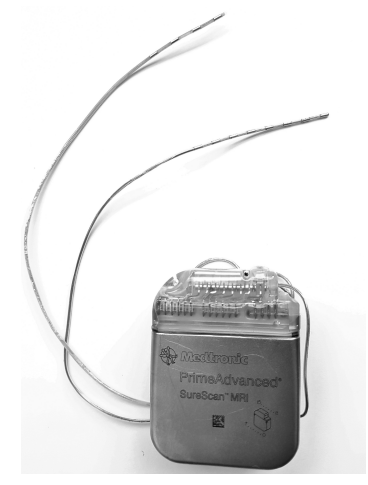

(a)

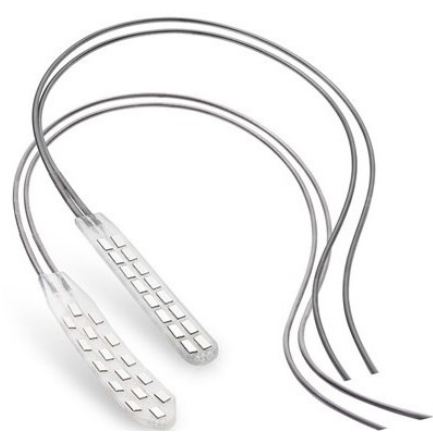

(b)

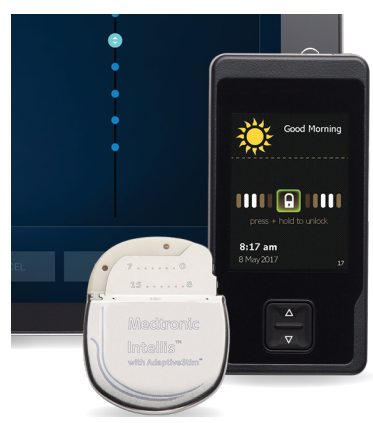

(c)

Figure 2.3: SCS therapy system. (a) Percutaneous electrodes of four and eight contacts connected to a non-rechargeable IPG (Prime, Medtronic). (b) Paddle electrodes (Medtronic). Image courtesy of Medtronic, Inc. (c) Rechargeable IPG (Intellis, Medtronic) and patient's controller. Image courtesy of Medtronic, Inc. IPG: implantable pulse generator.

2.3(b)). Due to their shape, the surgical procedure to introduce them in the spinal canal is more invasive, involving a small incision in the back and a laminectomy (procedure that removes a portion of the vertebral bone called the lamina). The main advantages of this type of electrodes are that they have more electrical contacts over a greater area of the spinal cord which allows greater flexibility in terms of stimulation patterns; and, as they are fixed over the dura mater, they rarely displace away from their intended position, which is a common problem with percutaneous electrodes.

The electrodes are connected to the IPG. The IPG contains the battery to power the stimulator system to produce the required electrical pulses. It is usually implanted under the skin in gluteus. There are two types of IPG [112]:

- Non-rechargeable: A non-rechargeable IPG usually lasts from two to four years, since it depends on how high the stimulation parameters are (i.e. how much current it is delivering). When the IPG's battery is running out, the 
IPG has to be surgically replaced. The advantage of a non-rechargeable IPG is that the patient does not need to learn the recharging procedure. However, this type of battery requires replacement every few years because of the short duration.

- Rechargeable: A rechargeable IPG has a battery duration of 9 years (see Fig. 2.3(c)). The patient usually has to recharge it every few days using a recharge system, although how often this is necessary depends on the stimulation parameters applied. The main advantage of rechargeable IPGs is that they reduce the number of battery replacement surgeries. In addition, rechargeable IPGs are smaller than non-rechargeable IPGs. The disadvantage is that there are patients who may find the recharging procedure difficult.

The patients also have a controller to modify and adjust the amplitude of the stimulation to the conditions in which they are (body position, weather, moment of the day) (see Fig. 2.3(c)). Therefore, the patients are who control their own stimulation therapy.

The surgical procedure of SCS system implant is shown in Fig. 2.4. The SCS system implant is usually performed in two stages [112]:

- First time stage: This stage is based on the implant of the electrodes. First, the electrodes are inserted to the epidural space of the spinal cord through a hollow needle (see Fig. 2.4(a)). To visually verify that the electrodes are well-positioned, intraoperative fluoroscopy is used (see Fig. 2.4(b)). When the correct position of the electrodes is checked by the intraoperative images (radiographies), an intraoperative stimulation test is performed by a biomedical engineer to verify that paresthesia covers the painful dermatomes of the patient. If the patient reports he does not feel the paresthesia in his painful dermatomes, the electrodes are relocated until finding the optimal position, i.e. the position with which higher paresthesia coverage is achieved. Once the stimulation test finishes, a small incision is performed to fix the electrodes to avoid their migration. Then, the electrodes are con- 


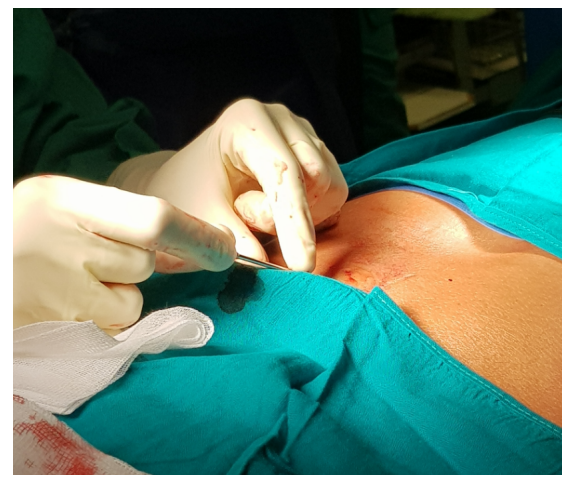

(a) First time surgery

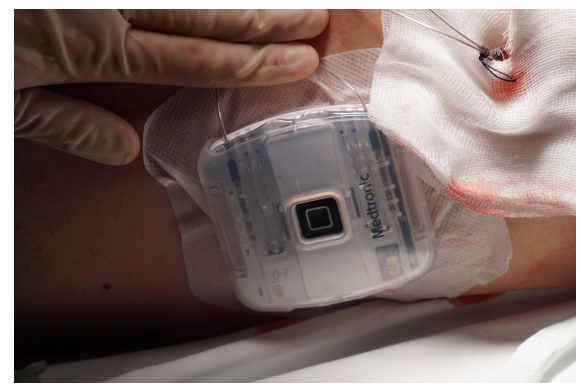

(c) External neurostimulator (Medtronic))

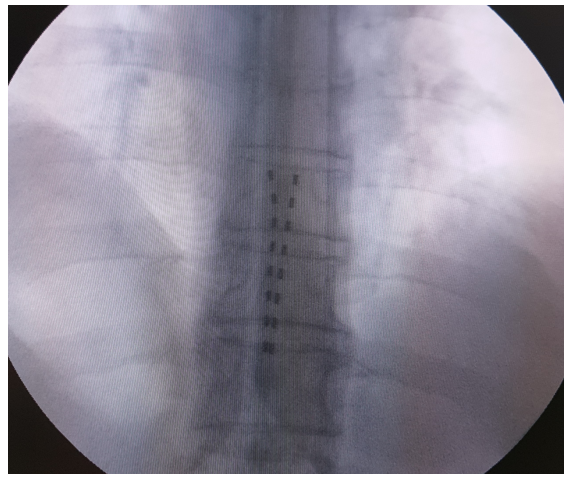

(b) Radiography of the electrodes position

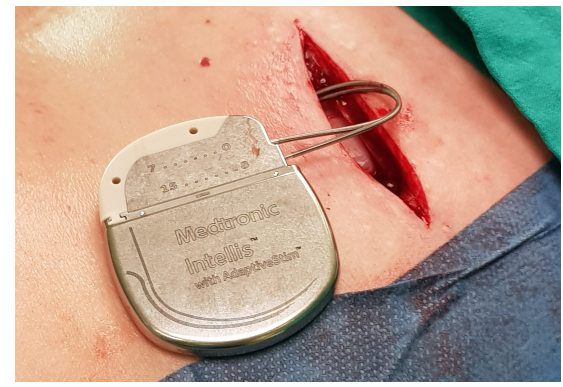

(WENS (d) IPG (Intellis (Medtronic)) implant in the second time surgery

Figure 2.4: Surgical procedure of the SCS system.

nected to temporary extension leads, and these to an external neuroestimulator that the patient will wear outside the body (see Fig. 2.4(c)). From this moment, the patient will have fifteen days to check if the stimulation produces is beneficial not. If it is effective, the patient will undergo to the second stage. If not, the electrodes will be surgically removed.

- Second time stage: In this stage the implant of the neurostimulator is performed. First, the temporary extension leads are removed. Then, the wires 
from the electrodes are passed under the skin to be connected to the IPG. An incision is made to implant the IPG, and the electrodes are connected to it (see Fig. 2.4(d)). Finally, an impedance test is performed by a biomedical engineer to make sure all parts and connections of the SCS system work properly.

SCS therapy has been proved to be effective in most of chronic pain conditions but, although it is often described as a save and relatively easy technique, complications are reported in $20-75 \%$ of cases [73]. The main complications of SCS therapy are divided as follows:

\section{- Hardware complications:}

- Electrode migration: electrode displacement is the most common complication of SCS. It is suspected when there is a change in the paresthesia coverage location, which is usually associated with a loss of pain relief. Generally, this problem is treated by readjusting the stimulation parameters but, if electrodes are highly displaced, reprogramming may not work. When stimulation parameters reprogramming fails, surgical electrode repositioning is mandatory. In fact, this is one of the main causes of surgical revision in permanent implanted patients. This complication is more common within the first four weeks after implantation, because after this period, the tip of the electrode is kept in place by connective tissue [12].

- Electrode fracture: the incidence of electrode fracture is approximately 3-9\%. This problem almost usually results in a loss of pain relief due to SCS dysfunction. The damage of the electrode or the wires can be produced by repetitive folding and straightening of the electrode, because of spinal movements. If electrode fracture is suspected, impedance checking can be performed to determine if it is elevated or not. Elevated impedance is usually associated to electrode fracture. Then, the broken electrode must be withdrawn and replaced by a new one [12].

- Battery failure: this complication is less frequent than electrode migration or electrode fracture. Battery failure can occur when electrode 
disconnection is produced or when battery requires replacement before the expected date, which was previously determined by the programming parameters that are applied to the patient [12].

\section{- Biological complications:}

- Pain related to device components: patients implanted with neuromodulation devices often report pain concerning the site of the device components such as pain around the IPG site or over the electrode anchor site [38].

- Infection: this is one of the major complications of SCS, with incidences of $4 \%$ to $10 \%$, and it is a common cause for SCS system explant. The generator pocket site is the most common location of infection. Potential risk factors for infection or poor wound healing included diabetes, debilitated status, malnutrition, extremely thin body habitus, obesity, autoimmune disorder, corticosteroid use, decubitus ulcers, pre-existing infection, poor hygiene, urinary or fecal incontinence and malabsorption syndrome. The treatment for SCS infection is the complete removal of the system and treatment with antibiotics [38].

- Spinal cord stimulation side effects: Electrical SCS-induced non-analgesic effects occurs about $35 \%$ of cases [73]. The most common side effects are lower-limb electrical shocks induced by position changes and intercostal neuralgia at the stimulated thoracic level [73]. In this cases, reprogramming the stimulation parameters could help but, generally, it rarely works because stimulation is still more annoying than effective. Then, if the patient's quality of life worsens, the stimulation is turned off and the SCS system is removed in a surgical intervention.

Nevertheless, despite the many complications, SCS is a safe technique if the appropriate recommendations are followed and the patients are wisely selected [73]. 


\subsection{Stimulation parameters and SCS therapy concepts}

The four basic parameters which need to be programmed in SCS therapy are amplitude, pulse width, frequency and polarity, whose combination satisfies an individual's pain coverage needs [48].

As for amplitude, a fundamental concept of SCS is the usage range. The perception threshold (PT) is defined as the amplitude necessary for the patient's initial experience of paresthesia. The discomfort threshold (DT) is the point at which the patient can no longer tolerate the paresthesia. Thus, the usage range is the interval of amplitudes that are between the PT and the DT [111].

Frequency and pulse width are usually combined to produce different stimulation waveforms to the patient in SCS therapy. There are three types of stimulation that can be applied in SCS therapy:

- Tonic stimulation: this stimulation is characterized by the delivery of electrical current with a frequency of $40-50 \mathrm{~Hz}$ and a pulse width that falls between 150-500 $\mu$ s [87]. The mechanism of action of SCS in this stimulation can be understood through the gate-control theory [20, 65, 100, 130]. Thus, when $\mathrm{A} \beta$-fibers are activated, pain signals are inhibited and the patient starts experiencing the paresthesia [3].

- Burst stimulation: it uses bursts of pulses rather than a continuous stream of pulses. Burst stimulation is a series of five $1000-\mu$ s pulses at a frequency of $500 \mathrm{~Hz}$, with an interspike interval of $1000 \mu$ s and spike trains repeated at a rate of $40 \mathrm{~Hz}$ [3]. The cumulative charge of five $1000 \mu$ s spikes is charge-balanced passively and immediately after the burst. Burst stimulation produces pain suppression without generating paresthesia in patients (paresthesia-free) [3]. However, the process by which burst SCS imparts clinical efficacy is still unclear [20]. To our knowledge, a study reported by Tang et al. showed that, unlike tonic stimulation, no activity on the gracile nucleus was produced in burst SCS [146]. Several studies postulated instead that burst stimulation may modulate dorsal column and dorsal horn activ- 
ity [20], showing that burst stimulation 1) modulates low-threshold, tactile C-fibers that are known to be antinociceptive and 2) mediates multiplexing which could contribute to supra- spinal analgesic and modulation of cortical attentional mechanisms [33, 64, 84].

- High frequency (HF) stimulation: HF stimulation involves the use of kilohertz tonic stimulation (up to $10 \mathrm{kHz}$ ) to treat neuropathic pain without paresthesia. It has been developed to improve the clinical results of tonic SCS. There are three hypotheses of the mechanism of action of HF stimulation: (a) that HF stimulation induces a depolarizing block; (b) that HF stimulation induces the desynchronization of neural signals from clusters of neurons firing; and (c) that impulses reaching a neuron within a certain time frame may depolarize it and fire an action potential although every individual impulse is insufficient. Nevertheless, these hypotheses have not been demonstrated yet, leading to the current unknowledge of the neural structures that are involved in high-frequency stimulation [3].

Finally, polarity is defined as the combination of anodes (positive amplitude) and cathodes (negative amplitude) that are programmed in the electrode contacts. As percutaneous electrodes usually have eight contacts, a huge number of combinations can be used. Hitherto, this stimulation parameter allows to modulate the electric field displacement to produce better paresthesia coverage in patients [106]. In the clinical scenario, polarity is determined by eliciting the patient's oral responses to the trial and error-based application of the stimulation. The effect of some polarities on paresthesia have been studied in the last years, as bipolar (in which an anode is followed by a cathode), monopolar (in which a cathode and the anode are two-contact separated) and guarded cathode (in which a cathode is programmed between anodes) [60, 92, 93].

\subsection{Myelinated nerve fiber models}

SCS computational modeling has been a valuable tool to understand basic mechanisms of nerve fiber excitation modulated by stimulation parameters, such as 
amplitude, pulse width, polarity, and frequency [78]. SCS modeling usually combines a spinal cord volume conductor model with a myelinated nerve fiber model. During the last 70 years, several nerve fiber models have been developed, and its selection is pivotal to obtain accurate SCS model-based predictions.

Myelinated nerve fibers are nerve fibers which are insulated by a myelin sheath. Myelin is a fatty substance that insulates the nerve cell axons in order to increase the speed at which information travels from one nerve cell body to another. Then, these nerve fibers have nodes of Ranvier, which are the spaces between the myelin coatings on the neuron's axon, and internodes, which are the parts of the axon that are recovered by the myelin [157].

The activation of myelinated nerve fibers occurs when an action potential (AP) is produced in the nodes of Ranvier and propagated along the axon. An AP can be defined as the sudden and reversal change in membrane potential in response to a threshold stimulus [52]

In the last 50 years, several myelinated nerve fiber models have been developed and used for SCS modeling studies to simulate the action potential propagation, i.e. the neural activation, as shown in Fig. 2.5.

The first nerve fiber models were unicellular models which reproduced the membrane dynamics of a specific type of cells. The first unicellular model was developed by Frankenhaeuser and Huxley in 1964 [44]. This model simulates the AP in a myelinated nerve fiber of Xenopus Laevis (amphibian). Later, in 1979, Chiu et al. showed a new unicellular model which described membrane currents in rabbit myelinated nerve (mammal) [22]. And it was not until 1995 when Schwarz et al. presented the first unicellular model of membrane dynamics in human peripheral myelinated nerve fibers [127].

From these unicellular models, more sophisticated and realistic myelinated nerve fiber models were developed to simulate the action potential propagation. The first myelinated nerve fiber model was developed by McNeal in 1976 [97]. 


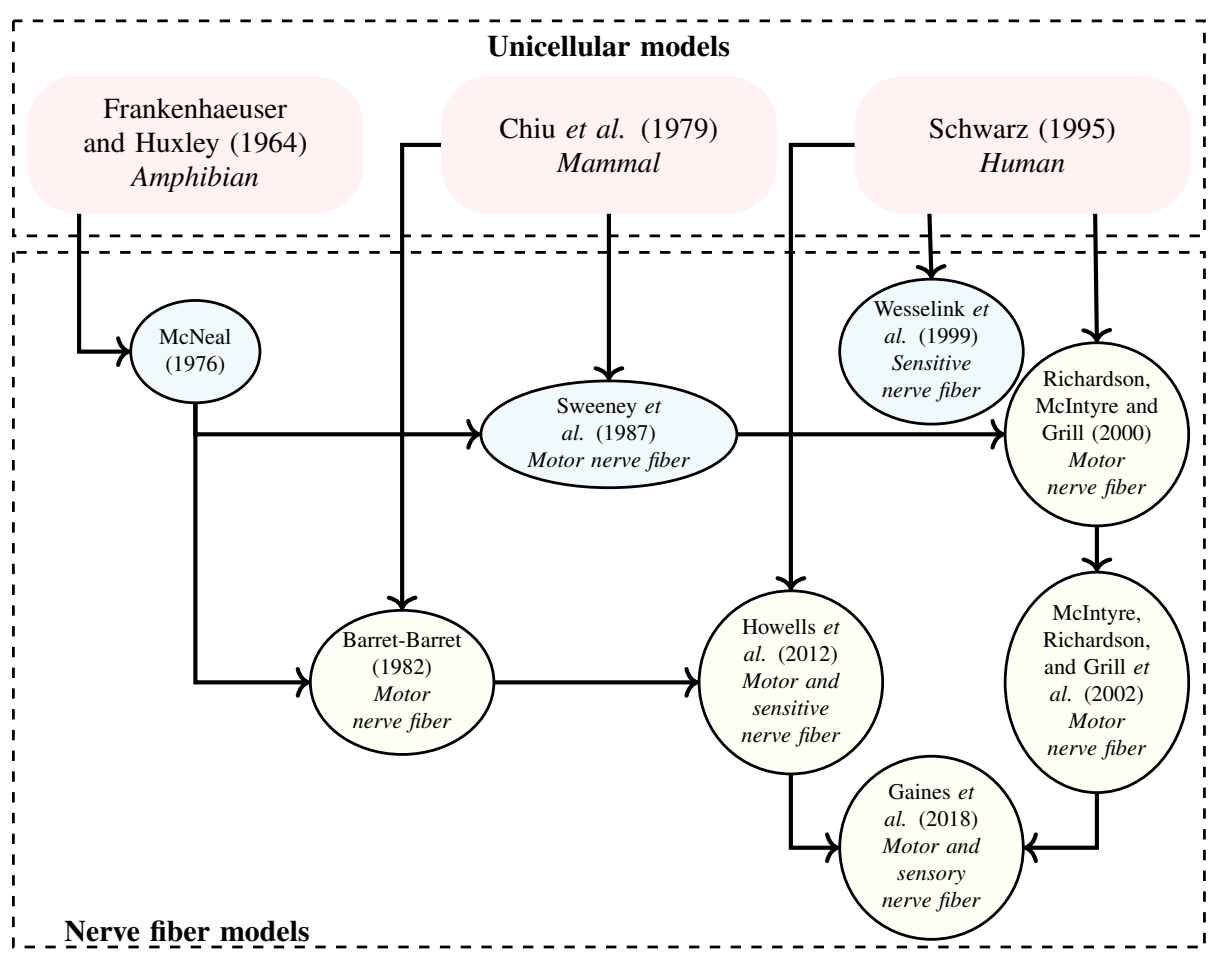

Figure 2.5: Nerve fiber models developed during the last 50 years. The blue colored nerve fiber models are based on the cable model. The yellow colored nerve fiber models are based on the double-cable model.

This model was based on Frankenhaeuser and Huxley membrane dynamics equations. The novelty of this model was that it considers the extracellular stimulation of the nerve fiber. However, the AP propagation cannot be simulated. On the other hand, myelin is modeled as a perfect insulator [97], which is not realistic because of current losses are not produced in the internodal compartments [121]. From McNeal's model, two more nerve fiber models appeared. On the one hand, Sweeney et al. developed the first mammal myelinated nerve fiber model, based on Chiu et al. membrane dynamics, in 1987. This model also considered the 


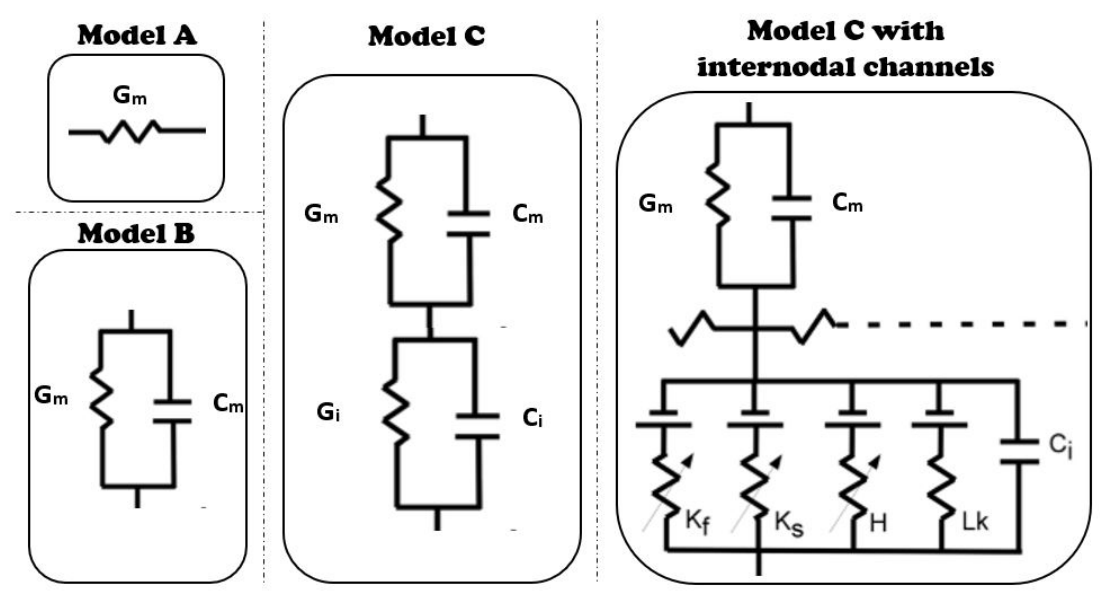

Figure 2.6: Myelin models included in the nerve fiber models. Model A: perfect insulator. Model B: cable model, imperfect insulator. Model C: double-cable model, imperfect insulator. Figure modified from Gaines et al. [46].

myelin as a perfect insulator but it simulated the AP in the peripheral nerve in functional neuromuscular stimulation [143]. On the other hand, in 1982, Barret and Barret developed another nerve fiber model, based on Chiu et al. membrane dynamics, where the myelin is considered as an imperfect insulator and it is modeled as a double-cable. This model does not simulate the AP propagation, but it simulates the depolarizing afterpotentials and nerve fiber hyperpolarization. Then, in 1999, Wesselink et al. presented the first human sensory nerve fiber model, based in Schwarz et al. unicellular model. In this model, the myelin is also considered as a perfect insulator, but it predicts the stimulation threshold of the targeted neurons of tonic stimulation in SCS therapy. Moreover, AP propagation can be simulated. Based on Schwarz et al. unicellular model and Sweeney et al. mammal myelinated nerve fiber model, one of the most used nerve fiber models in SCS modeling was developed in 2000: the Richardson, McIntyre and Grill (RMG) nerve fiber model [121]. This model studies the effect of three myelin models (see Fig. 2.6): perfect insulator (model A) and imperfect insulator (modeled as cable (model B) and double-cable (model C)). The main conclusion is 
that myelin has to be considered as an imperfect insulator in nerve fiber models to obtain more accurate and realistic results. However, the use of model B or model $\mathrm{C}$ will depend on the accuracy need of the study to be performed [121]. The three models simulate the AP propagation [121]. Furthermore, all electrical parameters are in function of measured geometrical parameters of myelinated nerve fibers, being then possible to simulate the AP in different fiber diameters [96]. Next, McIntyre et al. developed a motor nerve fiber model from RMG model, most known as MRG model [96]. In this case, apart from including the more complex myelin model (model C), the MRG model also simulates the depolarizing (DAP) and hiperpolarizing (AHP) afterpotentials that are produced on the recovery cycle.

Later, a myelinated nerve fiber model was developed by Howells et al. in 2012 [62]. This model is based on Schwarz et al. unicellular model and Barret-Barret nerve fiber model. It is a double-cable model whose electrical membrane dynamics parameters were adapted and validated to human sensory nerve fiber recordings. Although this is the first model to include $I_{h}$ channels in order to get a more depolarized nerve fiber, it does not simulate the AP propagation and it is not possible to simulate the AP in different nerve fiber diameters [62]. Recently, Gaines et al. [46] developed a myelinated nerve fiber model (motor and sensory) from the MRG model [96] and the Howells model [62], resulting in axon models that could reproduce experimental results for conduction velocity, strength-duration curves and activation threshold for both human motor and sensory axons.

\subsection{SCS computational models}

SCS computational models have been fundamental to the understanding of clinical observations and the design of therapies with optimal results [151]. Computational models use the finite element method (FEM) to find only an approximate solution to the problem. The advantage of the FEM is that the solution region is considered to be built up of many small, interconnected subregions (finite elements), thus enabling the problem to be replaced by a simpler one when attempting to find a solution [116]. Spinal cord volume conductor models appeared later than myelinated nerve fiber models. During the last 40 years, several spinal cord 


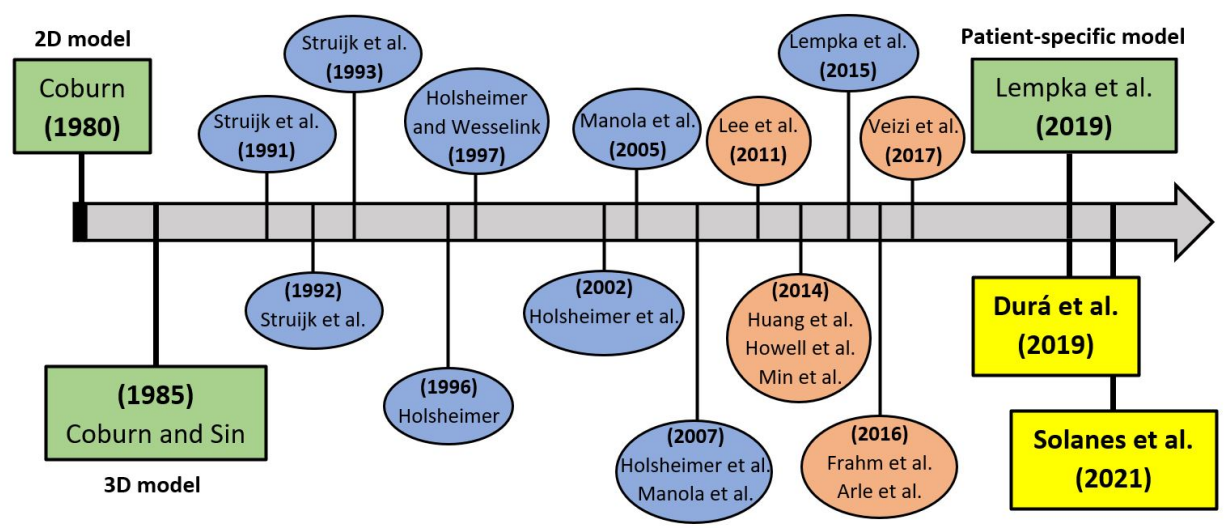

Figure 2.7: SCS models from 1980 to 2021. Blue bubbles are models developed and used for studies about stimulation parameters effect on neural response. Red bubbles are models developed and used for studies about the effect of different stimulation types. Green squares are models developed with innovative features. Yellow squares are models developed by our research group.

models have been developed to investigate the effect of electrical stimulation on neural response.

As shown in Fig. 2.7 The first spinal cord model was developed by Coburn in 1980 [23]. This model was a two-dimensional finite-element model representing non-homogeneous electrical conductivity of the human thorax in the mid-sagittal and transverse planes. With this model, Coburn suggested that the effect of the cathode of bipolar epidural electrodes was approximately equivalent to an epidural monopolar cathodic current source place at the same level. However, to understand how electric fields affects neural activation, three-dimensional solutions were indispensable.

Therefore, from the previous computational model, Coburn and Sin developed the first three-dimensional spinal cord model in 1985 [25]. This model, in addition to be successfully developed in three dimensions, also includes a biophysical model of the myelinated nerve axon (McNeal model [97]) in DCs and 
DRs [24]. The novelty of using a mathematical model for myelinated nerve fibers in conjunction with three-dimensional spinal cord finite-element model allowed the threshold predictions for several DC fiber diameters.

Then, as technological benefits improved and interest of the effect of electrical stimulation on neural activation grew, many studies about SCS have been published.

In 1991, Struijk et al. calculated the effect of mediodorsal cathodal and anodal epidural stimulation. It was concluded that with cathodal stimulation, longitudinal fibers are depolarized, while dorsoventral fibers are hyperpolarized. With anodal stimulation, the opposite will occur. It was found that parameters substantially affecting the potential distribution in the DCs are the conductivity of the white matter and both the width and conductivity of the cerebrospinal fluid (CSF) layer [142]. Later, collateral branching was included in the myelinated nerve fiber model of the Struijk computational model in order to develop a more realistic spinal cord model [141]. In 1993, the influence of CSF layer thickness, the contact separation in bipolar stimulation and the laterality of the electrodes on paresthesia thresholds were validated with clinical data by Struijk et al. [139].

From the Struijk spinal cord model, Holsheimer's research group published many studies related to neural structures involved in inducing paresthesia coverage and the effect of electrode configuration on their activation. For example, as for paresthesia coverage, Holsheimer suggested that assuming that the largest $\mathrm{A} \beta$-fibers in a DR have a diameter of $15 \mu \mathrm{m}$, the smallest ones to be recruited at DT would be $12 \mu \mathrm{m}$ [55]; and that, to increase DC fibers recruitment, DR fibers activation should be reduced [59]. On the other hand, regarding electrode configurations, Holsheimer et al. found that paresthesia coverage is increased when the space between the SCS electrode and the spinal cord gets smaller [57]; Manola et al. showed that DC fibers recruitment increased with electrodes having small contact spacing and being centered on the spinal cord midline just outside the dura mater [92] and that paresthesia coverage can be controlled by cathodal field steering [93]. 
Other spinal cord computational models have been developed to compare the different ways of stimulation types that can be produced. For instance, Huang et al. and Howell et al. compared SCS profiles from intra- and extradural electrode arrangements, concluding that intradural stimulation allows the increase of DC fibers recruitment [61,63]. Min et al. compared dermatome selectivity of single- and multiple-current source systems and they suggested that multiplecurrent source system may not provide incremental therapeutic benefit [104]. On the other hand, Frahm et al. studied fiber activation in peripheral field stimulation, suggesting that no anodal blocking was observed and it may be relevant to investigate the overall position of the target nerve fibers before electrode placement [43]. Arle et al. studied the effect of scar on SCS, concluding that scarring produces significant current distribution changes [6]. And, a recent study of Veizi et al., showed that 3D neural targeting SCS and its associated hardware flexibility provide effective treatment for both chronic leg and chronic axial low back pain that is significantly superior to traditional SCS [154].

Next-generation of computational models were more sophisticated, and studies were focused on the effect of the stimulation parameters on neural activation [151]. As for polarity, Holsheimer and Wesselink suggested that guarded cathode polarity produces the deepest and widest paresthesia coverage, although no quantitative parameters were evaluated [60]. On the other hand, Lee et al. studied the effect of pulse width in SCS, showing that DC area is increased with larger pulse width values [78], which was in concordance with a clinical study results from Yearwood et al. [51]. Relating to stimulation frequency, Lempka et al. suggested that kilohertz frequency SCS may not function through direct activation or conduction block of DC or DR nerve fibers [79]. Nevertheless, Arle et al. proposed that, in high-frequency stimulation, larger-diameter fibers are blocked while smaller and medium fibers are recruited [8].

Recently, SCS modeling focused on patient-specific modeling. For instance, Lempka et al. compare the results of SCS simulations obtained from a canonical SCS model versus a patient-specific SCS model. The results showed that the 
patient-specific model predicted sensory thresholds that are more consistent with the clinical measurements [81]. From 2019 onwards, our research group has developed a realistic generalized SCS model [36], and a patient-specific SCS model [136] with innovative features, as we will see troughout this thesis. 


\section{Chapter 3}

\section{SCS computational modeling. General methodology}

Generally, SCS computational models consist of a combination of two submodels: the spinal cord volume conductor model, and the myelinated nerve fiber model.

On the one hand, the volume conductor model includes the different tissues that compound the spinal cord: white and grey matter, cerebrospinal fluid (CSF), dura matter, epidural fat, and vertebral bones. Therefore, both the geometrical parameters and the electrical properties of the spinal cord are considered. Moreover, the stimulation electrodes are also modeled and included in the model, with their respective geometry and electrical properties. Thus, the volume conductor model is used to simulate the electric field distribution within the spinal cord when an electrical stimulation is applied.

On the other hand, the myelinated nerve fiber model includes the membrane dynamics of a sensory fiber, the ion channels responsible of the action potential generation, the electrical properties, and the fiber size. Hence, the nerve fiber model simulates the activation -or not activation- of a neuron under the effect of an electric field. 
The fiber diameter of afferent $\mathrm{A} \beta$ fibers in human DC ranges between 1-15 $\mu \mathrm{m}[40,90]$. The large axon diameters $(>11.5 \mu \mathrm{m}$, i.e. from 12 to $15 \mu \mathrm{m})$ increase significantly from the midline to DR entry zone $[40,160]$. Thus, although 12.8- $\mu \mathrm{m}$ axon diameter has a low density in the DC [40], we can assume that the largest fibers recruited first in the DC have a diameter of $12 \mu \mathrm{m}$ and $15 \mu \mathrm{m}$ in the DR $[55,56,78,79,92,93]$, since the highest axon diameters are located in the dorsolateral columns and are farther from the stimulation electrode [40]. As experimental morphology measurements are available for 12.8 and $15-\mu \mathrm{m}$ axon diameters [96], the SCS models developed in this thesis (the generalized and the patient-specific SCS models) include a population of $12.8-\mu \mathrm{m}$ axon diameter in the DC and $15-\mu \mathrm{m}$ axon diameter in the DR.

The workflow followed to simulate the neural response in the DCs and DRs of the spinal cord is shown in Fig. 3.1. First, the electric field distribution is simulated in the volume conductor model, using COMSOL Multiphysics ${ }^{\circledR}$ v. 5.6. The electric potential values on the nodes of Ranvier in every nerve fiber considered in the model are then imported to the nerve fiber model, which is developed in MATLAB $^{\circledR}$ R2017a. To quantitatively evaluate the electrical stimulation result, several evaluation parameters, which are related to paresthesia coverage and stimulation parameters in SCS therapy, are calculated (see Figure 3.2):

- Perception threshold (PT): defined as the lowest voltage needed to activate the first $\mathrm{DC} 12.8-\mu \mathrm{m}\left(\mathrm{PT}_{\mathrm{DC}}\right)$ or $\mathrm{DR} 15-\mu \mathrm{m}$ diameter $\left(\mathrm{PT}_{\mathrm{DR}}\right)$ nerve fiber. This value is the electrode voltage and is expressed as the voltage programmed in a pole (the leading edge of the stimulation pulse, in $\mathrm{V}$ ).

- Discomfort threshold (DT): this is the clinical value that produces painful paresthesia. In the volume conductor models, DT is ratio between the perception threshold and discomfort obtained from the real patients per PT and thus may be the ratio value per $\mathrm{PT}_{\mathrm{DC}}$ or the ratio value per $\mathrm{PT}_{\mathrm{DR}}$, since both neural structures could be involved in PT [65].

- Recruitment ratio $\left(\mathbf{R}_{\mathrm{DC} / \mathrm{DR}}\right)$ : the ratio between $\mathrm{PT}_{\mathrm{DC}}$ and $\mathrm{PT}_{\mathrm{DR}}$, which indicates the nerve fibers most likely to be activated first: DR (values equal to or higher than 1) or DC nerve fibers (lower than 1). 


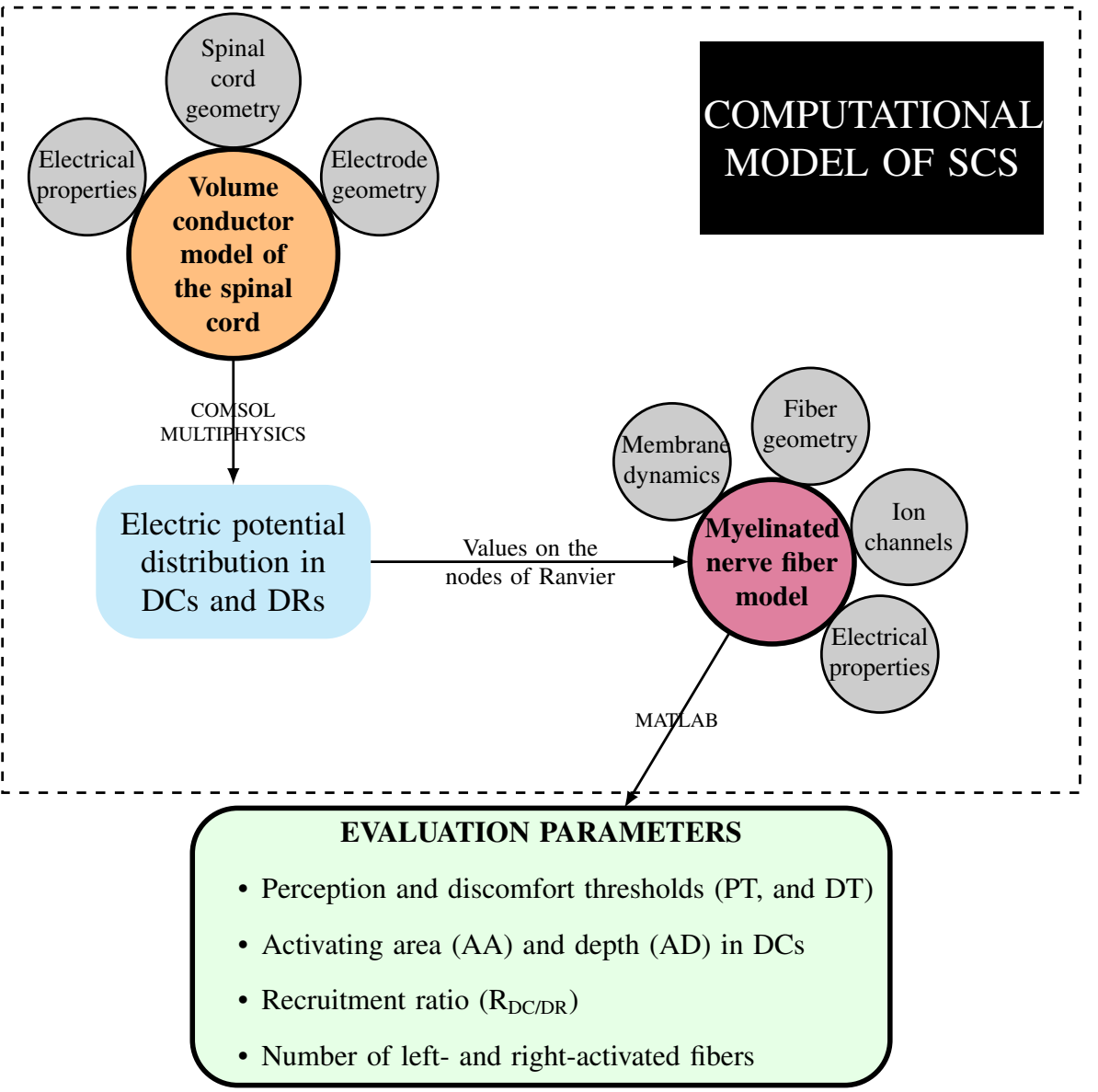

Figure 3.1: SCS computational model submodels and workflow. DC: dorsal column; PT: perception threshold; DT: discomfort threshold; AA: activating area; AD: activating depth; AP: action potential.

- Activating area (AA): defined as the maximum transversal area of the DCs within which DC nerve fibers are activated at DT.

- Activating depth (AD): the maximum cross-sectional depth of the DCs 


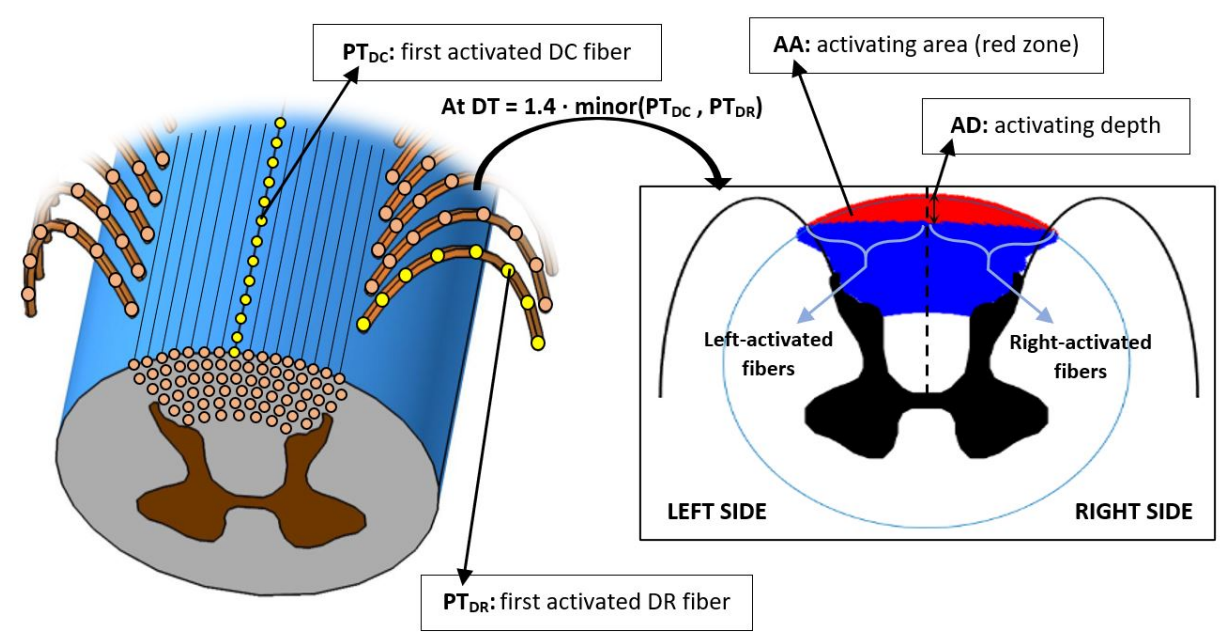

Figure 3.2: Evaluation parameters obtained from the SCS model. DC: dorsal columns; DR: dorsal roots; $\mathrm{PT}_{\mathrm{DC}}$ : perception threshold in $\mathrm{DC}$; $\mathrm{PT}_{\mathrm{DR}}$ : perception threshold in $\mathrm{DR}$; DT: discomfort threshold; AA: activating area; AD: activating depth.

within which DC nerve fibers are activated at DT.

- Number of left and right activated fibers: defined as the transverse (left or right) cross-sectional area that is stimulated (in $\mu \mathrm{m}^{2}$ ) per density of $12.8-\mu \mathrm{m}$ fibers in the DC $\left(0.11 \cdot 10^{-3}\left(\mu \mathrm{m}^{2}\right)^{-1}\right.$, according to Feirabend et al. [40]). It represents the number of fibers that would be activated. 


\section{Chapter 4}

\section{Development of a human $\mathrm{A} \beta$ sensory nerve fiber model}

The publications related to this chapter are:

1.- Carmen Solanes, Jose L. Durá, Jose De Andrés, Javier Saiz, What is the role of frequency on neural activation in tonic stimulation in SCS therapy? A computational study on sensory A $\beta$ nerve fibers, In IEEE Access, 9, 107446-107461, 2021, https: / / ieeexplore.ieee.org/document / 9495784 . (Impact Factor 2020: 3.367 Q2 (94/273) Engineering, Electrical \& Electronic).

2.- Carmen Solanes, Jose L. Durá, Jose De Andrés, Javier Saiz, A human A $\beta$ sensory nerve fiber model for accurate neural activation prediction in tonic spinal cord stimulation modeling, In 15th International Conference in Advanced Biomedical Engineering and Biomechanics Conference (ICABEB 2021). Pag 815. 25-26 March, 2021, Madrid, Spain. 


\subsection{Motivation}

This chapter is aimed to accomplish the first specific objective stated in Chapter 1 , which is the development of a human $\mathrm{A} \beta$ sensory nerve fiber model. This work will also contribute to the performance of a realistic SCS computational model to study the effect of the stimulation parameters, that is the main goal of this thesis.

During the last 50 years, different nerve fiber models have been used in SCS modeling to predict the stimulation parameters, and neural activation in the DC. Simplified models are useful to decrease the computational cost, but they assume intrinsic errors that should be avoided in SCS modeling [46, 121]. Others, which consider the effect of the ionic channels and pumps in the internodes that may play a role in the excitation properties of the axon, are suitable to study changes in post-action potential excitability, but the high computational complexity, and the parameter uncertainty of the dynamic properties of the internode ionic channels and pumps, make them not be the best option for tonic SCS studies [46, 62, 96]. In SCS therapy, the aim of tonic stimulation is to activate large $\mathrm{A} \beta$ sensory fibers to produce paresthesia coverage in the painful dermatomes of the patients with neuropathic pain [20, 100]. Tonic SCS modeling is therefore aimed to simulate neural activation at one stimulation pulse, where post-action potentials are not considered.

Thus, this chapter proposes a simplified but more accurate human $\mathrm{A} \beta$ sensory nerve fiber model for tonic SCS computational modeling. Moreover, a model validation is performed to ensure that the nerve fiber model behaves electrically as human sensory nerve fibers. Finally, due to the need of understanding how the stimulation parameters (amplitude, pulse width, polarity, and frequency) influences neuronal response, the last part of this chapter includes a study about the effect of frequency on the electrical response of $\mathrm{A} \beta$ sensory nerve fibers in tonic stimulation, using the developed nerve fiber model. 


\subsection{Nerve fiber model description}

The sensory nerve fiber developed is a combination of the Wesselink-HolsheimerBoom (WHB) sensory nerve fiber model and the Richardson-McIntyre-Grill (RMG) motor nerve fiber model B. The parameters of the membrane kinetics were taken from [159], which are described in Appendix A. The values of the electrical parameters of the nodal and internodal (myelin) compartments are shown in Table 4.1. To yield an action potential shape that includes hyperpolarizing afterpotential that matches experimental data from the electrical behavior of sensory nerve fibers, the following parameters of the model were adjusted.

The axoplasmic resistivity $\left(\rho_{\mathrm{ax}}\right)$ is shown to produce significant changes in $\mathrm{CV}$ values [121]. The WHB model has a $\rho_{\mathrm{ax}}$ value of $33 \Omega \cdot \mathrm{cm}$. In our model, this value was increased to $70 \Omega \cdot \mathrm{cm}$ to match CV values to experimental data for fiber diameters ranging from 5.7 to $16 \mu \mathrm{m}$. On the other hand, to avoid spontaneous firing and match the action potential characteristics to experimental data,

Table 4.1: Electrical parameters of the developed sensory nerve fiber model.

\begin{tabular}{|llll|}
\hline \hline Symbol & Parameter & Value & Unit \\
\hline$p_{N a}$ & $\mathrm{Na}^{+}$channel permeability & $7.04 \cdot 10^{3}$ & $\mathrm{~cm} \cdot \mathrm{s}^{-1}$ \\
$g_{K}$ & Slow K $\mathrm{K}^{+}$channel conductivity & 30 & $\mathrm{mS} \cdot \mathrm{cm}^{-2}$ \\
$g_{L k}$ & Leak channel conductivity & 60 & $\mathrm{mS} \cdot \mathrm{cm}^{-2}$ \\
{$[N a]_{\text {out }}$} & $\mathrm{Na}^{+}$channels extracellular concentration & 154 & $\mathrm{mM}$ \\
{$[N a]_{\text {in }}$} & $\mathrm{Na}^{+}$channels intracellular concentration & 30 & $\mathrm{mM}$ \\
$F$ & Faraday constant & 96485 & $\mathrm{C} / \mathrm{mol}$ \\
$R$ & Gas constant & 8314.4 & $\mathrm{mV} / \mathrm{K} \mathrm{mol}$ \\
$T$ & Temperature & 310.15 & $\mathrm{~K}$ \\
$E_{K}$ & $\mathrm{~K}^{+}$channel equilibrium potential & -84 & $\mathrm{mV}$ \\
$E_{L k}$ & Leak channel equilibrium potential & -84.14 & $\mathrm{mV}$ \\
$V_{r e s t}$ & Resting potential & -84 & $\mathrm{mV}$ \\
$\rho_{a x}$ & Axoplasmic resistivity & 70 & $\Omega \mathrm{cm}$ \\
$\rho_{\text {ext }}$ & External resistivity & 300 & $\Omega \mathrm{cm}$ \\
$c_{n}$ & Specific nodal capacitance & 2 & $\mu \mathrm{F} \cdot \mathrm{cm}^{-2}$ \\
$c_{m}$ & Specific myelin capacitance & 0.1 & $\mu \mathrm{F} \cdot \mathrm{cm}^{-2}$ \\
$g_{m}$ & Specific myelin conductance & 1 & $\mathrm{mS} \cdot \mathrm{cm}^{-2}$ \\
\hline \hline
\end{tabular}


CHAPTER 4. Development of a human $\mathrm{A} \beta$ sensory nerve fiber model

the membrane kinetics was calibrated by adjusting the sodium activation and inactivation gate coefficients ( $\alpha_{\mathrm{m}}$ and $\alpha_{\mathrm{h}}$, respectively). Therefore, we used the $\alpha_{\mathrm{m}}$ and $\alpha_{\mathrm{h}}$ voltage and time-dependent parameters obtained from the Howells model for sensory nerve fibers (see Appendix A) [62].

In Fig. 4.1, the electrical diagram of the developed sensory nerve fiber model is presented. As the figure shows, the internode (myelin) is modeled as in the RMG model B, represented by a conductance connected to a capacitor in parallel. In this manner, the myelin behaves as an imperfect insulator, which means that current losses are considered. On the other hand, the model of the nodes of Ranvier includes three ionic currents: sodium current, fast potassium current, and leakage current. The equations of the ionic currents, the myelin parameters, and the gates' probabilities of the ionic channels are shown in Appendix A.

Applying Kirchhoff's law, the membrane currents at each compartment $\mathrm{n}$ is equal to the sum of the incoming axial currents and to the sum of the capacitive and ionic currents (if the compartment is a node of Ranvier) through the membrane. Thus, two first-order differential equations are required: one for nodal compartments (Eq. 4.1) and one for internodal compartments (Eq. 4.2):

$$
\begin{aligned}
& \frac{d V_{n}}{d t}=\left(G _ { a } \left(V_{m, n-1}-2 V_{m, n}+V_{m, n+1}+\right.\right. \\
& \left.\left.V_{e, n-1}-2 V_{e, n}+V_{e, n+1}\right)-\pi d l I_{i o n, n}\right) / C_{n} \\
& \frac{d V_{n}}{d t}=\left(G _ { a } \left(V_{m, n-1}-2 V_{m, n}+V_{m, n+1}+V_{e, n-1}\right.\right. \\
& \left.-2 V_{e, n}+V_{e, n+1}\right)-G_{m}\left(V_{m, n}-V_{r e s t}\right) / C_{m}
\end{aligned}
$$

where $G_{a}$ is the axial conductance between two compartments $(m S), C_{n}$ is the nodal membrane capacitance $(\mathrm{mF}), \mathrm{G}_{\mathrm{m}}$ is the myelin membrane conductance $(\mathrm{mS}), \mathrm{C}_{\mathrm{m}}$ is the myelin membrane capacitance $(\mathrm{mF}), \mathrm{V}_{\mathrm{m}, \mathrm{n}}$ is the membrane potential value at $\mathrm{n}$ compartment $(\mathrm{mV}), d$ is the nodal diameter $(\mathrm{cm}), l$ is the nodal length $(\mathrm{cm}), \mathrm{I}_{\mathrm{ion}, \mathrm{n}}$ is the sum of the ionic currents at $\mathrm{n}$ nodal compartment $\left(\mathrm{mA} / \mathrm{cm}^{2}\right)$, 


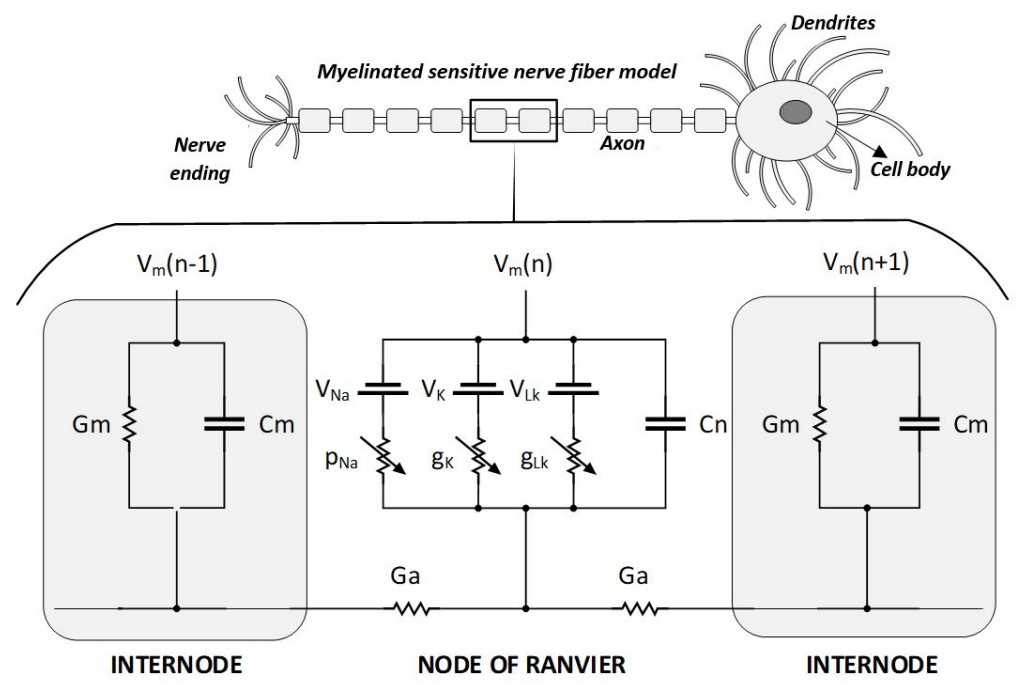

Figure 4.1: Electrical diagram of the developed sensitive nerve fiber model.

$\mathrm{V}_{\text {rest }}$ is the resting potential $(\mathrm{mV})$, and $\mathrm{V}_{\mathrm{e}, \mathrm{n}}$ is the external electric potential in $\mathrm{n}$ compartment $(\mathrm{mV})$. A complete description of these parameters is presented in Appendix A. The total number of differential equations to be solved depends on the number of nodes of Ranvier we consider the nerve fiber has.

\subsubsection{Shape of the AP}

Several parameters were calculated using the developed nerve fiber model to characterize the simulated action potential.

The amplitude of the action potential corresponded to the absolute value measured from the resting potential up to the peak amplitude. It was measured with an stimulus amplitude of $1.2 \mathrm{~V}_{\text {th }}$.

Conduction velocity $(\mathrm{CV})$ was used to compare the behavior of the model with experimental data. It was measured from two consecutive nodes of Ranvier with 

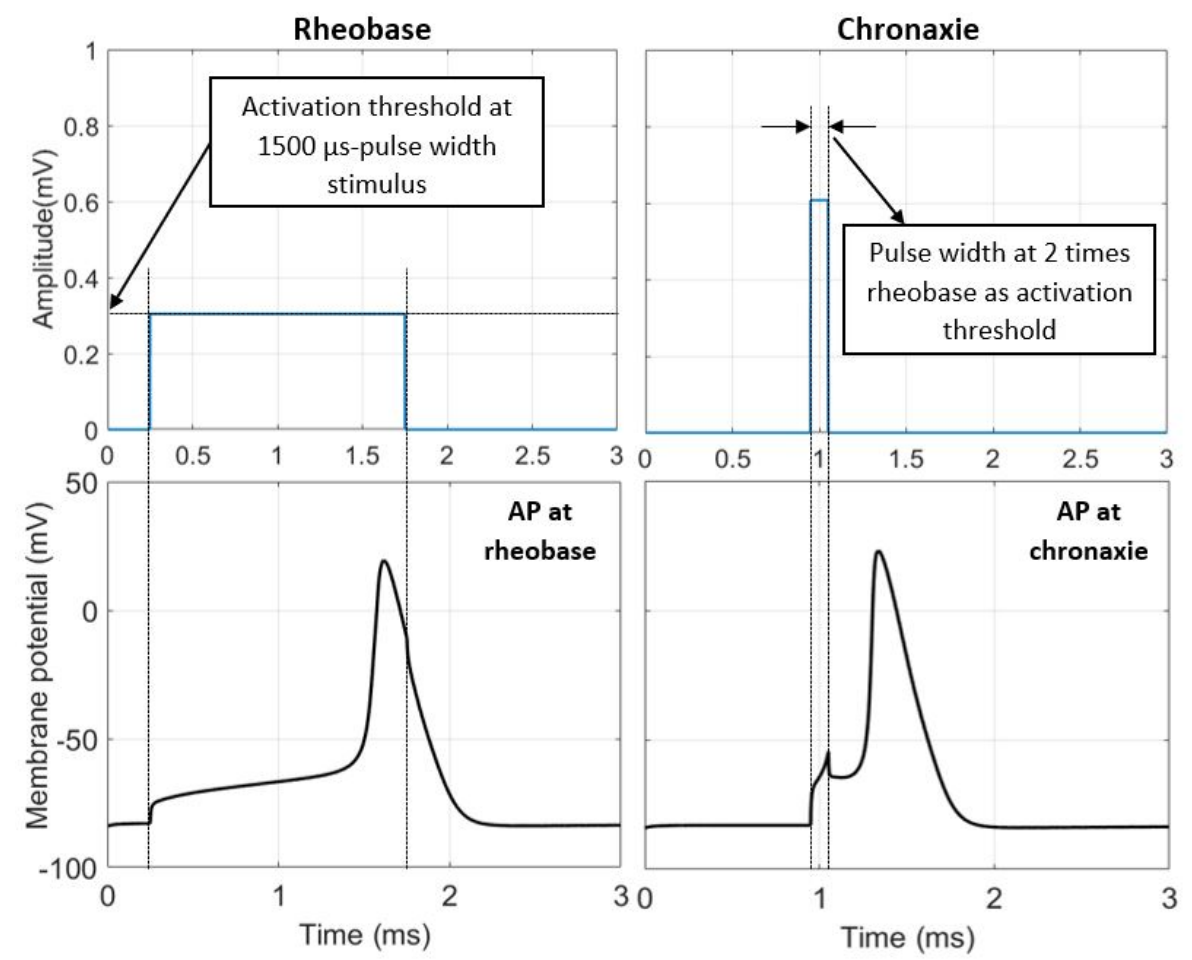

Figure 4.2: Methodology for rheobase (left) and chronaxie (right) values calculation. Electrode-to-axon distance: $500 \mu \mathrm{m}$; nerve fiber diameter: $12.8 \mu \mathrm{m}$.

a stimulus amplitude of 1.2 the voltage threshold $\left(\mathrm{V}_{\text {th }}\right)$.

Chronaxie was also measured and compared to experimental data values. As shown in Fig. 4.2, chronaxie value corresponded to the stimulation pulse width needed to activate a nerve fiber at $2 \mathrm{~V}_{\text {th }}$. $\mathrm{V}_{\text {th }}$ is first measured using a pulse width of $1500 \mu$ s, which is known as rheobase.

Absolute and relative refractory periods were also calculated using the developed nerve fiber model to characterize the refractory behavior of the model. The 
methodology for ARP and RRP calculation is shown in Fig. 4.3. First, to produce an initial action potential, a stimulation pulse width of $100 \mu$ s and an amplitude of $20 \%$ above of the $\mathrm{V}_{\text {th }}$ were used. Then, to elicit a second action potential, the same pulse width of $100 \mu$ s was used, but the amplitude was risen to $4 \mathrm{~V}_{\text {th }}$. Thus, the absolute refractory period corresponded to the maximum interval between two pulses in which no second potential can be produced; and the relative refractory period corresponded to the maximum interval in which an elevated stimulus was required to elicit a second propagating action potential [159].

The simulated action potential obtained from the developed sensory nerve fiber model can be seen in Fig. 4.4. The characteristics measured from the simulation of the action potential were compared against the values estimated from experimental data (see Table 4.2).

We first calculated the action potential amplitude. For this parameter, we obtained a value of $108.5 \mathrm{mV}$. Experimentally, the action potential amplitude in human nerve fibers is around $117 \mathrm{mV}$, according to Schwarz et al. [127]. However, this experimental value corresponded to an action potential produced from a nerve fiber at $25^{\circ} \mathrm{C}$ and not at body temperature $\left(37^{\circ} \mathrm{C}\right)$.

As for $\mathrm{CV}$, the developed nerve fiber model presented a value that was within the physiologic range $(25-70 \mathrm{~m} / \mathrm{s})$ obtained from several experimental studies $[107,115,124,153]$. CV depends directly on nerve fiber diameter; thus, CV increases with fiber diameter. In this case, the value obtained $(50 \mathrm{~m} / \mathrm{s})$ corresponded to a $12.8 \mu \mathrm{m}$-diameter nerve fiber.

Chronaxie values were also calculated. Here, experimental data from mammalian myelinated axons show chronaxie values in the range of 70-90 $\mu \mathrm{s}$ [115], while the experimental range of myelinated axons from rat brain is 106-400 $\mu \mathrm{s}$ [110]. The developed nerve fiber model presented a chronaxie value of $103 \mu \mathrm{s}$, a value $14.44 \%$ higher than the maximum value of the experimental range mammalian DC myelinated axons (90 $\mu$ s) [115], and 2.9\% lower than the minimum value of the experimental data from rat brain [110]. 

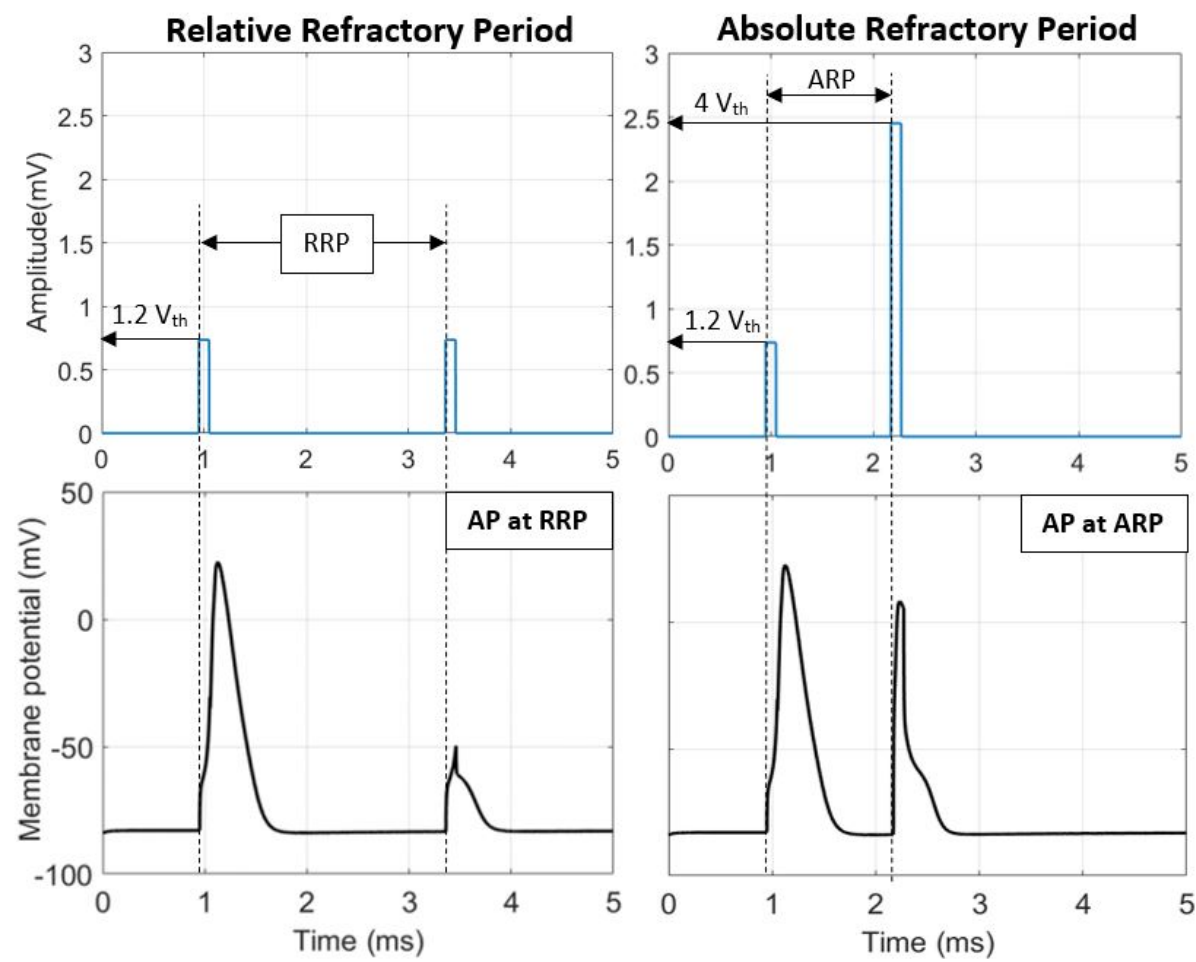

Figure 4.3: Methodology for RRP (left) and ARP (right) values calculation. ARP: absolute refractory period; RRP: relative refractory period. Electrode-to-axon distance: 500 $\mu \mathrm{m}$; nerve fiber diameter: $12.8 \mu \mathrm{m}$.

The absolute and the relative refractory periods (ARP and RRP, respectively) were also measured. ARP was $1.23 \mathrm{~ms}$, which is $55.7 \%$ higher than the maximum value of the experimental range $(0.79 \mathrm{~ms})$. And RRP was $2.42 \mathrm{~ms}$, a value that is within the experimental range (2-3.95 ms) measured from human median and sural nerves [144]. Therefore, the refractoriness of the developed sensory nerve fiber model approximates to sensory human nerve fibers experimental data. 

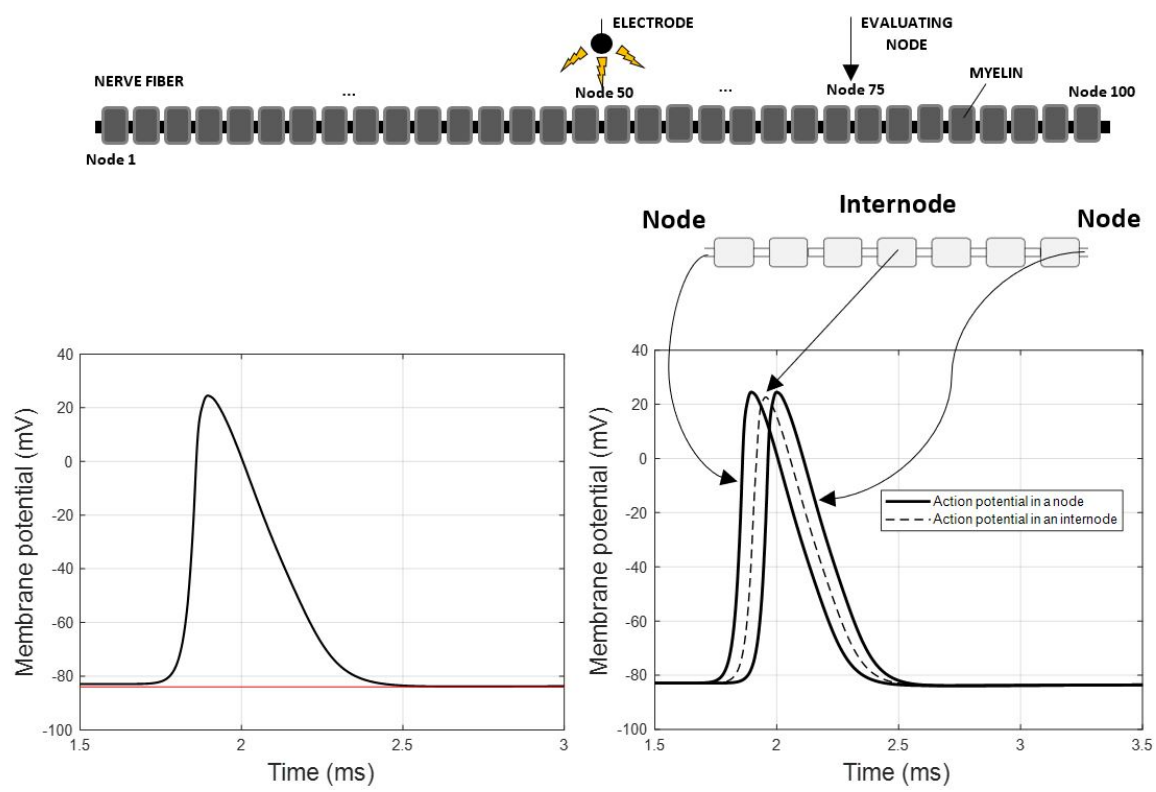

Figure 4.4: Simulated action potentials at $37^{\circ} \mathrm{C}$ obtained with the developed model (left). The horizontal line represents the rest potential considered $(-84 \mathrm{mV})$; and action potential propagation through two nodes of Ranvier and one internode located between them (right). A nerve fiber of $12.8 \mu \mathrm{m}$ in diameter was stimulated with a stimulus of $300 \mu \mathrm{s}$ of pulse width and an amplitude of $1.2 \mathrm{~V}_{\text {th }}$. A separation of 6 nodes of Ranvier between the two nodes was selected to clearly see the action potential propagation. The internode that was just in the middle of the two selected nodes was the one whose action potential is represented in the graph.

On the other hand, the propagation of the action potential through the myelin compartment of the nerve fiber was also simulated (see Fig. 4.4). The myelin is modeled as an imperfect insulator and, when the action potential is propagated through the myelin, current losses are produced. The action potential amplitude is $108.5 \mathrm{mV}$ in the first node of Ranvier but, in the myelin compartment, the amplitude is decreased to $106.7 \mathrm{mV}$ (1.66\% lower). Then, when the action potential is propagated to the following node of Ranvier, the amplitude value remains as in the previous node of Ranvier $(108.5 \mathrm{mV})$. Thus, the figure shows that current 
losses are produced at every internode compartment.

Fig. 4.5 shows the action potential shape of the WHB model and the new nerve fiber model during the afterpotential of a $12.8 \mu \mathrm{m}$-diameter fiber. The figure reveals that neither depolarizing afterpotential nor hyperpolarizing are generated in the WHB model. Therefore, when the action potential is over, the membrane potential is maintained at the initial resting potential $(-84 \mathrm{mV})$, showing no voltage fluctuations. Nevertheless, the new nerve fiber model developed generates a hyperpolarizing afterpotential. In this case, the membrane voltage reaches 0.88 $\mathrm{mV}$ below resting potential immediately following the action potential, then rising gradually back to the resting potential $(-84 \mathrm{mV})$. This voltage fluctuation had

Table 4.2: Characteristics of the Wesselink sensory nerve fiber model and experimentally determined characteristics of myelinated nerve fibers. Calculated values with monopolar stimulus of $100 \mu$ s of pulse width; $12.8 \mu \mathrm{m}$ nerve fiber diameter and $0.5 \mathrm{~mm}$ of distance between the electrode and the nerve fiber. DC: dorsal column; WM: white matter.

\begin{tabular}{|c|c|c|c|c|}
\hline Parameter & $\begin{array}{l}\text { Model val- } \\
\text { ues }\end{array}$ & $\begin{array}{l}\text { Experimen } \\
\text { values }\end{array}$ & data & $\begin{array}{l}\text { Specifications of the } \\
\text { experimental data }\end{array}$ \\
\hline $\begin{array}{l}\begin{array}{l}\text { Amplitude } \\
(\mathrm{mV})\end{array} \\
\end{array}$ & 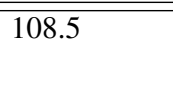 & 117 & [127] & Human, $25^{\circ} \mathrm{C}$ of temperature \\
\hline $\begin{array}{l}\text { Conduction ve- } \\
\text { locity }(\mathrm{m} / \mathrm{s})\end{array}$ & 50 & $\begin{array}{l}25-65 \\
25-70 \\
9-65\end{array}$ & $\begin{array}{l}{[115]} \\
{[153]} \\
{[126]}\end{array}$ & $\begin{array}{l}\text { Mammalian, DC myelinated } \\
\text { axons, WM } \\
\text { Human sural nerve, body tem- } \\
\text { perature } \\
\text { Human peripheral nerves, body } \\
\text { temperature }\end{array}$ \\
\hline Chronaxie $(\mu \mathrm{s})$ & 103 & $\begin{array}{c}70-90 \\
106-400\end{array}$ & $\begin{array}{l}{[115]} \\
{[110]}\end{array}$ & $\begin{array}{l}\text { Mammalian, DC myelinated } \\
\text { axons, WM } \\
\text { Rat brain, myelinated axons, } \\
\text { WM }\end{array}$ \\
\hline $\begin{array}{l}\text { Absolute Re- } \\
\text { fractory Period } \\
(\mathrm{ms})\end{array}$ & 1.23 & $0.58-0.79$ & [144] & Human median and sural nerves \\
\hline $\begin{array}{l}\text { Relative Re- } \\
\text { fractory Period } \\
(\mathrm{ms})\end{array}$ & 2.42 & $2-3.95$ & [144] & Human median and sural nerves \\
\hline
\end{tabular}



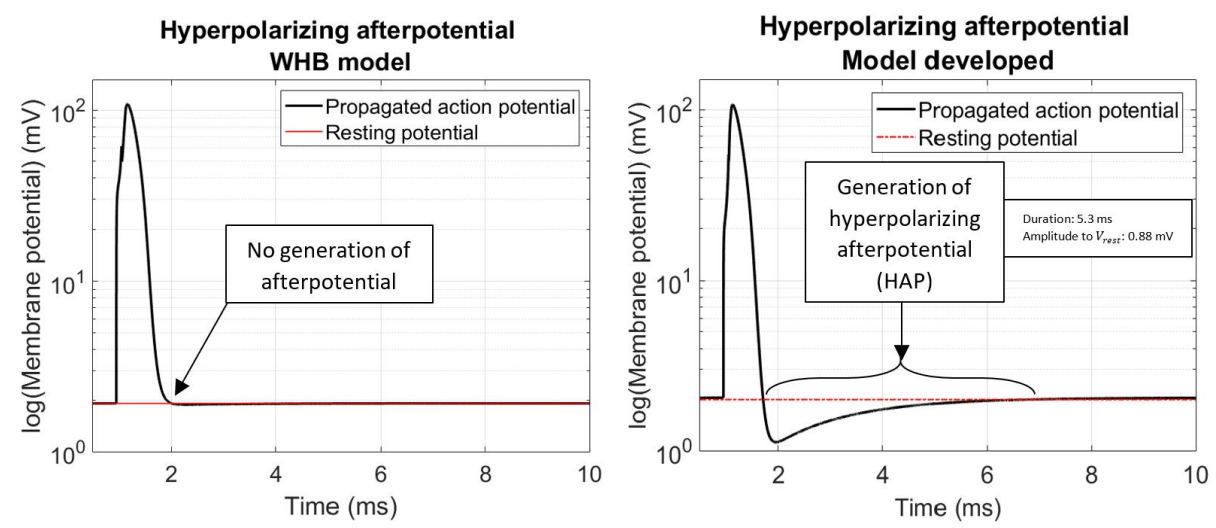

Figure 4.5: Hyperpolarizing afterpotentials obtained with the Wesselink-HolsheimerBoom nerve fiber model (left), and the new nerve fiber developed (right). The curves of the models' response shown are semilog plot of the action potential. The electric response corresponds to a $12.8 \mu \mathrm{m}$-diameter nerve fiber stimulated with a $100 \mu \mathrm{s}$-duration monophasic rectangular pulse. Electrode is located $0.5 \mathrm{~mm}$ from the middle of the axon.

a duration of $5.3 \mathrm{~ms}$. From experimental data, it is shown that motor nerve fibers generate a depolarizing afterpotential following the action potential [29], while sensory nerve fibers produce a hiperpolarizing afterpotential [138]. Therefore, the afterpotential generated by the new nerve fiber model behaves as a sensory nerve fiber.

On the other hand, differences between the action potential durations were also observed. The action potential in the WHB model had longer duration than the new nerve fiber model (1 versus $0.8 \mathrm{~ms}$, respectively). Experimental recordings showed an action potential duration of $2.6 \mathrm{~ms}$. Thus, both the WHB and the new nerve fiber model action potentials were shorter than the experimental data (56.5 and $65.2 \%$ lower, respectively). 
CHAPTER 4. Development of a human $\mathrm{A} \beta$ sensory nerve fiber model

\subsubsection{Electrical behavior of the model}

To examine the electrical behavior of the developed sensory nerve fiber model, conduction velocity-diameter, strength-duration curve, current-distance, and currentdiameter relationships were generated. The strength-duration and CV-diameter curves were also compared to experimental data and previous nerve fiber models (WHB sensory model, MRG motor model, and Gaines et al. sensory model).

The CV-diameter curve also presents differences between the nerve fiber developed and previous nerve fiber models (see Fig. 4.6). Comparing to the MRG motor fiber model, the three sensory nerve fiber models (the WHB model, Gaines et al. model, and the new model developed) show lower $\mathrm{CV}$ for all fiber diameters considered (5-16 $\mu \mathrm{m})$, which matched better to the experimental data obtained from sensory fibers $[126,153]$. The CV values from 5.7 to $8 \mu \mathrm{m}$ in Gaines et al. model and the developed model were lower than the experimental data from Van Veen et al. [153]. However, in the range of 8.7-12.8 $\mu$, both models fitted well to experimental data from Schalow et al. [126]. Thus, the new nerve fiber model presents $\mathrm{CV}$ values that are within the experimental range of sensory nerve fibers, with the advantage of being more realistic than the WHB model, and less computationally complex than the Gaines et al. model.

The strength-duration curve was normalized to the rheobase voltage, as shown in Fig. 4.7. The new nerve fiber model data presents a similar shape to curves obtained with previous nerve fiber models, experimental data, and clinical. The developed model shows lower stimulation threshold values than the experimental, clinical data, and the other computational models for pulse durations below 400 $\mu \mathrm{s}$. For instance, for $100 \mu \mathrm{s}$-duration, threshold stimulus in the developed model is 28.42 and $38.2 \%$ lower than the experimental and the clinical data (2.04 versus 2.85 , and 3.3 the rheobase voltage, respectively), while Gaines et al. model has a threshold stimulus that is 45 and $68.4 \%$ higher (4.8 versus 2.85 , and 3.3 the rheobase voltage, respectively). The WHB sensory fiber model and the MRG motor fiber model present values that are 17.6 and $22.5 \%$ higher than the threshold stimulus obtained with the developed model ( 2.4 and 2.5 versus 2.04 the rheobase voltage, respectively). 


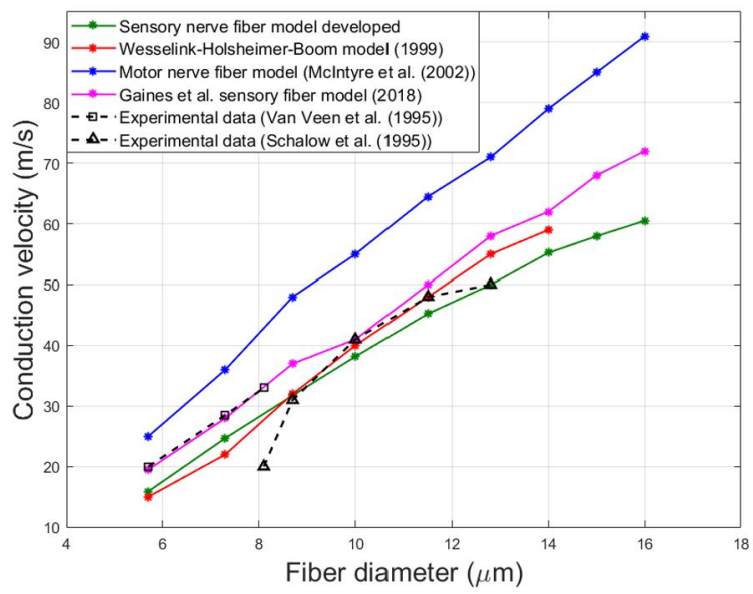

Figure 4.6: Conduction velocity for different fiber diameters $(5.7-16 \mu \mathrm{m})$ of the developed model, WHB model [159], MRG model [96], Gaines et al. model [46], and experimental data from Van Veen et al. [153] and Schalow et al. [126].

The current-distance relationship, i.e. threshold activation as a function of electrode-to-axon distance, was also generated for distance ranging from 100 to $1000 \mu \mathrm{m}$ (see Fig. 4.8). The figure reveals that higher electrode-to-axon distance requires higher threshold stimulation to activate the nerve fiber. Here, the strengthduration curve from the MRG motor nerve fiber model is also shown to compare the results. In this case, the developed sensory nerve fiber model presents higher activation threshold values than the MRG motor nerve fiber model. According to Gaines et al. [46], a sensory nerve fiber model should obtain lower activation threshold values than a motor nerve model, as in real sensory and motor neurons behavior. The unexpected results obtained could be explained by the different $\rho_{\text {ext }}$ value considered in each model. In the developed model the external medium isotropic, thus $\rho_{\text {ext }}$ has a value of $300 \Omega \cdot \mathrm{cm}$. However, to obtain the currentdistance curve, McIntyre et al. considered the nerve fiber within an anisotropic medium, therefore $\rho_{\text {ext }}$ has a longitudinal value $(300 \Omega \cdot \mathrm{cm})$ and transversal $(1200$ $\Omega \cdot \mathrm{cm}$ ) [96]. As higher resistivity values produce lower activation threshold val- 


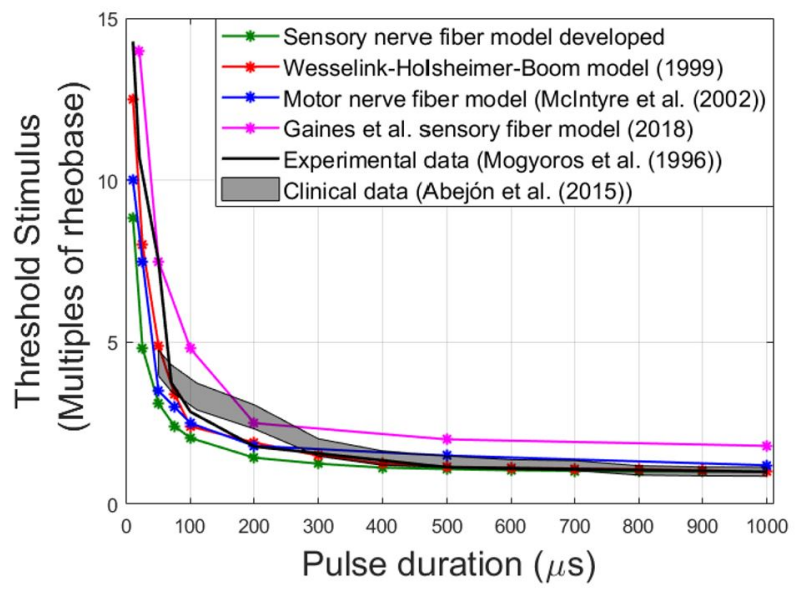

Figure 4.7: Strength-duration curve of the developed model compared to WHB model [159], MRG model [96], Gaines et al. model [46], experimental data (Mogyoros et al. [105]) and clinical (Abejón et al. [1]).

ues (see Section 4.2.3), it could explain why the MRG motor nerve fiber presents lower activation threshold values than the developed sensory nerve fiber model. 

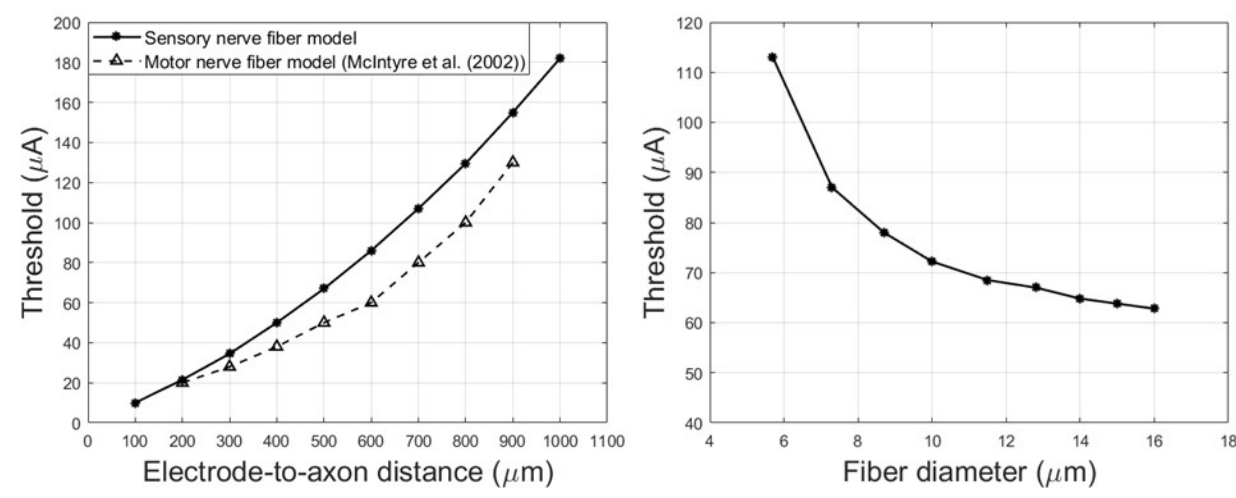

Figure 4.8: Current-distance (left) and current-diameter (right) relationships. Stimulus applied for the current-distance curve: cathodical rectangular monophasic pulse of 100 $\mu$ m-duration. Nerve fiber diameter: $12.8 \mu \mathrm{m} ; \rho_{\text {ext }}: 300 \Omega \cdot \mathrm{cm}$. Stimulus applied for MRG motor nerve fiber model results [96]: cathodical rectangular monophasic pulse. Nerve fiber diameter: $10 \mu \mathrm{m} ; \rho_{\text {ext }}: 300 \Omega \cdot \mathrm{cm}$ (longitudinal) and $1200 \Omega \cdot \mathrm{cm}$ (transversal)). Stimulus applied for the current-diameter curve: cathodical rectangular monophasic pulse of $100 \mu \mathrm{m}$-duration. Electrode-to-axon distance: $500 \mu \mathrm{m}$.

Moreover, the activation threshold stimulus against nerve fiber diameter ranging from 5.7 to $16 \mu \mathrm{m}$ has been obtained (see Fig. 4.8). Here, as nerve fiber diameter increases, activation threshold decreases. This model behavior is in accordance with several previous studies, such as Gaines et al. [46], McIntyre et al. [96], Wesselink et al. [160], and Holsheimer [55]. Thus, the developed sensory nerve fiber model electrically behaves as expected.

\subsubsection{Sensitivity analysis}

Owing the model representation of the myelin as well as the resistivity parameters have an effect on the action potential characteristics, the excitation and conduction properties of the axon model [121], a sensitivity analysis has been carried out examining the relative changes in action potential amplitude, $\mathrm{CV}$, absolute and refractory periods (ARP and RRP, respectively), chronaxie, and activation threshold resulting from scaling: $\mathrm{g}_{\mathrm{m}}$ (specific myelin conductance), $\mathrm{c}_{\mathrm{m}}$ (specific 
CHAPTER 4. Development of a human $\mathrm{A} \beta$ sensory nerve fiber model
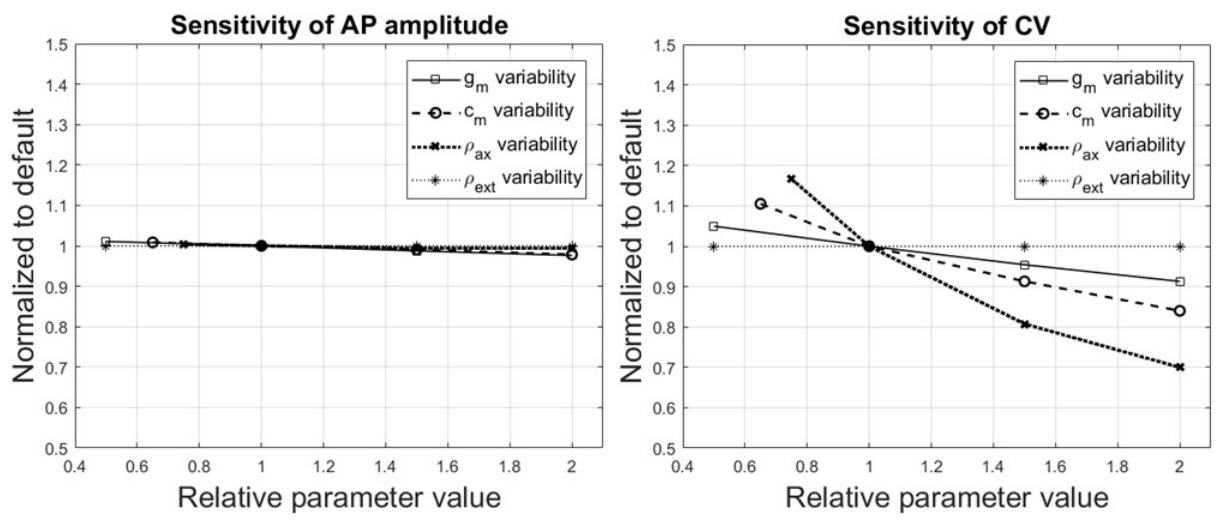

Figure 4.9: Sensitivity analysis of AP (action potential) amplitude (left) and CV (conduction velocity) (right). All parameter values are expressed as multiples of default parameter value. All AP amplitude and CV values are normalized to their respective values obtained with default parameters. Default values: $\mathrm{g}_{\mathrm{m}}: 1 \mathrm{mS} \cdot \mathrm{cm}^{-2} ; \mathrm{c}_{\mathrm{m}}: 0.1 \mu \mathrm{F} \cdot \mathrm{cm}^{-2} ; \rho_{\mathrm{ax}}: 70$ $\Omega \cdot \mathrm{cm} ; \rho_{\text {ext }}: 300 \Omega \cdot \mathrm{cm} ;$ AP amplitude: $108.5 \mathrm{mV} ; \mathrm{CV}: 49.25 \mathrm{~m} / \mathrm{s}$.

myelin capacitance), $\rho_{\mathrm{ax}}$ (axoplasmic resistivity), and $\rho_{\text {ext }}$ (external medium resistivity). The results of the sensitivity analysis were generated by stimulating a 12 $\mu \mathrm{m}$-diameter neve fiber with an extracellular electrode located $500 \mu \mathrm{m}$ from the central node of the axon, applying a monopolar rectangular monophasic pulse of $100 \mu$ s-pulse width.

Fig. 4.9 shows the relative changes of AP amplitude and CV. The figure reveals that AP amplitude is not sensitive to changes in either of $\rho_{\mathrm{ax}}$, and $\rho_{\text {ext }}$, and little sensitive to $g_{m}$ and $c_{m}$ changes, having a maximum of $2.16 \%$ of variation in AP amplitude when the default values are doubled.

On the other hand, $\mathrm{CV}$ also presented no sensitivity to $\rho_{\mathrm{ext}}$ variations. However, changes in $\mathrm{g}_{\mathrm{m}}, \mathrm{c}_{\mathrm{m}}$, and $\rho_{\mathrm{ax}}$ produced significant changes in $\mathrm{CV}$ value (see Fig. 4.9). For instance, when these parameters are doubled, CV decreases by 8.7 , 26 , and $30 \%$ its default value $(49.25 \mathrm{~m} / \mathrm{s})$, respectively. And, when $\mathrm{g}_{\mathrm{m}}, \mathrm{c}_{\mathrm{m}}$, and $\rho_{\mathrm{ax}}$ are 50,35 , and $25 \%$ reduced, CV value increases in the vicinity of 5,11 , and 

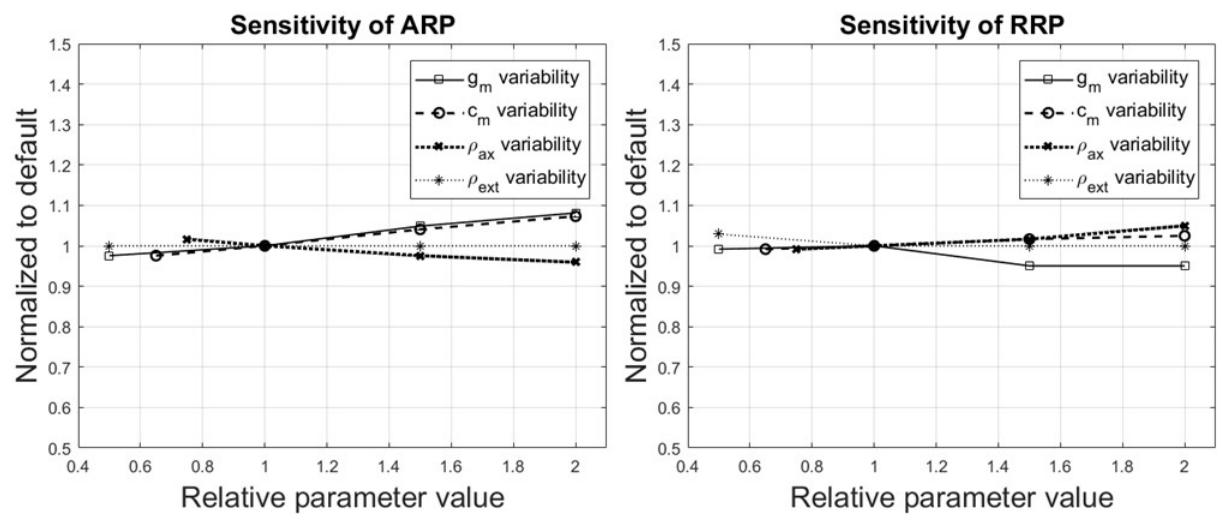

Figure 4.10: Sensitivity analysis of ARP (absolute refractory period) (left) and RRP (relative refractory period) (right). All parameter values are expressed as multiples of default parameter value. All AP amplitude and CV values are normalized to their respective values obtained with default parameters. Default values: $\mathrm{g}_{\mathrm{m}}: 1 \mathrm{mS} \cdot \mathrm{cm}^{-2} ; \mathrm{c}_{\mathrm{m}}: 0.1 \mu \mathrm{F} \cdot \mathrm{cm}^{-2}$; $\rho_{\mathrm{ax}}: 70 \Omega \cdot \mathrm{cm} ; \rho_{\text {ext }}: 300 \Omega \cdot \mathrm{cm}$; ARP: $1.23 \mathrm{~ms}$; RRP: $2.42 \mathrm{~ms}$.

$17 \%$, respectively. Thus, the results also show that $\mathrm{CV}$ is most sensitive to $\rho_{\mathrm{ax}}$ variability.

As for the absolute and refractory periods (ARP and RRP, respectively), the sentivity analysis is shown in Fig. 4.10. In this case, little changes are produced in both ARP and RRP values, not exceeding $10 \%$ of change in any variation of the considered parameters. However, differences were observed between ARP and RRP sensitivity results. For example, ARP is most sensitive to $\mathrm{g}_{\mathrm{m}}, \mathrm{c}_{\mathrm{m}}$ variations, while RRP is most sensitive to $\mathrm{g}_{\mathrm{m}}$ and $\rho_{\mathrm{ax}}$. Moreover, when $\rho_{\mathrm{ax}}$ is doubled, ARP decreases around $4 \%$ the default value $(1.23 \mathrm{~ms})$ while RRP increases by $5 \%$ its default value $(2.42 \mathrm{~ms})$; instead, when $\mathrm{g}_{\mathrm{m}}$ is doubled, ARP reaches the maximum increasing value change $(8.1 \%)$ while RRP reaches the maximum decreasing value change $(5 \%)$. 
CHAPTER 4. Development of a human $\mathrm{A} \beta$ sensory nerve fiber model
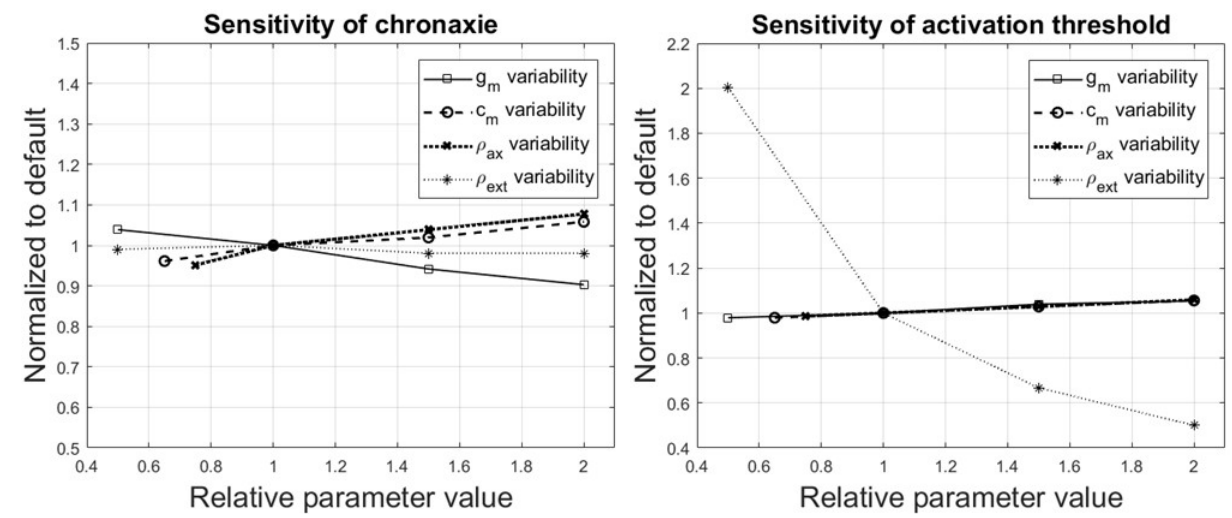

Figure 4.11: Sensitivity analysis of chronaxie (left) and activation threshold (right). All parameter values are expressed as multiples of default parameter value. All AP amplitude and $\mathrm{CV}$ values are normalized to their respective values obtained with default parameters. Default values: $\mathrm{g}_{\mathrm{m}}: 1 \mathrm{mS} \cdot \mathrm{cm}^{-2} ; \mathrm{c}_{\mathrm{m}}: 0.1 \mu \mathrm{F} \cdot \mathrm{cm}^{-2} ; \rho_{\mathrm{ax}}: 70 \Omega \cdot \mathrm{cm} ; \rho_{\mathrm{ext}}: 300 \Omega \cdot \mathrm{cm}$; chronaxie: $103 \mathrm{~ms}$; activation threshold: $66.4 \mu \mathrm{A}$.

Finally, Fig. 4.11 shows the sensitivity analysis results of chronaxie and activation threshold.

Chronaxie shows little changes to $\rho_{\mathrm{ext}}$ variability, since a maximum of $2 \%$ of change is obtained when $\rho_{\text {ext }}$ is doubled. Nevertheless, significant variations are produced when $\mathrm{g}_{\mathrm{m}}, \mathrm{c}_{\mathrm{m}}$, and $\rho_{\mathrm{ax}}$ changed. For instance, chronaxie value presents an increase of 4, 3.9, and $2 \%$ when $\mathrm{g}_{\mathrm{m}}$ is half-reduced, and $\mathrm{c}_{\mathrm{m}}$ and $\rho_{\mathrm{ax}}$ are halfincreased, respectively. On the contrary, chronaxie decreases by 6,4 , and $5 \%$ when $\mathrm{g}_{\mathrm{m}}$ is half-increased, and $\mathrm{c}_{\mathrm{m}}$ and $\rho_{\mathrm{ax}}$ are 35 and $25 \%$ reduced, respectively.

As for activation threshold sensitivity results, the figure shows that activation threshold is most sensitive to $\rho_{\mathrm{ext}}$. Although little variations are produced when $\mathrm{g}_{\mathrm{m}}, \mathrm{c}_{\mathrm{m}}$, and $\rho_{\mathrm{ax}}$ are doubled, i.e. activation threshold approximately increases $6 \%$, the maximum change occurs when $\rho_{\text {ext }}$ is half-reduced, producing an increase of $100 \%$ of the activation threshold default value (133 versus $66.4 \mu \mathrm{A})$. Furthermore, the activation threshold is $50 \%$ lower when $\rho_{\text {ext }}$ is doubled (33.2 versus $\left.66.4 \mu \mathrm{A}\right)$. 

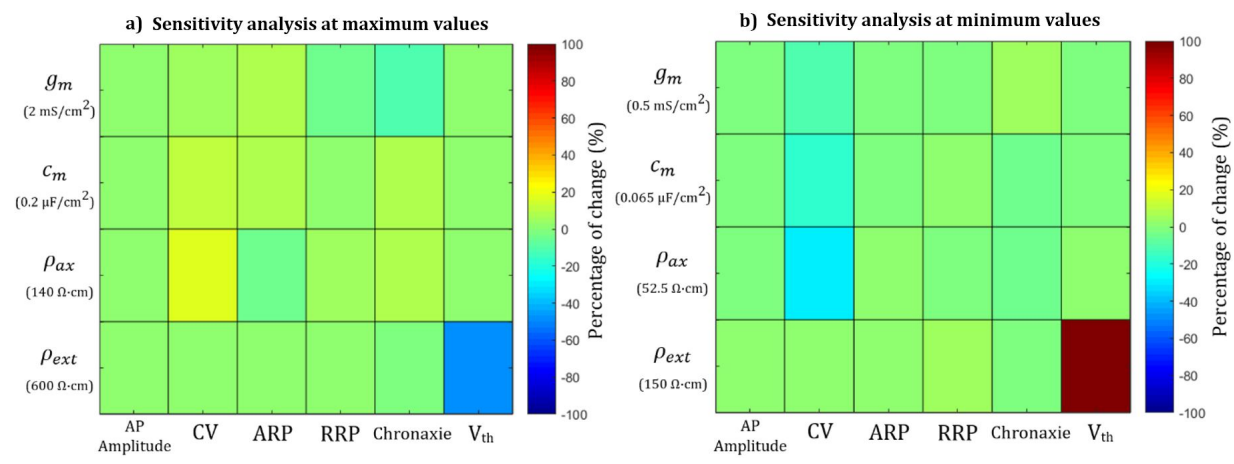

Figure 4.12: Summary of the sensitivity analysis results at a) maximum, and b) minimum values of $\mathrm{g}_{\mathrm{m}}, \mathrm{c}_{\mathrm{m}}, \rho_{\mathrm{ax}}$, and $\rho_{\mathrm{ext}}$ values. The colormap represents the percentage of change in AP (action potential) amplitude, CV (comduction velocity), ARP (absolute refractory period), RRP (refractory relative period), chronaxie, and $\mathrm{V}_{\text {th }}$ (threshold stimulation).

In Fig. 4.12, the results of the sensitivity analysis are shown in a colormap. The figure represents the percentage of change of the AP amplitude, CV, ARP, RRP, chronaxie, and $\mathrm{V}_{\text {th }}$ when $\mathrm{g}_{\mathrm{m}}, \mathrm{c}_{\mathrm{m}}, \rho_{\mathrm{ax}}$, and $\rho_{\text {ext }}$ are at their maximum and minimum values. On the whole, the sensitivity analysis shows that $\mathrm{CV}$ is the most sensitive parameter to $\mathrm{g}_{\mathrm{m}}, \mathrm{c}_{\mathrm{m}}$, and $\rho_{\mathrm{ax}}$ changes; and that activation threshold is the most sensitive parameter to $\rho_{\text {ext }}$ changes (see Fig. 4.12). For the rest of the parameters (AP amplitude, ARP, RRP, and chronaxie), no more than $10 \%$ of change has been obtained at different $\mathrm{g}_{\mathrm{m}}, \mathrm{c}_{\mathrm{m}}, \rho_{\mathrm{ax}}, \rho_{\mathrm{ax}}$ variations. 


\subsection{The role of frequency on $\mathrm{A} \beta$ sensory nerve fibers ac- tivation in tonic stimulation.}

The investigation of the effect of the stimulation parameters by computational modeling is useful for SCS therapy programming optimization. The management of amplitude, pulse width, and electrode configuration on neural activation has been widely studied and is well-established in tonic stimulation, such as Lee et al. [78], that predicted greater activation of medial dorsal column fibers with increased pulse width, which correlated with a clinical study from Yearwood et al. [51]; Holsheimer et al. [60], who observed the major determinant of dorsal column and dorsal root activation is electrode polarity; or Durá et al. [36], that predicted higher dorsal column fibers activation with dual-guarded cathode polarity. However, how to manage frequency remains unclear. Thus, the aim of this work is to study the effect of frequency on the electrical response of sensory $\mathrm{A} \beta$ neurons in tonic stimulation. As for frequency, the recent growing use of new stimulation strategies in clinical practice, such as $10 \mathrm{kHz}[69,148]$ and burst stimulation [32, 114], has increased the interest of studying, by computational modeling, the effect of high-frequency stimulation on $\mathrm{A} \beta$ fibers electrical response, despite the limitation that the mechanisms of actions are still not well-understood for these types of stimulation $[8,79,87]$. Nonetheless, although the mechanisms of action are wellknown for tonic stimulation [20,87, 103, 151], little is known about how "low" stimulation frequency management affects sensory $\mathrm{A} \beta$ nerve fibers activation.

Frequencies between $2-1,200 \mathrm{~Hz}$ can be delivered by most neurostimulators [155]. However, tonic stimulation usually applies an electrical stimulus with a "low" frequency that ranges between $40-60 \mathrm{~Hz}$, a pulse width of 150-500 $\mu \mathrm{s}$, and amplitude producing comfortable tingling sensation (paresthesia) in the painful area of the patient $[20,80,87,103]$. Several studies show that different type of neurons could likely entrain electrical stimulation below $200 \mathrm{~Hz}$ [11, 15, 147], and even at $900 \mathrm{~Hz}$ [103].

The goal of this study is to investigate the electrical response of sensory $\mathrm{A} \beta$ nerve fibers to different frequencies that are available in tonic stimulation. To achieve this, the developed sensory nerve fiber model is used to simulate, by com- 
4.3. The role of frequency on $\mathrm{A} \beta$ sensory nerve fibers activation in tonic stimulation.

putational modeling, the action potential and the evolution of the gates' probabilities of the ionic channels and the firing rate of a nerve fiber at different stimulation frequencies. Finally, the electrical response of two nerve fiber diameters (5.7 and $12.8 \mu \mathrm{m})$ is also shown.

\subsubsection{Effect on nerve fiber activation}

In this study, several stimulation frequencies $(50,350,600,800$, and $1000 \mathrm{~Hz}$ ) were considered to simulate the action potential and the gates' probabilities of the ionic channels of a $12.8 \mu \mathrm{m}$ nerve fiber diameter. A common frequency used in tonic stimulation for SCS therapy is $50 \mathrm{~Hz}$. As shown in Fig. 4.13, when a 50 $\mathrm{Hz}$ stimulus is applied, an action potential every pulse is obtained. At each pulse, the gates' probabilities of sodium ( $\mathrm{m}$ and $\mathrm{h}$ gates) and potassium ( $\mathrm{n}$ gate) channels are ready to electrically depolarize the axon. The time between pulses $(20 \mathrm{~ms})$ is higher than the refractory period of the nerve fiber $(2.42 \mathrm{~ms})$, so the gates of the ionic channels have enough time to recover and are available to be activated again at the next stimulation pulse.

When the stimulation frequency is increased to $350 \mathrm{~Hz}$, an action potential per pulse is also obtained (see Fig. 4.13). In this case, the gates' probabilities of the ionic channels are not totally recovered when the next pulse is applied, since the time between pulses is $11.6 \%$ higher than the relative refractory period ( 2.7 versus $2.42 \mathrm{~ms}$ ), and $119.5 \%$ higher than the absolute refractory period ( 2.7 versus 1.23 $\mathrm{ms}$ ). As shown in Fig. 4.13, at the time the second pulse starts, $\mathrm{m}$ gate (sodium channel) and $\mathrm{n}$ gate (potassium channel) are totally recovered, but $\mathrm{h}$ gate has a value of 0.469 , i.e. it is $76.94 \%$ recovered, which means that the nerve fiber is still in the refractory state. However, the stimulus amplitude applied $\left(1.2 \mathrm{~V}_{\text {th }}\right)$ is strong enough to depolarize the axon again, generating an action potential every pulse.

Fig. 4.14 reveals that at a frequency of $600 \mathrm{~Hz}$ the firing rate of the nerve fiber is reduced by half $(300 \mathrm{~Hz})$ i.e., an action potential is obtained every two pulses. Here, after the first pulse, the axon is depolarized, and then the recovery cycle starts. For this stimulation frequency, the time between pulses is $1.67 \mathrm{~ms}$, which is $35.8 \%$ higher than the absolute refractory period ( $1.23 \mathrm{~ms}$ ) and $31 \%$ lower than 

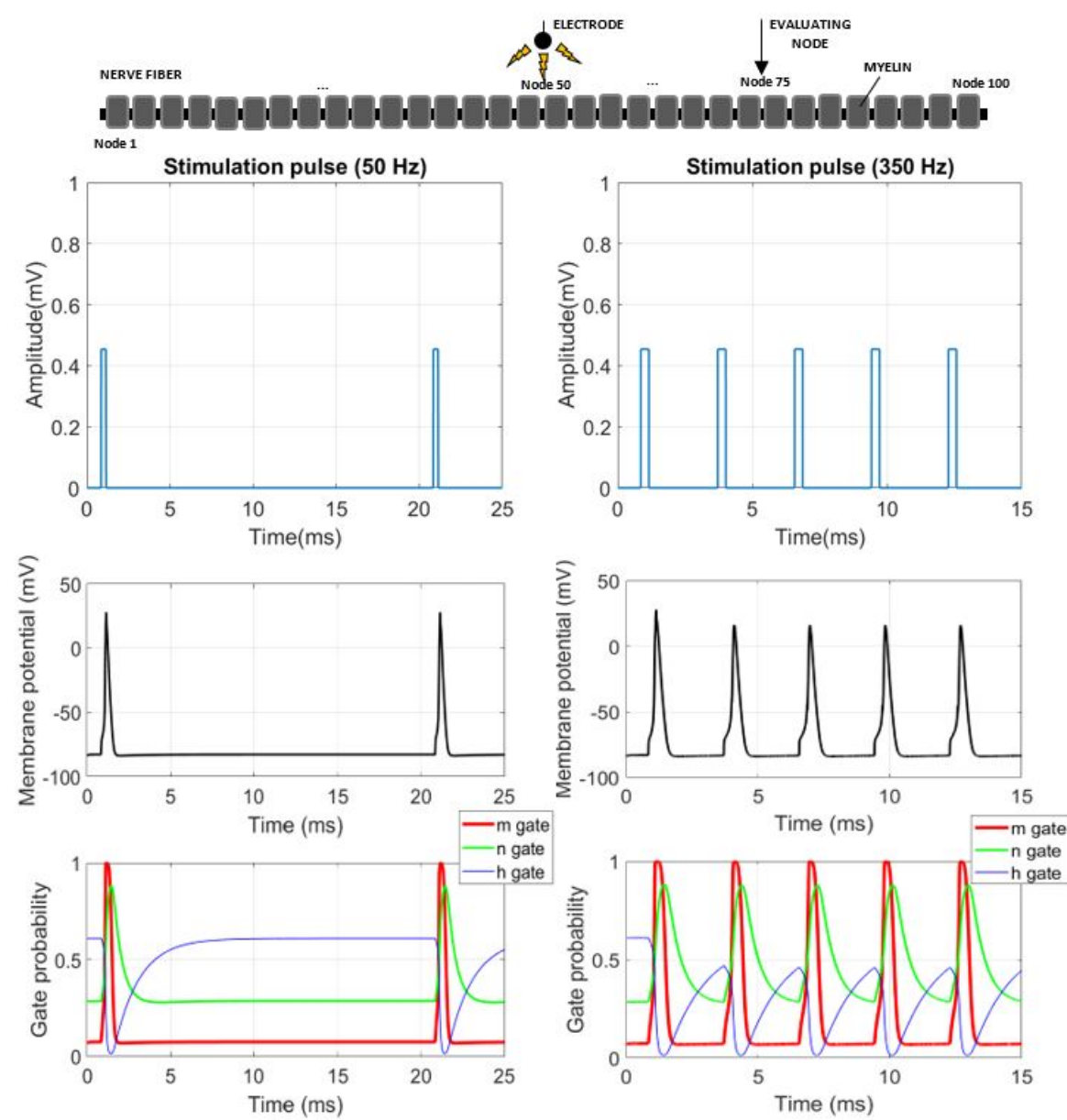

Figure 4.13: Electric response of a $12.8 \mu \mathrm{m}$ nerve fiber during a stimulus with a frequency of $50 \mathrm{~Hz}$ (left) and $350 \mathrm{~Hz}$ (right), and pulse width of $300 \mu \mathrm{s}$. The figures above show the stimulus pattern applied. The figures below show the action potential and the evolution of the gates' probabilities in the node 75 of the nerve fiber at each pulse stimulus. The amplitude applied is $1.2 \mathrm{~V}_{\text {th }}$ (threshold stimulus). Electrode is located at $0.5 \mathrm{~mm}$ from the middle of the axon. 
4.3. The role of frequency on $\mathrm{A} \beta$ sensory nerve fibers activation in tonic stimulation.
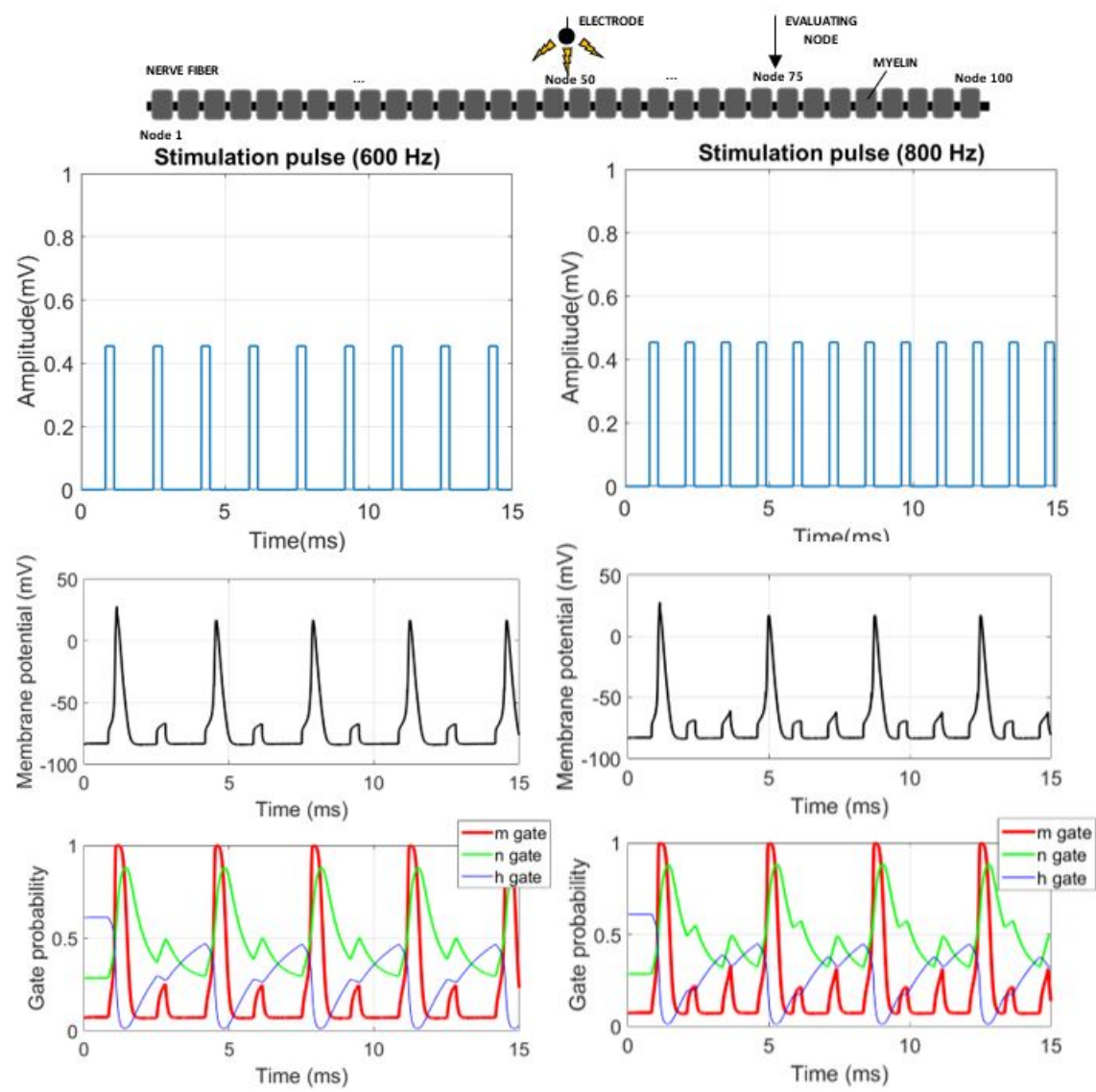

Figure 4.14: Electric response of a $12.8 \mu \mathrm{m}$ nerve fiber during a stimulus with a frequency of $600 \mathrm{~Hz}$ (left) and $800 \mathrm{~Hz}$ (right), and pulse width of $300 \mu$ s. The figures above show the stimulus pattern applied. The figures below show the action potential and the evolution of the gates' probabilities in the node 75 of the nerve fiber at each pulse stimulus. The amplitude applied is $1.2 \mathrm{~V}_{\text {th }}$ (threshold stimulus). Electrode is located at $0.5 \mathrm{~mm}$ from the middle of the axon.

the relative refractory period $(2.42 \mathrm{~ms})$. Although the nerve fiber would be in the refractory state, now the amplitude applied $\left(1.2 \mathrm{~V}_{\text {th }}\right)$ is not strong enough to pro- 
CHAPTER 4. Development of a human $\mathrm{A} \beta$ sensory nerve fiber model

duce another axon depolarization in the second pulse. As shown in Fig. 4.14, m gate (sodium channel) is recovered, but $\mathrm{n}$ gate (potassium channel) has a value of 0.3698 and h gate (sodium channel) is 0.2946 , being at $71.28 \%$ and $48.3 \%$ of their recovery, respectively. Instead, when the third pulse starts, the recovery cycle has progressed; $\mathrm{m}$ and $\mathrm{n}$ gates of the ionic sodium and potassium channels are recovered while $\mathrm{h}$ gate is almost at their initial value (0.4664 versus 0.6096$)$, thus an action potential can be generated again.

On the other hand, with an $800 \mathrm{~Hz}$-stimulus, the sensory fiber is depolarized every three pulses, producing a firing rate that is reduced to one third of the stimulation frequency (see Fig. 4.14). In this scenario, the time between pulses is $1.25 \mathrm{~ms}$, which is $1.63 \%$ higher than the absolute refractory period $(1.23 \mathrm{~ms})$ and $51.65 \%$ lower than the relative refractory period $(2.42 \mathrm{~ms})$. The evolution of the gates' probabilities shows that at the first pulse the action potential is produced. When the second pulse is applied, the fiber had not enough time to recover and leave from the absolute refractory period. Although $\mathrm{m}$ gate (sodium channel) is recovered, $\mathrm{n}$ gate (potassium channel) and $\mathrm{h}$ gate (sodium channel) are still at $28.6 \%(0.4924)$ and $32.46 \%(0.197)$ of their initial values $(0.2873$ and 0.6096 , respectively), hence no depolarization is produced. At the third pulse, the gates of the ionic channels had more time to recover. The time between the third and the first pulses is $2.5 \mathrm{~ms}$, which means that the nerve should have finished the recovery cycle (the relative refractory period is $3.3 \%$ lower than the time between pulses (2.42 versus $2.5 \mathrm{~ms})$ ). However, although the second pulse did not generate an action potential, the gates' probabilities were lightly reverted. Hence, at the third pulse, $\mathrm{m}$ gate is totally recovered, $\mathrm{n}$ gate value is almost at its initial value $(0.3204$ versus 0.2873 , respectively), and h gate recovery has increased to $64.1 \%$. In this case, the stimulation amplitude is not high enough yet, thus an action potential is not produced. But, at the fourth pulse, although the recovery cycle is not finished yet ( $\mathrm{m}$ and $\mathrm{n}$ gates are recovered, but $\mathrm{h}$ gate is at $74 \%$ of its recovery), the time between the first and fourth pulses is $3.75 \mathrm{~ms}$, which is about $55 \%$ higher than the relative refractory period $(2.42 \mathrm{~ms})$, thus the nerve fiber is not in the refractory state and it can be depolarized again. 


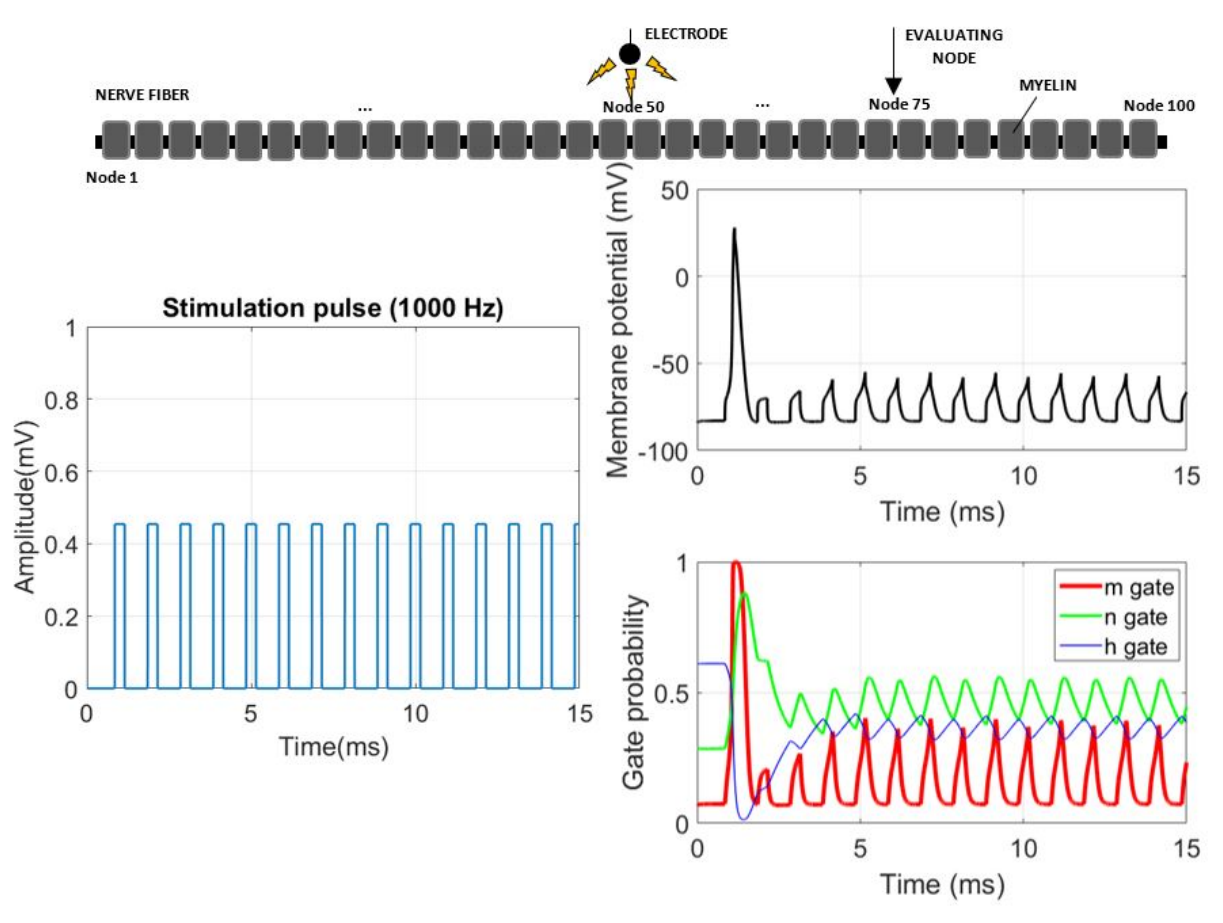

Figure 4.15: Electric response of a $12.8 \mu \mathrm{m}$ nerve fiber during a stimulus with a frequency of $1000 \mathrm{~Hz}$ and pulse width of $300 \mu \mathrm{s}$. The figure above show the stimulus pattern applied. The figure below show the action potential and the evolution of the gates' probabilities in the node 75 of the nerve fiber at each pulse stimulus. The amplitude applied is $1.2 \mathrm{~V}_{\text {th }}$ (threshold stimulus). Electrode is located at $0.5 \mathrm{~mm}$ from the middle of the axon.

The electrical response of a sensory nerve fiber to a $1000 \mathrm{~Hz}$-stimulus is shown in Fig. 4.15. The figure reveals that after the first pulse depolarization, no more action potentials can be generated again. The time between pulses is $1 \mathrm{~ms}$, which is $18.7 \%$ lower than the absolute refractory period $(1.23 \mathrm{~ms})$. At the second pulse, the fiber is still in the absolute refractory period, and the stimulus cannot elicit an action potential. At the third pulse, the nerve fiber would be in the refractory state. But, although the gates have partly recovered, the stimulus is not strong enough to depolarize the fiber. From this point, Fig. 4.15 shows that the recovery 
CHAPTER 4. Development of a human $\mathrm{A} \beta$ sensory nerve fiber model

of the ionic channels gates is slower than in previous pulses. As there is only 1 ms between pulses, the fiber has no time to advance in the refractory state i.e., the recovering produced between pulses is always reverted by the stimulation pulse. Although $\mathrm{m}$ gate recovers completely, $\mathrm{n}$ gate and $\mathrm{h}$ gate recover a maximum of $81 \%$ and $68.72 \%$, respectively. Owing the fiber cannot enter an excitable state as well as the stimulus amplitude is not sufficient to depolarize the nerve fiber, the rest of pulses do not generate action potentials, and the firing rate of the nerve fiber is overridden.

\subsubsection{Patterns of activity and nerve fiber diameter}

According to a histological study from Feirabend et al. [40], the largest fibers that can be recruited in the medial DC have a diameter of $12 \mu \mathrm{m}$. However, the maximum fibers density in the medial DC corresponds to fibers diameters $<7.1$ $\mu \mathrm{m}$. As there are available data for the geometric parameters of 5.7 and $12.8 \mu \mathrm{m}-$ diameter fibers [96], and previous computational models also considered these fiber diameters [79, 82, 141], we simulated the activation pattern of a 5.7 and 12.8 $\mu \mathrm{m}$-diameter nerve fiber in function of the stimulation frequency at different pulse widths: 100,300 , and $500 \mu$ s.

Fig. 4.16 shows that higher stimulation frequencies generate lower firing rates in both fiber diameters $(5.7$ and $12.8 \mu \mathrm{m})$. Moreover, there are frequencies where the firing rate of a $5.7 \mu \mathrm{m}$ nerve fiber is lower than the one of a $12.8 \mu \mathrm{m}$ nerve fiber. For instance, in a $100 \mu$ s-stimuli, a $400 \mathrm{~Hz}$-stimulus produced $400 \mathrm{~Hz}$ of firing rate in a $12.8 \mu \mathrm{m}$-diameter fiber while it is reduced by half $(200 \mathrm{~Hz})$ in a $5.7 \mu$ m-diameter fiber. In a $300 \mu$ s-stimuli, it is with a $600 \mathrm{~Hz}$-stimulus when the firing rate of a $12.8 \mu$ m-diameter fiber is reduced by half $(300 \mathrm{~Hz})$ while it is one-third reduced in a $5.7 \mu \mathrm{m}$-diameter fiber $(200 \mathrm{~Hz})$. A similar effect is obtained with a $500 \mu$ s-stimuli $300 \mathrm{~Hz}$-stimulus, where the firing rate of a 12.8 $\mu$ m-diameter fiber is equivalent to the stimulation frequency $(300 \mathrm{~Hz})$, but the firing rate of a $5.7 \mu \mathrm{m}$-diameter fiber is reduced to one-third $(200 \mathrm{~Hz})$. Therefore, there are ranges of stimulation frequency where the neural activity of small nerve fibers is reduced, and the activity of the large axons is higher. For example, in a $100 \mu$ s-stimuli, the activity of large nerve fibers would be greater than small fibers 
4.3. The role of frequency on $\mathrm{A} \beta$ sensory nerve fibers activation in tonic stimulation.
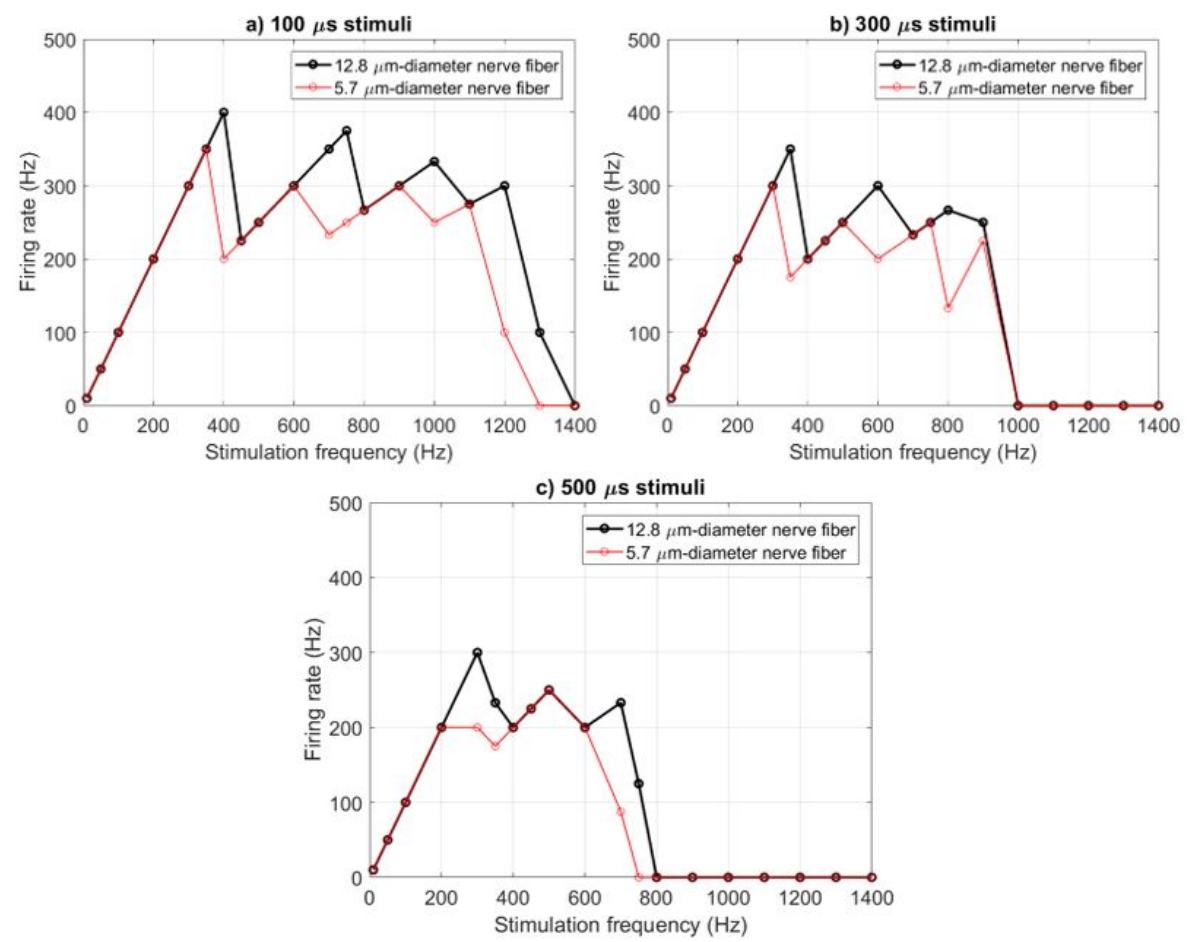

Figure 4.16: Firing rate in function of stimulation frequency for 5.7 and $12.8 \mu \mathrm{m}$ diameter nerve fiber when applying a pulse width stimuli of: a) $100 \mu \mathrm{s}$; b) $300 \mu \mathrm{s}$; and c) $500 \mu \mathrm{s}$. The nerve fibers are stimulated with a rectangular monophasic pulse, and an amplitude of $1.2 \mathrm{~V}_{\text {th }}$ (threshold stimulus). Electrode is located at $0.5 \mathrm{~mm}$ from the middle of the axon.

at $375-425 \mathrm{~Hz}, 600-800 \mathrm{~Hz}, 900-1100 \mathrm{~Hz}$, and $1100-1300 \mathrm{~Hz}$. Instead, in a 500 $\mu$ s-stimuli, the activity of large nerve fibers would be greater than small fibers at 200-400 Hz, and 600-800 Hz.

Fig. 4.16 also reveals that the higher the pulse width is, the firing rate is limited to a lower range of frequencies. Thus, a $100 \mu$ s-stimuli generates firing rates 
from 1 to $1300 \mathrm{~Hz}$; a $300 \mu$ s-stimuli produces firing rates from 1 to $900 \mathrm{~Hz}$; and the firing rate of a $500 \mu$ s-stimuli is produced between 1 and $775 \mathrm{~Hz}$.

Fig. 4.17 shows the neural activity produced when applying a $300 \mu \mathrm{s}, 350 \mathrm{~Hz}$ stimulus in 5.7 and $12.8 \mu \mathrm{m}$-diameter nerve fibers. In $12.8 \mu \mathrm{m}$ nerve fiber, every pulse generates an action potential, while an action potential every two pulses is generated in $5.7 \mu \mathrm{m}$ nerve fiber. At the second pulse, $\mathrm{m}$ (sodium channel) and $\mathrm{n}$ (potassium channel) gates are totally recovered in both nerve fiber diameters, however, the $\mathrm{h}$ gate (sodium channel) value is 0.496 ( $81.4 \%$ recovered) for the $12.8 \mu \mathrm{m}$-diameter fiber and 0.4676 (76.7\% recovered) for the $5.7 \mu \mathrm{m}$-diameter fiber, i.e. the $\mathrm{h}$ gate recovery is faster in the $12.8 \mu \mathrm{m}$ nerve fiber than in the 5.7 $\mu \mathrm{m}$ one. The threshold stimulus needed to activate both fibers is different. In this case, the threshold stimulus to activate a $5.7 \mu \mathrm{m}$-diameter fiber is $80 \%$ higher than the one for a $12.8 \mu \mathrm{m}$-diameter fiber ( 0.81 versus 0.45 , respectively).

\subsection{Discussion}

\subsubsection{New nerve fiber model}

This chapter presents a human $\mathrm{A} \beta$ sensory nerve fiber model that is a combination of the most used nerve fiber models in SCS modeling: a sensory nerve fiber model (the WHB model, which is the one that most approximates to human nerve fibers behavior [159]) and a motor nerve fiber model (the RMG model B, which is the one that most approximates to the real electrical behavior of the myelin [121]).

The main difference between the WHB model and the RMG model B is that they consider different ion channels. While the WHB model considers sodium, fast potassium, and leakage currents to have an approximate behavior of a human sensory nerve fibers, the RMG model B considers fast and persistent sodium current, slow potassium, and leakage currents with the aim of having an approximate behavior of mammalian motor nerve fibers. Moreover, they present a different myelin model; the WHB model considers the myelin as a perfect insulator, which is known to be an incorrect approximation, and thus a limitation of the model [97, 


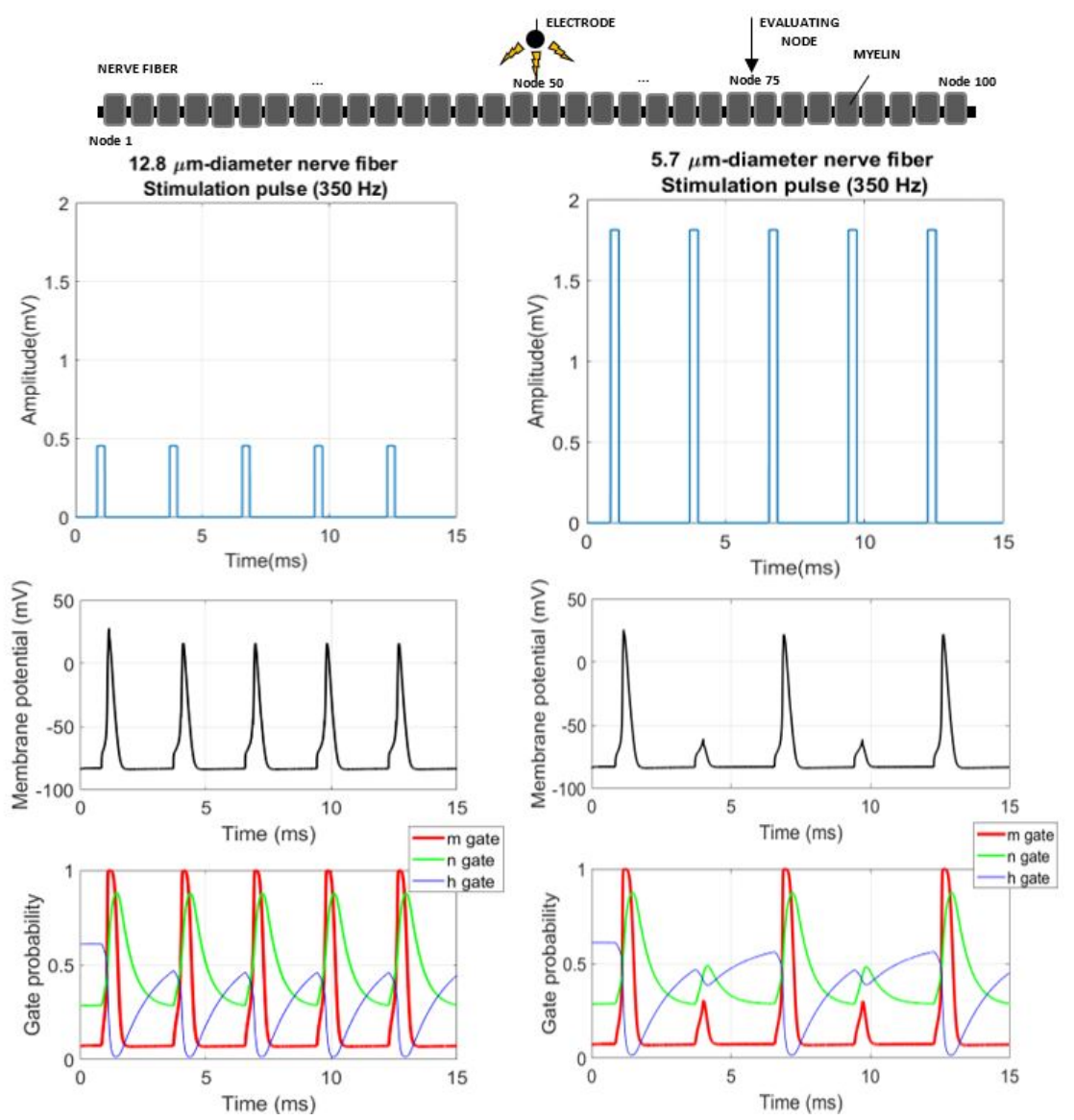

Figure 4.17: Electric response of a $12.8 \mu \mathrm{m}$ nerve fiber (left) and $5.78 \mu \mathrm{m}$ nerve fiber (right) during a stimulus with a frequency of $350 \mathrm{~Hz}$ and pulse width of $300 \mu \mathrm{s}$. The figures above show the stimulus pattern applied to $12.8 \mu \mathrm{m}$ nerve fiber (left) and 5.7 $\mu \mathrm{m}$ nerve fiber (right). The figures of the right column show the action potential and the evolution of the gates' probabilities in the node 75 of the nerve fiber at each pulse stimulus. The amplitude applied is $1.2 \mathrm{~V}_{\text {th }}$ (threshold stimulus). Electrode is located at $0.5 \mathrm{~mm}$ from the middle of the axon. 
159]; and, on the other hand, the RMG model B considers the myelin as an imperfect insulator, i.e. with current losses, which make the model more physiological accurate [121]. With the objective of having a more accurate sensory nerve fiber model, a combination between these two models has been made.

Thus, the new model maintains the same ion channels of the WHB model, and the myelin is modeled as in the RMG model B, i.e., as an imperfect insulator. Some model parameters were calibrated using action potential characteristics derived from physiological data and/or validated in previous computational studies (see Appendix A).

To validate the electrical behavior of the new sensory nerve fiber model, we studied the shape and propagation of the action potential, the generation of afterpotentials, the CV-diameter, strength-duration, current-distance, and currentdiameter relationships.

We observed that amplitude, $\mathrm{CV}$, chronaxie, absolute and relative refractory periods values obtained from the new model present a good approximation to experimental data (see Table 4.2). The inclusion of the myelin as an imperfect insulator had significant changes in the fiber response. On the one hand, when the action potential is propagated to an internodal compartment, there is a decrease of the action potential amplitude, for this model considers current losses produced in the internodes of a myelinated nerve fiber. This effect produced a reduction of the CV, which is in concordance with McIntyre et al. [96]. On the other hand, the finite impedance myelin model considered also produced changes in the strengthduration and CV-diameter curves. From the strength-duration relationship results, the model developed presented a lower threshold stimulus than the WHB model. Furthermore, while the WHB had higher values than the MRG motor model for pulse durations below $200 \mu \mathrm{s}$, the model developed in this study showed lower values than the MRG motor fiber for all pulse durations. This outcome is in concordance with previous modeling results and experimental data [41, 46, 62, 91, 105], which show that sensory nerve fibers have lower stimulation thresholds than motor nerve fibers. 
The CV-diameter curve also showed that the nerve fiber model of this study had lower $\mathrm{CV}$ values than the WHB sensory model for diameters above $8.7 \mu \mathrm{m}$. However, the $\mathrm{CV}$ obtained were within the experimental range from mammalian DC axons [115] and was also lower than the MRG motor nerve fiber, which is in accordance with Dawson et al. [30], who showed that sensory nerve fibers have lower $\mathrm{CV}$ than motor nerve fibers from human experimental data.

Moreover, we adjusted the voltage and time-dependent parameters of the sodium activation and inactivation coefficients. These changes avoided spontaneous firing and favored the generation of hyperpolarizing afterpotential following the action potential (see Fig. 4.13). However, no depolarizing afterpotentials were generated. Both depolarizing and hyperpolarizing afterpotentials can be produced in motor and sensory nerve fibers [96]. However, experimental recordings show that depolarizing afterpotentials are produced after the action potential in motor nerve fibers [29] while hyperpolarizing afterpotentials are produced after the action potential in sensory fibers [138]. According to previous studies [16, 88, 96], the afterpotential phenomena can extend tens of milliseconds after the action potential ( $\sim 20 \mathrm{~ms}$ or more). Therefore, as the maximum timeframe of this study is 20 ms (in $50 \mathrm{~Hz}$-stimulus), we can just consider the hyperpolarization after a spike that affects the refractory time of the nerve fiber model [8].

The current-distance and current-diameter relationships were also generated. Both curve shapes fitted to previous computational modeling studies, i.e. higher distance increases the activation threshold [13, 96, 117, 122, 158], and higher fiber diameter decreases threshold values [46, 55, 97, 163].

To identify the parameters that most affect the nerve fiber model-based predictions, a sensitivity analysis has been performed. The outcome show that CV is the most sensitive parameter to $\mathrm{g}_{\mathrm{m}}, \mathrm{c}_{\mathrm{m}}$, and $\rho_{\mathrm{ax}}$ changes, which is in agreement with Richardson et al. [121]. On the other hand, activation threshold is the most sensitive parameter to $\rho_{\text {ext }}$ changes. For the rest of the parameters (AP amplitude, ARP, RRP, and chronaxie), no more than $10 \%$ of change has been obtained at 
different $\mathrm{g}_{\mathrm{m}}, \mathrm{c}_{\mathrm{m}}, \rho_{\mathrm{ax}}, \rho_{\mathrm{ax}}$ variations.

Hence, the agreement of the nerve fiber model electrical behavior with experimental data and computational modeling studies results makes this computational model valid for SCS computational studies for tonic stimulation.

\subsubsection{Effect of frequency on nerve fiber activation}

Using the developed human $\mathrm{A} \beta$ sensory nerve fiber model, a study was performed to investigate the role of frequency on neural activation. The action potential and the gates' probabilities were simulated at 50, 350, 600, 800, and $1000 \mathrm{~Hz}-$ stimulus, with a pulse width of $300 \mu$ s.

The results show that frequency is the stimulation parameter that allows to increase or decrease the electrical activity of a sensory $\mathrm{A} \beta$ nerve fiber. Thus, while $50 \mathrm{~Hz}$-stimulus produces a firing rate of $50 \mathrm{~Hz}$ in a $12.8 \mu$ m-diameter, the firing rate could be maximized to 350 by applying a $350 \mathrm{~Hz}$-stimulus, since an action potential is obtained every pulse (see Fig. 4.13). North et al. stated that the stimulation rate of the neurons could be doubled by frequency doubling [109], which is in accordance with our results, since a higher stimulation frequency can increase the firing of large sensory $\mathrm{A} \beta$ nerve fibers. On the other hand, the results obtained in this study are also in agreement with the hypothetical neuron response stated by Miller et al. [103], who showed a neuron that would generate an action potential every three pulses when frequency was increased. As shown in Fig. 4.14, at 600$\mathrm{Hz}$ pulse the nerve fiber fires every two pulses while it fires every third pulse at 800 Hz-stimulus. This outcome is in accordance with an experimental study, based on rat DC single axons recordings, from Crosby et al. [27], who showed that the increase of the kilohertz-frequency SCS from 1 to $20 \mathrm{kHz}$ lowered the neuronal activity in the DC. Furthermore, according to Bowman and McNeal [14], stimulation frequencies higher than $1000 \mathrm{~Hz}$ generated a firing decrease and/or blockade of the action potential conduction of single alpha motoneurons from cats. This finding is also presented in Fig. 4.15, which shows how $1000 \mathrm{~Hz}$-stimulus would override the electrical activation of a $12.8 \mu \mathrm{m}$-diameter nerve fiber (only an action 
potential is obtained at the first pulse). As for the gates' probabilities, the results show that $\mathrm{m}$ (sodium channel) gate recovers faster than $\mathrm{n}$ (potassium channel) and $\mathrm{h}$ (sodium) gates, playing an important role in nerve fiber depolarization, but not in repolarization. Although $\mathrm{n}$ and $\mathrm{h}$ gates participate in nerve fiber repolarization, the recovery is slower for h gate. Indeed, Fig. 4.13 and Fig. 4.14 show that the fiber cannot be depolarized until having h gate around 70-75\% recovered. At 1000 Hz-stimulus (see Fig. 4.15), the time between pulses only allows $h$ gate to recover a maximum of $68.72 \%$, then no more action potentials are obtained after the first nerve depolarization. This outcome reveals that sodium channels, and more especifically the $\mathrm{h}$ gates, are the responsible of the sensory nerve fiber excitability, which is in agreement with Bucher and Goaillard [15], who stated that the nerve fiber pattern activity is limited by the refractory period as well as the sodium channel inactivation. Another experimental study from Ackermann et al. [2] showed that fast sodium conductances play a role in determining the frequency at which the fiber was blocked. And a previous kilohertz-stimulation computational study from Arle et al. also stated that $\mathrm{h}$ gate was one of the primary ionic gate dynamics leading to high frequency blocking phenomena [8].

Therefore, the results of this study suggest that, in tonic stimulation, i.e., supra-threshold stimulation, low- (from 1 to $50 \mathrm{~Hz}$ ), mid- $(50-500 \mathrm{~Hz}$ ), and high$(>500 \mathrm{~Hz})$ frequency stimulation could have important implications in clinical practice. For instance, low-frequency would activate $\mathrm{A} \beta$ fibers at each pulse, yielding pain relief with a low duty cycle (low energy consumption) [103, 129]. Mid-frequency would also produce A $\beta$ fibers firing at each pulse up to $350 \mathrm{~Hz}$, which would suppose the increase of $\mathrm{A} \beta$ neurons activity at the cost of increasing energy consumption. In this case, the cost-efficacy in terms of energy consumption of stimulation frequencies ranging from 50 to $350 \mathrm{~Hz}$ should be analyzed clinically to determine the stimulation frequency that is more efficient to produce pain relief. And high-frequency $(>500 \mathrm{~Hz})$, instead, would increase energy consumption without increasing sensory $\mathrm{A} \beta$ fibers firing, even going so far as to override the electrical activity of the sensory A $\beta$ fibers $(1000 \mathrm{~Hz})[103]$.

On the other hand, not only does the stimulation pattern of an axon depend on 
the pulse frequency, but it also depends on the pulse width utilized and the size of the nerve fiber. As shown in Fig. 4.17, there are ranges of frequencies where the firing rate of large $(12.8 \mu \mathrm{m}$-diameter) fibers is higher than the one of small (5.7 $\mu$ m-diameter) fibers. This outcome demonstrate the hypothesis proposed by Miller et al. [103], who stated that the percentage of activated axons at any point in time would depend on the charge delivered as well as the depolarization and refractory period state. Moreover, Parker et al. provided direct electrophysiological evidence of recruitment of large-diameter, high-conduction-velocity $\mathrm{A} \beta$ sensory nerve fibers in the dorsal columns of the human spinal cord from measurements of evoked compound action potentials from patients undergoing SCS for pain relief [113]. According to Richardson et al. [121], variations in both the myelin conductance and capacitance $\left(\mathrm{G}_{\mathrm{m}}\right.$ and $\left.\mathrm{C}_{\mathrm{m}}\right)$ influence the excitation and conduction properties of the neuron, such as the chronaxie time, conduction velocity, or rheobase amplitude. As both the $G_{m}$ and the $C_{m}$ depend on the geometric parameters of the nerve fiber considered (see Appendix), the higher electrical response observed in the $12.8 \mu \mathrm{m}$-diameter fiber compared to the $5.7 \mu \mathrm{m}$-diameter fiber could be explained by the differences produced in the internodal parameters. Hence, as the refractory period is higher in small sensory fibers, it could be possible to modulate the neural activation of different neural structures to maximize the activity of the large $\mathrm{A} \beta$ neurons in SCS. This finding is in accordance with Mahmud and Vassanelli [89], who showed that the difference in membrane conductance properties of excitatory and inhibitory neurons allows modulating their firing by the stimulation wave parameters.

Besides, the results show that the firing rate of a nerve fiber depends on the pulse width, since frequency and pulse width are inversely related when rectangular stimulation pulses are used [103]. Hitherto, the increase of pulse width produces lower firing rates, for the range of stimulation frequencies are also reduced (see Fig. 4.16).

Therefore, the knowledge of the electrical and geometrical properties of different neural structures, such as motoneurons, pyramidal neurons, sensory neurons, glial cells, etc., and the posterior development of computational neural models 
could help to better manage the frequency stimulation parameter to increase (or decrease) the activity of the targeted neural structures in a population of neurons.

In SCS therapy for chronic pain treatment, the stimulation protocols that are used in clinical practice can be divided into two groups: paresthesia-based SCS, known as tonic or "low" frequency stimulation; and paresthesia-free SCS, such as burst, high-frequency, and 10-kHz high-frequency SCS. While tonic stimulation uses supra-threshold stimulus and the mechanisms of action are well-known, the paresthesia-free protocols use sub-threshold stimulus, and the mechanisms of action are still unrevealed $[20,67,151]$. However, the advantage of paresthesia-free SCS is that patients can have pain relief without noticing the paresthesia sensation $[3,123]$. In terms of energy cost, tonic stimulation is the most efficient, for it produces pain relief with the lowest duty cycle compared to burst or $10-\mathrm{kHz}$ stimulation (4.6\% versus 20 and 30\%, respectively), as stated by Miller et al. [103]. Hence, the increase of alternative frequencies and stimulation patterns to improve patient's experience makes necessary the performance of computational studies that help us to understand the effect of the stimulation parameters for the better management of SCS therapy.

\subsubsection{Limitations}

In the sensory nerve fiber model developed in this chapter, the myelin is modeled as a linear conductance in parallel with the membrane capacitance. There are more sophisticated sensory nerve fiber models developed, such as Howells et al. [62], Zhu et al. [163], and Gaines et al. [46], that include different segments (paranodal, juxtaparanodal, and internodal), in addition to ionic channels (fast $\mathrm{K}^{+}$, slow $\mathrm{K}^{+}$, leak, and hyperpolarization-activated cyclic-nucleotide gated $(\mathrm{HCN}))$ in the internodes, which have a significant influence on the resting potential, and fiber accommodation [62]. Although these models are physiologically more accurate, the added computational complexity, and the parameter uncertainty of the dynamic behavior of the internodal channels these models present justify the use of the simplified sensory nerve fiber model developed in this study [46, 96, 121]. Nonetheless, a recent study from Joosten and Franken [67] indicates that tonic SCS can depolarize the sensory $\mathrm{A} \beta$ fibers in both the antidromic and or- 
thodromic directions. Antidromically, due to sensory $\mathrm{A} \beta$ fibers are branched, the inhibitory interneurons located in the dorsal horn can be activated, inhibiting then the incoming signals from nociceptors and thus closing the "spinal gate of pain". Therefore, future sensory nerve fiber models should include branch points since it could increase the accuracy of the model-based predictions when investigating the excitability of sensory $\mathrm{A} \beta$ nerve fibers.

The study performed in Section 4.3 of this chapter is focused on the simulation of the effect of frequency on neural activation in tonic stimulation. It is wellknown that stimulation frequencies ranging between $40-60 \mathrm{~Hz}$ produce paresthesia and increase GABA neurotransmitter release from GABAergic inhibitory interneurons that are activated by $\mathrm{A} \beta$ fibers inputs, according to the gate-control mechanism of action [50]. However, higher frequencies seem to produce other mechanisms that help to relief neuropathic pain, such as $100 \mathrm{~Hz}$, that likely activates endogenous $\delta$-opioid systems; or $500 \mathrm{~Hz}$, that was shown to improve peripheral blood flow $[50,103]$. The developed nerve fiber model does not consider any transsynaptic network processing nor any neurotransmitters release, which are known processes involved in the tonic SCS mechanisms of action [67]. Thus, the real clinical effects could differ from the clinical implications exposed from the results of this work.

A recent computational study from Arle et al. [7] shows that threshold accommodation is higher in the large-diameter fibers than in the small ones, yielding thus the inversion of larger and smaller diameter fiber thresholds. Unlike tonic spinal cord stimulation, the accommodation phenomenon could suppose the recruitment of smaller DC fibers (medium-diameter fibers) in burst stimulation and high-frequency stimulation, which could explain the paresthesia-free mechanism of action treatments [7]. Fiber accommodation phenomenon is produced after applying a single or a train of conditioning pulses, which help us to investigate the fiber's excitability [7, 62, 85, 86]. Owing to conditioning pulses are not used in SCS therapy, nor are different stimulus pulses applied simultaneously, we did not analyze the threshold accommodation phenomenon in this work. Nonetheless, future computational studies that use conditioning stimulus should consider this 
effect to investigate the influence of fiber accommodation.

The effect of the stimulation amplitude to different stimulation frequencies on the neuronal activation pattern was not included in this study. According to Miller et al. [103], the amplitude should be considered when discussing the neural mechanisms of SCS frequency. For example, with moderate-high amplitude, the high frequency could induce axonal blocking mechanisms, while subthreshold stimulation could favor non-activating neuronal mechanisms, such as temporal summation, or desynchronization of the neural activity [71, 79]. Thus, future computational studies related to the effect of frequency on neural response in SCS therapy for chronic pain treatment should include the influence of the stimulation amplitude.

The findings of this computational study are based on the electrical response of a single sensory $\mathrm{A} \beta$ nerve fiber under extracellular stimulation. Although the outcome of this work has been extrapolated to possible clinical implications in tonic SCS, both a computational study using a realistic SCS model, and a clinical study related to the effect of the stimulation frequency in tonic SCS should be performed to validate the results. The nerve fiber distribution in the dorsal columns, the electrical properties of the spinal cord, and the different spinal elements involved in the mechanisms of action of tonic SCS are elements that should be considered in future research works to increase the accuracy of the model-based predictions in SCS therapy.

\subsection{Summary}

In this chapter, a human $\mathrm{A} \beta$ sensory myelinated nerve fiber model is first described. The main novelty of this model is that it reproduces the electrical behavior of human $\mathrm{A} \beta$ sensory fibers, which are the SCS therapy target in tonic stimulation. The model is based on human nerves experimental data. Moreover, it includes a realistic internodal (myelin) model with low computational complexity.

To examine the electrical behavior of the developed nerve fiber model, the 
shape of the action potential is analized, including the measurements of the following parameters: action potential amplitude, conduction velocity, chronaxie, and both absolute and relative refractory periods. In addition to this, conduction velocity-diameter, strength-duration, current-distance, and current-diameter relationships are generated and compared to previous experimental data and computational modeling studies, showing a well-matching.

The chapter also includes a sensitivity analysis that was conducted to identify the parameters of the developed model that most affect the model-based predictions. the results show that conduction velocity is the most sensitive parameter to changes in specific myelin conductance $\left(\mathrm{g}_{\mathrm{m}}\right)$ and capacitance $\left(\mathrm{c}_{\mathrm{m}}\right)$, and axonal resistivity $\left(\rho_{\mathrm{ax}}\right)$. And, as for the absolute activation threshold value, it showed to be the most sensitive to external resistivity $\left(\rho_{\text {ext }}\right)$.

In the last section of the chapter, a study is performed to investigate the role of frequency on $\mathrm{A} \beta$ human sensory nerve fibers activation in tonic stimulation, using the sensory nerve fiber developed. According to the results, frequency could have a considerable implication on the modulation of the firing rate of a nerve fiber. Thus, the frequency could play an important role to select and increase the activity of specific neural elements of the spinal cord in SCS therapy. 


\section{Chapter 5}

\section{Development of a realistic generalized spinal cord volume conductor model}

The publications related to this chapter are:

1.- Jose L. Durá, Carmen Solanes, Jose De Andrés, Javier Saiz, Computational Study of the Effect of Electrode Polarity on Neural Activation Related to Paresthesia Coverage in Spinal Cord Stimulation Therapy, In Neuromodulation, Vol 22, 2019, Pag 269-279, ISSN 1094-7159, https: // doi.org/10.1111/ner.1290 9. (Impact Factor 2019: 4.029 Q1 (46/204) Clinical Neurology) (Co-first author. José Luis Durá and Carmen Solanes contributed equally to this work).

2.- Carmen Solanes, Jose L. Durá, Jose De Andrés, Javier Saiz, Effect of electrode polarity on paresthesia coverage in spinal cord stimulation, In World Congress on Medical Physics \& Biomedical Engineering. Pag 389. 3-8 June, 2018, Prague, Czech Republic.

3.- Carmen Solanes, Jose L. Durá, Jose De Andrés, Javier Saiz, Estudio del efecto de la posición, polaridad y número de electrodos sobre el área de 
CHAPTER 5. Development of a realistic generalized spinal cord volume 72 conductor model

parestesia en la terapia de EME mediante el uso de un modelo 3D de médula espinal, In XXXV Congreso Anual de la Sociedad Española de Ingeniería Biomédica (CASEIB 2017). Pag 353-356. 29th November-1st December, 2017, Bilbao, Spain.

\subsection{Motivation}

This chapter is aimed to accomplish the second specific objective stated in Chapter 1 , which is the development of a realisitc generalized spinal cord volume conductor computational model. This work will also contribute to the study of the effect of one of the stimulation parameters (polarity) to optimize SCS therapy, that is the main goal of this thesis.

Generalized spinal cord models have shown to be useful to study the effect of the stimulation parameters on neural response with low computational cost. In fact, over the past 40 years, several spinal cord models have been developed, becoming more accurate and realistic thanks to the increased spinal cord geometric data availability and computing capabilities. In this sense, the first SCS models, such as Coburn et al. [25] and Struijk et al. [142], are based on cervical measurements from cadavers, and included geometric parameters that were poorly known, such as the CSF layer. When a study about magnetic resonance (MR) spinal cord assessment of C4-C5, T5-T6, and T11-T12 vertebral levels in healthy subjects conducted by Holsheimer et al. was published [53], more realistic SCS models were developed, such as Manola et al. [93], Lee et al. [78], Arle et al.[6], and Veizi et al [154]. And others, although the SCS models include more detailed tissue anatomy, such the spinal cord vasculature in Khadka et al. [70], or the dorsal root entry zone arc length in Viljoen et al. [156], they include tissues that are still based on cadaveric measurements $[4,79]$.

Owing to the lack of realistic SCS models for T8-T10 vertebral levels, where electrodes are usually implanted for epidural stimulation, this chapter proposes a new SCS model based on in vivo spinal cord measurements from high-resolution MR images. Besides, a sensitivity analysis is performed to identify the geometric 
and electrical parameters that most affect the model results. Finally, to show the generalized SCS model usefulness, a computational study of the effect of electrode polarity on neural activation is conducted, comparing the most known polarities used in clinical practice.

\subsection{Generalized SCS model description}

A 3D volume conductor model of the spinal cord for T8, T9, and T10 vertebral levels was developed using real geometric parameters from a magnetic resonance imaging (MRI) study of the human spinal cord of 23 volunteers [42] (see Fig. 5.1).

The measurements considered are the following: the anteroposterior diameter ( $\varnothing \mathrm{AP})$, transverse diameter $(\varnothing \mathrm{T})$, distance between the dura mater and spinal cord in anterior $(\mathrm{A})$, posterior $(\mathrm{P})$, right $(\mathrm{R})$, and left $(\mathrm{L})$ directions, and posterior width (PW) (see Fig. 5.2(a)) [42]. All measurements were taken in the prone position. The values of all gemetric parameters of $\mathrm{T} 8, \mathrm{~T} 9$, and $\mathrm{T} 10$ vertebral levels are shown in Appendix C (Table C.1). A FEM model was created in COMSOL Multiphysics $^{\circledR}$ (version 5.6) which included the following tissues: grey and white matter, cerebrospinal fluid (CSF), dura mater, fat, and bone (see Fig. 5.2(b)).

In the model, dura mater has a thickness of $0.3 \mathrm{~mm}$, for the maximum dura mater thickness in the human spinal cord at the L2-L4 levels is $0.3 \mathrm{~mm}$, according to previous studies $[119,120,161,162]$. The fat tissue has $4 \mathrm{~mm}$, and bone has $10 \mathrm{~mm}$.

The electrodes model corresponds to a common stimulation lead size used in SCS therapy. Thus, they are modeled as multipole percutaneous leads with the electrode contacts (poles), the insulation, and the electrode-tissue interface (see Fig. 5.2(d)). Eight poles are considered since commonly used percutaneous leads have eight contacts. Percutaneous leads are modeled as cylinders with a length of $24 \mathrm{~mm}$ and a diameter of $1.3 \mathrm{~mm}$. The contacts (conducting domains) have a length of $3 \mathrm{~mm}$, and they are spaced $4 \mathrm{~mm}$ apart with the application of an insulating polymer (non-conductive domains). The electrode-tissue interface is modeled 
CHAPTER 5. Development of a realistic generalized spinal cord volume 74 conductor model
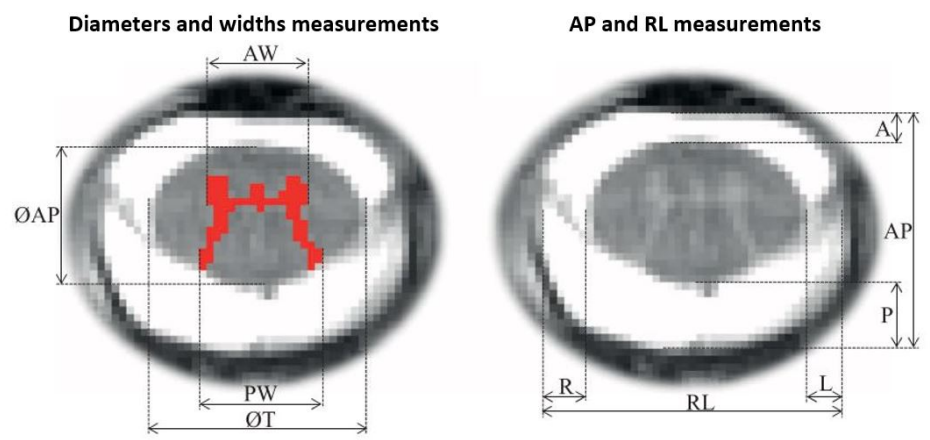

Figure 5.1: Measurements from a MRI of the human spinal cord. Image modified from Fradet et al. [42].

as a $0.1 \mathrm{~mm}$-thickness howllow cylinder which covers the active contacts. Until now, this structure has only been considered in a deep brain stimulation model developed by Butson et al. $[18,98]$. The electrodes model is located in the epidural space of the SCS model. The distance between electrodes and the electrode-dura mater distance are defined according to the study to be performed.

Table 5.1: Tissue electrical conductivities considered in the conductor volume model of the spinal cord.

\begin{tabular}{l|l|l} 
Material & Electrical conductivity $(\mathbf{S} / \mathbf{m})$ & References \\
\hline \hline Grey matter & 0.23 & {$[6,55,76]$} \\
\hline \multirow{2}{*}{ White matter } & $\begin{array}{l}\text { Transversal: } 0.083 \\
\text { Longitudinal: } 0.6\end{array}$ & {$[6,55,76]$} \\
\hline Cerebrospinal fluid (CSF) & 1.7 & {$[6,55,76]$} \\
\hline Dura mater & 0.03 & {$[111]$} \\
\hline Fat & 0.04 & {$[6,55,76]$} \\
\hline Bone & 0.02 & {$[76],[111]$} \\
\hline Poles (platinum-iridium alloy) & $5.278 \cdot 10^{6}$ & {$[26]$} \\
\hline Insulation & 0.002 & {$[111]$} \\
\hline Electrode-tissue interface & 0.15 & {$[95]$} \\
\hline \hline
\end{tabular}




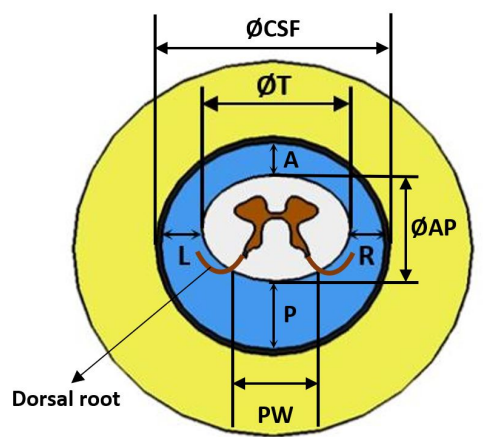

(a) Geometric parameters of the model.

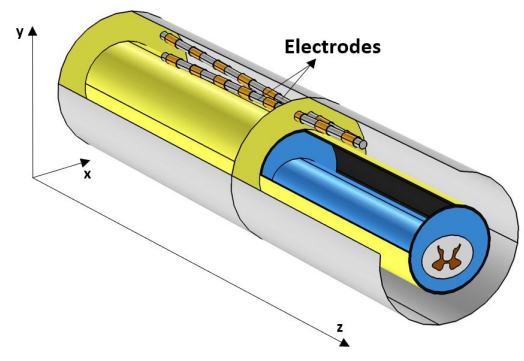

(c) Dimensions of the generalized model. Electrodes are in the epidural space. Bone tissue is not shown.

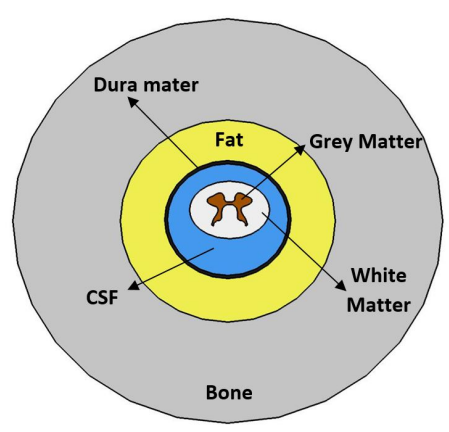

(b) Tissues considered in the model.

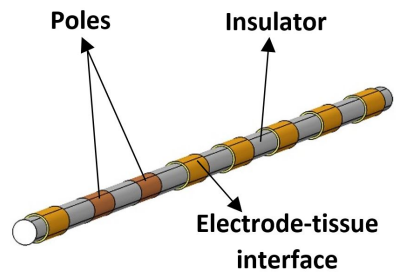

(d) Parts of the electrode model.

Figure 5.2: Generalized volume conductor model of the spinal cord.

The electrical tissue conductivities considered were obtained from $[6,26,55$, 76, 95, 111] (see Table 5.1). The volume conductor model measured 45 (x) mm $\times 42(\mathrm{y}) \mathrm{mm} \times 88(\mathrm{z}) \mathrm{mm}$, as shown in Fig. 5.2(c).

A tetrahedral adaptive mesh was used to avoid errors in the narrow and edge zones (see Fig. 5.3). The model uses just under 3,800,000 elements with a maximum element edge length of $1.94 \mathrm{~mm}$ and a minimum of $0.05 \mathrm{~mm}$. In the white 
CHAPTER 5. Development of a realistic generalized spinal cord volume 76 conductor model

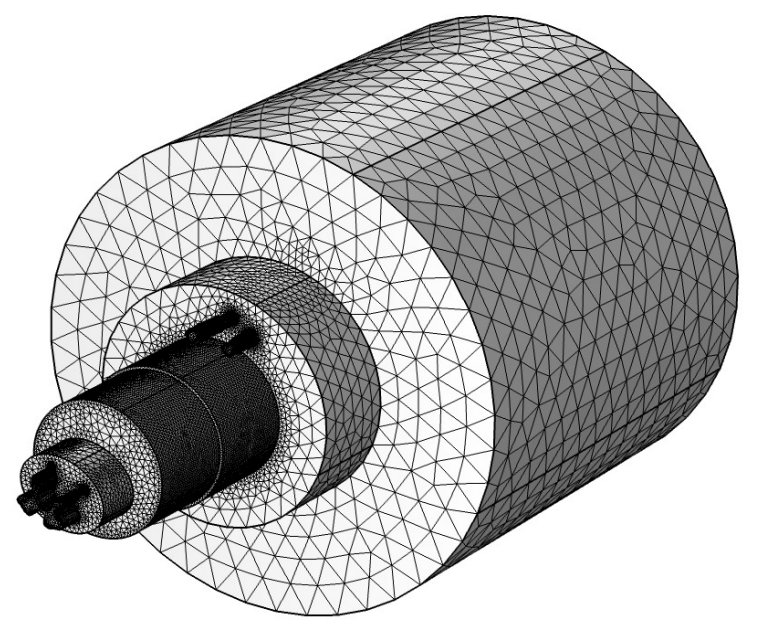

Figure 5.3: Tetrahedral adaptive mesh of the generalized spinal cord volume conductor model. Smaller edge length is used in the region of interest (grey matter, white matter, $\mathrm{CSF}$ ) and small structures (dura mater, electrode). A larger edge length is used in the rest of the tissues (fat, bone).

matter tissue, the edge length ranged between 50-194 $\mu \mathrm{m}$. According to Arle et al. [6] these mesh resolutions are accurate enough to resolve axons electrically down to the dimension of their internodal distances. The mesh properties details are shown in Table 5.2.

To avoid possible edge effects, the Dirichlet boundary condition (electric insulation) was imposed on the most external surfaces of the model. We also imposed an electric potential boundary on the surfaces of the active contacts of the electrode (see Table 5.2).

The FEM was used for the calculation of the electrical potential distribution as an approximate solution of the Laplace equation $\left(\nabla^{2} \mathrm{~V}=0\right)$. The current density $(\mathrm{J}(\mathrm{x}, \mathrm{y}, \mathrm{z}))$ was obtained from the generalized version of Ohm's Law (see Equations 
5.1 and 5.2):

$$
\begin{aligned}
\mathbf{J} & =\sigma \cdot \mathbf{E} \\
\mathbf{E} & =-\nabla V_{e}
\end{aligned}
$$

where $\mathrm{V}_{e}$ is the electrical potential of a specific point of the volume conductor model, $\mathbf{E}$ is the electric field, $\mathbf{J}$ is the current density, and $\sigma$ is the electrical conductivity tensor. The electric field, the electric potential, and the electric current were calculated using the conjugate gradient iterative method solver [63].

To include the nerve fiber distribution in the generalized SCS model, the following procedure is followed. As the geometry in the generalized model is symmetrical, 20 surfaces of $200 \times 800$ points of resolution are defined in COMSOL Multiphysics $^{\circledR}$. Each surface is a point matrix which includes the position of the node of Ranvier in the model's $\mathrm{x}, \mathrm{y}$ and $\mathrm{z}$-axis, and the electric potential value in that node after an electric field is applied. The first surface is located just in the DC border (see Fig. 5.4) and the following surfaces are located below each other at a separation of $50 \mu \mathrm{m}$. Each surface includes 100 longitudinally distributed fibers, thus a total of 2,000 fibers are considered within the model, as shown in the axial view in Fig. 5.4. As the generalized model measures $88 \mathrm{~mm}$ in length, each nerve fiber has 66 nodes of Ranvier.

Table 5.2: Boundary conditions and mesh resolution data of the generalized SCS model.

Boundary conditions

\begin{tabular}{l|l}
\hline \hline External bounds & Zero current (Electric insulation) \\
\hline Bounds of lead contacts & User-defined tension (Electric potential) \\
\hline \hline \multicolumn{2}{|c}{ Mesh resolution } \\
\hline \hline Type & Adaptive \\
\hline Number of elements & $3,724,378$ \\
\hline Maximum element size $(\mathrm{mm})$ & 1.94 \\
\hline Minimum element size $(\mathrm{mm})$ & 0.05 \\
\hline Maximum element grow rate & 1.35 \\
\hline Resolution of curvature & 0.3 \\
\hline Resolution of narrow regions & 0.85 \\
\hline \hline
\end{tabular}


CHAPTER 5. Development of a realistic generalized spinal cord volume conductor model

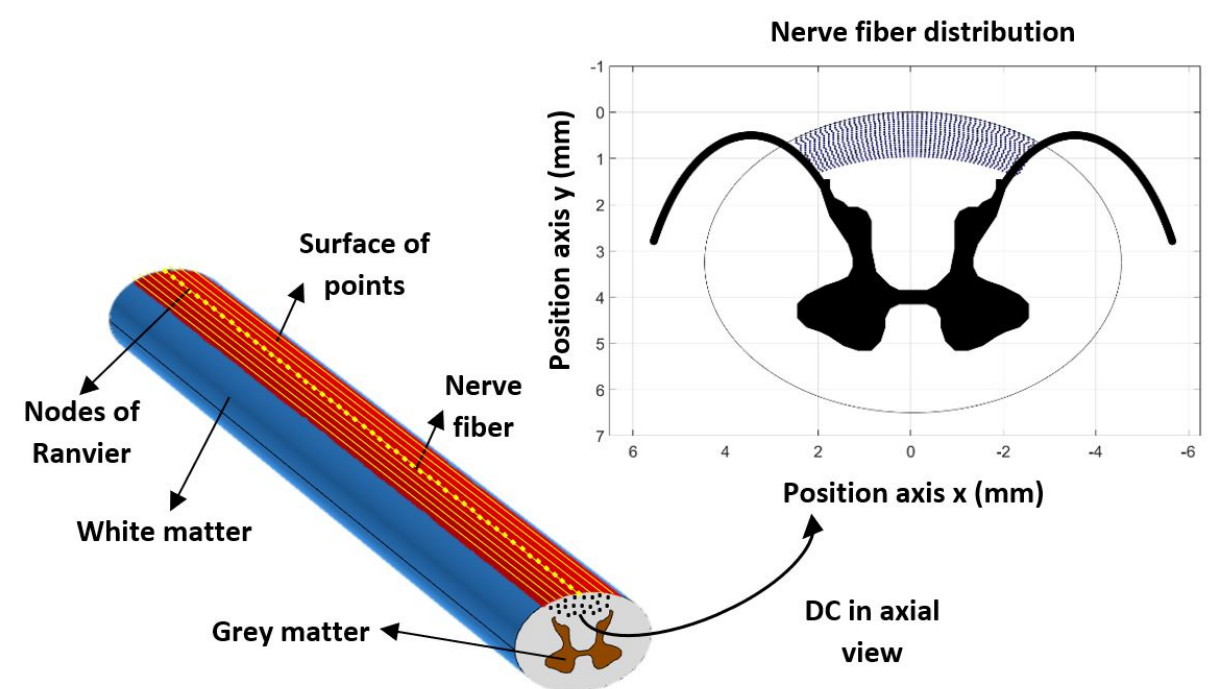

Figure 5.4: Nerve fiber distribution in the dorsal columns (DC) in the generalized volume conductor model. In the axial view, each blue point represents a nerve fiber in that position.

For the DR fibers two parametric surfaces of points (at left and right sides of the spinal cord) are defined in COMSOL Multiphysics ${ }^{\circledR}$, which mimic the shape of a DR (see Fig. 5.5), i.e. they start in the CSF and enter the white matter in a curve (known as Dorsal Root Entry Zone (DREZ)) until reaching the dorsal horn of the grey matter. The distance between the left and right DREZs is PW, defined above in Fig. 5.2(a). Each surface includes $80 \mathrm{DR}$ (1 mm spaced), so that a total of $160 \mathrm{DR}$ fibers are included in the model. DR fibers have a diameter of $15 \mu \mathrm{m}$ and consist of 5 nodes of Ranvier. Since a low-thoracic segment is modeled (from T8 to T10 level), the type A1 DR fiber model as described by Struijk et al. is used [140].

All the simulations are performed with a rectangular monophasic pulse stimulus, which is similar to the clinical stimulation scenario that includes a lower amplitude passive charge recovery phase [103]. Although the frequency is set to 


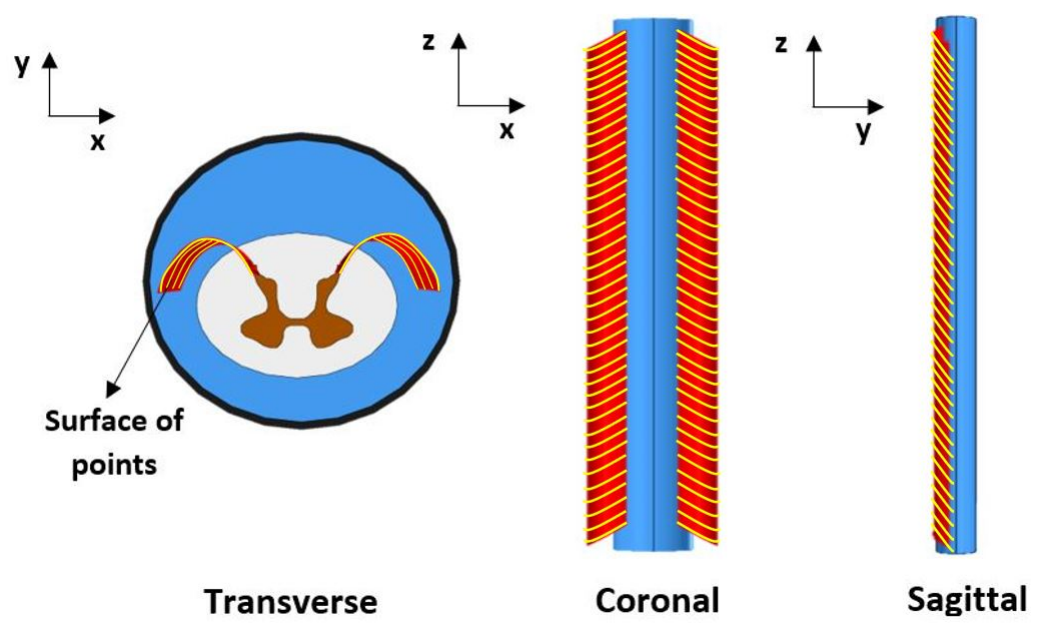

Figure 5.5: Nerve fiber distribution in the dorsal roots (DR) in the generalized volume conductor model. The figure above shows the definition of the $\mathrm{x}, \mathrm{y}$ and $\mathrm{z}$ axes in the model. The figures below show the spatial location of the surfaces of points (shown in red) where the $168 \mathrm{DR}$ fibers are included in transverse (left), coronal (center) and sagittal (right) views.

$50 \mathrm{~Hz}$ clinically, in the simulations we apply just one pulse, for nerve fibers are activated at each pulse in tonic stimulation [103]. This assumption considers electrical stimulation as a quasi-static phenomenon, which is valid for frequencies up to $10 \mathrm{kHz}$ [13]. Hence, the simulations of the electric field distribution are run as static models in COMSOL Multiphysics ${ }^{\circledR}$.

\subsubsection{Myelinated nerve fiber model}

To determine nerve fiber activation (in the DC or DR), we used the Richardson, McIntyre, and Grill (RMG) myelinated nerve fiber model [121]. The model was implemented using MATLAB ${ }^{\circledR}$ R2017a. We used model B because its conduction velocity $\left(61 \mathrm{msec}^{-1}\right)$ was within the experimental range for a $10-\mu \mathrm{m}$ fiber (47-63 $\mathrm{msec}^{-1}$ ) [121]. The model incorporates a finite impedance single-cable myelin 
CHAPTER 5. Development of a realistic generalized spinal cord volume

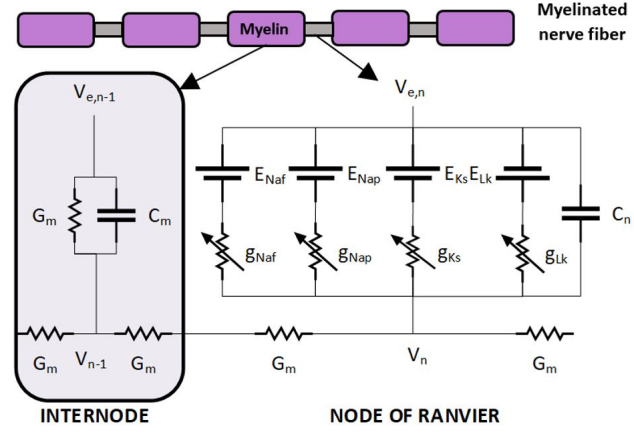

(a) RMG model.

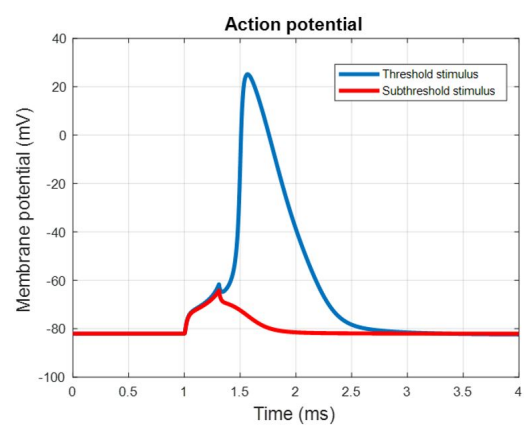

(b) Fiber model response.

Figure 5.6: a) Schematic diagram of myelinated nerve fiber and equivalent electric circuit. b. Action potential when the nerve fiber is stimulated at threshold stimulus (blue line) and at subthreshold stimulus (red line).

sheath. This is important, because representation of myelin is a significant factor in axon excitability and conduction [121]. The electrical representation for both the myelin and nodes of Ranvier are shown in Fig. 5.6(a). The MRG model allows for the calculation of the membrane potential in each node of $\operatorname{Ranvier}\left(\mathrm{V}_{\mathrm{n}}\right)$, taking into account $\mathrm{V}_{\mathrm{e}}$ values obtained from equation 5.3, by solving the following equation:

$$
\begin{array}{r}
\frac{d V_{n}}{d t}=\left(G _ { \text { axial } } \left(V_{m, n-1}-2 V_{m, n}+V_{m, n+1}+V_{e, n-1}\right.\right. \\
\left.-2 V_{e, n}+V_{e, n+1}\right)-\pi d\left(I_{i o n, n}\right) / C_{m, n}
\end{array}
$$

where $\mathrm{n}$ is the corresponding node of Ranvier, $\mathrm{C}_{\mathrm{m}}$ is the membrane capacity $(\mu \mathrm{F}), \mathrm{I}_{\text {ion }}$ is the total sum of the ionic currents $(\mathrm{mA})$, and $\mathrm{G}_{\text {axial }}$ is the conductance between the centers of two adjacent compartments $(\mathrm{mS})$. For more details about MRG model equations, see Richardson et al. [121], and for details of the geometric parameters, see McIntyre et al. [96]. All the parameters used in the model are 
also shown in Appendix B. When equation 5.3 is solved for each node of Ranvier, we obtain the temporal evolution of the membrane potential, which is known as the action potential. Thus, if a nerve fiber measuring $12.8 \mu \mathrm{m}$ in diameter is stimulated by a square stimulus pulse of $300 \mu \mathrm{sec}$ of duration and $2 \mathrm{~V}$ of amplitude, a specific action potential is produced, as shown in Fig. 5.6(b) (blue line). However, for a subthreshold stimulus ( $1.9 \mathrm{~V}$ of amplitude), no action potential is produced (Fig. 5.6(b) (red line)), and the fiber is not activated.

\subsubsection{Model behavior}

We reproduced two previous studies and compared our results with those from other research groups.

The first study consisted in analyzing the evolution of $\mathrm{PT}_{\mathrm{DC}}$ vs. dorsal CSF (dCSF) thickness. Holsheimer et al. [56] obtained $\mathrm{PT}_{\mathrm{DC}}$ considering a nerve fiber measuring $12 \mu \mathrm{m}$ in diameter. As displayed in Fig. 5.7(a), our results showed that a higher dCSF thickness required a higher $\mathrm{PT}_{\mathrm{DC}}$ (solid line), as also shown by Holsheimer et al. (dotted line). The absolute values of $\mathrm{PT}_{\mathrm{DC}}$ were similar to Holsheimer's. The main difference was how fast $\mathrm{PT}_{\mathrm{DC}}$ grew with dCSF thickness. Thus, for example, in our results, at maximum dCSF thickness $(4.8 \mathrm{~mm}), \mathrm{PT}_{\mathrm{DC}}$ was $725 \%$ greater than at minimum dCSF thickness $(0.8 \mathrm{~mm} ; 5.8$ vs. $0.8 \mathrm{~V}$, respectively). However, Holsheimer et al. obtained an increase of $1166 \%$ of $\mathrm{PT}_{\mathrm{DC}}$ (7 vs. $0.6 \mathrm{~V}$, respectively).

We also analyzed the effect of fiber diameter on $\mathrm{PT}_{\mathrm{DC}}$. The results are shown in 5.7(b). Consistent with Holsheimer et al. [55] (dotted line), we found that the larger the nerve fiber diameter is, the lower the $\mathrm{PT}_{\mathrm{DC}}$ required (solid line). Holsheimer et al. observed that their data points were best fitted by power function and showed the equation and the square correlation. We also verified that the best fit of our data points was by power function. We obtained the maximum difference of PTDC ( $200 \%$ greater than the Holsheimer group results [9.8 vs. $4.88 \mathrm{~V}$, respectively]) when a fiber measuring $5.7 \mu \mathrm{m}$ in diameter is stimulated. 


\section{CHAPTER 5. Development of a realistic generalized spinal cord volume}

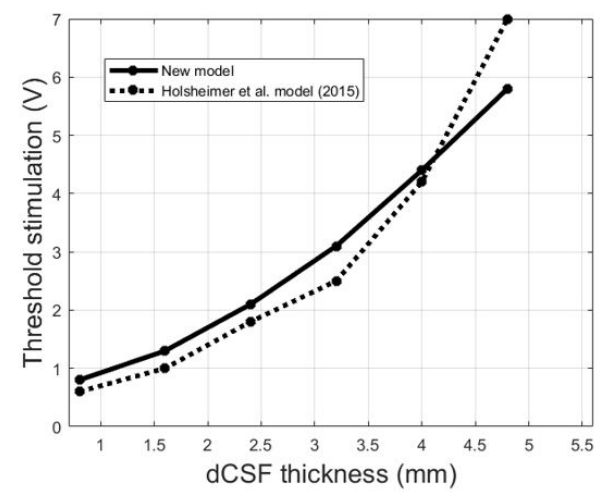

(a)

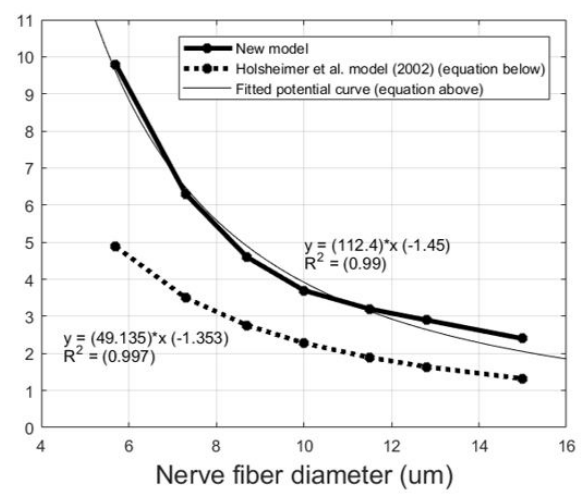

(b)

Figure 5.7: a) Threshold stimulation as a function of dCSF thickness. Solid line: results obtained using our model. Dotted line: results from Holsheimer's group [56]. b) Threshold stimulation as a function of nerve fiber diameter. Solid line: results obtained using our model. Dotted line: results from Holsheimer's group [55].

The differences observed in Fig. 5.7 between these two studies and our results could arise from the respective differences between the spinal cord models. On the one hand, Holsheimer's group used a T11 vertebral level, whereas we used a T10 vertebral level model. Each vertebral level has a different dCSF thickness, which is greater in the case of T10. On the other hand, we used an MRG nerve fiber model while Holsheimer's group used a Wesselink nerve fiber model in both studies. The main difference between the two models is that the myelin in the MRG model undergoes current losses because it is modeled as an imperfect insulator. As these two differences could affect the excitability of the nerve fibers, they could explain the differences observed. Besides, the stimulated fiber size and the stimulation pulse width used in our simulations are different from the Holsheimer's group (12.8 versus $12 \mu \mathrm{m}$ and 300 versus $210 \mu \mathrm{m}$, respectively). Despite these distinctions, the behavior of the model is very similar to that reported by Holsheimer's group, since both behave as a power function. 


\subsection{Sensitivity analysis}

As shown in previous studies [106], the stimulation parameters $\left(\mathrm{PT}_{\mathrm{DC}}, \mathrm{PT}_{\mathrm{DR}}, \mathrm{AA}\right.$ and $\mathrm{AD}$ ) are all influenced by the geometry of the spinal cord and the electrode position in the epidural space. Therefore, a sensitivity analysis was conducted with the generalized model to identify the geometric and electrical parameters of the spinal cord that had the greatest effect on the stimulation parameters.

\subsubsection{Geometric parameters of the spinal cord}

In this section, we examined the relative changes in $\mathrm{PT}_{\mathrm{DC}}, \mathrm{PT}_{\mathrm{DR}}, \mathrm{AA}$ and $\mathrm{AD}$ that resulted from varying the following geometric parameters: $\varnothing \mathrm{AP}, \varnothing \mathrm{T}, \mathrm{CSF}$ diameter, dorsal CSF (dCSF) thickness, and dura mater thickness in their physiological range for T9 vertebral level (see Table 5.3) [42].

Fig. 5.8 reveals that $\mathrm{PT}_{\mathrm{DC}}$ and $\mathrm{PT}_{\mathrm{DR}}$ are most sensitive to variations in $\varnothing \mathrm{AP}$. When $\varnothing \mathrm{AP}$ increases, $\mathrm{PT}_{\mathrm{DC}}$ is $12.77 \%$ lower, while $\mathrm{PT}_{\mathrm{DR}}$ is $8.65 \%$ higher. The opposite effect is produced when $\varnothing \mathrm{AP}$ decreases, i.e. $\mathrm{PT}_{\mathrm{DC}}$ is $8.5 \%$ higher, and $\mathrm{PT}_{\mathrm{DR}}$ is $11.07 \%$ lower. AA and $\mathrm{AD}$ are also influenced by changes in $\varnothing \mathrm{AP}$, being 5.38 and $12.5 \%$ higher when $\varnothing \mathrm{AP}$ decreases by $6.15 \%$, respectively. However, at maximum value of $\varnothing \mathrm{AP}(6.9 \mathrm{~mm}), \mathrm{AD}$ is maintained and $\mathrm{AA}$ is around $3 \%$ lower.

Table 5.3: Geometric parameters considered in the sensitivity analysis. Minimum and maximum values are taken from in vivo MRI measurements of the human spinal cord, T9 vertebral level [42].

\begin{tabular}{l|l|l|l} 
Geometric parameter & $\begin{array}{l}\text { Minimum value } \\
(\mathbf{m m})\end{array}$ & $\begin{array}{l}\text { Maximum value } \\
(\mathbf{m m})\end{array}$ & References \\
\hline \hline$\varnothing \mathrm{AP}$ & 6.1 & 6.9 & {$[42]$} \\
\hline$\varnothing \mathrm{T}$ & 8.3 & 9.7 & {$[42]$} \\
\hline CSF diameter & 12 & 16 & {$[42]$} \\
\hline dCSF thickness & 3.14 & 4.83 & {$[42]$} \\
\hline Dura mater thickness & 0.3 & 0.410 & {$[120]$} \\
\hline \hline
\end{tabular}




\section{CHAPTER 5. Development of a realistic generalized spinal cord volume}

conductor model
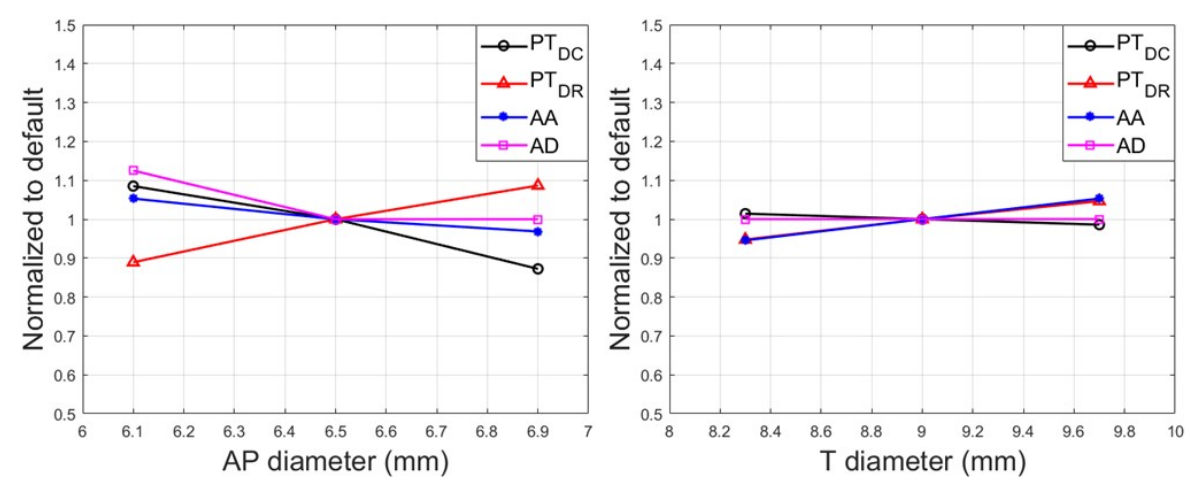

Figure 5.8: Sensitivity of perception threshold on $\mathrm{DC}\left(\mathrm{PT}_{\mathrm{DC}}\right)$, perception threshold on $\mathrm{DR}\left(\mathrm{PT}_{\mathrm{DR}}\right)$, activating area (AA), and activating depth $(\mathrm{AD})$ to variations in anteroposterior (AP) diameter (left) and transversal (T) diameter (right) of the spinal cord. All parameter values are expressed as multiples of default parameter value. $\mathrm{All}_{\mathrm{PT}} \mathrm{DC}, \mathrm{PT}_{\mathrm{DR}}$, $\mathrm{AA}$, and $\mathrm{AD}$ are normalized to their respective values obtained with default parameters. Default parameters: AP diameter: $6.5 \mathrm{~mm}$; T diameter: $9 \mathrm{~mm}$. Vertebral level: T9. Stimulation parameters applied: rectangular monophasic pulse; guarded cathode configuration; pulse width: $300 \mu$ s.

On the other hand, little changes are observed in $\varnothing \mathrm{T}$ variations, as shown in Fig. 5.8. The most sensitive parameters are $\mathrm{PT}_{\mathrm{DR}}$ and $\mathrm{AA}$. For instance, $\mathrm{PT}_{\mathrm{DR}}$ and AA are 4.63 and $5.38 \%$ increased when $\varnothing \mathrm{T}$ is at its maximum value $(9.7 \mathrm{~mm})$. Nevertheless, no significant changes are produced for $\mathrm{PT}_{\mathrm{DC}}$ and $\mathrm{AD}$.

Thus, the stimulus parameters are more sensitive to $\varnothing \mathrm{AP}$ than to $\varnothing \mathrm{T}$ changes.

Fig. 5.9 shows how the stimulation parameters vary from changes in dCSF, CSF diameter and dura mater thickness.

The figure reveals that $\mathrm{PT}_{\mathrm{DC}}$ and $\mathrm{AA}$ are most sensitive to changes in $\mathrm{dCSF}$ thickness. For instance, $\mathrm{PT}_{\mathrm{DC}}$ increases in the vicinity of $35 \%$ when dCSF is at its maximum value $(4.83 \mathrm{~mm})$; and AA decreases about $16 \%$ when dCSF decreases to $3.14 \mathrm{~mm}$. $\mathrm{PT}_{\mathrm{DR}}$ and $\mathrm{AD}$ also present variations, but they are less sensitive, 

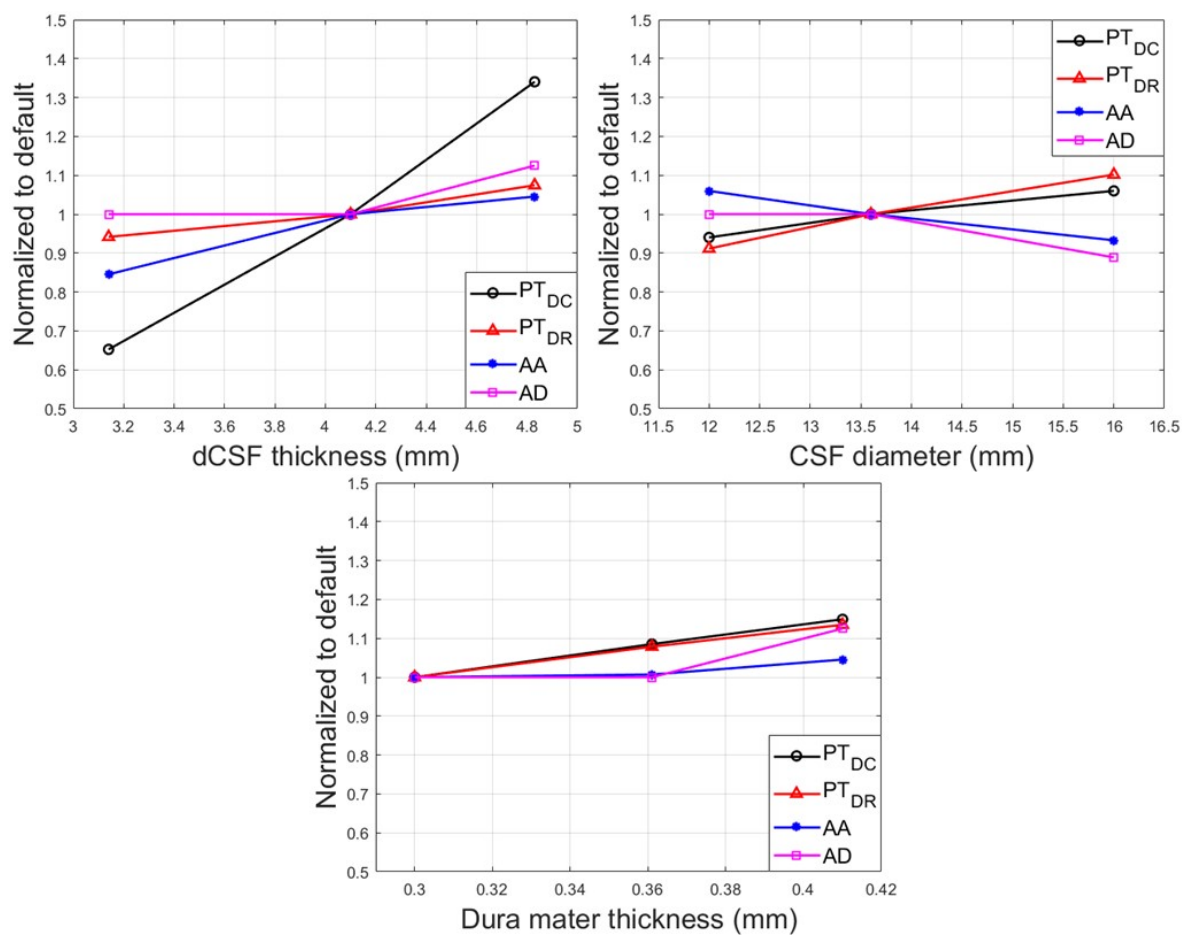

Figure 5.9: Sensitivity of perception threshold on $\mathrm{DC}\left(\mathrm{PT}_{\mathrm{DC}}\right)$, perception threshold on $\mathrm{DR}\left(\mathrm{PT}_{\mathrm{DR}}\right)$, activating area $(\mathrm{AA})$, and activating depth $(\mathrm{AD})$ to variations in cerebrospinal fluid (CSF) diameter, dorsal CSF (dCSF) thickness, and dura mater thickness. All parameter values are expressed as multiples of default parameter value. All $\mathrm{PT}_{\mathrm{DC}}, \mathrm{PT}_{\mathrm{DR}}$, $\mathrm{AA}$, and $\mathrm{AD}$ are normalized to their respective values obtained with default parameters. Default parameters: CSF diameter: $13.6 \mathrm{~mm}$; dCSF: $4.25 \mathrm{~mm}$; dura mater thickness: 0.3 $\mathrm{mm}$. Vertebral level: T9. Stimulation parameters applied: rectangular monophasic pulse; guarded cathode configuration; pulse width: $300 \mu \mathrm{s}$.

since maximum changes of 7.4 and $12.5 \%$ are obtained, respectively, when dCSF increases $0.7 \mathrm{~mm}$.

CSF diameter also produces significant changes in the stimulation parameters. In this case, when CSF diameter increases, the $\mathrm{PT}_{\mathrm{DR}}$ increase is higher than the 
CHAPTER 5. Development of a realistic generalized spinal cord volume
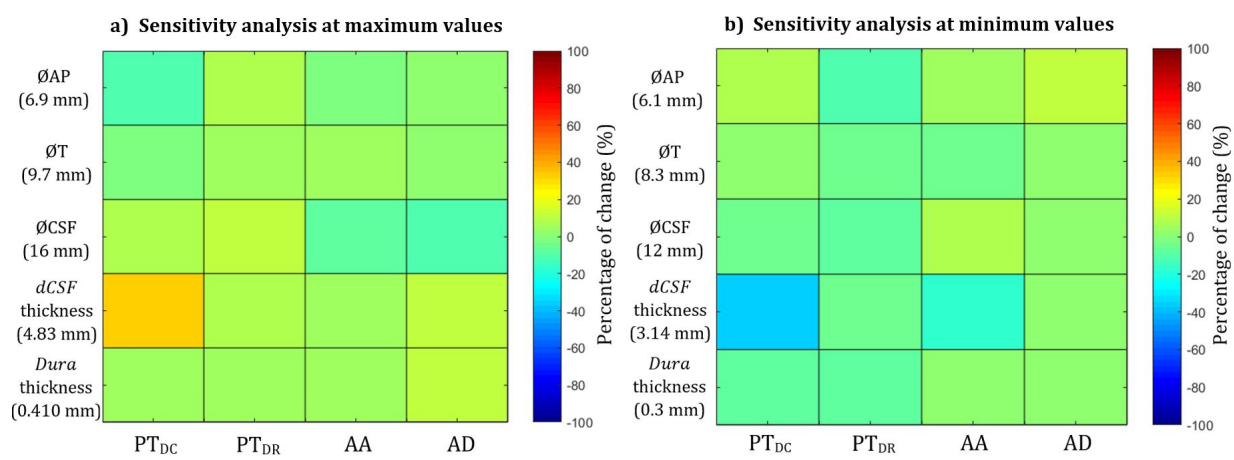

Figure 5.10: Summary of the sensitivity analysis results at a) maximum, and b) minimum values of $\varnothing \mathrm{AP}, \varnothing \mathrm{T}, \varnothing \mathrm{CSF}, \mathrm{dCSF}$ thickness, and dura mater thicknes. The colormap represents the percentage of change in $\mathrm{PT}_{\mathrm{DC}}$ (perception threshold in dorsal columns), $\mathrm{PT}_{\mathrm{DR}}$ (perception threshold in dorsal roots), AA (activating area), and $\mathrm{AD}$ (activating depth).

$\mathrm{PT}_{\mathrm{DC}}$ one (10.16 versus $6 \%$, respectively). The same occurs when CSF diameter is reduced to $12 \mathrm{~mm}$, i.e. $\mathrm{PT}_{\mathrm{DR}}$ decreases more than $\mathrm{PT}_{\mathrm{DC}}(8.85$ versus $6 \%$, respectively). Instead, AA and AD are inversely related to CSF diameter increasing, thus both parameters show a decrease of 6.72 and $11.1 \%$, respectively, when CSF diameter is at the maximum value of $16 \mathrm{~mm}$. However, at $12 \mathrm{~mm}$ of CSF diameter no changes are observed for $\mathrm{AD}$ values, while AA increses by $6 \%$ its default value.

As for dura mater thickness changes, $\mathrm{PT}_{\mathrm{DC}}$ and $\mathrm{PT}_{\mathrm{DR}}$ are the most sensitive parameters. In fact, with $0.06 \mathrm{~mm}$ of increase in dura mater thickness, $\mathrm{PT}_{\mathrm{DC}}$ and $\mathrm{PT}_{\mathrm{DR}}$ increase 8.5 and $7.8 \%$, respectively, while only $0.7 \%$ of variation is obtained for $\mathrm{AA}$ and no changes for $\mathrm{AD}$ parameter. But, when dura mater thickness increases $0.05 \mathrm{~mm}$ more, $\mathrm{PT}_{\mathrm{DC}}$ and $\mathrm{PT}_{\mathrm{DR}}$ increase 6.4 and $5.7 \%$ more, $\mathrm{AD}$ has an increase of $12.5 \%$, and AA increases $3.8 \%$.

Fig. 5.10 represents the results of the sensitivity analysis in a colormap. The figure reveals that $\mathrm{PT}_{\mathrm{DC}}$ is the most sensitive stimulation parameter to dCSF thickness. Instead, although the rest of parameters $\left(\mathrm{PT}_{\mathrm{DR}}, \mathrm{AA}\right.$, and $\left.\mathrm{AD}\right)$ are also sensi- 
tive to changes in the geometric parameters of the spinal cord, no more than $15 \%$ of change is produced in any of the stimulation parameters considered.

\subsubsection{Electrical conductivities of the spinal cord tissues}

In this section, we examined the relative changes in $\mathrm{PT}_{\mathrm{DC}}, \mathrm{PT}_{\mathrm{DR}}, \mathrm{AA}$ and $\mathrm{AD}$ that resulted from varying the electrical conductivities of the following tissues: bone, fat, dura mater, CSF, white matter (transversal and longitudinal), and grey matter in their physiological range (see Table 5.4).

Fig. 5.11 shows the stimulation parameters variation to bone, fat, dura mater and grey matter electrical conductivity changes.

In general, almost all parameters are sensitive to electrical conductivity changes in fat and dura mater tissues, but not to bone and grey matter tissues ones.

In both fat and dura mater tissues, as electrical conductivity increases, $\mathrm{PT}_{\mathrm{DC}}$ and $\mathrm{PT}_{\mathrm{DR}}$ values decrease. In fat tissue, these parameters values are reduced by 48.94 and $54.12 \%$, respectively, while they are 57.1 and $55.1 \%$ reduced in dura mater tissue. Instead, AA and AD are more sensitive to changes in fat electrical conductivity than in dura mater electrical conductivity. For instance, when fat

Table 5.4: Tissue electrical conductivities considered for the sensitivity analysis.

\begin{tabular}{l|l|l|l} 
Tissue & $\begin{array}{l}\text { Minimum } \\
\text { value }^{1}(\mathbf{S} / \mathbf{m})\end{array}$ & $\begin{array}{l}\text { Maximum } \\
\left.\text { value }^{2} \mathbf{( S / m}\right)\end{array}$ & References \\
\hline \hline Bone & 0.0024 & 0.06 & ${ }^{1}[102],{ }^{2}[94]$ \\
\hline Fat (epidural space) & 0.02 & 0.6 & ${ }^{1}[102],{ }^{2}[94]$ \\
\hline Dura mater & 0.03 & 0.461 & ${ }^{1}[9,142],{ }^{2}[94]$ \\
\hline CSF & 1 & 2.51 & ${ }^{1}[45],{ }^{2}[94]$ \\
\hline $\begin{array}{l}\text { White matter (transver- } \\
\text { sal) }\end{array}$ & 0.023 & 0.439 & ${ }^{1}[102],{ }^{2}[47]$ \\
\hline $\begin{array}{l}\text { White matter (longitu- } \\
\text { dinal) }\end{array}$ & 0.0543 & 0.915 & ${ }^{1,2}[94]$ \\
\hline Grey matter & 0.033 & 0.23 & ${ }^{1}[102],{ }^{2}[47]$ \\
\hline \hline
\end{tabular}


CHAPTER 5. Development of a realistic generalized spinal cord volume
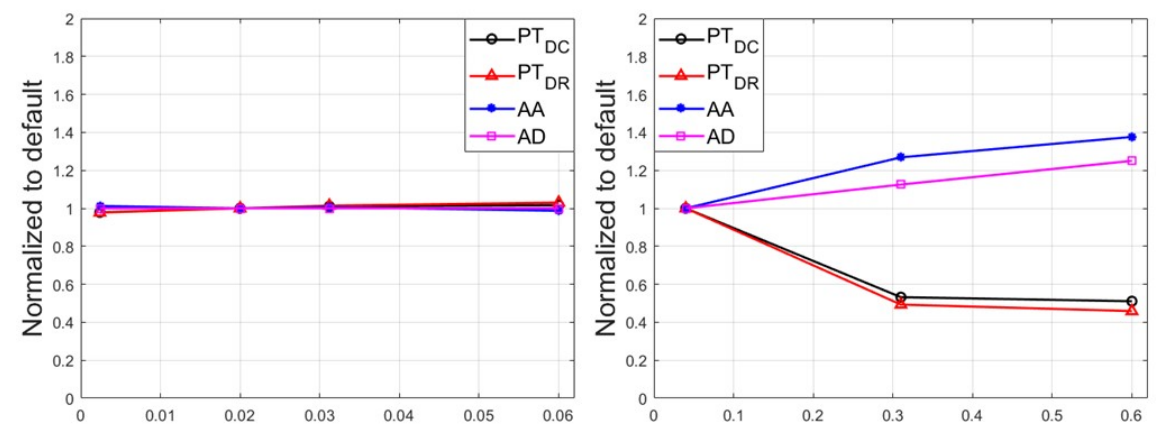

Bone tissue. Electrical conductivity $(\mathrm{S} / \mathrm{m})$
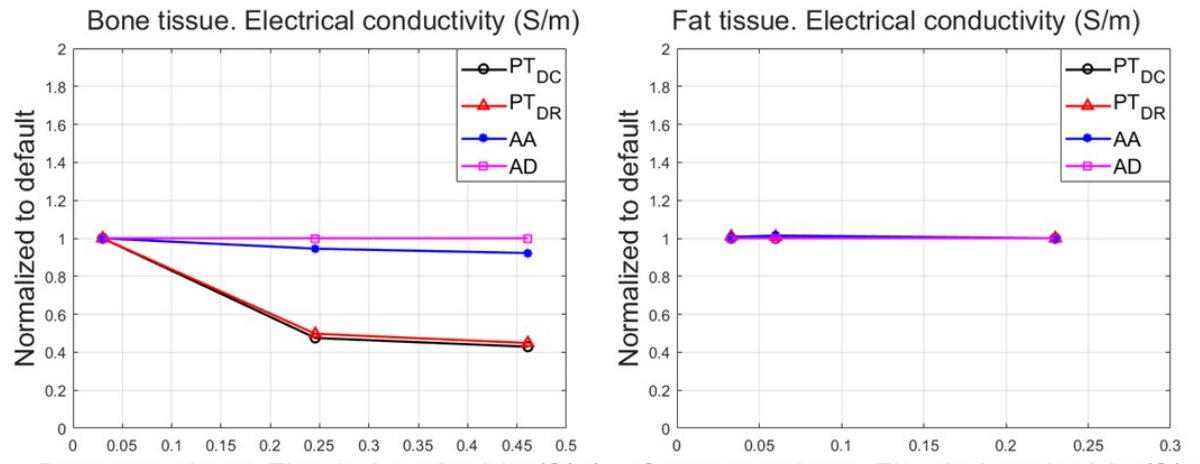

Dura mater tissue. Electrical conductivity $(\mathrm{S} / \mathrm{m})$

Grey matter tissue. Electrical conductivity (S/m)

Figure 5.11: Sensitivity of perception threshold on $\mathrm{DC}\left(\mathrm{PT}_{\mathrm{DC}}\right)$, perception threshold on $\mathrm{DR}\left(\mathrm{PT}_{\mathrm{DR}}\right)$, activating area (AA), and activating depth $(\mathrm{AD})$ to variations in electrical conductivity of bone, fat, dura mater, and grey matter tissue. All parameter values are expressed as multiples of default parameter value. $\mathrm{All}_{\mathrm{PT}} \mathrm{DC}_{\mathrm{DC}} \mathrm{PT}_{\mathrm{DR}}, \mathrm{AA}$, and $\mathrm{AD}$ are normalized to their respective values obtained with default parameters. Default parameters: $\sigma_{\text {bone }}: 0.02 \mathrm{~S} / \mathrm{m} ; \sigma_{\text {fat }}: 0.04 \mathrm{~S} / \mathrm{m}$; $\sigma_{\text {dura mater }}: 0.03 \mathrm{~S} / \mathrm{m} ; \sigma_{\text {grey matter }}: 0.23 \mathrm{~S} / \mathrm{m}$. Vertebral level: T9. Stimulation parameters applied: rectangular monophasic pulse; guarded cathode configuration; pulse width: $300 \mu \mathrm{s}$.

electrical conductivity is at its maximum value $(0.6 \mathrm{~S} / \mathrm{m})$, AA and AD increase 37.6 and $45 \%$ the default value, respectively. On the contrary, at the highest value of dura mater electrical conductivity $(0.461 \mathrm{~S} / \mathrm{m})$, AA is decreased $7.76 \%$, and no changes are produced in $\mathrm{AD}$ value. 


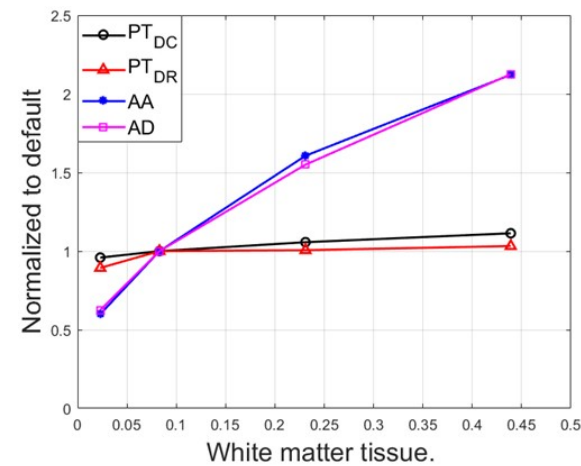

Transversal electrical conductivity (S/m)

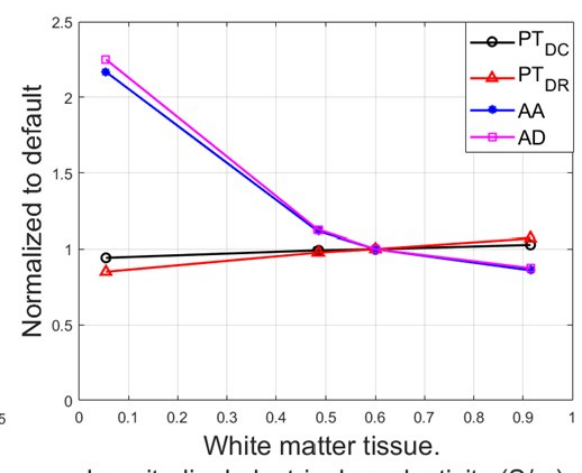

Longitudinal electrical conductivity (S/m)

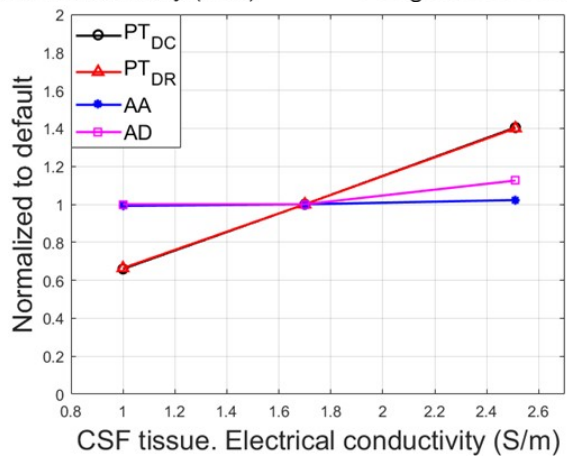

Figure 5.12: Sensitivity of perception threshold on $\mathrm{DC}\left(\mathrm{PT}_{\mathrm{DC}}\right)$, perception threshold on $\mathrm{DR}\left(\mathrm{PT}_{\mathrm{DR}}\right)$, activating area $(\mathrm{AA})$, and activating depth $(\mathrm{AD})$ to variations in electrical conductivity of transversal white matter $\left(\mathrm{WM}_{\text {trans }}\right)$, longitudinal white matter $\left(\mathrm{WM}_{\text {long }}\right)$, and cerebrospinal fluid (CSF) tissue. All parameter values are expressed as multiples of default parameter value. $\mathrm{All}_{\mathrm{PT}} \mathrm{PC}_{\mathrm{DC}}, \mathrm{PT}_{\mathrm{DR}}, \mathrm{AA}$, and $\mathrm{AD}$ are normalized to their respective values obtained with default parameters. Default parameters: $\sigma_{\mathrm{WM}_{\text {trans }}}: 0.083 \mathrm{~S} / \mathrm{m} ; \sigma_{\mathrm{WM}_{\text {long }}}$ : $0.6 \mathrm{~S} / \mathrm{m} ; \sigma_{\text {CSF }}: 1.7 \mathrm{~S} / \mathrm{m}$. Vertebral level: T9. Stimulation parameters applied: rectangular monophasic pulse; guarded cathode configuration; pulse width: $300 \mu \mathrm{s}$.

On the other hand, the relative changes in the stimulation parameters values to variations in white matter (transversal and longitudinal directions), and CSF electrical conductivity changes are shown in Fig. 5.12. 
CHAPTER 5. Development of a realistic generalized spinal cord volume conductor model
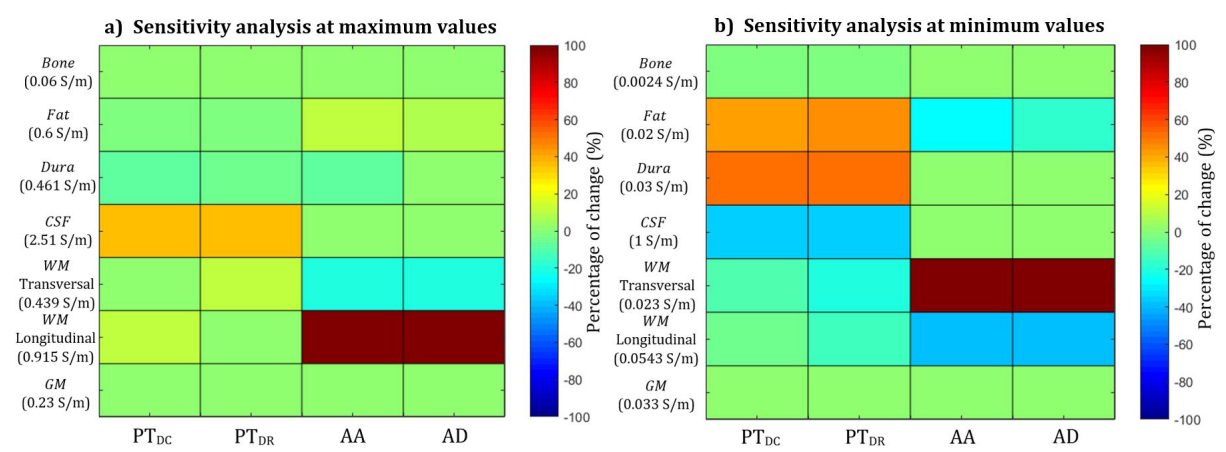

Figure 5.13: Summary of the sensitivity analysis results at a) maximum and b) minimum values of bone, fat, dura mater, CSF (cerebrospinal fluid), WM (transversal and longitudinal) (white matter), and GM (gray matter). The colormap represents the percentage of change in $\mathrm{PT}_{\mathrm{DC}}$ (perception threshold in dorsal columns), $\mathrm{PT}_{\mathrm{DR}}$ (perception threshold in dorsal roots), AA (activating area), and AD (activating depth).

The figure reveals that $\mathrm{AA}$ and $\mathrm{AD}$ parameters are more sensitive to both transversal and longitudinal white matter electrical conductivity changes than to CSF electrical conductivity. The difference observed between increasing transversal and longitudinal white matter electrical conductivity is that AA and AD are directly related to transeversal electrical conductivity, while they are inversely related to longitudinal electrical conductivity. For example, at maximum value of transversal electrical conductivity $(0.45 \mathrm{~S} / \mathrm{m})$, both AA and AD increase $125 \%$ the default value, however, $\mathrm{AA}$ and $\mathrm{AD}$ are reduced to around $14 \%$ the default value at maximum value of longitudinal electrical conductivity $(0.915 \mathrm{~S} / \mathrm{m})$.

On the contrary, $\mathrm{PT}_{\mathrm{DC}}$ and $\mathrm{PT}_{\mathrm{DR}}$ are most sensitive to changes in CSF electrical conductivity. The parameters are directly related to CSF electrical conductivity variations. At the maximum CSF electrical conductivity $(2.51 \mathrm{~S} / \mathrm{m}), \mathrm{PT}_{\mathrm{DC}}$ and $\mathrm{PT}_{\mathrm{DR}}$ values are in the vicinity of $40 \%$ higher than the default value. However, when CSF electrical conductivity is at its minimum value $(1 \mathrm{~S} / \mathrm{m})$, both stimulation parameters are decreased around $34 \%$ the default value.

Fig. 5.13 represents the results of the sensitivity analysis in a colormap. The 
figure shows that $\mathrm{AA}$ and $\mathrm{AD}$ are the most sensitive parameters to changes in fat, WM (transversal and longitudinal) electrical conductivities, while $\mathrm{PT}_{\mathrm{DC}}$ and $\mathrm{PT}_{\mathrm{DR}}$ are the most sensitive parameters to variations in CSF electrical conductivity. Moreover, $\mathrm{PT}_{\mathrm{DC}}$ and $\mathrm{PT}_{\mathrm{DR}}$ are also sensitive to the decrease of fat and dura mater electrical conductivity.

\subsubsection{Geometry and electrical conductivity of the stimulation elec- trode}

In this section, the relative changes in the stimulation parameters values to variations of the electrical conductivities of the poles, insulators, and electrode-tissue interface of the electrode as well as the effect of electrode-tissue interface and electrode-dura mater distance $\left(\mathrm{D}_{\mathrm{e}-\mathrm{d}}\right)$ in their possible range of values are examined (see Table 5.5).

Fig. 5.14 shows the stimulation parameters variations to poles, insulation, and electrode-tissue interface changes.

Table 5.5: Lead parameters considered for the sensitivity analysis.

Electrical conductivity

\begin{tabular}{l|l|l|l}
\hline \hline Material & $\begin{array}{l}\text { Minimum } \\
\text { value }^{1}(\mathbf{S} / \mathbf{m})\end{array}$ & $\begin{array}{l}\text { Maximum } \\
\text { value }^{2}(\mathbf{S} / \mathbf{m})\end{array}$ & References \\
\hline $\begin{array}{l}\text { Poles (platinum- } \\
\text { iridium) }\end{array}$ & $2.86 \cdot 10^{6}$ & $5.278 \cdot 10^{6}$ & ${ }^{1}[28],{ }^{2}[26]$ \\
\hline $\begin{array}{l}\text { Insulators } \\
\text { polyurethane) }\end{array}$ & $1 \cdot 10^{-7}$ & 0.002 & ${ }^{1}[75],{ }^{2}[111]$ \\
\hline $\begin{array}{l}\text { Electrode-tissue inter- } \\
\text { face }\end{array}$ & 0.05 & 0.2 & ${ }^{1}[17],{ }^{2}[95]$ \\
\hline \multicolumn{3}{|l}{ Geometric parameters $\mathbf{( m m )}$} & \\
\hline $\begin{array}{l}\text { Electrode-tissue inter- } \\
\text { face thickness }\end{array}$ & 0.01 & 1 & ${ }^{1,2}[17]$ \\
\hline $\mathrm{D}_{\mathrm{e}-\mathrm{d}}$ & 0 & 2 & User defined \\
\hline \hline
\end{tabular}


CHAPTER 5. Development of a realistic generalized spinal cord volume conductor model
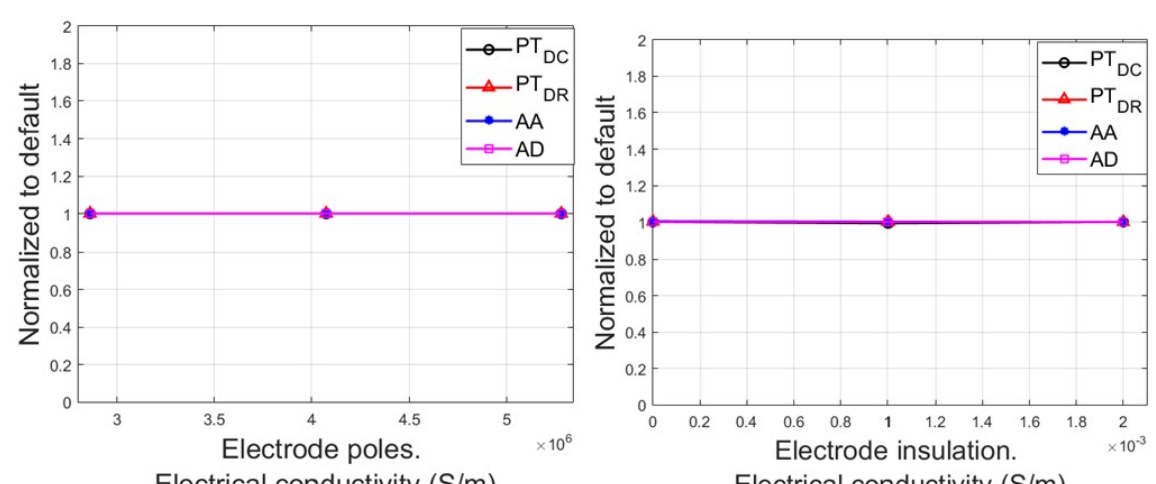

Electrical conductivity (S/m) Electrical conductivity (S/m)

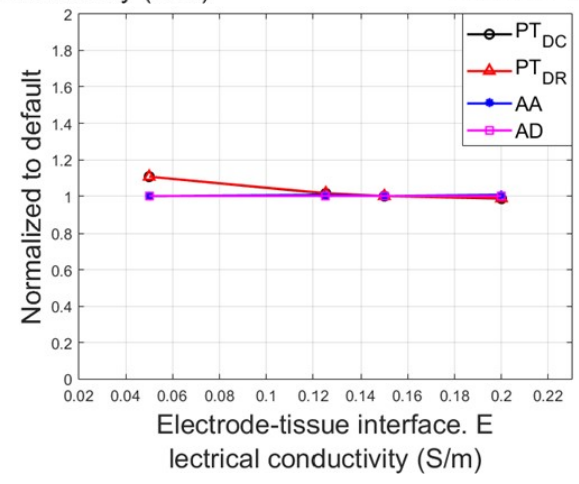

Figure 5.14: Sensitivity of perception threshold on $\mathrm{DC}\left(\mathrm{PT}_{\mathrm{DC}}\right)$, perception threshold on $\mathrm{DR}\left(\mathrm{PT}_{\mathrm{DR}}\right)$, activating area (AA), and activating depth $(\mathrm{AD})$ to variations in electrical conductivity of poles, insulation, and electrode-tissue interface of the electrode. All parameter values are expressed as multiples of default parameter value. All $\mathrm{PT}_{\mathrm{DC}}, \mathrm{PT}_{\mathrm{DR}}$, $\mathrm{AA}$, and $\mathrm{AD}$ are normalized to their respective values obtained with default parameters. Default parameters: $\sigma_{\text {pole }}: 5.278 \cdot 10^{6} \mathrm{~S} / \mathrm{m}$; $\sigma_{\text {insulation }}: 0.002 \mathrm{~S} / \mathrm{m} ; \sigma_{\text {interface }}: 0.15 \mathrm{~S} / \mathrm{m}$. Vertebral level: T9. Stimulation parameters applied: rectangular monophasic pulse; guarded cathode configuration; pulse width: $300 \mu \mathrm{s}$.

The figure reveals that $\mathrm{PT}_{\mathrm{DC}}, \mathrm{PT}_{\mathrm{DR}}, \mathrm{AA}$, and $\mathrm{AD}$ are not sensitive to changes in poles and insulation electrical conductivities. However, although no changes are observed for $\mathrm{AA}$ and $\mathrm{AD}$ values when electrode-tissue interface electrical conductivity changes either, $\mathrm{PT}_{\mathrm{DC}}$ and $\mathrm{PT}_{\mathrm{DR}}$ present significant variations. In 

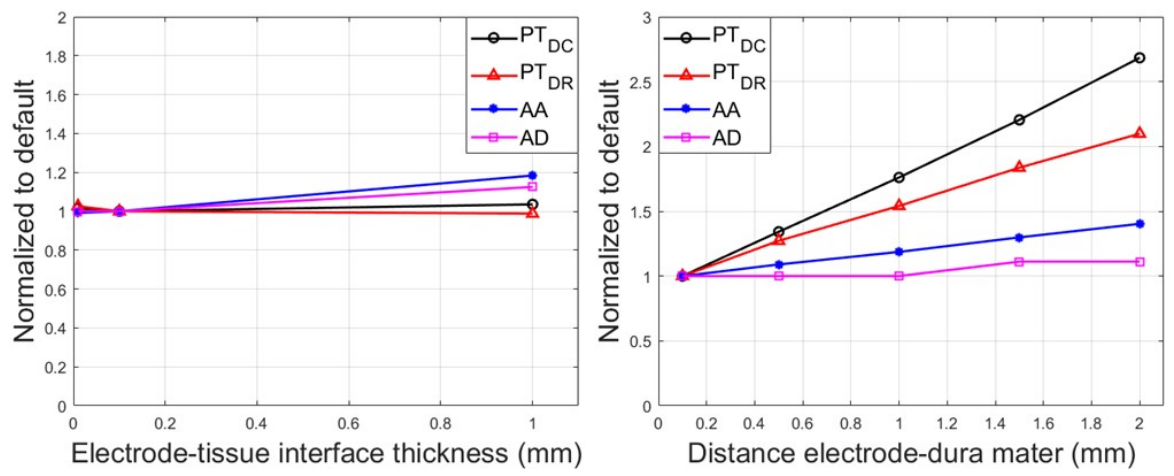

Figure 5.15: Sensitivity of perception threshold on $\mathrm{DC}\left(\mathrm{PT}_{\mathrm{DC}}\right)$, perception threshold on $\mathrm{DR}\left(\mathrm{PT}_{\mathrm{DR}}\right)$, activating area (AA), and activating depth $(\mathrm{AD})$ to variations in electrodetissue interface thickness and distance electrode-dura mater $\left(\mathrm{D}_{\mathrm{e}-\mathrm{d}}\right)$. All parameter values are expressed as multiples of default parameter value. All $\mathrm{PT}_{\mathrm{DC}}, \mathrm{PT}_{\mathrm{DR}}, \mathrm{AA}$, and $\mathrm{AD}$ are normalized to their respective values obtained with default parameters. Default parameters: electrode-tissue interface thickness: $0.1 \mathrm{~mm}$; $\mathrm{D}_{\mathrm{e}-\mathrm{d}}: 0.1 \mathrm{~mm}$. Stimulation parameters applied: rectangular monophasic pulse; guarded cathode configuration; pulse width: 300 $\mu \mathrm{s}$.

this case, when electrode-tissue interface electrical conductivity is $0.05 \mathrm{~S} / \mathrm{m}$ (minimum value), $\mathrm{PT}_{\mathrm{DC}}$ and $\mathrm{PT}_{\mathrm{DR}}$ increase around $11 \%$. When electrode-tissue interface electrical conductivity is at its maximum value $(0.2 \mathrm{~S} / \mathrm{m}), \mathrm{PT}_{\mathrm{DC}}$ and $\mathrm{PT}_{\mathrm{DR}}$ reduce about $4 \%$ the default value.

The relative changes in $\mathrm{PT}_{\mathrm{DC}}, \mathrm{PT}_{\mathrm{DR}}, \mathrm{AA}$, and $\mathrm{AD}$ to electrode-tissue interface thickness and $\mathrm{D}_{\mathrm{e}-\mathrm{d}}$ variations are shown in Fig. 5.15.

As for electrode-tissue thickness variation, AA and AD are most sensitive than $\mathrm{PT}_{\mathrm{DC}}$ and $\mathrm{PT}_{\mathrm{DR}}$. For instance, at $1 \mathrm{~mm}$ of electrode-tissue thickness, $\mathrm{AA}$ and $\mathrm{AD}$ values are 18.4 and $12.5 \%$ higher, instead $\mathrm{PT}_{\mathrm{DC}}$ increases $3.5 \%$ while $\mathrm{PT}_{\mathrm{DC}}$ decreases about $2 \%$ its default value. However, when electrode-tissue interface is reduced to $0.01 \mathrm{~mm}$, no more than $3 \%$ of change is obtained for either of the stimulation parameter. 
CHAPTER 5. Development of a realistic generalized spinal cord volume
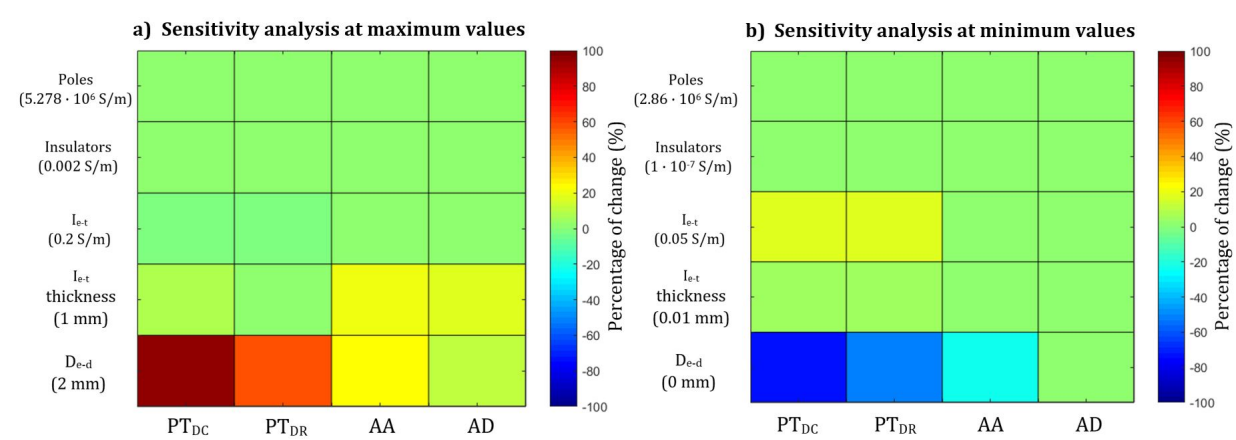

Figure 5.16: Summary of the sensitivity analysis results at a) maximum and b) minimum values of poles, insulators, and $\mathrm{I}_{\mathrm{e}-\mathrm{t}}$ (electrode-tissue interface) electrical conductivities, and $\mathrm{I}_{\mathrm{e}-\mathrm{t}}$ and $\mathrm{D}_{\mathrm{e}-\mathrm{d}}$ (electro-dura mater distance) thickness. The colormap represents the percentage of change in $\mathrm{PT}_{\mathrm{DC}}$ (perception threshold in dorsal columns), $\mathrm{PT}_{\mathrm{DR}}$ (perception threshold in dorsal roots), AA (activating area), and AD (activating depth).

On the other hand, the figure reveals that $\mathrm{PT}_{\mathrm{DC}}$ and $\mathrm{PT}_{\mathrm{DR}}$ are most sensitive to $\mathrm{D}_{\mathrm{e}-\mathrm{d}}$. The increase of $\mathrm{D}_{\mathrm{e}-\mathrm{d}}$ causes the increase of $\mathrm{PT}_{\mathrm{DC}}$ and $\mathrm{PT}_{\mathrm{DC}}$. In fact, 1 mm increase in $\mathrm{D}_{\mathrm{e}-\mathrm{d}}$ increases $\mathrm{PT}_{\mathrm{DC}}$ by $76.1 \%$ and $\mathrm{PT}_{\mathrm{DR}}$ by $54.1 \%$. AA is also shown to be sensitive to $\mathrm{D}_{\mathrm{e}-\mathrm{d}}$. Variations in $\mathrm{D}_{\mathrm{e}-\mathrm{d}}$ causes the increase of $\mathrm{AA}$. In this case, $1 \mathrm{~mm}$ increase of $\mathrm{D}_{\mathrm{e}-\mathrm{d}}$ increases $\mathrm{AA}$ by $18.7 \%$. Variations in $\mathrm{D}_{\mathrm{e}-\mathrm{d}}$ causes similar changes in $\mathrm{AD}$, i.e. a $11 \%$ maximum increase in $\mathrm{AD}$ is obtained when $\mathrm{D}_{\mathrm{e}-\mathrm{d}}$ increases to its maximum value $(2 \mathrm{~mm})$.

In Fig. 5.16, the representation of the results of the sensitivity analysis is shown in a colormap. The figure illustrates that $\mathrm{PT}_{\mathrm{DC}}$ and $\mathrm{PT}_{\mathrm{DR}}$ are the most sensitive parameters to variations in $\mathrm{D}_{\mathrm{e}-\mathrm{d}}$ and $\mathrm{I}_{\mathrm{e}-\mathrm{t}}$ electrical conductivity (see the red and blue squared in Fig. 5.16), followed by AA, which is also sensitive to variations in $\mathrm{D}_{\mathrm{e}-\mathrm{d}}$ and $\mathrm{I}_{\mathrm{e}-\mathrm{t}}$ thickness (see the yellow and light blue squares in Fig. 5.16). Instead, the parameters related to the material of the electrodes (poles, and insulators electrical conductivities) show no changes in any of the stimulation parameters considered (see the green squares in Fig. 5.16). 
5.4. Effect of electrode polarity on neural activation in single-lead stimulation 95

\subsection{Effect of electrode polarity on neural activation in single-lead stimulation}

The four basic stimulation parameters which need to be programmed in SCS therapy are amplitude, pulse width, frequency, and polarity, whose combination satisfies an individual's pain coverage needs [48]. From the mentioned stimulation parameters, polarity is one of the most complicated to determine. Percutaneous electrodes have from four to eight poles, thus a huge number of anode-cathode combinations can be used. For instance, 6558 combinations could be used when using two four-contact stimulation electrodes. A study conducted by Holsheimer and Wesselink suggested that guarded cathode polarity produced the deepest and widest paresthesia coverage, however no quantitative parameters were evaluated [60]. In clinical practice, polarity is determined by eliciting the patient's oral responses to the trial and error-based application of stimulation, which may be time-consuming. For these reasons, the goal of the present study is to quantitatively investigate the effect of electrode polarity on neural activation by computational simulation and to propose a new strategy to maximize paresthesia coverage in clinical practice.

\subsubsection{Methods}

We used the 3D volume conductor model of the spinal cord at the T10 level described in Section 5.2. In this study, the volume conductor model measures 45 (x) $\mathrm{mm}$ x 42 (y) mm x 44 (z) mm and includes 80 DRs (40 DRs per side) spaced $1 \mathrm{~mm}$ apart throughout the longitudinal axis of the volume conductor model (see Fig. 5.17(a)). The purpose of this overpopulation of DR fibers was to ensure that the lowest DR stimulation threshold could be determined and to minimize the effect of the relative position of the cathode with respect to the DR in the longitudinal axis. We used a tetrahedral adaptive mesh to avoid incorrect solutions in the narrow and edge zones of the model. The element size ranged from 0.067 to 1.57 $\mathrm{mm}$. The model had 1,536,452 elements.

As shown in Fig. 5.17, we modeled multipole percutaneous leads, including 
CHAPTER 5. Development of a realistic generalized spinal cord volume conductor model

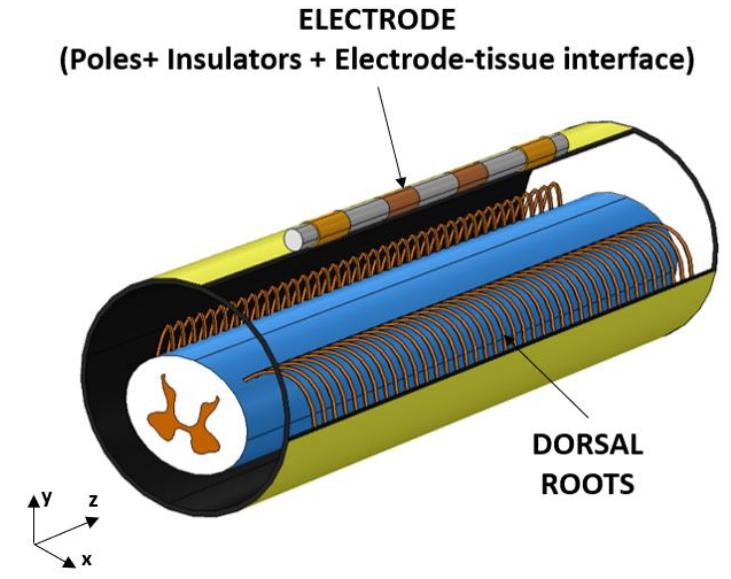

(a) Spinal cord model.

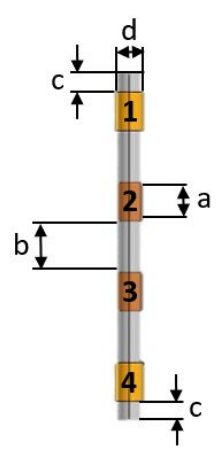

(b) Electrode model.

Figure 5.17: a) Dorsal roots and electrode modeling. Model dimensions: $x$ : $45 \mathrm{~mm}, \mathrm{y}$ : $42 \mathrm{~mm}$, and z: $44 \mathrm{~mm}$. b) Geometric parameters of the lead size: contact length (a) is 3 $\mathrm{mm}$; insulator length (b) is $4 \mathrm{~mm}$; insulator length in the extremes (c) is $1.5 \mathrm{~mm}$ and lead diameter (d) is $1.3 \mathrm{~mm}$.

the electrode contacts, the insulation, and the electrode-tissue interface. Usually, percutaneous leads have eight contacts, but we only included four contacts in the model because, in our clinical practice, no more than four consecutive contacts are programmed. Despite the availability of different percutaneous lead sizes, we only used one lead size because we wished to see the effect of polarity and not the effect of lead geometry on neural activation. The geometry we used can be seen in [99]. The electrodes were then modeled as cylinders measuring $24 \mathrm{~mm}$ in length and $1.3 \mathrm{~mm}$ in diameter. The poles (conducting domains) had a length of $3 \mathrm{~mm}$ and were spaced $4 \mathrm{~mm}$ apart with the application of an insulating polymer (nonconductive domains). The insulator at the extremes of the electrodes had a length of $1.5 \mathrm{~mm}$ (see Fig. 5.17(b)). Moreover, we included the electrode-tissue interface as a hollow cylinder with a $0.1-\mathrm{mm}$ thickness, which covered the active contacts. To date, this structure has only been considered in a deep brain stimulation model developed by Butson et al. [17, 18]. Finally, the percutaneous lead 
5.4. Effect of electrode polarity on neural activation in single-lead stimulation 97

model was positioned in the midline of the transversal plane of the model. The electrodes was $0.1 \mathrm{~mm}$ from the dura mater.

Based on a previous study by Holsheimer [55], we considered two nerve fiber sizes in the SCS model. On the DC surface, $12.8-\mu \mathrm{m}$ nerve fibers are the largest that can be activated. However, the DR nerve fibers can have a diameter of 15 $\mu \mathrm{m}[40,160]$. As the geometric parameters of 12.8 - and $15-\mu \mathrm{m}$ nerve fibers have been published (36), we used these fiber sizes in our simulations. In the model, the fiber distribution consisted of a set of 30 rows of 100 nerve fibers (a total of 3000 fibers) spaced $50 \mu \mathrm{m}$ apart and running from the DC surface to a depth of $2.25 \mathrm{~mm}$ (see blue zones in Figs. 5.19).

\subsubsection{Simulation results}

We analyzed and compared the effect of electrode polarity in single-lead stimulation and studied the effect of having different discomfort thresholds (DTs) in all considered polarities for both the AA and AD in the spinal cord. The electrode polarities considered for the study are shown in Fig. 5.18, which are the most common polarities used in single-lead stimulation: bipolar 1 (B1), bipolar 2 (B2), guarded cathode (GC), and dual-guarded cathode (DGC).

Table 5.6: Evaluation parameters values of single-lead stimulation with different polarities: B1 (bipolar 1), B2 (bipolar 2), GC (guarded cathode) and DGC (dual-guarded cathode).

\begin{tabular}{l|l|l|l|l|l} 
Electrode polarity & $\mathbf{P T}_{\mathbf{D C}}$ & $\mathbf{P T}_{\mathbf{D R}}$ & $\mathbf{R}_{\mathbf{D C} / \mathbf{D R}}$ & $\begin{array}{l}\text { Activating } \\
\text { area }\left(\mathbf{m m}^{2}\right)\end{array}$ & $\begin{array}{l}\text { Activating } \\
\text { depth }(\mu \mathbf{m})\end{array}$ \\
\hline \multicolumn{6}{|c}{ Single-lead stimulation } \\
\hline \hline B1 & 2.1 & 3.1 & 0.68 & 2.1 & 450 \\
\hline B2 & 2 & 2.5 & 0.80 & 2.8 & 550 \\
\hline GC & 1.6 & 4.4 & 0.38 & 1.5 & 350 \\
\hline DGC & 1.4 & 2.7 & 0.52 & 3.1 & 600 \\
\hline \hline
\end{tabular}


CHAPTER 5. Development of a realistic generalized spinal cord volume 98 conductor model

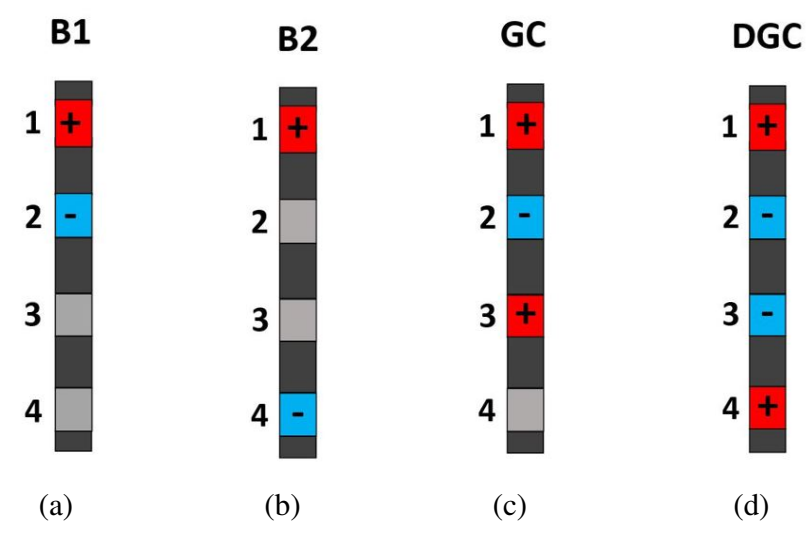

Figure 5.18: Single-lead polarities considered in this study. Positive symbols represent the anodes (positive voltage) and negative symbols represent the cathodes (negative voltage). Only four electrode contacts are represented because no more than four contacts are programmed. a) Bipolar 1 (B1). b) Bipolar 2 (B2). c) Guarded cathode (GC). d) Dualguarded cathode (DGC).

First, we simulated the $\mathrm{AA}$ and $\mathrm{AD}$ at three $\mathrm{DT}$ values $\left(1.2 \mathrm{PT}_{\mathrm{DC}}, 1.4 \mathrm{PT} \mathrm{T}_{\mathrm{DC}}\right.$, and 1.8P $\mathrm{PT}_{\mathrm{DC}}$ ) (see Fig. 5.19). The figure reveals that, regardless of the performed polarity, as DT increases, both AA and AD also increase. It also shows that DGC and $\mathrm{B} 2$ are the polarities within which it is possible to get higher AA and AD. On the other hand, evaluation parameters were calculated at a DT of $1.4 \mathrm{PT}_{\mathrm{DC}}$ to quantitatively compare the effect of using different polarities. As we can see in Table 5.6, the polarity with a better DC stimulation preference versus DR stimulation is $\mathrm{GC}$, with a $\mathrm{R}_{\mathrm{DC} / \mathrm{DR}}$ of 0.38 . However, GC polarity produces the lowest AA and AD values ( $1.5 \mathrm{~mm}^{2}$ and $350 \mu \mathrm{m}$, respectively). Nevertheless, B1 and B2 polarities present higher $\mathrm{AA}$ and $\mathrm{AD}$ with the disadvantage that $\mathrm{R}_{\mathrm{DC} / \mathrm{DR}}$ increases to $79 \%$ and $110 \%$, respectively, whereas the results show that DGC polarity provides double the $\mathrm{AA}$ and $\mathrm{AD}$ of GC polarity with a reduction of $12.5 \%$ of $\mathrm{PT}_{\mathrm{DC}}$. But, in comparison to GC polarity, DGC polarity increases $\mathrm{R}_{\mathrm{DC} / \mathrm{DR}}$ by $36 \%$. 

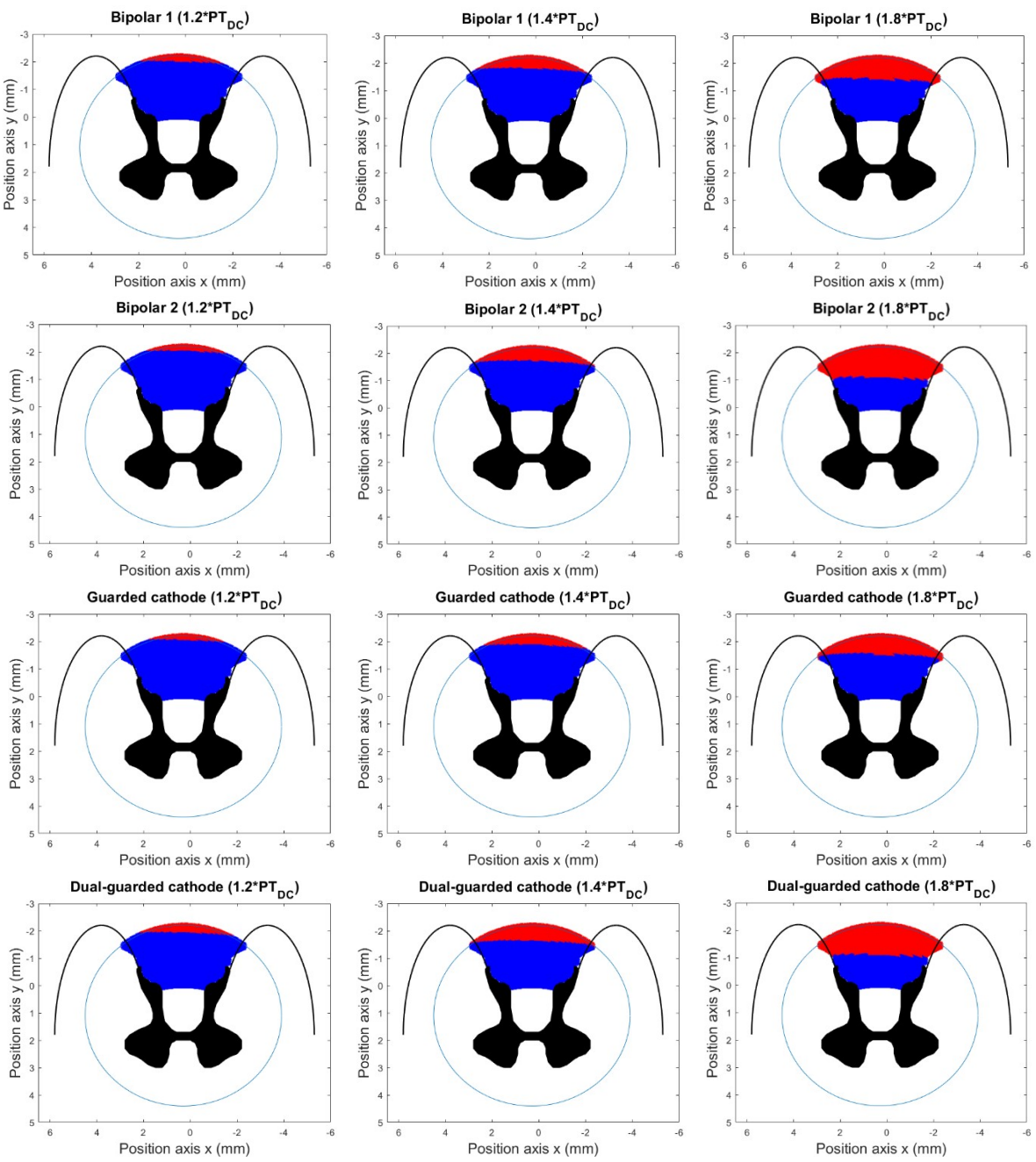

Figure 5.19: Activating area and depth obtained in different single-lead polarities in the $\mathrm{DC}$ at different DTs $\left(1.2 \mathrm{PT}_{\mathrm{DC}}, 1.4 \mathrm{PT}_{\mathrm{DC}}\right.$, and $\left.1.8 \mathrm{PT}_{\mathrm{DC}}\right)$. Blue zones represent the nerve fibers that are not activated and red zones represent the activated nerve fibers. 
CHAPTER 5. Development of a realistic generalized spinal cord volume 100 conductor model

\subsection{Discussion}

We developed a 3D generalized spinal cord model that includes the following novel aspects. First, the geometry of the model is based on measurements of all spinal cord levels from high-resolution in vivo T2-weighted magnetic resonance images acquired at 3T [42]. Therefore, as in a real spinal cord, the white matter is not centered within the spinal canal in the spinal cord model. This is an important contribution, since it enables us to see that, owing to the midline offset of the white matter modeled, in single-lead stimulation, the AA is not central, but lateral. However, previous models, besides not including the midline offset of the white matter, used anatomical data taken from the rat spinal cord atlas [19], postmortem measurements of human spinal cord [6], or in vivo human measurements at some vertebral levels (C4-C6, T5-T6 and T11-T12) from low-resolution in vivo $\mathrm{T} 2$-weighted magnetic resonance images acquired at $1.5 \mathrm{~T}[92,93]$. The second novel aspect is that our model is the first to include the electrode-tissue interface around the active contacts of the electrode in a spinal cord model. It is important to consider this element, because it affects the stimulation threshold values of the nerve fibers and, therefore, the remaining evaluation parameters.

It is indisputable that SCS computational models are useful to study the effect of the electric field on neural activation. However, these models must include the appropiate level of detail to accurately predict the neural response to SCS and to correlate model predictions with clinical outcomes [162]. Performing a sensitivity analysis, we determined the anatomic, electrical and technical factors that may affect model-based predictions of neural activation.

Spinal cord geometry has a biological variability [42], i.e. all geometric parameters has a biological range of values. Most of SCS computational models use cadaveric measurements $[4,79]$ or mean values from in vivo measurements for the geometric parameters [36]. To investigate the effect of geometric variations on evaluation parameters prediction, we performed a sensitivity analysis. The results show that $\mathrm{PT}_{\mathrm{DC}}, \mathrm{PT}_{\mathrm{DR}}, \mathrm{AA}$, and $\mathrm{AD}$ are most sensitive to dCSF thickness (a maximum of $35 \%$ of change in $\mathrm{PT}_{\mathrm{DC}}$ is obtained). All evaluation parameters are 
affected by changes in $\varnothing \mathrm{AP}, \varnothing \mathrm{T}, \mathrm{CSF}$ diameter, and duramater, although no more than $15 \%$ of change is produced.

Electrical properties of the tissues can also affect SCS model predictions. The sensitivity analysis was conducted for variations in bone, fat, dura mater, grey matter, transversal and longitudinal white matter, and CSF electrical conductivities. The outcome of the study reveals that the activation thresholds $\left(\mathrm{PT}_{\mathrm{DC}}\right.$ and $\mathrm{PT}_{\mathrm{DR}}$ ) are most sensitive to fat, dura mater, and CSF tissue electrical conductivity, obtaining up to $60 \%$ of change in the threshold prediction. This result is in agreement with Zander et al. [162], who stated that lowered dura mater conductivity produced significant changes in activating function values. As for AA and AD, a high sensitivity to fat and white matter (transversal and longitudinal) conductivities was obtained. However, no evaluation parameter was sensitive to changes in bone and grey matter conductivities.

Technical design and position of the stimulation electrode could also influence SCS model outcome. The results of the sensitivity analysis showed that changes in electrical conductivity of electrode materials (poles and insulators) had no effect on the evaluation parameters prediction. On the other hand, variations in electrical conductivity and thickness of the electrode-tissue interface (or encapsulation) increased around $15-20 \%$ the evaluation parameters, which is in concordance with Zander et al. results [162]. However, all evaluation parameters were most sensitive to changes in $\mathrm{D}_{\mathrm{e}-\mathrm{d}}$ (up to $160 \%$ of change in activation thresholds prediction).

The sensitivity analysis demonstrates that the geometric and electrical parameters of the spinal cord tissues and the stimulation electrode determine the magnitude and direction of the electric field, thus current flow, generated during SCS.

The modeling study we present quantitatively compares the effect of electrode polarity in single-lead stimulation on neural activation in SCS therapy and determines which one maximizes the AA and AD in DC. To the best of our knowledge, there are some works that also studied the effect of polarity in SCS [60, 92, 93, $125]$ and even the effect of using a multiple current versus single current source 
CHAPTER 5. Development of a realistic generalized spinal cord volume 102 conductor model

stimulation $[78,104]$. However, this is the first study that considers and compares the effect of the most known and used electrode polarities (B1, B2 and GC) including, in addition, DGC polarity. To date, the most commonly analyzed polarities have been B1, B2, and GC [58, 59]. Thus, several studies from Holsheimer's group proved that GC produced the greatest recruitment of DC fibers and the widest paresthesia coverage [58, 59, 60, 92]. However, the effect of DGC polarity has never been compared with that of the other polarities in SCS. This effect has only been evaluated in a peripheral nerve field stimulation study from Frahm et al. [43], where DGC presented a larger AA than GC, and in a cathodal field steering study from Manola et al. [93], where DGC showed extended recruitment of DC fibers as compared with dual cathode (two consecutive cathodes without anodes). Therefore, given the lack of studies on the effect of electrode polarity in SCS and the wider paresthesia coverage obtained empirically using DGC in our clinical practice, we included DGC polarity in this study.

From the simulations results, DGC performed the best to maximize AA and $\mathrm{AD}$ values. $\mathrm{B} 1$ and $\mathrm{B} 2$ polarities also achieved high $\mathrm{AA}$ and $\mathrm{AD}$, but $\mathrm{DR}$ stimulation was more easily produced. This effect was previously found by Barolat $e t$ al. [10], who observed that narrower spacing between bipolar contacts increased $\mathrm{DC}$ fiber selectivity. However, as for $\mathrm{R}_{\mathrm{DC} / \mathrm{DR}}$, the best performing polarity was GC, since it presented the lowest value, meaning that it is less likely to activate DR nerve fibers, as predicted in previous studies [10, 60, 92, 106]. In addition, $\mathrm{B} 2$ presented the highest $\mathrm{R}_{\mathrm{DC} / \mathrm{DR}}$ value; therefore, these polarities were likely to stimulate DR nerve fibers, reducing paresthesia coverage to only two dermatomes and producing a stimulation which would not be sufficient to cover all pain dermatomes.

In our clinical practice, polarity is established by trial and error and asking the patient about the location of the tingling sensation. In addition, polarity is the first parameter to be programmed, because it determines the electric field, and therefore, the location of the nerve fibers that will be activated. By selecting this location, we can select the dermatomes to be activated. Then, according to the results, a new strategy is proposed to establish polarity. The strategy consists first 
in using DGC with the aim of maximizing the AA and AD. However, if the DR was activated, then paresthesia coverage would be reduced to only one or two dermatomes. This could result in inefficient stimulation for the patient in terms of paresthesia coverage. Therefore, in these cases, the appropriate following step would be to use GC polarity to ensure DC nerve fiber activation, owing to its low recruitment ratio.

\subsubsection{Limitations}

One of the main limitations of SCS research is the lack of available clinical data. Clinical studies are complicated to perform owing to the highly subjective and sensitive nature of the data obtained from the patient's sensations. Thus, to date, it has been not possible to clinically validate the model presented in this study. Further research would require clinical data from a specific group of patients (with a specific age, sex, disease, electrode geometry, and position in the vertebral level) to clinically validate the computational model. This would provide more accurate and realistic SCS models because computer modeling helps us to understand SCS effects, improve the stimulation parameters management, and design better electrodes and devices [49].

On the other hand, lead position in the computational model is unrealistic, in the sense that it is perfectly situated in the midline of the spinal cord. This position is complicated to reproduce in a real patient, because it is not possible to know the exact location of the physiologic midline of the spinal cord in each patient.

Moreover, nerve fiber distribution within the DC is a complex feature, which requires further research. In current mathematical models, some studies use several nerve fiber sizes [78, 92], whereas others maintain a fixed nerve fiber size distribution $[6,93]$. This uncertainty of how fiber size changes with depth affects both AA and AD.

Finally, the nerve fiber model used does not consider any connectivity between nerve fibers. It is possible that the activation of one nerve fiber contributes 
CHAPTER 5. Development of a realistic generalized spinal cord volume 104 conductor model

to the activation of other nerve fibers positioned around it. If this assumption is proven to be true, the results reported may be affected, because the stimulation threshold values ( $\mathrm{PT}_{\mathrm{DC}}$ and $\mathrm{PT}_{\mathrm{DR}}$ ) would probably be reduced, and the remaining parameters $\left(\mathrm{R}_{\mathrm{DC} / \mathrm{DR}}\right.$, $\mathrm{AA}$ and $\left.\mathrm{AD}\right)$ that depend on these values would be different. Therefore, to have a more realistic model of the spinal cord, nerve fiber connectivity would have to be considered in further studies. However, the inclusion of this new feature in the model would not affect the main conclusions of the present study.

\subsection{Summary}

In this chapter, a 3D realistic generalized volume conductor spinal cord model is first presented. One of the main novelties of the model is that it is based on mean values from in vivo high-resolution MRI of the human spinal cord. Moreover, the spinal cord offset, as well as the electrode-tissue interface, are also considered.

Two studies were reproduced to compare the model behavior to previous SCS models. The developed model showed excellent agreement with Holsheimer's group model results.

In addition to this, a sensitivity analysis was conducted to identify the geometric, electrical and technical parameters that most affect the model-based predictions, showing that model accuracy is limited with regards to absolute values prediction.

The last part of the chapter shows a study performed with the developed generalized SCS model. The goal of this study is to investigate the effect of electrode polarity on neural activation and to propose a strategy to maximize paresthesia coverage in clinical practice. According to the results, DGC polarity is the best to expand the activating area in DCs, while GC lowers neural activation in DC with the benefit of reducing DRs fibers activation. Thus, the clinical strategy proposal is to first use DGC to maximize activation in DC but, if DRs activation is produced, polarity should be changed to GC polarity to increase DCs fibers rather 
than DRs fibers activation. 



\section{Chapter 6}

\section{Development of a patient-specific spinal cord volume conductor model}

The publications related to this chapter are:

2.- Carmen Solanes, Jose L. Durá, M Ángeles Canós, Jose De Andrés, Luis Martí-Bonmatí, Javier Saiz, 3D patient-specific spinal cord computational model for SCS management: potential clinical applications, In Journal of Neural Engineering, 18, 036017, 2021 https://doi.org/10.1088/ $1741-2552$ / abe 44 f. (Impact Factor 2020: 5.379 Q1 (19/105) Engineering, Biomedical).

2.- Carmen Solanes, Jose L. Durá, M Ángeles Canós, Jose De Andrés, Luis Martí-Bonmatí, Javier Saiz, Predicción de la activación neuronal en estimulación tónica en la terapia de EME: uso de modelos $3 D$ de médula espinal personalizados al paciente frente a modelos generalizados, In XXXVIII Congreso Anual de la Sociedad Española de Ingeniería Biomédica (CASEIB 2020). Pag 306-309. 25-27th November, 2020, Valladolid, Spain. 
CHAPTER 6. Development of a patient-specific spinal cord volume conductor 108 model

\subsection{Motivation}

This chapter is aimed to accomplish the third specific objective stated in Chapter 1 , which is the development of a patient-specific spinal cord volume conductor model. This work will also contribute to the performance of a realistic SCS computational model to carry out clinical applications that help to optmize SCS therapy, that is the main goal of this thesis.

In the spinal cord geometry at each spinal level, the size and shape of the spinal cord and spinal canal, the relative location of the spinal cord within the spinal canal and the amount of CSF between the epidural location of the SCS lead and the dorsal column (DC) fibers all vary between patients. All these geometrical parameters play a significant role in selecting the programming parameters (polarity, amplitude, pulse width and frequency) to optimize neural activation, i.e. paresthesia coverage, for individual SCS patients [83]. In fact, owing the changes in spinal cord geometric parameters, a variation of the evaluation parameters (activation thresholds and activating area and depth in DCs) is produced, as shown in Chapter 5, Section 5.3.1.

The first proposal of a patient-specific SCS model was made by Lempka et $a l$. in 2019, which model predicted sensory thresholds consistent with the clinical measurements. However, the spinal cord dimensions of the model are the average patient measurements of the T9 spinal cord anatomy [81]. As the electrodes can be located at different vertebral levels, using average measurements for the geometrical parameters in the computational models and including only one vertebral level may limit the results obtained, since it is not possible to reproduce the location of the electrodes within the spinal cords of individual patients.

In this context, the aim of this chapter is to develop a more detailed 3D patientspecific spinal cord model which includes the authentic anatomical structure and spinal cord dimensions of the different vertebral levels at which percutaneous electrodes are usually implanted (from T8 to T10). The previously developed generalized model is also used to compare the model-based predictions of both models 
to two real cases. Then, two studies are performed with the patient-specific SCS model. The first one is a proposal of a clinical application to perform a preimplantation selection of the electrode polarity; and the second one is focused on the investigation of the effect of electrode offset on the displacement of neural activation and paresthesia coverage prediction in a patient.

\subsection{Workflow}

The steps followed to develop the patient-specific volume conductor model are shown in Fig. 6.1.

First, the T2- and T1-weighted MRI are acquired before the SCS system implant. Then, two softwares (Spinal Cord Toolbox [31] and Seg3D) are used to segment the spinal cord (white and gray matter) and its surrounding tissues (CSF and vertebral bones). Once the segmentationas are obtained, Amira-Avizo ${ }^{\text {TM }}$ is used to smooth them. This step is pivotal to avoid any geometric error that could be produced during the segmentation process, such as sharped edges, or holes.

After the postprocessed of the segmentations, they are imported to COMSOL Multiphysics ${ }^{\circledR}$, where the rest of the surrounding tissues are added (fat and dura mater). At this point, the electrodes are also included in the model to calculate the electric field distribution. To compare the model-based predictions with the clinical data, the electrodes' location in the patient is obtained from the X-rays acquired after the SCS system implant. However, if the aim of the study is to perform a clinical application, the user is who defines the location of the electrodes.

Once the entire geometry of the spinal cord and the electrodes are in COMSOL Multiphysics ${ }^{\circledR}$, the electrical conductivities are asigned, the boundary conditions are defined, the mesh is created, and the electric field distribution is then calculated.

This workflow summarizes the main steps that are followed to develop the 
CHAPTER 6. Development of a patient-specific spinal cord volume conductor 110 model

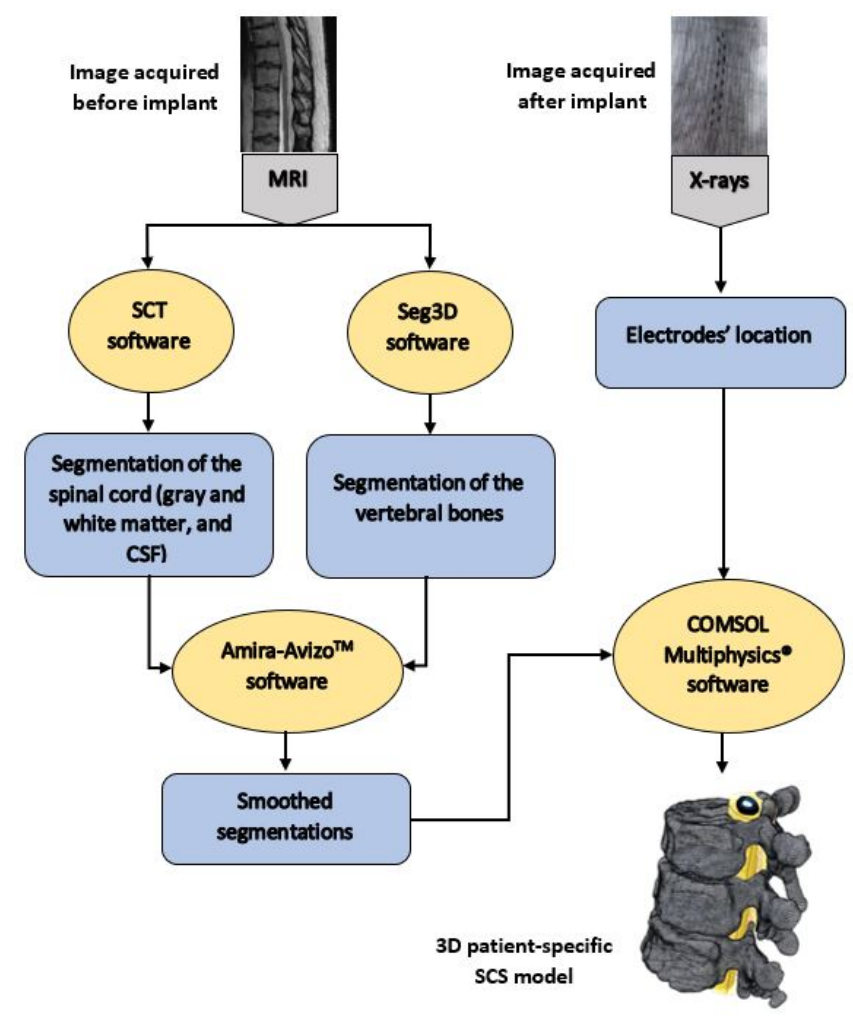

Figure 6.1: Workflow for the developement of the patient-specific volume conductor model.

patient-specific volume conductor model of a patient. The details of each step showed in this section (see Fig. 6.1) are widely explained in the next section (Section 6.3).

\subsection{Patient-specific SCS model}

The patient-specific SCS model considers the same tissues (and the same electrical conductivities) as the generalized volume conductor model (see Chapter 5, Section 


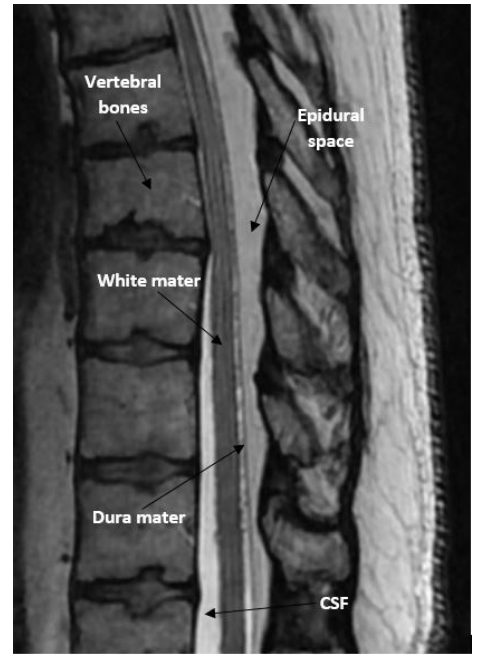

(a) $\mathrm{T} 2 \mathrm{w}$ MR image at $3 \mathrm{~T}$

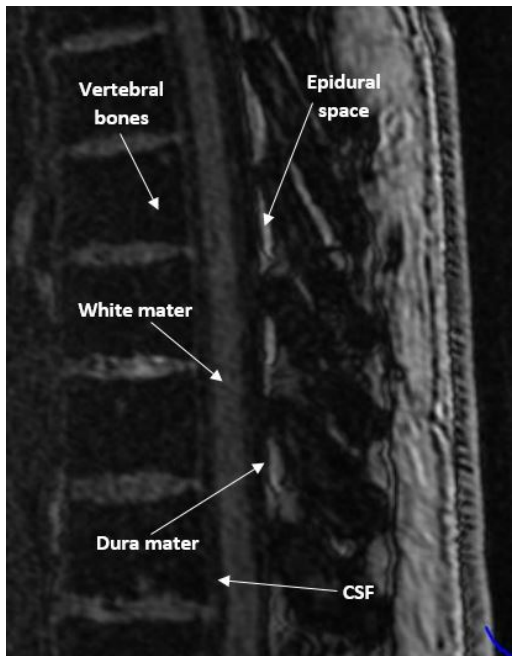

(b) T1 MR image at 3T

Figure 6.2: High-resolution MRI modalities of the spinal cord from T4 to L1 vertebral levels of a patient. CSF: cerebrospinal fluid.

5.2). The difference is that here the segmentation of each anatomical structure of the spinal cord from the own patient is required. Thus, a high-resolution anatomical magnetic resonance image of the patient is needed to develop the patientspecific model.

In this work, preoperative 3T high-resolution MRI scans were used without contrast media administration of the thoracic spine to obtain the patient-specific spinal cord anatomy. The scans consisted of T2-weighted and T1-weighted images with a sagittal orientation, as seen in Fig. 6.2(a) and 6.2(b), where white matter, CSF, fat tissue (epidural space) and vertebral bone can be differentiated. The sagittal T2-weighted and T1-weighted images were obtained using the protocol for spinal cord MRI acquisition from the Standard Operating Procedure (SOP) given by De Leener et al. [31] (T2-weighted image parameters: scanning sequence $=$ cube, magnetic field $=3 \mathrm{~T}$, field of view $=25.6 \mathrm{~mm}$, number of slices $=$ 
CHAPTER 6. Development of a patient-specific spinal cord volume conductor 112 model
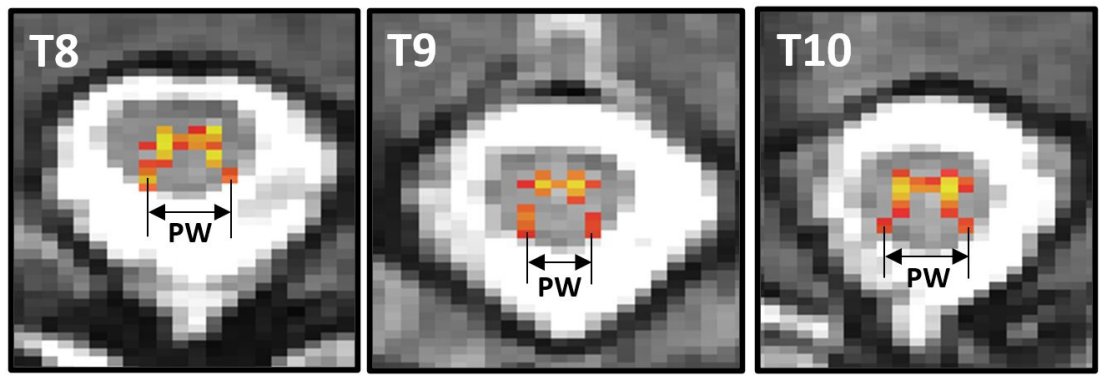

(a) GM segmentation in T8 (PW=5.4 mm), T9 (PW=4.8 mm), and T10 (PW=5.1 mm) vertebral levels of a patient's spinal cord (axial).

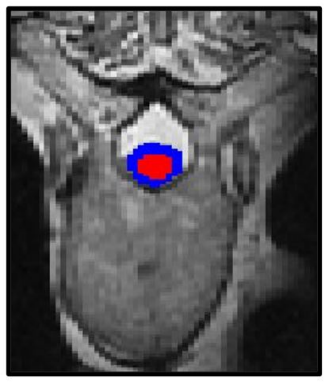

(b) CSF (blue) and WM (red) segmentation (axial)

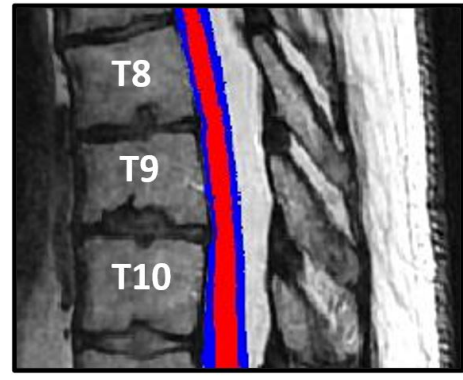

(c) CSF (blue) and WM (red) segmen- (d) tation (sagittal)

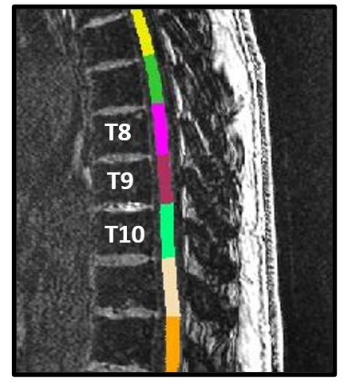

(d) Vertebral levels labels (sagittal)

Figure 6.3: Grey mater, white matter, CSF layer, and vertebral levels automatic segmentation results from SCS toolbox software in axial and sagittal views. MR images used: T2- and T1-weighted. GM: grey matter; PW: posterior width; WM: white matter; CSF: cerebrospinal fluid.

60 , slice thickness $=0.8 \mathrm{~mm}$. T1-weighted image parameters: sequence $=$ SPGR, magnetic field $=3 \mathrm{~T}$, field of view $=32 \mathrm{~mm}$, number of slices $=60$, slice thickness $=1 \mathrm{~mm}$ ). The scans were obtained with the patient in supine position. The Spinal Cord Toolbox (SCT) developed by De Leener et al. [31] was used to automatically segment the grey matter, the white matter, and the CSF layer from T8 to T10. Fig. 6.3 show the superimposed grey matter (Fig. 6.3(a)), white matter and 


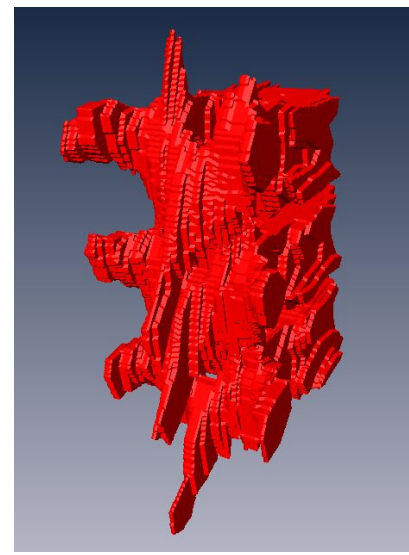

(a) Bone segmentation view in (b) Smooth bone segmentation Amira-Avizo ${ }^{\mathrm{TM}}$ software

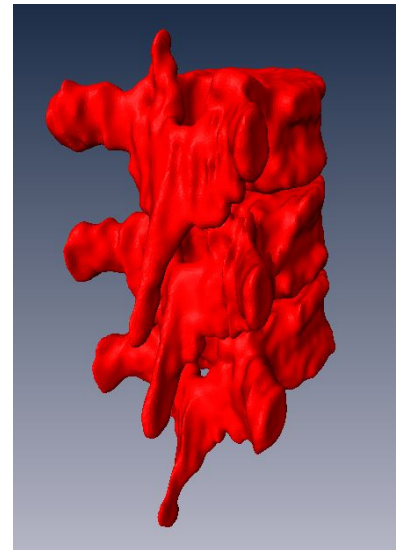

from Amira-Avizo ${ }^{\mathrm{TM}}$ software

Figure 6.4: Vertebral bone segmentation process.

CSF segmentations in axial and sagittal views (Fig. 6.3(b) and Fig. 6.3(c)) with the T2w MRI, and the vertebral levels labelling (Fig. 6.3(d)) with the T1w MRI. All segmentations were verified by visual inspection. MR images were obtained at the Hospital Politècnic i Universitari La Fe using General Electric equipment.

Bone segmentation was performed manually on Seg3D software in $400.8 \mathrm{~mm}$ thick cuts of the MR image to segment the vertebral bones (see Fig. 6.4(a)).

All the segmentations (bone, CSF and white matter) were smoothed by AmiraAvizo $^{\mathrm{TM}}$ software to reduce meshing and geometrical errors for solving the FEM model in COMSOL Multiphysics ${ }^{\circledR}$. As an example, Fig. 6.4(b) shows the result of the smoothing process, with notably reduced sharp edges.

The segmentations were imported to COMSOL Multiphysics ${ }^{\circledR}$ software to calculate the electric field distribution in the spinal cord (see Fig. 6.5). Dura mater was not segmented from the patient's MRI since the image resolution was 
CHAPTER 6. Development of a patient-specific spinal cord volume conductor 114 model

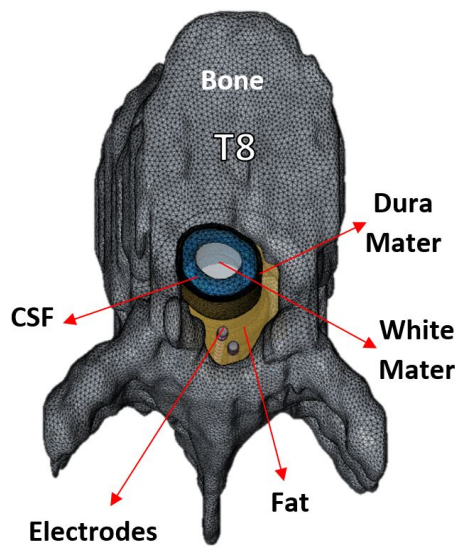

(a) Axial view

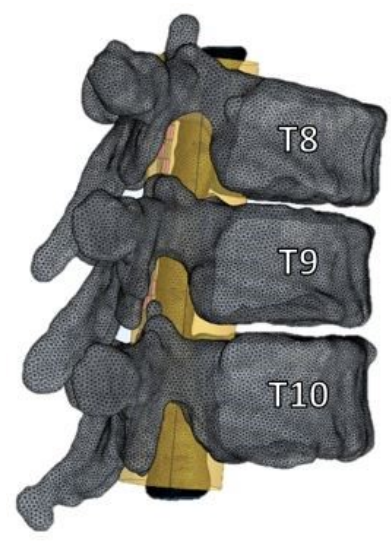

(b) Sagittal view

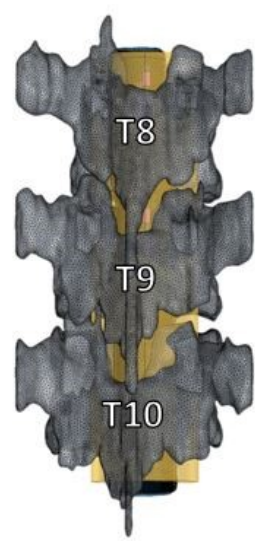

(c) Coronal view

Figure 6.5: Patient-specific model in COMSOL Multiphysics ${ }^{\circledR}$.

not good enough to differentiate it from the rest of the tissues. However, based on previous studies [119, 120, 162], the maximum value of the dura mater thickness in the human spinal cord at the L2-L4 levels is $0.3 \mathrm{~mm}$. Therefore, dura mater was included in the model by creating in COMSOL Multiphysics ${ }^{\circledR}$ a layer of 0.3 mm thick that covers the CSF. Fatty tissue was included by adding a cylinder to cover the entire spinal canal. The dorsal root (DR) anatomy was not included explicitly, following Zander et al. [162], who stated that the anatomy of the dorsal rootlets can be ignored in FEM design. As we were interested in the activation of the DC nerve fibers, grey matter was not included in the volume conductor model to reduce the computational cost. To confirm that excluding the grey matter did not produce differences in the model predictions, we performed a sensitivity analysis, which suggested that the grey matter could be ignored in the FEM design, since there were small errors in the perception thresholds for the $\mathrm{DC}\left(\mathrm{PT}_{\mathrm{DC}}\right)$ and $\mathrm{DR}\left(\mathrm{PT}_{\mathrm{DR}}\right)$ nerve fibers, and thus, the activating area (AA) (see Apendix C, Table C.2). However, the grey matter segmentation was used to locate the DR nerve fibers, since posterior width (PW) could be measured (see Fig. 6.3(a)). 
Electrodes were modeled as eight-pole percutaneous leads located in the epidural space (see Fig. 6.5(a)). The electrode-tissue interface was included as a 0.1$\mathrm{mm}$ thick hollow cylinder with $0.15 \mathrm{~S} / \mathrm{m}$ electrical conductivity [36] covering the active electrode poles. The model's electrode bipolar impedance was approximately $1 \mathrm{k} \Omega$, consistent with clinical bipolar impedance measurements, so that a conversion of $1 \mathrm{~V}$ to $1 \mathrm{~mA}$ can be used as an approximation of the relative currentcontrolled stimulus magnitudes for the voltage-controlled stimulation.

A tetrahedral adaptive mesh was used to avoid errors in the narrow and edge zones. The patient-specific model used around 12,300,000 elements, with a maximum element edge length of $2.4 \mathrm{~mm}$ (in the bone and fat tissues) and a minimum of $0.024 \mathrm{~mm}$ (in the white matter tissue). The white matter element edge length ranged between 24-240 $\mu \mathrm{m}$. According to Arle et al. [6] these mesh resolutions are accurate enough to resolve axons electrically down to the dimension of their internodal distances. In Table 6.1 the details for the boundary conditions and mesh resolution data of the patient-specific volume conductor model are shown.

As the geometry of the spinal cord is asymmetric in the patient-specific model, in order to locate the nerve fiber distribution, the middle line of the spinal cord (white matter) is first determined in COMSOL Multiphysics ${ }^{\circledR}$ (see Fig. 6.6). The middle line is determined manually for each of the three vertebral levels (T8, T9

Table 6.1: Boundary conditions and mesh resolution data.

Boundary conditions

\begin{tabular}{l|l}
\hline External bounds & Zero current (Electric insulation) \\
\hline Bounds of lead contacts & User-defined tension (Electric potential) \\
\hline Mesh resolution & Adaptive \\
\hline Type & $12,229,088$ \\
\hline Number of elements & 2.4 \\
\hline Maximum element size $(\mathrm{mm})$ & 0.024 \\
\hline Minimum element size $(\mathrm{mm})$ & 1.3 \\
\hline Maximum element grow rate & 0.2 \\
\hline Resolution of curvature & 1 \\
\hline Resolution of narrow regions &
\end{tabular}


CHAPTER 6. Development of a patient-specific spinal cord volume conductor 116 model

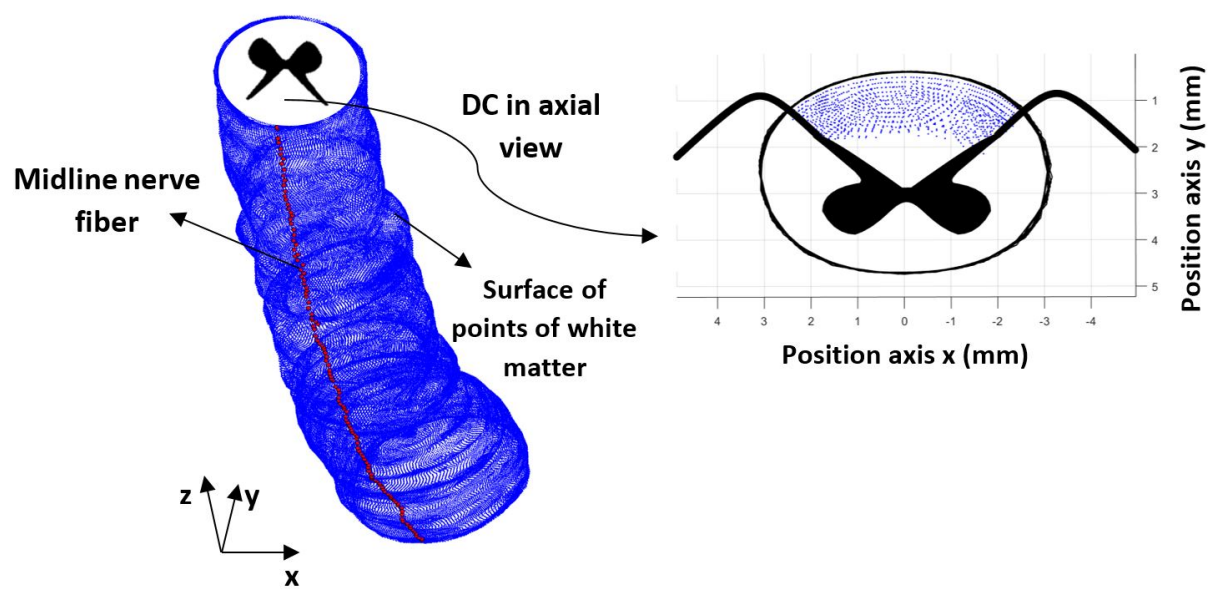

Figure 6.6: Definition of the middle line in DC of the patient-specific model. Middle line is defined for the three vertebral level (T8 (red), T9 (green)and T10 (yellow)) manually in COMSOL Multiphysics ${ }^{\circledR}$. After assigning the points (in positions $\mathrm{x}, \mathrm{y}$ and $\mathrm{z}$ ) on the surface of the white matter of the previously defined middle line the rest of the nerve fibers are selected applying a lateral separation of 66-79 $\mu \mathrm{m}$ (in $\mathrm{x}$-axis) and a depth separation of $50 \mu \mathrm{m}$ (in y-axis). Each blue point of the DC represents a node of Ranvier of a nerve fiber in that position.

and T10). Using MATLAB ${ }^{\circledR}$ R2017a, we then selected the points on the surface of the white matter closest to the points on the middle line that we had defined previously in COMSOL Multiphysics ${ }^{\circledR}$ (see Fig. 6.6). The new middle line represents a nerve fiber located longitudinally along the white matter. From this nerve fiber we obtained the location of the rest of the nerve fibers. As in the generalized model, we included 100 nerve fibers per surface by selecting points 66-79 $\mu \mathrm{m}$ from the previous nerve fiber (50 nerve fibers from the middle nerve fiber to the left lateral and 50 nerve fibers from the middle nerve fiber to the right lateral). We then increased the depth to $50 \mu \mathrm{m}$ to select the 100 nerve fibers on the next surface. A total of 20 rows of 100 nerve fibers were included in the model $(2,000$ nerve fibers), each with 64 nodes of Ranvier. 

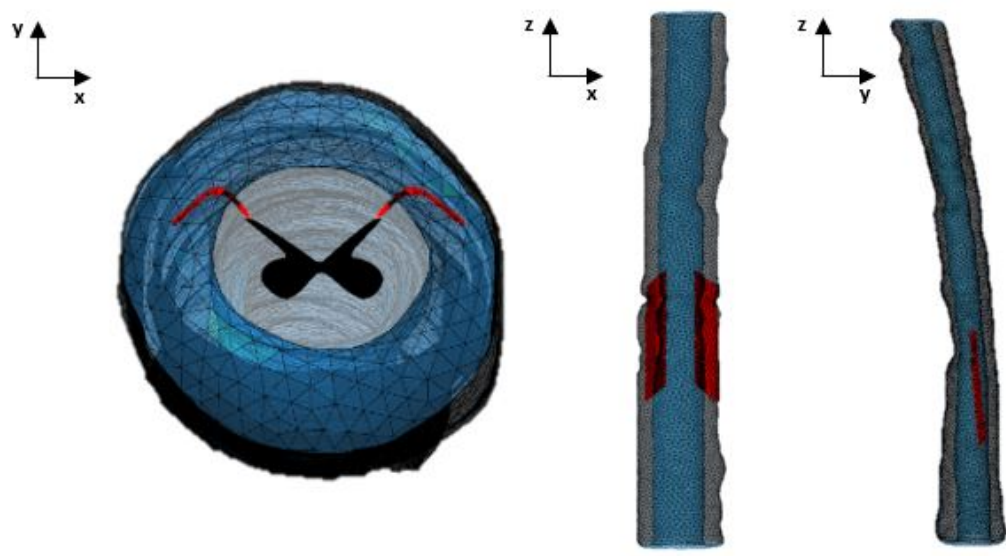

Transverse

Coronal

Sagittal

Figure 6.7: DR nerve fibers distribution in the patient-specific model. The surfaces of the (red) points defined to include the DRs in a specific zone of the spinal cord (between T9-T10) is shown for transverse (left), coronal (center) and sagittal (right) views. DR: dorsal root.

For DR fibers, two parametric surfaces of points (left and right sides of the spinal cord) are defined. In this case, the curvature and spatial position are adapted manually at each vertebral zone due to the geometric variation in the spinal cord and spinal canal of the model, as shown in Fig. 6.7. DR nerve fibers thus have between 5-7 nodes of Ranvier and a diameter of $15 \mu \mathrm{m}$.

Then, the points of the defined surfaces are exported from COMSOL Multiphysics ${ }^{\circledR}$ to MATLAB ${ }^{\circledR}$ R2017a. The model equations of the nerve fibers are solved using backward Euler implicit integration with a time step of $0.001 \mathrm{~ms}$ to obtain the first activated nerve fiber on the DC surface. If an action potential is obtained, $\mathrm{PT}_{\mathrm{DC}}$ is achieved. If not, we apply the minimum square method with a relative error of $0.05 \mathrm{~V}$ until $\mathrm{PT}_{\mathrm{DC}}$ is achieved. Threshold stimulation of DR $\left(\mathrm{PT}_{\mathrm{DR}}\right)$ nerve fibers is also calculated. A stimulation pulse is applied that consists of a rectangular-wave voltage pulse with $300 \mu$ s duration (a typical tonic stimula- 
CHAPTER 6. Development of a patient-specific spinal cord volume conductor 118 model

tion waveform).

\subsection{Clinical restrospective proof-of-concept}

The development of a patient-specific spinal cord model is a thorough and laborious process. Not only is the segmentation of all spinal cord features required, but the computing cost and time are also higher. Therefore, before performing clinical studies with several patients, it is pivotal to investigate if the effort of a patient-specific model development is worth it. Thus, this study is focused on determining if a patient-specific spinal cord model performs a more accurate neural response prediction than a generalized SCS model by comparing the model-based predictions from both the generalized and patient-specific models to clinical data from two patients undergoing SCS therapy.

\subsubsection{Methods}

Clinical data (perception and discomfort thresholds) were collected from two patients with neuropathic pain, after the SCS device implant, i.e. after the second time surgery. The values of the stimulation parameters (PT and DT) were obtained with the patients standing. PT was obtained when the patient started feeling a slight tingling sensation and DT when the stimulation amplitude was raised and the patient reported an unpleasant sensation. The selected polarity corresponds to the electrode configuration that best paresthesia coverage produced, according to the sensations reported by the patients.

For the computational simulations, the generalized SCS model used in this study was the one developed previously, which is described in Chapter 5, Section 5.2. The patient-specific SCS models were developed from the patient's MRI obtained before the SCS implant surgery, as decribed in this chapter (Section 6.3). Further details of the geometrical parameters of both models can be seen in figure $\mathrm{S} 1$ and table S1 in Appendix C. 
The nerve fiber model used for the simulation of the neural response was the combination of the WHM model and RMG model B, which is described in Chapter 4, Section 4.2. The equations, geometric and electrical parameters of the model are shown in Appendix A.

To compare the model-based predictions from both SCS models with the experimental data from the patients, electrodes were located in the same position as implanted in the real patient, using the $\mathrm{x}$-rays of the electrodes taken during the implantation procedure as a reference. Figure 6.8 shows how electrodes are definetely located in the epidural space (fat tissue), in both the generalized and patient-specific models, from a patient's x-rays obtained in antero-posterior (AP) and lateral views.

Finally, the following evaluation parameters were calculated: $\mathrm{PT}_{\mathrm{DC}}, \mathrm{PT}_{\mathrm{DR}}$, $\mathrm{DT}, \mathrm{R}_{\mathrm{DC} / \mathrm{DR}} \mathrm{AA}, \mathrm{AD}$, and right and left activated fibers in DC. The method to calculate these parameters is explained in Chapter 3 .

\subsubsection{Patient 1}

The first patient in the study was a 47-year-old woman diagnosed with failed back surgery syndrome who had reported chronic pain in both left lower limb and left lower back. We found guarded cathode $(\mathrm{GC})((+)(-)(+))$ and transverse guarded cathode (TGC) $((+)(-)(+)$ in one electrode and a $(+)$ located next to $(-)$ using the other electrode) polarities which produced paresthesia coverage in her pain dermatomes. As the patient reported an undesired pleasant tingling sensation in the right lower limb with GC polarity, TGC was used to manage her chronic pain. The collected PT and DT are shown in Table 6.2. Fig. 6.9 shows the induced paresthesia coverage in the front and back body and the programmed polarity.

Using the patient-specific and generalized models we calculated the stimulation parameters for GC $(5(+), 6(-), 7(+)$ (see Fig. 6.9(a))) stimulation, shown in Table 6.2. Fig. 6.10(c) reveals that there are more activated nerve fibers on 
CHAPTER 6. Development of a patient-specific spinal cord volume conductor 120 model

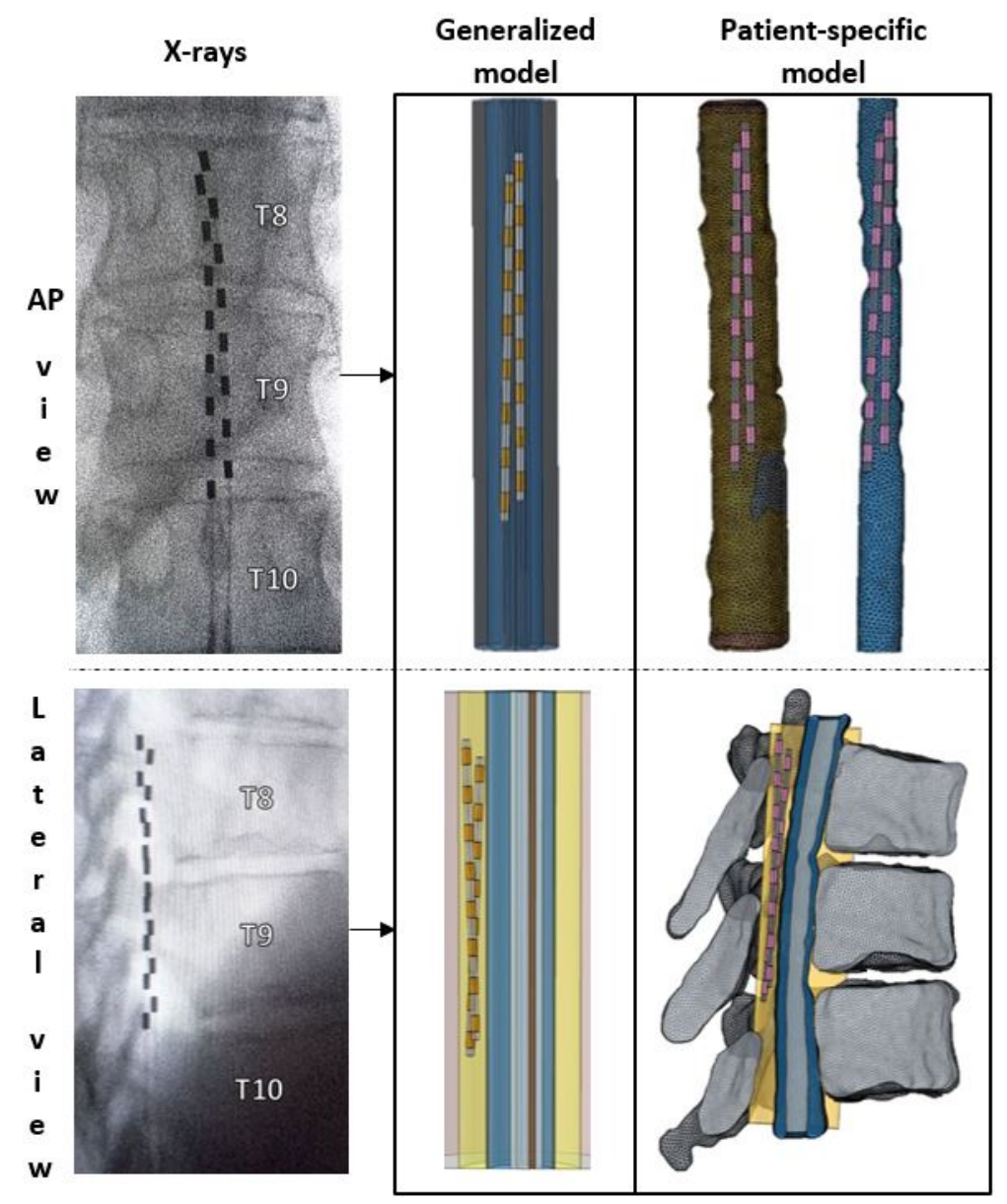

Figure 6.8: Left: intraoperative radiographies of the electrodes location after the second time surgery in AP (above) and lateral (below) views. Center: electrodes location in the generalized SCS model in AP (above) and lateral (below) views. Right: electrodes location in the patient-specific SCS model in AP (above, with bone and fat tissue hidden (left), and with dura mater and CSF also hidden (right) and lateral (below) views). AP: antero-posterior; SCS: Spinal Cord Stimulation. 


\section{Pleasant tingling sensation}

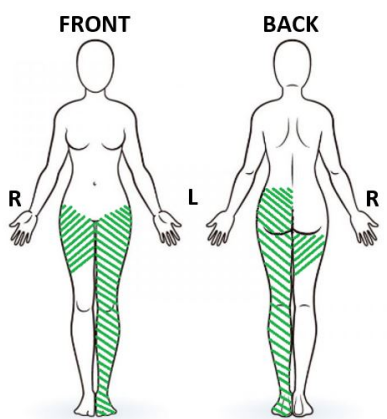

(a) GC polarity.
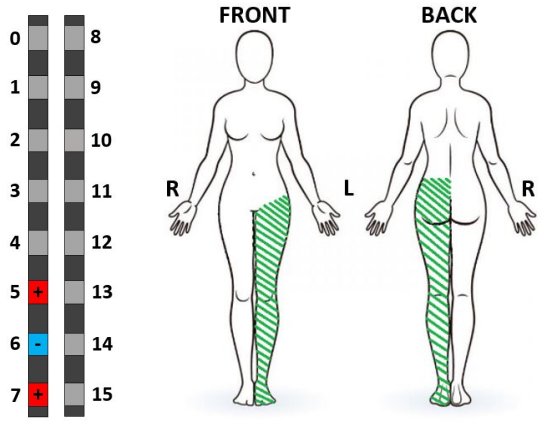

(b) TGC polarity.

Figure 6.9: Paresthesia coverage of patient 1. GC: guarded cathode; TGC: transverse guarded cathode. The striped green zones represent the zones where the patient feels a pleasant tingling sensation during stimulation. Left electrode: from pole 0 to pole 7 ; right electrode: from pole 8 to pole 15 . Vertebral level stimulated in both programs: T9. R: right; L: left.

the left side than on the right of the DCs in the generalized model. The same effect was obtained in the patient-specific model (see Fig. 6.10(a)) but fewer nerve fibers would be activated on the right side of the DC (34 nerve fibers versus 55 nerve fibers activated in the generalized model). Moreover, the opposite effect is obtained on the left, i.e. the number of fibers that would be activated is $17.21 \%$ higher than in the generalized model (143 versus 122). As for the stimulation parameters, we can see that AA does not change $\left(1.62 \mathrm{~mm}^{2}\right.$ for both models) and $\mathrm{AD}$ is $5.3 \%$ lower in the generalized than in the patient-specific model (500 versus $528 \mu \mathrm{m}$, respectively). On the other hand, $\mathrm{PT}_{\mathrm{DC}}$ is $190 \%$ higher using the generalized model (3.8 V versus $1.31 \mathrm{~V}$ ) and so DT is $189.9 \%$ and $\mathrm{PT}_{\mathrm{DR}}$ is $169.2 \%$ higher than the values obtained with the patient-specific model $(5.16 \mathrm{~V}$ versus $1.78 \mathrm{~V}$ and $11.2 \mathrm{~V}$ versus $4.16 \mathrm{~V}$, respectively). $\mathrm{R}_{\mathrm{DC} / \mathrm{DR}}$ prediction is similar in both models, more specifically $7.94 \%$ higher in the generalized model $(0.34$ versus 0.314 ). Fig. 6.10 also show the significant difference of the spinal cord size 
CHAPTER 6. Development of a patient-specific spinal cord volume conductor 122 model

between the generalized and the patient-specific model. In this case, the patient presented a narrowing of the spinal cord at $\mathrm{T} 9$ vertebral level, which influences the effect of the stimulation on the evaluation parameters, as shown in Table 6.2.

The results of the TGC $(5(+), 6(-), 7(+)$ and 14(+) (see Fig. 6.9(b))) polarity stimulation are shown in figures 6.10 (b) and 6.10(d). There are more activated nerve fibers on the left than the right side. Both the generalized and the patientspecific spinal cord model obtained the same results as GC polarity, i.e. more nerve fibers would be activated on the right in the generalized model (41 versus 25 nerve fibers). There is a similar difference in the stimulation parameters: AA and $\mathrm{AD}$ are $10.6 \%$ and $13.06 \%$ higher in the generalized than in the patient-specific model (1.46 versus $1.32 \mathrm{~mm}^{2}$ and 450 versus $\left.391 \mu \mathrm{m}\right), \mathrm{PT}_{\mathrm{DC}}$ is $181.57 \%$ higher using the generalized model, DT is $180.9 \%$ and $\mathrm{PT}_{\mathrm{DR}}$ is $184.4 \%$ higher than those obtained using the patient-specific model. $\mathrm{R}_{\mathrm{DC} / \mathrm{DR}}$ prediction is also similar but in this case is $1.06 \%$ lower in the generalized model ( 0.47 versus 0.475$)$. However, unlike GC, TGC polarity produces a neural activation displacement in the site opposite to where the transversal anode is programmed, reducing the number of activated nerve fibers by $26.47 \%$ on the right side of the DC ( 34 versus 25 nerve fibers using GC and TGC polarities in the patient-specific model, respectively).

Table 6.2: Evaluation parameters obtained from the real patient 1, the generalized spinal cord model and the patient-specific spinal cord model. $\mathrm{PT}_{\mathrm{DC}}$ : perception threshold in $\mathrm{DC}$; $\mathrm{PT}_{\mathrm{DR}}$ : perception threshold in DR; DT: discomfort threshold; $\mathrm{R}_{\mathrm{DC} / \mathrm{DR}}$ : recruitment ratio; AA: activating area; AD: activating depth.

\begin{tabular}{|c|c|c|c|c|c|c|}
\hline Source & $\begin{array}{l}\mathbf{P T}_{\mathbf{D C}} \\
(\mathbf{V})\end{array}$ & $\begin{array}{l}\mathbf{P T}_{\mathbf{D R}} \\
(\mathbf{V})\end{array}$ & $\begin{array}{l}\text { DT } \\
(\mathbf{V})\end{array}$ & $\mathbf{R}_{\mathrm{DC} / \mathrm{DR}}$ & $\begin{array}{l}\mathbf{A A} \\
\left(\mathbf{m m}^{2}\right)\end{array}$ & $\begin{array}{l}\text { AD } \\
(\mu \mathbf{m})\end{array}$ \\
\hline \multicolumn{7}{|c|}{ Guarded cathode polarity } \\
\hline Real patient 1 & 1.4 & - & 1.9 & - & - & - \\
\hline Generalized model & 3.8 & 11.2 & 5.16 & 0.34 & 1.62 & 500 \\
\hline Patient-specific model & 1.31 & 4.16 & 1.78 & 0.314 & 1.62 & 528 \\
\hline \multicolumn{7}{|c|}{ Transverse guarded cathode polarity } \\
\hline Real patient 1 & 1.6 & - & 2.2 & - & - & - \\
\hline Generalized model & 4.28 & 9.1 & 5.9 & 0.47 & 1.46 & 450 \\
\hline Patient-specific model & 1.52 & 3.2 & 2.1 & 0.475 & 1.32 & 391 \\
\hline
\end{tabular}




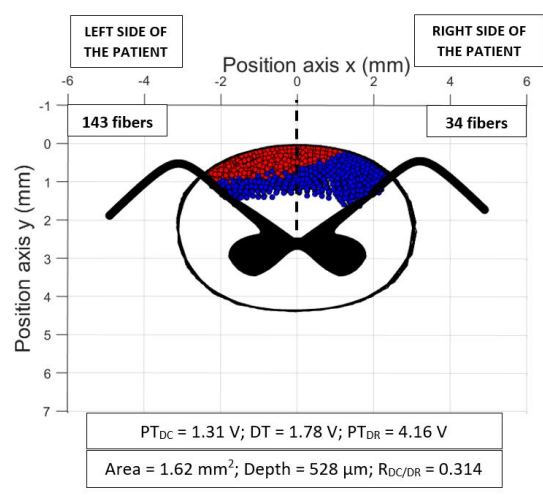

(a) Patient-specific model. GC polarity.

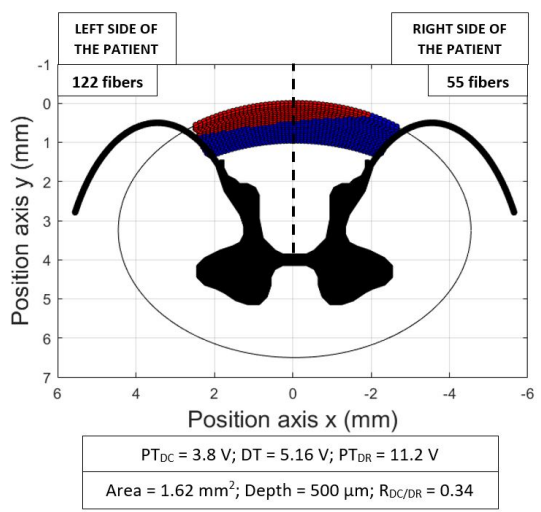

(c) Generalized model. GC polarity.

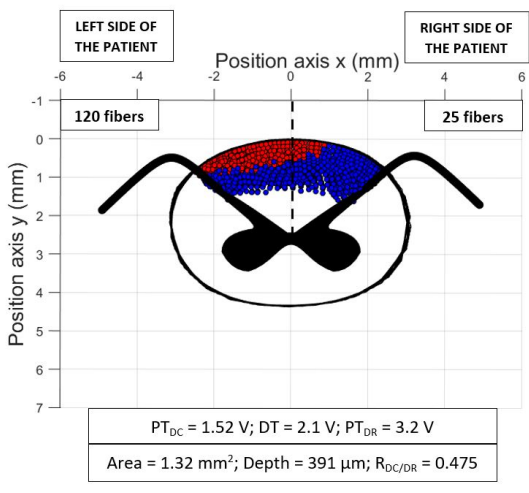

(b) Patient-specific model. TGC polarity.

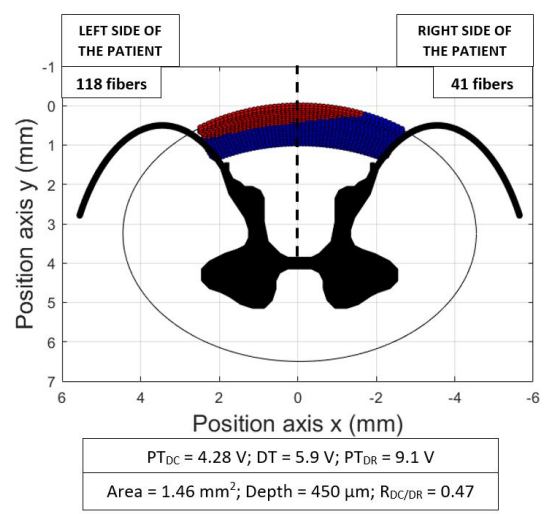

(d) Generalized model. TGC polarity.

Figure 6.10: Evaluation parameter prediction in TGC and GC polarities. Red points represent activated nerve fibers. Blue points are not activated nerve fibers. White areas are zones with no nerve fibers considered. Stimulus applied: a rectangular pulse of 300 $\mu$ s duration with an electrical strength of 1.357 PT for GC polarity and 1.375 PT for TGC in V. Dashed line represents the central line of the spinal cord. TGC: transverse guarded cathode; GC: guarded cathode; PT: perception threshold. 
CHAPTER 6. Development of a patient-specific spinal cord volume conductor 124 model

Table 6.2 shows the patient's evaluation parameters obtained from the generalized model and the patient-specific model. Although AA, AD and $\mathrm{R}_{\mathrm{DC} / \mathrm{DR}}$ are very similar in both models, the latter predicts the stimulation thresholds more accurately. For example, for TGC polarity, the real patient reported a $\mathrm{PT}_{\mathrm{DC}}$ of 1.6 $\mathrm{V}$. With the patient-specific model, the $\mathrm{PT}_{\mathrm{DC}}$ value is only $5 \%$ lower than the one from the real patient while it is $167.5 \%$ higher in the generalized model. The same effect occurs for $\mathrm{DT}$ and $\mathrm{PT}_{\mathrm{DR}}$ values prediction in $\mathrm{GC}$ and $\mathrm{TGC}$ polarities.

\subsubsection{Patient 2}

The second patient in the study was a 54-year-old woman diagnosed with failed back surgery syndrome who had reported chronic pain in the center-right lower back. Three programs were tested to cover her painful dermatomes. Only one of the programs (program 2) produced paresthesia coverage in the center lower back, which was used to manage her chronic pain. Fig. 6.11 shows the induced paresthesia coverage in the front and the back body and the programmed polarity. The collected values of the stimulation parameters (PT and DT) for the three programs are shown in Table 6.3.

The stimulation parameters were calculated for the three programs by using the patient-specific model and three versions of the generalized model (one for each vertebral level stimulated with the programs: T8, T9 and T10). The results are shown in Table 6.3.

In program 1, $\mathrm{PT}_{\mathrm{DC}}, \mathrm{PT}_{\mathrm{DR}}$ and $\mathrm{DT}$ are higher in the patient-specific than in the generalized model $(3.9 \%, 8.7 \%$, and $8.65 \%$ higher, respectively). In both models, the stimulation starts at the DR. However, $\mathrm{R}_{\mathrm{DC} / \mathrm{DR}}$ is $4.5 \%$ lower in the patientspecific model. This difference affects $\mathrm{AA}$ and $\mathrm{AD}$ predictions, which are higher in the patient-specific model $\left(0.346\right.$ versus $0.055 \mathrm{~mm}^{2}$ and 362.76 versus $50 \mu \mathrm{m}$, respectively). As shown in Fig. 6.12, no left fibers would be activated in both models, which is in agreement with the paresthesia coverage clinical data (see 


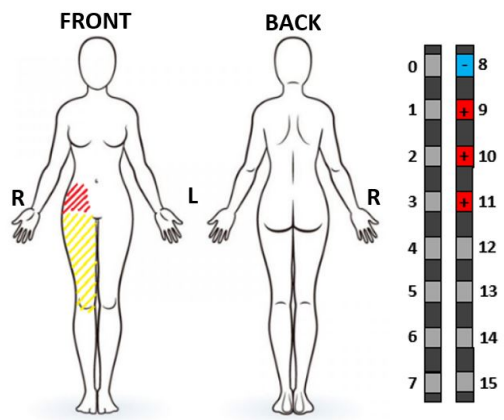

(a) Program 1. Vertebral level stimulated: T8.

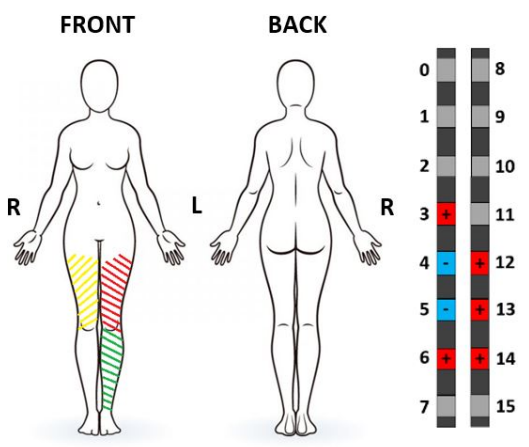

(c) Program 3. Vertebral level stimulated: T10.

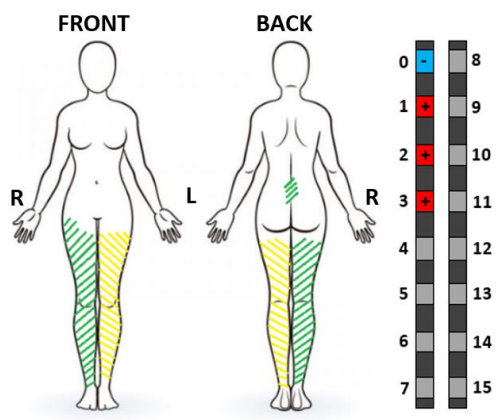

(b) Program 2. Vertebral level stimulated: T9.

\section{PARESTHESIA COVERAGE LEGEND \\ Soft tingling sensation \\ Pleasant tingling sensation \\ Unpleasant tingling sensation}

Figure 6.11: Paresthesia coverage of patient 2. The striped zones represent the anatomic location where the patient feels a tingling sensation during stimulation. Soft tingling (yellow): a slight tingling that is felt like the initial sensation that is produced when the perception threshold is achieved. Pleasant tingling (green): strong and comfortable sensation produced at a stimulus amplitude that is just below the discomfort threshold. Unpleasant tingling (red): discomfortable and painful sensation that is produced at (or above) the discomfort threshold. Left electrode: from pole 0 to pole 7; right electrode: from pole 8 to pole 15. R: right; L: left. 
CHAPTER 6. Development of a patient-specific spinal cord volume conductor 126 model

Fig. 6.11(a)), since no tingling sensation is felt in the left side. Nevertheless, in the patient-specific model more right fibers would be activated than in the generalized model (33 versus 6 , respectively).

In program 2, $\mathrm{PT}_{\mathrm{DC}}, \mathrm{PT}_{\mathrm{DR}}$, and $\mathrm{DT}$ are lower in the patient-specific than in the generalized model $(16.1 \%, 5.2 \%$, and $11.4 \%$ lower, respectively). Instead, $\mathrm{R}_{\mathrm{DC} / \mathrm{DR}}$ is higher in the generalized model (1.06 versus 0.934$)$, so the stimulation starts at the DR, while it does at the DC in the patient-specific model. However, although AA is higher in the generalized model $\left(0.76\right.$ versus $\left.0.56 \mathrm{~mm}^{2}\right), \mathrm{AD}$ is lower than in the patient-specific model (300 versus $423.74 \mu \mathrm{m}$, respectively). Fig. 6.12 shows that more right than left fibers would be activated in the patientspecific model ( 38 on the right versus 21 on the left). Instead, the opposite effect is obtained in the generalized model, i.e. more left fibers would be activated (52 on the left versus 32 on the right). According to paresthesia coverage clinical data (see Fig. 6.11(b)), more tingling sensation is felt in the right lower limb. Therefore, the patient-specific model results are in agreement with the clinical data.

Table 6.3: Evaluation parameters obtained from the real patient 2, the generalized spinal cord model and the patient-specific spinal cord model. $\mathrm{PT}_{\mathrm{DC}}$ : perception threshold in DC; $\mathrm{PT}_{\mathrm{DR}}$ : perception threshold in DR; DT: discomfort threshold; $\mathrm{R}_{\mathrm{DC} / \mathrm{DR}}$ : recruitment ratio; AA: activating area; AD: activating depth.

\begin{tabular}{l|l|l|l|l|l|l} 
Source & $\begin{array}{l}\mathbf{P T}_{\mathbf{D C}} \\
(\mathbf{V})\end{array}$ & $\begin{array}{l}\mathbf{P T}_{\mathbf{D R}} \\
(\mathbf{V})\end{array}$ & $\mathbf{D T}(\mathbf{V})$ & $\mathbf{R}_{\mathbf{D C} / \mathbf{D R}}$ & $\begin{array}{l}\mathbf{A A} \\
\left(\mathbf{m m}^{2}\right)\end{array}$ & $\begin{array}{l}\text { AD } \\
(\mu \mathbf{m})\end{array}$ \\
\hline \multicolumn{7}{c}{ Program 1. T8 vertebral level } \\
\hline Real patient 2 & 6 & - & 6.8 & - & - & - \\
\hline Generalized model & 5.1 & 4.6 & 5.2 & 1.11 & 0.055 & 50 \\
\hline Patient-specific model & 5.3 & 5 & 5.65 & 1.06 & 0.307 & 362.76 \\
\hline \multicolumn{7}{|}{ Program 2. T9 vertebral level } \\
\hline Real patient 2 & 4.5 & - & 5.6 & - & - & - \\
\hline Generalized model & 5.08 & 4.81 & 5.96 & 1.06 & 0.76 & 300 \\
\hline Patient-specific model & 4.26 & 4.56 & 5.28 & 0.934 & 0.56 & 423.74 \\
\hline \multicolumn{7}{|}{ Program 3. T10 vertebral level } \\
\hline Real patient 2 & 3.6 & - & 4.4 & - & - & - \\
\hline Generalized model & 3.36 & 3.66 & 4.1 & 0.918 & 1.29 & 450 \\
\hline Patient-specific model & 3.6 & 3.36 & 4.1 & 1.07 & 0.4 & 312.17 \\
\hline
\end{tabular}


PATIENT-SPECIFIC MODEL

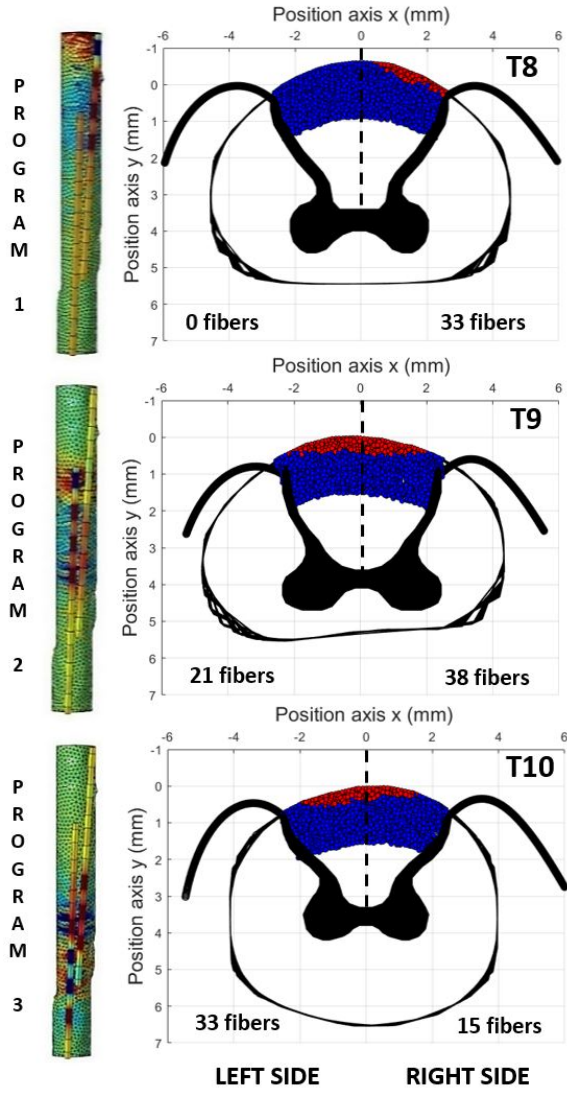

GENERALIZED MODEL
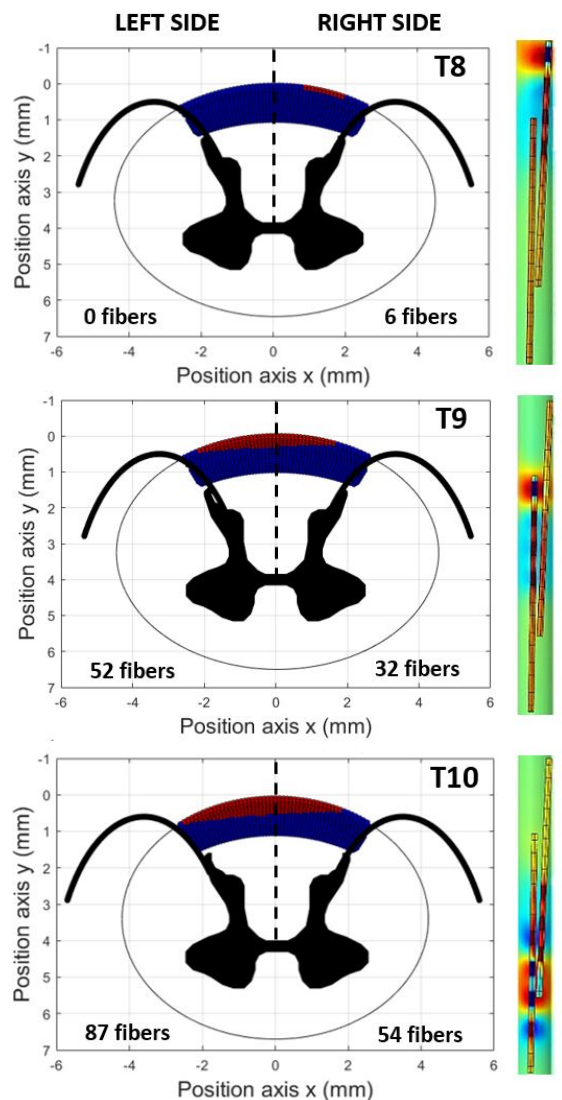

Figure 6.12: Evaluation parameter prediction for patient 2. Red points represent activated nerve fibers. Blue points are not activated nerve fibers. White areas are zones with no nerve fibers considered. Stimulus applied: a rectangular monophasic pulse of $300 \mu \mathrm{s}$ duration with an electrical strength of 1.13 PT for program 1 in V; 1.24 PT for program 2; and 1.22 PT for program 3. Dashed line represents the central line of the spinal cord.

In program 3 , the stimulation parameters values $\left(\mathrm{PT}_{\mathrm{DC}}, \mathrm{PT}_{\mathrm{DR}}\right.$, and $\left.\mathrm{DT}\right)$ are si- 
CHAPTER 6. Development of a patient-specific spinal cord volume conductor 128 model

milar in both models. While $\mathrm{PT}_{\mathrm{DC}}$ is $7.14 \%$ higher in the patient-specific model, $\mathrm{PT}_{\mathrm{DR}}$ is $8.2 \%$ lower. $\mathrm{R}_{\mathrm{DC} / \mathrm{DR}}$ is lower than 1 in the generalized model (0.918), so the stimulation starts at the DC. Conversely, in the patient-specific model, $\mathrm{R}_{\mathrm{DC} / \mathrm{DR}}$ is higher than 1 (1.07), so the activation is first produced at DR fibers. Consequently, AA and AD are higher in the generalized model $\left(1.29\right.$ versus $0.4 \mathrm{~mm}^{2}$ and 450 versus $312.17 \mu \mathrm{m}$, respectively). In terms of paresthesia coverage, the patient reported unpleasant sensation in the anterior lower left thigh, and a soft sensation in the anterior lower right thigh (see Fig. 6.11(c)). Both models predict right fibers activation (see Fig. 6.12), which is in agreement with the clinical data. However, in the patient-specific model lower right fibers would be activated than in the generalized model ( 15 versus 54 , respectively). And the same occurs on the left side, more left fibers would be activated in the generalized model (87 versus 33 in the patient-specific model).

As shown in Table 6.3, the patient-specific model predicts $\mathrm{PT}_{\mathrm{DC}}$ and $\mathrm{DT}$ values that are closer to clinical data. In program $1, \mathrm{PT}_{\mathrm{DC}}$ and $\mathrm{DT}$ are $11.67 \%$ and $16.91 \%$ lower than in the real patient $(5.3$ versus $6 \mathrm{~V}$ and 5.65 versus $6.8 \mathrm{~V}$, respectively), while they are $15 \%$ and $23.53 \%$ lower in the generalized model (5.1 versus $6 \mathrm{~V}$ and 5.2 versus $6.8 \mathrm{~V}$ ). In program 2, $\mathrm{PT}_{\mathrm{DC}}$ and DT are $5.3 \%$ and $5.71 \%$ lower than the clinical values. Conversely, the generalized model presents $\mathrm{PT}_{\mathrm{DC}}$ and DT values that are $12.88 \%$ and $6.43 \%$ higher than the clinical data. In program 3 , the generalized model $\mathrm{PT}_{\mathrm{DC}}$ value is $6.67 \%$ lower than the value of the real patient (3.36 versus $3.6 \mathrm{~V}$ ), while the patient-specific model $\mathrm{PT}_{\mathrm{DC}}$ is in agreement with the clinical data. As for DT value, both the generalized and patient-specific models are $6.81 \%$ lower than the clinical value ( 4.1 versus $4.4 \mathrm{~V}$, respectively).

\subsection{Pre-implantation selection of the electrode polarity. Clinical application}

Selecting stimulation parameters before SCS surgery could be a future application of a 3D patient-specific model. For this study we used the patient-specific model of the patient 1 . 

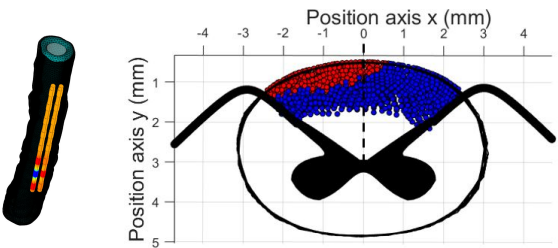

(a) Case 1. 5(+),6(-),7(+) and 14(+).
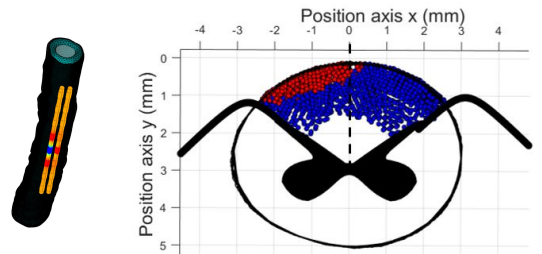

(c) Case 3. 3(+), 4(-),5(+) and 12(+).
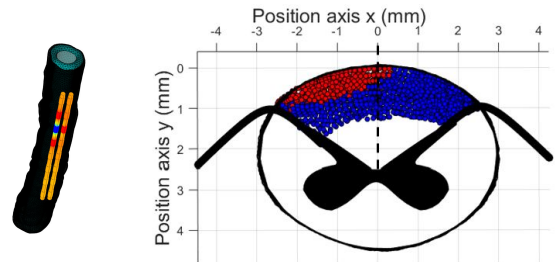

(e) Case 5. 1(+),2(-),3(+) and 10(+).
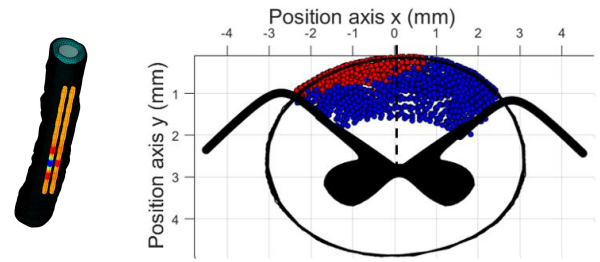

(b) Case 2. 4(+),5(-),6(+) and 13(+).
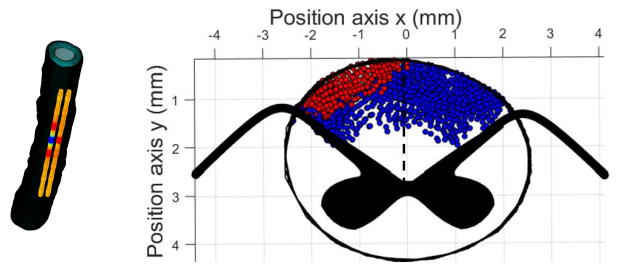

(d) Case 4. 2(+),3(-),4(+) and 11(+).
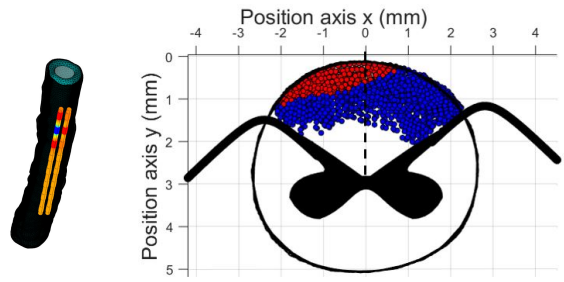

(f) Case 6. $0(+), 1(-), 2(+)$ and $9(+)$.

Figure 6.13: Activation area and depth at ideal electrode position in the $3 \mathrm{D}$ patientspecific model of patient 1. TGC polarity. Red points represent activated nerve fibers, blue points not activated nerve fibers. White area represents zones with no nerve fibers considered. Stimulus applied: a rectangular monophasic pulse of $300 \mu$ s duration with an electrical strength of 1.4 PT in V. Vertebral bodies and fat tissues are hidden to highlight electrode polarity. Red poles are anodes and blue poles cathodes. Dashed line is the central line of the spinal cord. PT: perception threshold. Programmed poles for each case: Case 1: $5(+) 6(-) 7(+)$ and $14(+)$; Case 2: $4(+) 5(-) 6(+)$ and $13(+)$; Case 3 : $3(+) 4(-) 5(+)$ and $12(+)$; Case 4: $2(+) 3(-) 4(+)$ and $11(+)$; Case 5: $1(+) 2(-) 3(+)$ and 10(+); Case 6: $0(+) 1(-) 2(+)$ and $9(+)$. 
CHAPTER 6. Development of a patient-specific spinal cord volume conductor 130 model

The electrodes were located at an ideal position (epidural space over the dura mater, parallel to the white matter and $2.5 \mathrm{~mm}$ center-to-center separation) to maximize neural activation on the left side of the spinal cord. The electrode program used for TGC polarity simulations has been experimentally shown to be the best to cover pain dermatomes in the real patient 1 . We then simulated the effect of moving electrode polarity from the poles below to those above the electrodes (six cases shown in Fig. 6.13) to determine the electrode program most likely to cover the patient's painful dermatomes.

As the white matter geometry changes at each slice, as shown in Fig. 6.13, the fibers to be activated depend on the stimulation poles selected and the electrode location. The evaluation parameters were calculated to find the differences for the six cases considered (see Table 6.4).

In general, Case 4 (Fig. 6.13(d)) maximizes the number of left-activated nerve fibers (213 versus 2 right-activated fibers), while Case 2 (Fig. 6.13(b)) activates more right fibers (23), maximizes AA $\left(1.77 \mathrm{~mm}^{2}\right)$ and minimizes $\mathrm{R}_{\mathrm{DC} / \mathrm{DR}}(0.275)$. In terms of $\mathrm{PT}_{\mathrm{DC}}$, Cases 2 (Fig. 6.13(b)), 3 (Fig. 6.13(c)) and 4 (Fig. 6.13(d)) present the lowest values (1.06, 1.03 and 1.08, respectively), since in these cases the electrodes are closer to the dura mater, due to the geometry of the patient's

Table 6.4: Evaluation parameters obtained from the patient-specific spinal cord model. $\mathrm{PT}_{\mathrm{DC}}$ : perception threshold in $\mathrm{DC} ; \mathrm{PT}_{\mathrm{DR}}$ : perception threshold in DR; DT: discomfort threshold; $\mathrm{R}_{\mathrm{DC} / \mathrm{DR}}$ : recruitment ratio; $\mathrm{AA}$ : activating area; $\mathrm{AD}$ : activating depth.

\begin{tabular}{|c|c|c|c|c|c|c|c|c|}
\hline Cases & $\begin{array}{l}\mathbf{P T}_{\mathbf{D C}} \\
(\mathbf{V})\end{array}$ & $\begin{array}{l}\mathbf{P T}_{\mathrm{DR}} \\
\text { (V) }\end{array}$ & $\begin{array}{l}\text { DT } \\
\text { (V) }\end{array}$ & $\mathbf{R}_{\mathbf{D C} / \mathrm{DR}}$ & $\begin{array}{l}\mathbf{A A} \\
\left(\mathbf{m m}^{2}\right)\end{array}$ & $\begin{array}{l}\text { AD } \\
(\mu \mathbf{m})\end{array}$ & $\begin{array}{l}\text { Left } \\
\text { fibers }\end{array}$ & $\begin{array}{l}\text { Right } \\
\text { fibers }\end{array}$ \\
\hline \multicolumn{9}{|c|}{ Parallel electrodes } \\
\hline Case $1.5(+) 6(-) 7(+)$ and $14(+)$ & 1.33 & 4.54 & 1.86 & 0.292 & 1.2 & 398.2 & 120 & 11 \\
\hline Case 2. $4(+) 5(-) 6(+)$ and $13(+)$ & 1.06 & 3.86 & 1.49 & 0.275 & 1.77 & 502.1 & 171 & 23 \\
\hline Case $3.3(+) 4(-) 5(+)$ and $12(+)$ & 1.03 & 3.33 & 1.44 & 0.31 & 1.52 & 500 & 163 & 4 \\
\hline Case $4.2(+) 3(-) 4(+)$ and $11(+)$ & 1.08 & 3.21 & 1.51 & 0.335 & 1.41 & 457.8 & 213 & 2 \\
\hline Case 5. 1(+)2(-)3(+) and 10(+) & 1.16 & 1.96 & 1.62 & 0.592 & 1.18 & 456 & 119 & 11 \\
\hline Case 6. $0(+) 1(-) 2(+)$ and $9(+)$ & 1.31 & 3.57 & 1.83 & 0.367 & 1.46 & 532 & 152 & 8 \\
\hline \multicolumn{9}{|c|}{ Parallel electrodes with offset } \\
\hline Case $2.4(+) 5(-) 6(+)$ and $13(+)$ & 0.86 & 2.87 & 1.2 & 0.3 & 1.71 & 462.6 & 129 & 58 \\
\hline
\end{tabular}


spinal cord. Instead, Cases 1 (Fig. 6.13(a)), 5 (Fig. 6.13(e)) and 6 (Fig. 6.13(f)) need higher $\mathrm{PT}_{\mathrm{DC}}$ values to activate the nerve fibers (between 12-29\% higher than Cases 2, 3 and 4). AD is also affected, being higher in Case $6(532 \mu \mathrm{m})$ and lower in Case $1(398.2 \mu \mathrm{m})$. In Cases 2 and 3, AD is about $500 \mu \mathrm{m}$, while it is about $10 \%$ lower in Cases 4 and 5 (457.8 $\mu \mathrm{m}$ and $456 \mu \mathrm{m}$, respectively).

\subsection{Effect of electrode offset}

The effect of electrode offset on neural activation was studied by using the patientspecific model of patient 1 . Implanted electrodes may be either perfectly parallel, i.e. with the poles of the two electrodes facing each other, or one can be offset to avoid them facing each other.

We compared AA and AD with parallel electrodes against parallel electrodes with a vertical offset of $3.5 \mathrm{~mm}$, i.e. interspersed poles. As Case 2 would activate more right nerve fibers, this case was used to study the effect of electrode offset.

Fig. 6.14 shows that the effect of electrode offset is the loss of the electric field displacement achieved with TGC polarity. The evaluation parameter values are also shown in Table 6.4. When TGC is applied with the electrodes in parallel, the number of left-activated nerve fibers is $32.56 \%$ higher than with electrode offset (171 versus 129 nerve fibers) and the number of right-activated nerve fibers increases by $52.17 \%$ with offset electrodes ( 23 versus 58 , respectively). In terms of $\mathrm{AA}$ and $\mathrm{AD}$, offset electrodes also reduce these parameters $\left(1.77 \mathrm{~mm}^{2}\right.$ versus $1.71 \mathrm{~mm}^{2}$ and $502.1 \mu \mathrm{m}$ versus $462.6 \mu \mathrm{m}$, respectively). $\mathrm{R}_{\mathrm{DC} / \mathrm{DR}}$ is about $9 \%$ higher than paralleled electrodes $(0.275$ versus 0.3$)$. However, $\mathrm{PT}_{\mathrm{DC}}$ is about $20 \%$ lower with offset $(1.06 \mathrm{~V}$ versus $0.86 \mathrm{~V})$ since the first activated nerve fiber is closer to the electrode and there is no electric field displacement. 
CHAPTER 6. Development of a patient-specific spinal cord volume conductor 132 model
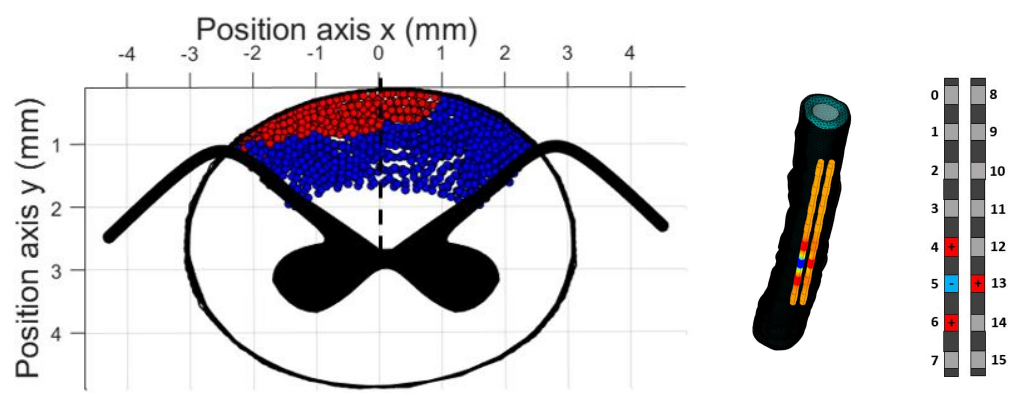

(a) Parallel electrodes
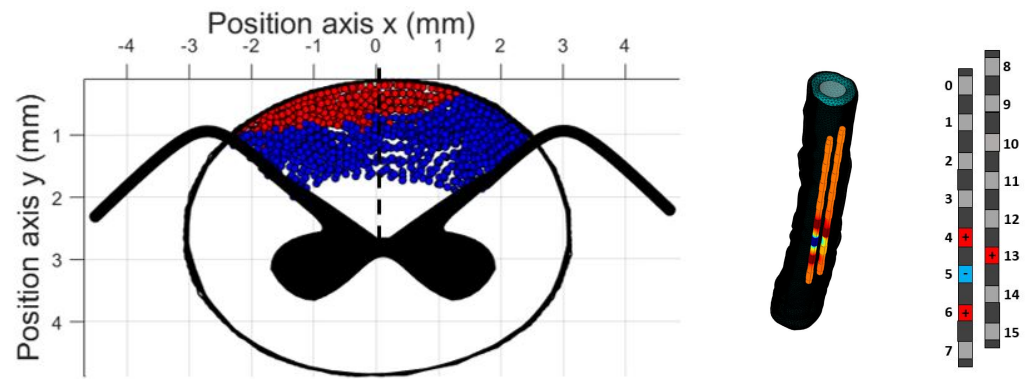

(b) Parallel electrodes with offset.

Figure 6.14: Electrode offset effect on activation area and depth. TGC polarity. Red points represent activated and blue not activated nerve fibers. White area represents zones with no nerve fibers considered. Stimulus applied: a rectangular monophasic pulse 300 $\mu$ s duration with an electrical strength of 1.4 PT in V. Programmed poles: 4(+),5(-),6(+) and $14(+)$. Red poles are anodes and blue poles cathodes. Vertebral bodies and fat tissues are hidden to highlight electrode polarity. Offset is generated by raising the right electrode position on the y axis by $3.5 \mathrm{~mm}$. Dashed line is the central line of the spinal cord. PT: perception threshold.

\subsection{Discussion}

The SCS patient-specific model developed is the first that includes the spinal cord geometry variation along three vertebral levels (from T8 to T10), which solves one 
of the main limitations reported by Lempka et al., i.e. the use of the same spinal cord dimensions for all the vertebral levels considered [81]. This is an important point as it is known that the different levels have different dimensions, and this could play an important role when programming or implanting electrodes. As an innovation, the model also includes the whole spinal cord geometry taken from 3T MR images of the patient, except the dura mater, whose thickness was based on measurements from human cadavers $[119,120]$. Moreover, the exact geometry of the patient's vertebral bodies is also considered. According to Zander et al. [162], albeit vertebral bone could be simplified as a cylindrical domain, the inclusion of detailed 3D anatomical vertebrae is fundamental to consider potential threshold changes. Vertebral body anatomy determines the geometry of the epidural space at the different vertebral levels. Therefore, the relative position of the stimulating electrodes is included in the patient-specific model, and potential threshold changes can be considered.

Apart from the 3D patient-specific model development, this chapter was also aimed to examine the significance of a patient-specific model over a generalized model.

The results show that the patient-specific model stimulation threshold prediction fits better with the clinical data than the generalized model, which is in agreement with the results obtained by Lempka et al. [81]. In patient 1, the generalized model predicted higher thresholds for $\mathrm{PT}_{\mathrm{DC}}$, and DT (see Table 6.2). On the base of the sensitivity analysis results, the stimulation parameters are strongly sensitive to dCSF thickness, and electrode position $\left(\mathrm{D}_{\mathrm{e}-\mathrm{d}}\right)$ (see Fig. 5.9 and Fig. 5.15 from Chapter 5, Sections 5.3.1 and 5.3.3, respectively). These geometrical parameters are significantly lower in the patient-specific than in the generalized model in patient 1 (see Appendix $\mathrm{C}$ for the geometry data, Table C.1), which explains the difference observed in thresholds prediction. In patient 2 , the generalized model predicted lower thresholds in programs 1 and 3, and higher thresholds in program 2 (see Table 6.3). In this case, $\mathrm{D}_{\mathrm{e}-\mathrm{d}}$ and dCSF thickness are similar in both the patient-specific and the generalized model (see Table C.1 in Appendix C for the geometry data). Hence, the difference in thresholds prediction is not as marked as 
CHAPTER 6. Development of a patient-specific spinal cord volume conductor 134 model

in patient 1. However, the patient-specific model also produced estimates of $\mathrm{PT}_{\mathrm{DC}}$ and DT that were more consistent with the clinical measurements.

Neural activation predictions at clinical DT were simulated in both patients. In patient $1, \mathrm{PT}_{\mathrm{DR}}$ is higher than $\mathrm{PT}_{\mathrm{DC}}$ in both models (see Table 6.2). Thus, the stimulation patterns are similar, i.e. there are more left-activated fibers. However, the generalized model predicted more right-activated fibers than the patient-specific model (see Fig. 6.10). Given that patient 1 reported a slight tingling sensation in the right thigh with GC polarity, in addition to no tingling sensation in the right side with TGC polarity, the patient-specific model produced axonal activation that is more consistent to clinical results. This outcome suggests that the laterality of the neural activation depends on the relative position of the electrodes, and the spinal cord offset within the spinal canal. Moreover, we compared the effect of TGC versus GC polarity in this patient. The results demonstrated that transverse polarity displaced the sweet spot (the first activated nerve fiber), which is in concordance with a previous study [37], and the clinical results (see Fig. 6.9). In patient 2, the stimulation pattern changes at each program. For instance, unlike the patient-specific model, the generalized model predicted DR stimulation and more left-activated fibers in program 2 (see Table 6.3 and Fig. 6.12), which was not in agreement with the clinical data (see Fig. 6.11(b)). From the sensitivity analysis results obtained in Chapter 5, Section 5.3.1, $\mathrm{PT}_{\mathrm{DR}}$ was more sensitive to CSF diameter than $\mathrm{PT}_{\mathrm{DC}}$ (see Fig. 5.9). Hence, variations in the $\mathrm{R}_{\mathrm{DC} / \mathrm{DR}}$ produced significant changes in the stimulation patterns. These results suggest that the inclusion of the patient's spinal cord anatomy is pivotal for predicting the effect of SCS accurately.

To examine the capability of the patient-specific model, a clinical application for electrode program planning was performed. In this case, we used the patientspecific model from patient 1 , who reported chronic pain in the left lower limb and left lower back. According to Taghva et al. [145], T9 and T10 are the most likely vertebral areas to cover most areas of the body. However, T8 is more likely to cover buttocks, back and thigh, and less likely to cover leg and foot. As T9 is less likely to cover the anterior leg and T10 is not likely to cover the low back above 
the waist, for this patient, in order to ensure paresthesia coverage in the left lower limb and back, the electrodes were located ideally across the T8 and T9 vertebral levels ( 5 poles per lead in T9 and 3 poles per lead in T8). Eight-pole percutaneous electrodes allowed us to stimulate the vertebral level using different programs and poles. This is useful because, when some electrode poles fail, electrode replacement surgery can be avoided by programming the working poles. The outcome of the use case (see Fig. 6.13) shows that the programmed poles used in Case 4 (see Fig. 6.13(d)) are the best to ensure paresthesia coverage on the left side of the body.

However, if non-targeted dermatomes are stimulated with this program or the stimulation is painful (since these poles in the patient-specific model are between T8 and T9), the programmed poles used in Case 3 (see Fig. 6.13(c)) or Case 1 (see Fig. 6.13(a)) would also allow us to maximize neural activation on the left side, and as these poles are at T9 they are likely to cover the patient's painful dermatomes. This use case therefore shows that it is possible to determine the poles that should be programmed first to maximize paresthesia coverage using a patient-specific spinal cord model.

On the other hand, the effect of offset electrodes on neural activation was also studied using the patient-specific model from patient 1 . Based on the results, with TGC polarity the offset reduces the capability of TGC polarity to activate the more lateral nerve fibers (see Fig. 6.14). As it was important for the patient studied to center activation on the left side of the DCs, electrode offset would not be beneficial since it would be more difficult to focus paresthesia coverage on the painful left dermatomes. In the event of non-paresthesia-based stimulation, leads with a staggered offset placement is used to cover the target areas in a contiguous fashion $[68,123]$. However, the results suggest that aligned electrodes should be implanted in tonic stimulation, for this leads placement could enhance right or left dermatomes selection, contributing to a better patient's paresthesia coverage. 
CHAPTER 6. Development of a patient-specific spinal cord volume conductor 136 model

\subsubsection{Limitations}

The results of this study exhibited excellent agreement between the 3D patientspecific model and clinical measurements, however the study had several limitations. This study was a proof-of-concept performed with two patients within which the geometrical spinal cord parameters that most affect SCS effect were identified. To obtain statistically significant results, a cohort of patients should be included in future studies. More electrode configurations should be tested along the three vertebral levels (from T8 to T10) to validate clinically the patient-specific model.

In terms of nerve fiber distribution, both the generalized and the patientspecific model include overpopulation of $12.8-\mu \mathrm{m}$ nerve fiber diameter in the DC. According to Feirabend et al. [40], nerve fiber diameters higher than $11.5 \mu \mathrm{m}$ are sparse in the DC. But it is well-known that large nerve fibers show lower stimulation thresholds than small nerve fibers [9, 55, 81]. Assuming that PT is obtained when the largest nerve fiber is activated in the DC, we only considered a $12.8-\mu \mathrm{m}$ nerve fiber diameter and overpopulated the DC in order to minimize the effect of the location of these fibers on the calculated thresholds. However, as previous studies show [78, 79, 81], the inclusion of different nerve fiber diameters is useful, notably when the aim of the study is related to the mechanisms of action or the effect of a stimulation parameter on neural activation. On the other hand, recent studies assume that $10 \%$ of fibers are activated at the perception threshold instead of a single nerve fiber [4, 19, 81]. According to Anaya et al. [4], although computational modeling results showed well-matching with the clinical data, there is still no relationship established between clinical measurements of PT or DT and the corresponding degrees of DC neural activation. This limitation could affect the PT values obtained in this study, which would explain the slightly lower thresholds obtained with the patient-specific model compared to the clinical data (see Table 6.2 and Table 6.3).

The generalized model is based on measurements from MRI acquisitions that were obtained with the patient in prone position. On the contrary, the MRI scans for the patient-specific model were obtained with the patient in supine position. 
The patient posture during X-ray scans was prone. Furthermore, we collected the stimulation thresholds ( $\mathrm{PT}_{\mathrm{DC}}$ and $\mathrm{DT}$ ) with the patient standing. Postural changes produce dCSF thickness variations, generating stimulation thresholds changes, as shown in previous studies $[72,83]$. Thus, the patient position could explain the differences observed between the models' stimulation thresholds prediction and the clinical measurements.

The grey matter is not included in the patient-specific volume conductor model. As the electric field does not seem to be affected by the grey matter [142] it was not included to reduce the computational cost. However, future patient-specific models should include this structure since recent SCS action mechanisms are focused on the dorsal horns of the grey matter [21].

Percutaneous electrodes are flexible and can be curved when implanted. However, in the SCS model, the electrodes are modeled as rigid solids so that in some cases it would be difficult to simulate the effect of the real electrode positions or to find the best electrode location. In order to perform more realistic simulations, future SCS models should therefore include flexible percutaneous electrodes.

After electrodes implantation, blood depositions and fibrin are produced on the surroundings of the leads [131]. The encapsulation layer domain considered in the models of this study did not take into consideration these tissue heterogeneities. According to Arle et al. [6], fibrosis affects both the neural activation pattern and the stimulation thresholds. Hence, the inclusion of the tissue heterogeneities would improve the accuracy of the SCS effect prediction.

We also performed a clinical application to predict electrode polarity before the SCS implant. The lack of a somatotopic map of the spinal cord at each vertebral level, in addition to the high variability in lead placement during the implant, makes it very difficult to place the leads ideally. The distance between electrodes and the alignment of the leads are parameters that can be controlled during the SCS implant. Using the patient-specific model and the paresthesia coverage atlas developed by Taghva et al. [145], these parameters could be determined, in addi- 
CHAPTER 6. Development of a patient-specific spinal cord volume conductor 138 model

tion to the electrode polarity. This approach would enhance paresthesia coverage in the patient. However, a clinical study with a cohort of patients would be needed to validate this hypothesis clinically.

\subsection{Summary}

In this chapter, a 3D patient-specific volume conductor spinal cord model has been developed. The main novelty of this model is that it is the first patient-specific model that includes the patient's spinal cord geometry from high-resolution MRI, without using cadaveric measurements.

A clinical retrospective proof-of-concept was conducted using clinical data from two patients undergoing SCS therapy. The outcome show that the patientspecific model prediction matched better with the clinical data than the generalized model.

Moreover, a clinical application was performed with the patient-specific SCS model to investigate the capability of the model to optimize the stimulation parameters in the clinical scenario, showing that the pre-implantation selection of the electrode polarity clinical application could be helpful to focus paresthesia coverage on the painful dermatomes of the patient more accurately.

The last study this chapter includes is the effect of electrode offset on neural activation displacement. The results suggest that aligned electrodes contribute to better right or left dermatomes selection, which could produce better paresthesia coverage in tonic stimulation. 


\section{Chapter 7}

\section{Conclusions and perspectives}

\subsection{Contributions}

The research described in this thesis has focused on three main issues related to SCS computational modeling. The first issue, presented in Chapter 4, concerned the realistic modeling and the computational complexity at the cellular level. The second one, shown in Chapter 5, was about realistic modeling in generalized SCS models. And the last issue, addressed in Chapter 6, concerned the 3D patientspecific SCS modeling approach to improve SCS model-based predictions in tonic stimulation.

From the described issues above, three computational models have been developed in this research work: one at the cellular level, which is a human $\mathrm{A} \beta$ sensory myelinated nerve fiber model, shown in Chapter 4; and two at the organic level: a realistic 3D generalized spinal cord volume conductor model, and a 3D patient-specific spinal cord volume conductor model, both described in Chapter 5 and Chapter 6, respectively.

Moreover, taking advantage of the usefulness of the three models developed in this thesis, three secondary issues related to SCS therapy have been addressed. The first issue concerned the role of frequency in human $\mathrm{A} \beta$ sensory activation 
patterns (see Chapter 4). On the other hand, the second issue concerned the effect of electrode polarity on neural activation in tonic stimulation, shown in Chapter 5. And the last issue concerned the clinical applications that could be performed using 3D patient-specific SCS models (see Chapter 6).

\subsubsection{On the development of a realistic human $\mathrm{A} \beta$ myelinated sen- sory nerve fiber computational model}

In Chapter 4, a human $\mathrm{A} \beta$ sensory myelinated nerve fiber model is proposed as a solution to the realisitc modeling and the computational complexity problems when simulating the electrical response of human $\mathrm{A} \beta$ sensory fibers [133]. The approach consisted of the combination of the WHB sensory nerve fiber model with the RMG model B, thus including a realistic internodal (myelin) model.

The model was validated by comparing the model-based action potential characteristics to experimental data (amplitude, conduction velocity, chronaxie, absolute and refractory periods), and examinig the electrical behavior of the model (conduction velocity-diameter, strength-duration, current-distance, and currentdiameter relationships). The results show a well-matching AP characteristics and electrical behavior to experimental data from sensory nerve fibers.

Also shown in Chapter 4 was the investigation of the role of stimulation frequency in human $\mathrm{A} \beta$ sensory nerve fiber electrical response. The results of this study showed that frequency had a significant influence on the reduction or increase of the neuron activity. Thus, it could play an important role on the selection of the targeted neural elements in SCS therapy.

\subsubsection{On the development of a realistic generalized spinal cord vol- ume conductor computational model}

Chapter 5 presented a 3D generalized spinal cord volume conductor model that is based on in vivo 3T high-resolution MRI from human spinal cord, including thus a realistic spinal cord geometry [36]. 
The model was validated by comparing both threshold-dCSF thickness and threshold-diameter relationships to a previous SCS computational model-based predictions. The electrical behavior outcome showed a good agreement with the previous SCS model results [36]. Moreover, a sensitivity analysis of the geometric and electrical parameters of the generalized volume conductor model was conducted. In this case, the results showed that geometric and electrical conductivity variations produced significant changes in the absolute model-based predictions, highlighting then the importance of including a realistic spinal cord geometry to improve the model-based predictions accuracy [135].

In Chapter 5, the study of the effect of the electrode polarity on neural activation in single-lead stimulation is shown. The study included the comparison of the most used and known polarities: bipolar 1, bipolar 2, guarded cathode, and dual-guarded cathode. The results showed that dual-guarded cathode increased the AA and AD while guarded cathode reduced them [134]. Therefore, a clinical programming strategy was proposed to ensure paresthesia coverage in the patient. The novel strategy was using dual-guarded cathode first to maximize paresthesia coverage and, in the event of DR fibers activation, using guarded cathode to focus the stimulation in DCs [36].

\subsubsection{On the developement of a patient-specific spinal cord volume conductor model}

Chapter 6 presented a novel 3D patient-specific volume conductor model that included the entire anatomical structure and spinal cord dimensions of the three vertebral levels where electrodes are usually implanted in SCS therapy (T8, T9, and T10) [136]. The approach was based on the spinal cord segmentation from 3T high-resolution MR from patients undergoing SCS therapy. Up to our knowledge, this feature had never been included in a SCS computational model. Thus, to date, the patient-specific volume conductor model developed in this work is one of the most innovative SCS computational model.

In this case, the model was validated by comparing the model-based predictions to the collected clinical data. Moreover the same model-based predictions 
were compared to the model results obtained with the 3D generalized spinal cord model developed, decribed in Chapter 5. The outcome showed that the patientspecific SCS model predicted more accurate model-based predictions than the generalized model, i.e. the model-based predictions fitted better to the clinical data [136, 132].

In Chapter 6, the investigation of clinical applications that could be performed using the 3D patient-specific SCS model is also presented. On the one hand, the results showed that the pre-implantation selection of the electrode polarity determined the poles that should be programmed first, leading to better overlapping paresthesia coverage to the painful dermatomes of the patient. On the other hand, the effect of offset electrodes was also investigated, showing that, unlike nonparesthesia-based stimulation, leads with a staggered offset placement would not beneficial in tonic stimulation due to the difficulty of focusing the stimulation in the right- or left-side of the DCs [136].

\subsection{Perspectives}

The work performed in this thesis and the contributions obtained open several research lines concerning the improvement of SCS modeling, and several clinical applications concerning SCS therapy management.

\subsubsection{Future research lines}

The future of medicine goes to personalized therapies. SCS model-based predictions strongly depend on the complexity of the nerve fiber computational model. To our knowledge, nerve fiber models can simulate the AP of healthy nerve fibers, and they are getting more and more accurate. However, the nerve fibers from a patient with $\mathrm{CP}$ disease are not healthy. The malfunction of a specific ion channel, in addition to the effect of some neurotransmissor (such as GABA) should be identified to each CP disease and included in the myelinated nerve fiber model. In this manner, more accurate results could be obtained, and maybe the reason why SCS therapy may not work in a specific patient could be also identified. 
On the other hand, another research line could be focused on improving the spinal cord volume conductor model. Current SCS computational models are monodomain models, i.e. both intra- and extracellular domains have equal anisotropy ratios. The advantage of monodomain models is that, although they are not physiologically accurate, in some cases they are adequate and have reduced complexity. However, it would be interesting to develop a bidomain SCS model in order to provide greater physiological accuracy.

Finally, to simulate a realistic paresthesia coverage prediction, SCS model should include how nerve fibers are distributed in DCs, the size and the type of fibers that can be stimulated and the possible connections between them. The best way to advance in the knowledge of these issues is through histological or functional RM images studies. Nevertheless, these type of studies are sometimes difficult to perform in vivo. Thus, SCS computational models should be also used to make new hypothesis about how neural activation is affected by the stimulation parameters with the aim of helping the scientific medical community to find out the neurophysiological mechanisms of action that are behind SCS therapy.

\subsubsection{Future clinical applications}

This research work has been carried out under the Industrial Doctorate modality in the UPV, in collaboration with the company: Biotecnología y Salud, S.L. The result of performing this thesis together with clinical feedback from physicians shows that the transference of the learnt knowledge to the clinical practice is necessary. Thus, clinical applications development should be performed to improve the management and efficacy of SCS therapy.

An interesting application could be the development of a stimulation parameters programming guide. The fact of having eight-contact electrodes increases the number of combinations between the four stimulation parameters (polarity, pulse width, amplitude and frequency) that can be performed to stimulate the patient. Most of times, patient programming sessions are time-consuming because stim- 
ulation parameters have to be refined to produce the best paresthesia coverage to the patient. However, owing most of patients cannot stand or be in the same position for a long time, during the programming sessions they usually get tired and stop being collaborative when reporting the stimulation sensation. In this sense, a programming guide which explains how to manage each stimulation parameter in different possible real cases could help physicians and biomedical engineers to reduce the programming time, and thus, to improve feedback with the patient, which is fundamental to produce a good paresthesia coverage.

Other future application is related to patient-specific SCS models. The advantage of working with the real geometry of the patient's spinal cord is that electrodes location could be planned before the implantation. This would be a useful tool to help physicians to know in advance which is the best electrodes location to ensure paresthesia coverage in the painful dermatomes of the patient. Furthermore, the prediction of the stimulation parameters could be performed using the patient-specific model, predicting then which would be the battery consumption. In this manner, the physician's decision of implanting a rechargeable or not rechargeable neurostimulator would be based on quantitative parameters and would may help them to reduce expenses and surgical reinterventions for battery replacements, in addition to the reduction of possible infections to the patient. 


\section{Chapter 8}

\section{Contributions}

This work has led to several publications in the biomedical engineering community. Here are the contributions with the corresponding publications:

\section{JCR Journal Papers}

1.- Carmen Solanes, Jose L. Durá, Jose De Andrés, Javier Saiz, What is the role of frequency on neural activation in tonic stimulation in SCS therapy? A computational study on sensory A $\beta$ nerve fibers, In IEEE Access, 9 , 107446-107461, 2021, https: // ieeexplore.ieee.org/document/ 9495784 . (Impact Factor 2020: 3.367 Q2 (94/273) Engineering, Electrical \& Electronic).

2.- Carmen Solanes, Jose L. Durá, M Ángeles Canós, Jose De Andrés, Luis Martí-Bonmatí, Javier Saiz, 3D patient-specific spinal cord computational model for SCS management: potential clinical applications, In Journal of Neural Engineering, 18, 036017, 2021 https://doi.org/10.1088/ 1741-2552/ abe 4 f. (Impact Factor 2020: 5.379 Q1 (19/105) Engineering, Biomedical).

3.- Jose L. Durá, Carmen Solanes, Jose De Andrés, Javier Saiz, Computational Study of the Effect of Electrode Polarity on Neural Activation Re- 
lated to Paresthesia Coverage in Spinal Cord Stimulation Therapy, In Neuromodulation, Vol 22, 2019, Pag 269-279, ISSN 1094-7159, https: // doi.org/10.1111/ner.12909. (Impact Factor 2019: 4.029 Q1 (46/204) Clinical Neurology) (Co-first author).

\section{International Conference Papers}

1.- Carmen Solanes, Jose L. Durá, Jose De Andrés, Javier Saiz, A human A $\beta$ sensory nerve fiber model for accurate neural activation prediction in tonic spinal cord stimulation modeling, In 15th International Conference in Advanced Biomedical Engineering and Biomechanics Conference (ICABEB 2021). Pag 815. 25-26 March, 2021, Madrid, Spain.

2.- Carmen Solanes, Jose L. Durá, Jose De Andrés, Javier Saiz, Effect of electrode polarity on paresthesia coverage in spinal cord stimulation, In World Congress on Medical Physics \& Biomedical Engineering. Pag 389. 3-8 June, 2018, Prague, Czech Republic.

\section{National Conference Papers}

1.- Carmen Solanes, Jose L. Durá, M Ángeles Canós, Jose De Andrés, Luis Martí-Bonmatí, Javier Saiz, Predicción de la activación neuronal en estimulación tónica en la terapia de EME: uso de modelos 3D de médula espinal personalizados al paciente frente a modelos generalizados, In XXXVIII Congreso Anual de la Sociedad Española de Ingeniería Biomédica (CASEIB 2020). Pag 306-309. 25-27th November, 2020, Valladolid, Spain.

2.- Carmen Solanes, Jose L. Durá, Jose De Andrés, Javier Saiz, Estudio del efecto de la posición, polaridad y número de electrodos sobre el área de parestesia en la terapia de EME mediante el uso de un modelo $3 D$ de médula espinal, In XXXV Congreso Anual de la Sociedad Española de Ingeniería Biomédica (CASEIB 2017). Pag 353-356. 29th November-1st December, 2017, Bilbao, Spain. 
Moreover, during this thesis, several research awards have been obtained, as follows:

\section{Research Awards}

1.- Best presentation award in 15th International Conference in Advanced Biomedical Engineering and Biomechanics Conference (ICABEB 2021) for the work presentation: A human A $\beta$ sensory nerve fiber model for accurate neural activation prediction in tonic spinal cord stimulation modeling. March, 2021, Madrid, Spain.

2.- First runner-up prize of XVI Premi científico-tècnic Ciutat d'Algemesí per a joves investigadors for the work: Spinal Cord Stimulation therapy optimization through the use of patient-specific computational models. November, 2020, Algemesí, Spain.

3.- Second prize of Premio José María Ferrero Corral for the work: Estudio del efecto de la posición, polaridad y número de electrodos sobre el área de parestesia en la terapia de EME mediante el uso de un modelo $3 D$ de médula espinal in XXXV Congreso Anual de la Sociedad Española de Ingeniería Biomédica, December, 2017, Bilbao, Spain.

In addition to these contributions, it has been collaborating with other colleague in his research and projects, giving rise to be co-author in several conference paper publications.

\section{Other collaborations}

\section{International Conference Papers}

1.- Jose L. Durá, Carmen Solanes, Jose De Andrés, Javier Saiz, Influence of the Space between the Lead Contacts on the Parameters of the Spinal Cord Tonic Stimulation, In 10th World Congress of the World Institute of Pain (WIP). Pag 94. 29 August, 2020, Rome, Italia. 
2.- Jose L. Durá, Carmen Solanes, Jose De Andrés, Javier Saiz, Programming Strategies in Post-Implant Clinical Sessions: Usefulness of Computer Model to Predict the Paresthesia Area Displacement in the Transversal Direction, In International Neuromodulation Society's 14th World Congress. Neuromodulation: Leading a Global Medical Revolution. Pag 343. 30 May, 2019, Sidney, Australia.

3.- Jose L. Durá, Carmen Solanes, Jose De Andrés, Javier Saiz, Study of Tonic Spinal Cord Stimulation with a 3D Mathematical Model. What is the optimal distance between leads?, In 22nd Annual Meeting of the North American Neuromodulation Society . Pag 149-151. 20 January, 2019, Las Vegas, EEUU.

4.- Jose L. Durá, Carmen Solanes, Jose De Andrés, Javier Saiz, Study of Tonic Spinal Cord Stimulation with a 3D Mathematical Model: the Role of Polarity, In 21st Annual Meeting of the North American Neuromodulation Society . Pag 12-13. 14 January, 2018, Las Vegas, EEUU.

\section{National Conference Papers}

1.- Jose L. Durá, Carmen Solanes, Jose De Andrés, Javier Saiz, Modelos computacionales en neuroestimulación medular, In $26^{a}$ Reunión Anual ESRA España. Pag 356-372. 2 October, 2020, Zaragoza, Spain.

2.- Jose L. Durá, Carmen Solanes, Jose De Andrés, Javier Saiz, Estimulación medular: optimización de la distancia entre polos de estimulación a partir de modelos de simulación, In XXXVIII Congreso Anual de la Sociedad Española de Ingeniería Biomédica (CASEIB 2020). Pag 290-293. 25-27 November, 2020, Valladolid, Spain.

Finally, during this thesis, several degree and postgrad projects has been guided.

\section{Final Degree and Postgrad Projects Guided}

1.- Desarrollo y validación de un modelo $3 D$ cerebral para la simulación de la terapia de estimulación cerebral profunda (DBS) en la enfermedad de 
Parkinson, by Jorge Ramírez Zamora. Guided by Francisco Javier Saiz Rodríguez, Antonio Gutiérrez Martín, and Carmen Solanes Galbis. July 2021, ETSII, Universitat Politècnica de València (Spain).

2.- Desarrollo y validación de un modelo de estimulación cerebral profunda (DBS) para la optimización de la posición del electrodo con respecto a la orientación de las fibras., by Albert Escamilla Muñoz. Guided by Francisco Javier Saiz Rodríguez, Antonio Gutiérrez Martín, and Carmen Solanes Galbis. July 2021, ETSII, Universitat Politècnica de València (Spain).

3.- Diseño, desarrollo y validación de una plataforma informática para la simulación computacional del efecto del campo eléctrico sobre la actividad neuronal de la médula espinal, by María del Alba Díaz Martínez. Guided by Francisco Javier Saiz Rodríguez, Rafa Ors Carot, and Carmen Solanes Galbis. July 2019, ETSII, Universitat Politècnica de València (Spain). 



\section{Appendix A}

\section{A.1 Equations, geometric and electrical parameters of the $\mathbf{A} \beta$ human sensory myelinated nerve fiber model developed}

The new sensory nerve fiber model and its parameters at body temperature $\left(37^{\circ} \mathrm{C}\right)$.

Fiber geometry parameters [96]:

$D$ : axon diameter $(\mathrm{cm})$

$F_{d}$ : fiber diameter $(\mathrm{cm})$

$L$ : internodal length $(\mathrm{cm})$

$l$ : nodal length $(\mathrm{cm})$ (its value is $1 \cdot 10^{-4}$ )

$d$ : nodal diameter $(\mathrm{cm})$ (value depends on fiber diameter)

$l a m_{m e m b}:$ number of myelin lamellas (value depends on fiber diameter)

lam: number of lamella membranes per lamella (its value is 2)

$$
\begin{aligned}
D & =C_{d} F_{d}-D_{d} \\
L & =C_{L} \log \left(D \cdot\left(D_{L}\right)^{-1}\right)
\end{aligned}
$$

Where $C_{d}=0.76, D_{d}=1.81 \cdot 10^{-6}, C_{L}=7.87 \cdot 10^{-4}$, and $D_{L}=3.44 \cdot 10^{-6}$.

The representative squeme of the geometric parameters is shown in Fig A.1. 


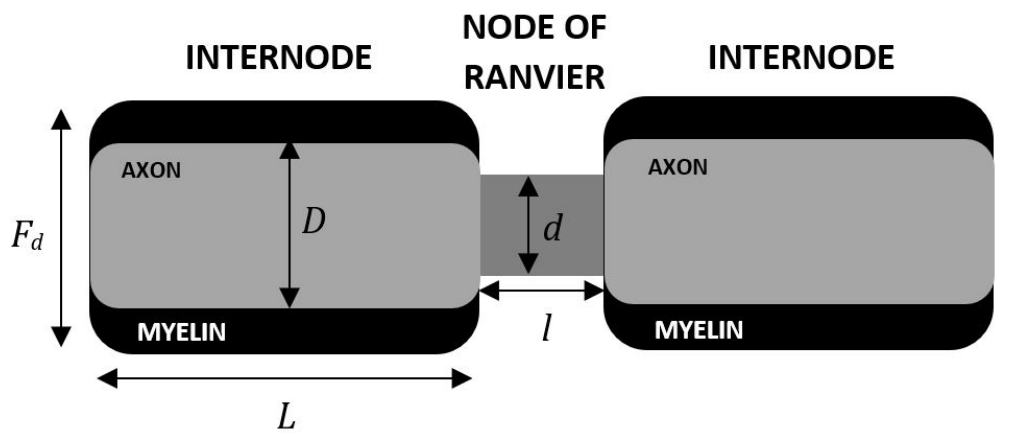

Figure A.1: Squeme of the geometric parameters considered in the new sesory nerve fiber model. $D$ : axon diameter; $F_{d}$ : fiber diameter; $L$ : internodal length; $l$ : nodal length; $d$ : nodal diameter.

The parameters $d$ and lam depend on fiber diameter as follows [96]:

\begin{tabular}{l|l|l} 
Fiber diameter $(\mu \mathbf{m})$ & $\mathbf{d}(\mu \mathbf{m})$ & lam \\
\hline \hline $\mathbf{5 . 7}$ & 1.9 & 80 \\
\hline $\mathbf{1 2 . 8}$ & 4.2 & 135 \\
\hline \hline
\end{tabular}

Gating parameters [159]:

Sodium $m$ gates activation ( $\alpha_{m}$ is taken from Howells et al. [62]):

$$
\begin{aligned}
\alpha_{m} & =\left[3.13 \cdot 10^{3}\left(V_{m}+36.3\right)\right] /\left[1-e^{\left(-36.3-V_{m}\right) / 10.3}\right] \\
\beta_{m} & =\left[0.33 \cdot 10^{3}\left(-22.7-V_{m}\right)\right] /\left[1-e^{\left(V_{m}+22.7\right) / 9.16}\right]
\end{aligned}
$$

Sodium $\mathrm{h}$ gates activation $\left(\alpha_{h}\right.$ is taken from Howells et al. [62]):

$$
\begin{aligned}
\alpha_{h} & =\left[0.153 \cdot 10^{3}\left(-113.8-V_{m}\right)\right] /\left[1-e^{\left(V_{m}+113.8\right) / 11.9}\right] \\
\beta_{h} & =\left[14.1 \cdot 10^{3} /\left[1+e^{\left(-28.8-V_{m}\right) / 13.4}\right]\right.
\end{aligned}
$$


A.1. Equations, geometric and electrical parameters of the $\mathrm{A} \beta$ human sensory myelinated nerve fiber model developed

Potassium $n$ gates activation:

$$
\begin{aligned}
\alpha_{n} & =\left[51.7\left(V_{m}+93.2\right)\right] /\left[1-e^{\left(-93.2-V_{m}\right) / 1.1}\right] \\
\beta_{n} & =\left[92\left(-76-V_{m}\right)\right] /\left[1-e^{\left(V_{m}+76\right) / 10.5}\right]
\end{aligned}
$$

Membrane potential $V_{m}$ in millivolts $(\mathrm{mV})$

Canonical gate probability equation:

$$
\frac{d \omega}{d t}=\alpha_{\omega}(1-\omega)-\beta_{\omega} \omega
$$

where $\omega=m, h, n$ and the initial conditions (when $t=0$ ) are:

$\mathrm{m}(0)=0.07427$

$\mathrm{h}(0)=0.6096$

$\mathrm{n}(0)=0.2873$

Internode parameters [121]:

$C_{m}$ : Myelin capacitance $(\mathrm{mF})$

$G_{m}$ Myelin conductance $(\mathrm{mS})$

$C_{n}$ : Nodal capacitance $(\mathrm{mF})$

$G_{a}$ : Conductance between compartments (mS)

$$
\begin{aligned}
& C_{m}=\left(c_{m} \pi F_{d} L\right)\left(\text { lam } \text { lam }_{\text {memb }}\right)^{-1} \\
& G_{m}=\left(g_{m} \pi F_{d} L\right)\left(\text { lam } \cdot \text { lam }_{m e m b}\right)^{-1} \\
& C_{n}=c_{n} \pi d l \\
& G_{a}=\left(\pi D^{2}\right)\left(4 \rho_{a x} L\right)^{-1}
\end{aligned}
$$

Membrane currents [159]:

$i_{N a}$ : Sodium channel current density $\left(\mathrm{mA} / \mathrm{cm}^{2}\right)$

$i_{K}$ : Fast potassium channel current density $\left(\mathrm{mA} / \mathrm{cm}^{2}\right)$ 
$i_{L k}:$ Leak channel current density $\left(\mathrm{mA} / \mathrm{cm}^{2}\right)$

$I_{\text {ion }}$ : Total ion current $\left(\mathrm{mA} / \mathrm{cm}^{2}\right)$

$$
\begin{aligned}
& i_{N a}=\left(p_{N a} m^{3} h V F^{2}\left([N a]_{o}-[N a]_{i} e^{\frac{V F}{R T}}\right)\right)\left(R T\left(1-e^{\frac{V F}{R T}}\right)\right)^{-1} \\
& i_{K}=n^{4} g_{K}\left(V_{m}-E_{K}\right) \\
& i_{L k}=g_{L k}\left(V_{m}-E_{L k}\right) \\
& I_{i o n}=i_{N a}+i_{K s}+i_{L k}
\end{aligned}
$$

The sodium equilibrium potential $\left(E_{N a}\right)$ can be calculated applying the Nerst equation:

$$
E_{N a}=\frac{R T}{F} \ln \frac{[N a]_{o}}{[N a]_{i}}
$$




\section{Appendix B}

\section{B.1 Equations, geometric and electrical parameters of the Richardson, McIntyre and Grill (RMG) model B.}

The geometric and electrical parameters used in the model and the membrane dynamics for nodes of Ranvier are shown (see Table B.1) [96, 121]. The dynamics are defined at $20^{\circ} \mathrm{C}$. The adequate $\mathrm{Q}_{10}$ scaling factors are shown below for each of the activation and inactivation parameters.

Fiber geometry parameters [96]:

$D$ : fiber diameter $(\mathrm{cm})$

$d$ : axon diameter $(\mathrm{cm})$

$L$ : internodal length $(\mathrm{cm})$

$l$ : nodal length $(\mathrm{cm})$ (its value is $1 \cdot 10^{-4}$ )

$n_{d}$ : nodal diameter $(\mathrm{cm})$ (value depends on fiber diameter)

$N$ : number of myelin lamellas (value depends on fiber diameter)

Table B.1: Geometric parameters of the nerve fibers.

\begin{tabular}{l|l|l|l|l|l} 
Fiber diameter $(\mu \mathbf{m})$ & $\mathbf{d}(\mu \mathbf{m})$ & $\mathbf{n}_{\mathbf{d}}(\mu \mathbf{m})$ & $\mathbf{I}(\mu \mathbf{m})$ & $\mathbf{L}(\mu \mathbf{m})$ & $\mathbf{N}$ \\
\hline \hline $\mathbf{1 2 . 8}$ & 9.2 & 4.2 & 1 & 1350 & 135 \\
\hline $\mathbf{1 5}$ & 11.5 & 1.9 & 1 & 1450 & 80 \\
\hline \hline
\end{tabular}


In Table B.2, the electrical parameters of the ion channels, the myelin and the node of Ranvier used in the model are indicated.

The equations of the membrane currents and the electric potential are given:

Internode parameters [121]:

$C_{m}$ : Myelin capacitance $(\mathrm{mF})$

$G_{m}$ Myelin conductance (mS)

$C_{n}$ : Nodal capacitance $(\mathrm{mF})$

$G_{a x}$ : Conductance in internodal compartment (mS)

$G_{a n}$ : Conductance in nodal compartment (mS)

$G_{\text {axial }}$ : Conductance between compartments (mS)

Table B.2: Electrical parameters of the RMG nerve fiber model B.

\begin{tabular}{|llll|}
\hline \hline Symbol & Parameter & Value & Unit \\
\hline$g_{N a f}$ & Fast $\mathrm{Na}^{+}$channel conductivity & $3 \cdot 10^{3}$ & $\mathrm{mS} \cdot \mathrm{cm}^{-2}$ \\
$g_{N a p}$ & Persistent $\mathrm{Na}^{+}$channel conductivity & 5 & $\mathrm{mS} \cdot \mathrm{cm}^{-2}$ \\
$g_{K s}$ & Slow $\mathrm{K}^{+}$channel conductivity & 80 & $\mathrm{mS} \cdot \mathrm{cm}^{-2}$ \\
$g_{L k}$ & Leak channel conductivity & 80 & $\mathrm{mS} \cdot \mathrm{cm}^{-2}$ \\
$E_{N a}$ & $\mathrm{Na}^{+}$channel equilibrium potential & 50 & $\mathrm{mV}$ \\
$E_{K}$ & $\mathrm{~K}^{+}$channel equilibrium potential & -84 & $\mathrm{mV}$ \\
$E_{L k}$ & Leak channel equilibrium potential & -83.38 & $\mathrm{mV}$ \\
$V_{r e s t}$ & Resting potential & -82 & $\mathrm{mV}$ \\
$\rho_{a x}$ & Axoplasmic resistivity & 70 & $\Omega \mathrm{cm}$ \\
$\rho_{e x}$ & External resistivity & 500 & $\Omega \mathrm{cm}$ \\
$c_{n}$ & Specific nodal capacitance & 2 & $\mu \mathrm{F} \cdot \mathrm{cm}^{-2}$ \\
$c_{m}$ & Specific myelin capacitance & 0.1 & $\mu \mathrm{F} \cdot \mathrm{cm}^{-2}$ \\
$g_{m}$ & Specific myelin conductance & 1 & $\mathrm{mS} \cdot \mathrm{cm}^{-2}$ \\
\hline \hline
\end{tabular}




$$
\begin{aligned}
& C_{m}=\left(c_{m} \pi D L\right)\left(\text { lam } \cdot \text { lam }_{\text {memb }}\right)^{-1} \\
& G_{m}=\left(g_{m} \pi D L\right)\left(\text { lam } \cdot \text { lam }_{\text {memb }}\right)^{-1} \\
& C_{n}=c_{n} \pi d l \\
& G_{a x}=\pi d^{2}\left(4 \rho_{a x}(L / 2)\right)^{-1} \\
& G_{a n}=\pi d^{2}\left(4 \rho_{a x}(l / 2)\right)^{-1} \\
& G_{\text {axial }}=\left(\left(1 / G_{a x}\right)+\left(1 / G_{a n}\right)\right)^{-1}
\end{aligned}
$$

Membrane currents [121]:

$i_{N a f}:$ Fast sodium channel current density $\left(\mathrm{mA} / \mathrm{cm}^{2}\right)$

$i_{\text {Nap }}$ : Persistent sodium channel current density $\left(\mathrm{mA} / \mathrm{cm}^{2}\right)$

$i_{K} s$ : Fast potassium channel current density $\left(\mathrm{mA} / \mathrm{cm}^{2}\right)$

$i_{L k}$ : Leak channel current density $\left(\mathrm{mA} / \mathrm{cm}^{2}\right)$

$I_{\text {ion }}$ : Total ion current $\left(\mathrm{mA} / \mathrm{cm}^{2}\right)$

$V_{m}(n, t)$ : Transmembrane potential at node $\mathrm{n}$ at moment $\mathrm{t}(\mathrm{mV})$

$V_{e}(n, t)$ : Field potential at node $\mathrm{n}$ at moment $\mathrm{t}(\mathrm{mV})$

$$
\begin{aligned}
& i_{N a f}=g_{N a f} m^{3} h\left(V_{m}-E_{N a}\right) \\
& i_{N a p}=g_{N a p} p^{3}\left(V_{m}-E_{N a}\right) \\
& i_{K s}=g_{K s} s\left(V_{m}-E_{K}\right) \\
& i_{L k}=g_{L k}\left(V_{m}-E_{L k}\right) \\
& I_{\text {ion }}=i_{N a f}+i_{N a p}+i_{K s}+i_{L k} \\
& I_{\text {int }}(\text { internode })=G_{a x}\left[V_{e}(j-1)-2 V_{e}(j)+V_{e}(j+1)\right] \\
& I_{\text {int }}(\text { node })=G_{a x}\left[V_{e}(j-1)-2 V_{e}(j)+V_{e}(j+1)\right]
\end{aligned}
$$

The equations of the gate probabilities and coefficients with their respective $\mathrm{Q}_{10}$ scaling factor are indicated below [121]: 
Fast sodium $m$ gates activation:

$$
\begin{aligned}
\alpha_{m} & =\left[1.86 \cdot 10^{3}\left(V_{m}+25.4\right)\right] /\left[1-e^{\left(-25.4-V_{m}\right) / 10.3}\right]\left(Q_{10}=2.2\right) \\
\beta_{m} & =\left[0.086 \cdot 10^{3}\left(-29.7-V_{m}\right)\right] /\left[1-e^{\left(V_{m}+29.7\right) / 9.16}\right]\left(Q_{10}=2.2\right)
\end{aligned}
$$

Fast sodium $\mathrm{h}$ gates activation:

$$
\begin{aligned}
\alpha_{h} & =\left[0.0336 \cdot 10^{3}\left(-118.0-V_{m}\right)\right] /\left[1-e^{\left(V_{m}+118.0\right) / 11.0}\right]\left(Q_{10}=2.9\right) \\
\beta_{h} & =\left[2.3 \cdot 10^{3} /\left[1+e^{\left(-35.8-V_{m}\right) / 13.4}\right]\left(Q_{10}=2.9\right)\right.
\end{aligned}
$$

Persistent sodium $m$ gates activation:

$$
\begin{aligned}
\alpha_{m} & =\left[0.86 \cdot 10^{3}\left(V_{m}+48.4\right)\right] /\left[1-e^{\left(-48.4-V_{m}\right) / 10.3}\right]\left(Q_{10}=2.2\right) \\
\beta_{m} & =\left[0.0086 \cdot 10^{3}\left(-42.7-V_{m}\right)\right] /\left[1-e^{\left(V_{m}+42.7\right) / 9.16}\right]\left(Q_{10}=2.2\right)
\end{aligned}
$$

Slow potassium $\mathrm{n}$ gates activation:

$$
\begin{aligned}
\alpha_{s} & =\left[0.00122\left(V_{m}+19.5\right)\right] /\left[1-e^{\left(-19.5-V_{m}\right) / 23.6}\right]\left(Q_{10}=3\right) \\
\beta_{s} & =\left[0.000739\left(-87.1-V_{m}\right)\right] /\left[1-e^{\left(V_{m}+87.1\right) / 21.8}\right]\left(Q_{10}=3\right)
\end{aligned}
$$

Membrane potential $V_{m}$ in millivolts $(\mathrm{mV})$

Canonical gate probability equation:

$$
\frac{d \omega}{d t}=\alpha_{\omega}(1-\omega)-\beta_{\omega} \omega
$$

where $\omega=m, p, h, s$ and the initial conditions (when $t=0$ ) are:

$$
\begin{aligned}
& \mathrm{m}(0)=0.0878 \\
& \mathrm{p}(0)=0.4209 \\
& \mathrm{~h}(0)=0.4012 \\
& \mathrm{~s}(0)=0.2866
\end{aligned}
$$




\section{Appendix C}

\section{C.1 Dimensions of the generalized and patient-specific spinal cord models}

The geometrical parameters of the spinal cord (see Fig. C.1) used in both generalized and patient-specific spinal cord models are listed in Table C.1:

A sensitivity analysis was performed to confirm that excluding grey matter

Table C.1: Geometrical parameters of the generalized and patient-specific spinal cord model. The values used for the generalized models are extracted from Fradet et al. [42].

\begin{tabular}{l|l|l|l|l|l} 
Parameter & $\begin{array}{l}\text { General } \\
\text { model } \\
\text { (mm) }\end{array}$ & $\begin{array}{l}\text { General } \\
\text { model } \\
\text { (mm) }\end{array}$ & $\begin{array}{l}\text { General } \\
\text { model } \\
\text { (mm) }\end{array}$ & $\begin{array}{l}\text { Patient-specific } \\
\text { model (Patient 1) } \\
\text { (mm) }\end{array}$ & $\begin{array}{l}\text { Patient-specific } \\
\text { model (Patient 2) } \\
\text { (mm) }\end{array}$ \\
\hline $\begin{array}{l}\text { Vertebral } \\
\text { level }\end{array}$ & $\mathrm{T} 8$ & $\mathrm{~T} 9$ & $\mathrm{~T} 10$ & from T8 to T10 & from T8 to T10 \\
\hline$\varnothing \mathrm{T}$ & 8.9 & 9 & 8.2 & from 6.64 to 7.9 & from 8.1 to 9.1 \\
\hline$\varnothing \mathrm{AP}$ & 6.2 & 6.5 & 6.6 & from 5.36 to 6.2 & from 5.3 to 6.55 \\
\hline $\mathrm{PW}$ & 5.3 & 5.9 & 5.7 & from 4.4 to 5.1 & from 4.8 to 5.4 \\
\hline $\mathrm{L}$ & 1.7 & 2.1 & 2.3 & from 2.1 to 2.57 & from 2 to 2.8 \\
\hline $\mathrm{R}$ & 2 & 2.5 & 2.9 & from 2.36 to 3.2 & from 3 to 3.7 \\
\hline $\mathrm{A}$ & 2 & 1.95 & 2.2 & from 2.57 to 3.64 & from 1.4 to 3 \\
\hline $\mathrm{P}$ & 4.95 & 4.1 & 4 & from 2.78 to 4.3 & from 4.25 to 4.8 \\
\hline$\varnothing \mathrm{CSF}$ & 12.6 & 13.6 & 13.4 & from 9 to 11.75 & from 13.8 to 15.6 \\
\hline
\end{tabular}




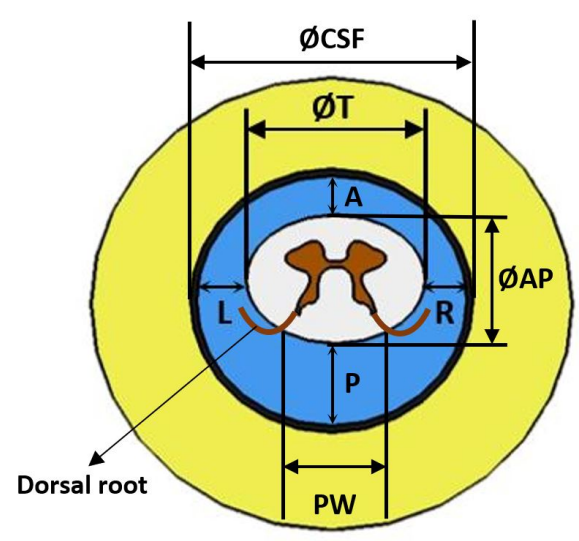

(a) Generalized spinal cord model.

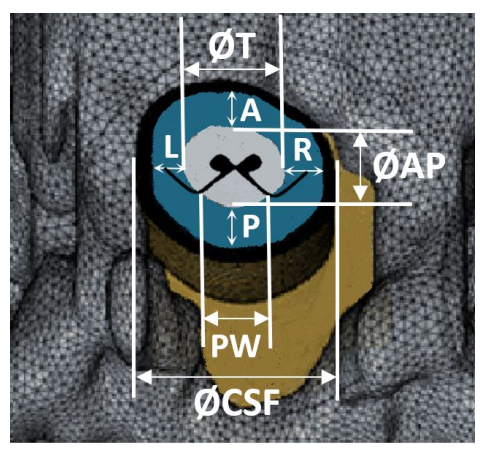

(b) Patient-specific spinal cord model.

Figure C.1: Geometrical parameters of the spinal cord. $\varnothing \mathrm{T}$ : transversal diameter, $\varnothing \mathrm{AP}$ : anteroposterior diameter, $\varnothing \mathrm{T}$ : cerebrospinal fluid diameter, L: left, R: right, A: anterior; $\mathrm{P}$ : posterior and PW: posterior width.

does not affect the model predictions. The results show small errors in the activation thresholds for the DC and DR nerve fibers ( $\mathrm{PT}_{\mathrm{DC}}$ and $\mathrm{DT}$ are $0.15 \%$ higher and $\mathrm{PT}_{\mathrm{DR}}$ is $0.625 \%$ lower), in the recruitment ratio ( $\mathrm{R}_{\mathrm{DC} / \mathrm{DR}}$ is $0.294 \%$ higher) and the activating area (AA is $1.85 \%$ higher), showing that grey matter can be ignored in this FEM design (see Table C.2).

Table C.2: Sensitivity analysis of excluding grey matter in the generalized volume conductor model. $\mathrm{PT}_{\mathrm{DC}}$ : perception threshold in $\mathrm{DC} ; \mathrm{PT}_{\mathrm{DR}}$ : perception threshold in $\mathrm{DR}$; $\mathrm{DT}$ : discomfort threshold (1.4 $\left.\mathrm{PT}_{\mathrm{DC}}\right)$; $\mathrm{R}_{\mathrm{DC} / \mathrm{DR}}$ : recruitment ratio; $\mathrm{AA}$ : activating area; $\mathrm{AD}$ : activating depth. Stimulation parameters: guarded cathode $(5(+), 6(-), 7(+))$ and a rectangular monophasic pulse $300 \mu$ s duration.

\begin{tabular}{l|l|l|l|l|l|l} 
Source & $\begin{array}{l}\mathbf{P T}_{\mathbf{D C}} \\
(\mathbf{V})\end{array}$ & $\begin{array}{l}\mathbf{P T}_{\mathbf{D R}} \\
(\mathbf{V})\end{array}$ & $\begin{array}{l}\mathbf{D T} \\
(\mathbf{V})\end{array}$ & $\mathbf{R}_{\mathbf{D C} / \mathbf{D R}}$ & $\begin{array}{l}\mathbf{A A} \\
\left(\mathbf{m m}^{2}\right)\end{array}$ & $\begin{array}{l}\mathbf{A D} \\
(\mu \mathbf{m})\end{array}$ \\
\hline FEM model with grey matter & 3.8 & 11.2 & 5.32 & 0.34 & 1.62 & 500 \\
\hline FEM model without grey matter & 3.806 & 11.13 & 5.328 & 0.341 & 1.65 & 500 \\
\hline
\end{tabular}




\section{Bibliography}

[1] David Abejón, Pablo Rueda, Javier del Saz, Sara Arango, Eva Monzón, and Fernando Gilsanz. "Is the introduction of another variable to the strength-duration curve necessary in Neurostimulation?" In: Neuromodulation: Technology at the Neural Interface 18.3 (2015), pp. 182-190.

[2] D Michael Ackermann, Niloy Bhadra, Meana Gerges, and Peter J Thomas. "Dynamics and sensitivity analysis of high-frequency conduction block". In: Journal of neural engineering 8.6 (2011), p. 065007.

[3] Shaheen Ahmed, Thomas Yearwood, Dirk De Ridder, and Sven Vanneste. "Burst and high frequency stimulation: underlying mechanism of action". In: Expert review of medical devices 15.1 (2018), pp. 61-70.

[4] Carlos J Anaya, Hans J Zander, Robert D Graham, Vishwanath Sankarasubramanian, and Scott F Lempka. "Evoked potentials recorded from the spinal cord during neurostimulation for pain: a computational modeling study". In: Neuromodulation: Technology at the Neural Interface 23.1 (2020), pp. 64-73.

[5] Pamela Andrews, M Steultjens, and J Riskowski. "Chronic widespread pain prevalence in the general population: a systematic review". In: European Journal of Pain 22.1 (2018), pp. 5-18.

[6] Jeffrey E Arle, Kris W Carlson, Longzhi Mei, and Jay L Shils. "Modeling effects of scar on patterns of dorsal column stimulation". In: Neuromodulation: Technology at the Neural Interface 17.4 (2014), pp. 320-333. 
[7] Jeffrey E Arle, Longzhi Mei, and Kristen W Carlson. "Fiber threshold accommodation as a mechanism of burst and high-frequency spinal cord stimulation". In: Neuromodulation: Technology at the Neural Interface 23.5 (2020), pp. 582-593.

[8] Jeffrey E Arle, Longzhi Mei, Kristen W Carlson, and Jay L Shils. "Highfrequency stimulation of dorsal column axons: potential underlying mechanism of paresthesia-free neuropathic pain relief". In: Neuromodulation: Technology at the Neural Interface 19.4 (2016), pp. 385-397.

[9] Giancarlo Barolat. "Epidural spinal cord stimulation: anatomical and electrical properties of the intraspinal structures relevant to spinal cord stimulation and clinical correlations". In: Neuromodulation: Technology at the Neural Interface 1.2 (1998), pp. 63-71.

[10] Giancarlo Barolat, Sergio Zeme, and Beth Ketcik. "Multifactorial analysis of epidural spinal cord stimulation". In: Stereotactic and functional neurosurgery 56.2 (1991), pp. 77-103.

[11] Bruce P Bean. "The action potential in mammalian central neurons". In: Nature Reviews Neuroscience 8.6 (2007), pp. 451-465.

[12] Damián Bendersky and Claudio Yampolsky. "Is spinal cord stimulation safe? A review of its complications". In: World neurosurgery 82.6 (2014), pp. 1359-1368.

[13] Chad A Bossetti, Merrill J Birdno, and Warren M Grill. "Analysis of the quasi-static approximation for calculating potentials generated by neural stimulation". In: Journal of neural engineering 5.1 (2007), p. 44.

[14] Bruce R Bowman and Donald R McNeal. "Response of single alpha motoneurons to high-frequency pulse trains". In: Stereotactic and Functional Neurosurgery 49.3 (1986), pp. 121-138.

[15] Dirk Bucher and Jean-Marc Goaillard. "Beyond faithful conduction: short-term dynamics, neuromodulation, and long-term regulation of spike propagation in the axon". In: Progress in neurobiology 94.4 (2011), pp. 307-346. 
[16] David Burke, Matthew C Kiernan, and Hugh Bostock. "Excitability of human axons". In: Clinical neurophysiology 112.9 (2001), pp. 1575-1585.

[17] Christopher R Butson, Christopher B Maks, and Cameron C McIntyre. "Sources and effects of electrode impedance during deep brain stimulation". In: Clinical Neurophysiology 117.2 (2006), pp. 447-454.

[18] Christopher R Butson and Cameron C McIntyre. "Current steering to control the volume of tissue activated during deep brain stimulation". In: Brain stimulation 1.1 (2008), pp. 7-15.

[19] Marco Capogrosso, Nikolaus Wenger, Stanisa Raspopovic, Pavel Musienko, Janine Beauparlant, Lorenzo Bassi Luciani, Grégoire Courtine, and Silvestro Micera. "A computational model for epidural electrical stimulation of spinal sensorimotor circuits". In: Journal of Neuroscience 33.49 (2013), pp. 19326-19340.

[20] Jacob Caylor, Rajiv Reddy, Sopyda Yin, Christina Cui, Mingxiong Huang, Charles Huang, Ramesh Rao, Dewleen G Baker, Alan Simmons, Dmitri Souza, et al. "Spinal cord stimulation in chronic pain: evidence and theory for mechanisms of action”. In: Bioelectronic medicine 5.1 (2019), p. 12.

[21] Krishnan Chakravarthy, Michael A Fishman, Xander Zuidema, Corey W Hunter, and Robert Levy. "Mechanism of Action in Burst Spinal Cord Stimulation: Review and Recent Advances". In: Pain Medicine 20.Supplement_1 (2019), S13-S22.

[22] SY Chiu, JM Ritchie, RB Rogart, and D Stagg. "A quantitative description of membrane currents in rabbit myelinated nerve." In: The Journal of physiology 292.1 (1979), pp. 149-166.

[23] B Coburn. "Electrical stimulation of the spinal cord: two-dimensional finite element analysis with particular reference to epidural electrodes". In: Medical and Biological Engineering and Computing 18.5 (1980), pp. 573-584.

[24] Barry Coburn. "A theoretical study of epidural electrical stimulation of the spinal cord-Part II: Effects on long myelinated fibers". In: IEEE transactions on biomedical engineering 11 (1985), pp. 978-986. 
[25] Barry Coburn and Wing Kee Sin. "A theoretical study of epidural electrical stimulation of the spinal cord part I: finite element analysis of stimulus fields". In: IEEE transactions on biomedical engineering 11 (1985), pp. 971-977.

[26] Collaboration for NDT Education. Conductivity and Resistivity Values for Nickel \& Alloys. Available on: http : / / www . mkckorea . com / catalog / conductivity / Sigmamonitor - 6010 / Conductivity_Misc.pdf. 2002.

[27] Nathan D Crosby, John J Janik, and Warren M Grill. "Modulation of activity and conduction in single dorsal column axons by kilohertz-frequency spinal cord stimulation". In: Journal of neurophysiology 117.1 (2017), pp. 136-147.

[28] AS Darling. "Iridium platinum alloys". In: Platinum Metals Review 4.1 (1960), pp. 18-26.

[29] Gavriel David, Barbara Modney, Karen A Scappaticci, John N Barrett, and Ellen F Barrett. "Electrical and morphological factors influencing the depolarizing after-potential in rat and lizard myelinated axons." In: The Journal of Physiology 489.1 (1995), pp. 141-157.

[30] GD Dawson. "The relative excitability and conduction velocity of sensory and motor nerve fibres in man". In: The Journal of physiology 131.2 (1956), pp. 436-451.

[31] Benjamin De Leener, Julien Cohen-Adad, and Samuel Kadoury. "Automatic segmentation of the spinal cord and spinal canal coupled with vertebral labeling". In: IEEE transactions on medical imaging 34.8 (2015), pp. 1705-1718.

[32] Dirk De Ridder, Mark Plazier, Niels Kamerling, Tomas Menovsky, and Sven Vanneste. "Burst spinal cord stimulation for limb and back pain". In: World neurosurgery 80.5 (2013), pp. 642-649.

[33] Dirk De Ridder, Tim Vancamp, and Sven Vanneste. "Fundamentals of burst stimulation of the spinal cord and brain". In: Neuromodulation. Elsevier, 2018, pp. 147-160. 
[34] Marc Dingman. Dorsal root - definition. Neuroscientifically Challenged (online). url: https : / / www . neuroscientificallychallenged . com / glossary / dorsal - root (Accessed September 27, 2019). 2015. (Visited on 09/27/2019).

[35] María Dueñas, Begoña Ojeda, Alejandro Salazar, Juan Antonio Mico, and Inmaculada Failde. "A review of chronic pain impact on patients, their social environment and the health care system". In: Journal of pain research 9 (2016), p. 457.

[36] Jose L Durá, Carmen Solanes, Jose De Andrés, and Javier Saiz. "Computational Study of the Effect of Electrode Polarity on Neural Activation Related to Paresthesia Coverage in Spinal Cord Stimulation Therapy". In: Neuromodulation: Technology at the Neural Interface 22.3 (2019), pp. 269-279.

[37] José L. Durá, Carmen Solanes, Jose De Andrés, and Javier Saiz. "Programming Strategies in Post-Implant Clinical Sessions: Usefulness of Computer Model to Predict the Paresthesia Area Displacement in the Transversal Direction". In: Invited Faculty Abstracts from the International Neuromodulation Society's 14th World Congress. Sidney, Australia, May 2019, e343.

[38] Sam Eldabe, Eric Buchser, and Rui V Duarte. "Complications of spinal cord stimulation and peripheral nerve stimulation techniques: a review of the literature". In: Pain Medicine 17.2 (2016), pp. 325-336.

[39] Lawrence J Epstein and Marco Palmieri. "Managing chronic pain with spinal cord stimulation". In: Mount Sinai Journal of Medicine: A Journal of Translational and Personalized Medicine 79.1 (2012), pp. 123-132.

[40] HKP Feirabend, H Choufoer, S Ploeger, J Holsheimer, and JD Van Gool. "Morphometry of human superficial dorsal and dorsolateral column fibres: significance to spinal cord stimulation". In: Brain 125.5 (2002), pp. 1137-1149. 
[41] Johanna C Forst, Derek C Blok, Julia P Slopsema, John M Boss, Lane A Heyboer, Carson M Tobias, and Katharine H Polasek. "Surface electrical stimulation to evoke referred sensation." In: Journal of Rehabilitation Research \& Development 52.4 (2015).

[42] Léo Fradet, Pierre-Jean Arnoux, Jean-Philippe Ranjeva, Yvan Petit, and Virginie Callot. "Morphometrics of the entire human spinal cord and spinal canal measured from in vivo high-resolution anatomical magnetic resonance imaging”. In: Spine 39.4 (2014), E262-E269.

[43] Ken Steffen Frahm, Kristian Hennings, Louis Vera-Portocarrero, Paul W Wacnik, and Carsten Dahl Mørch. "Nerve fiber activation during peripheral nerve field stimulation: importance of electrode orientation and estimation of area of paresthesia". In: Neuromodulation: Technology at the Neural Interface 19.3 (2016), pp. 311-318.

[44] B Frankenhaeuser and AF Huxley. "The action potential in the myelinated nerve fibre of Xenopus laevis as computed on the basis of voltage clamp data". In: The Journal of Physiology 171.2 (1964), pp. 302-315.

[45] Camelia Gabriel, Azadeh Peyman, and Edwin H Grant. "Electrical conductivity of tissue at frequencies below $1 \mathrm{MHz}$ ". In: Physics in medicine \& biology 54.16 (2009), p. 4863.

[46] Jessica L Gaines, Kathleen E Finn, Julia P Slopsema, Lane A Heyboer, and Katharine H Polasek. "A model of motor and sensory axon activation in the median nerve using surface electrical stimulation". In: Journal of computational neuroscience 45.1 (2018), pp. 29-43.

[47] Leslie A Geddes and Lee E Baker. "The specific resistance of biological material-a compendium of data for the biomedical engineer and physiologist". In: Medical and biological engineering 5.3 (1967), pp. 271-293.

[48] Assaf T Gordon, Sheng Ping Zou, Yong Kim, and Christopher Gharibo. "Challenges to setting spinal cord stimulator parameters during intraoperative testing: Factors affecting coverage of low back and leg pain". In: Neuromodulation: Technology at the Neural Interface 10.2 (2007), pp. 133-141. 
[49] Warren M Grill and Bryan Howell. Systems and methods for model-based optimization of spinal cord stimulation electrodes and devices. US Patent 10,096,386. Oct. 2018.

[50] Yun Guan. "Spinal cord stimulation: neurophysiological and neurochemical mechanisms of action". In: Current pain and headache reports 16.3 (2012), pp. 217-225.

[51] Bradley Hershey, CA Valencia, and Thomas L Yearwood. "Pulse width programming in spinal cord stimulation: a clinical study". In: Pain Physician 13 (2010), pp. 321-335.

[52] Alan L Hodgkin and Andrew F Huxley. "A quantitative description of membrane current and its application to conduction and excitation in nerve". In: The Journal of physiology 117.4 (1952), pp. 500-544.

[53] J Holsheimer, JA Den Boer, JJ Struijk, and AR Rozeboom. "MR assessment of the normal position of the spinal cord in the spinal canal." In: American journal of neuroradiology 15.5 (1994), pp. 951-959.

[54] Jan Holsheimer. Does dual lead stimulation favor stimulation of the axial lower back? 2000.

[55] Jan Holsheimer. "Which neuronal elements are activated directly by spinal cord stimulation". In: Neuromodulation: Technology at the Neural Interface 5.1 (2002), pp. 25-31.

[56] Jan Holsheimer and Jan R Buitenweg. "Bioelectrical mechanisms in spinal cord stimulation". In: Neuromodulation: Technology at the Neural Interface 18.3 (2015), pp. 161-170.

[57] Jan Holsheimer, Yasin N Khan, Shariq S Raza, and Elizabeth A Khan. "Effects of electrode positioning on perception threshold and paresthesia coverage in spinal cord stimulation". In: Neuromodulation: Technology at the Neural Interface 10.1 (2007), pp. 34-41.

[58] Jan Holsheimer, Johannes J Struijk, and Niels Roelof Tas. "Effects of electrode geometry and combination on nerve fibre selectivity in spinal cord stimulation". In: Medical and Biological Engineering and Computing 33.5 (1995), pp. 676-682. 
[59] Jan Holsheimer, Johannes J Struijk, and Wilbert A Wesselink. "Effects of electrode configuration and geometry on fiber preference in spinal cord stimulation". In: Proceedings of 18th Annual International Conference of the IEEE Engineering in Medicine and Biology Society. Vol. 1. IEEE. 1996, pp. 343-344.

[60] Jan Holsheimer and Wilbert A Wesselink. "Effect of anode-cathode configuration on paresthesia coverage in spinal cord stimulation". In: Neurosurgery 41.3 (1997), pp. 654-660.

[61] Bryan Howell, Shivanand P Lad, and Warren M Grill. "Evaluation of intradural stimulation efficiency and selectivity in a computational model of spinal cord stimulation". In: PloS one 9.12 (2014), e114938.

[62] James Howells, Louise Trevillion, Hugh Bostock, and David Burke. "The voltage dependence of Ih in human myelinated axons". In: The Journal of physiology 590.7 (2012), pp. 1625-1640.

[63] Qiujun Huang, Hiroyuki Oya, Oliver E Flouty, Chandan G Reddy, Matthew A Howard, George T Gillies, and Marcel Utz. "Comparison of spinal cord stimulation profiles from intra-and extradural electrode arrangements by finite element modelling". In: Medical \& biological engineering \& computing 52.6 (2014), pp. 531-538.

[64] Eugene M Izhikevich, Niraj S Desai, Elisabeth C Walcott, and Frank C Hoppensteadt. "Bursts as a unit of neural information: selective communication via resonance". In: Trends in neurosciences 26.3 (2003), pp. 161167.

[65] Melanie P Jensen and Robert M Brownstone. "Mechanisms of spinal cord stimulation for the treatment of pain: Still in the dark after 50 years". In: European Journal of Pain 23.4 (2019), pp. 652-659.

[66] Young Hoon Jeon. "Spinal cord stimulation in pain management: a review". In: The Korean journal of pain 25.3 (2012), p. 143.

[67] Elbert A Joosten and Glenn Franken. "Spinal cord stimulation in chronic neuropathic pain: mechanisms of action, new locations, new paradigms". In: Pain 161.1 (2020), S104. 
[68] Adnan Al-Kaisy, Stefano Palmisani, Thomas E Smith, Roy Carganillo, Russell Houghton, David Pang, William Burgoyne, Khai Lam, and Jonathan Lucas. "Long-term improvements in chronic axial low back pain patients without previous spinal surgery: a cohort analysis of 10-kHz highfrequency spinal cord stimulation over 36 months". In: Pain Medicine 19.6 (2018), pp. 1219-1226.

[69] Leonardo Kapural, Cong Yu, Matthew W Doust, Bradford E Gliner, Ricardo Vallejo, B Todd Sitzman, Kasra Amirdelfan, Donna M Morgan, Lora L Brown, Thomas L Yearwood, et al. "Novel 10-kHz highfrequency therapy (HF10 therapy) is superior to traditional low-frequency spinal cord stimulation for the treatment of chronic back and leg pain: the SENZA-RCT randomized controlled trial". In: Anesthesiology 123.4 (2015), pp. 851-860.

[70] Niranjan Khadka, Xijie Liu, Hans Zander, Jaiti Swami, Evan Rogers, Scott F Lempka, and Marom Bikson. "Realistic anatomically detailed open-source spinal cord stimulation (RADO-SCS) model". In: Journal of neural engineering 17.2 (2020), p. 026033.

[71] Kevin L Kilgore and Niloy Bhadra. "Reversible nerve conduction block using kilohertz frequency alternating current". In: Neuromodulation: Technology at the Neural Interface 17.3 (2014), pp. 242-255.

[72] Chong H Kim, Adam W Green, Drew E Rodgers, Mohammed A Issa, and Monica A Ata. "Importance of axial migration of spinal cord stimulation trial leads with position". In: Pain physician 16.6 (2013), E763-E768.

[73] J-C Kleiber, B Marlier, M Bannwarth, E Theret, P Peruzzi, and F Litre. "Is spinal cord stimulation safe? A review of 13 years of implantations and complications". In: Revue neurologique 172.11 (2016), pp. 689-695.

[74] Elliot Krames. "Spinal cord stimulation: indications, mechanism of action, and efficacy". In: Current review of pain 3.6 (1999), pp. 419-426.

[75] RP Kusy and DT Turner. "Electrical conductivity of a polyurethane elastomer containing segregated particles of nickel". In: Journal of Applied Polymer Science 17.5 (1973), pp. 1631-1633. 
[76] Josef Ladenbauer, Karen Minassian, Ursula S Hofstoetter, Milan R Dimitrijevic, and Frank Rattay. "Stimulation of the human lumbar spinal cord with implanted and surface electrodes: a computer simulation study". In: IEEE Transactions on Neural Systems and Rehabilitation Engineering 18.6 (2010), pp. 637-645.

[77] Anthony W Lee and Julie G Pilitsis. "Spinal cord stimulation: indications and outcomes". In: Neurosurgical focus 21.6 (2006), pp. 1-6.

[78] Dongchul Lee, Brad Hershey, Kerry Bradley, and Thomas Yearwood. "Predicted effects of pulse width programming in spinal cord stimulation: a mathematical modeling study". In: Medical \& biological engineering \& computing 49.7 (2011), p. 765.

[79] Scott F Lempka, Cameron C McIntyre, Kevin L Kilgore, and Andre G Machado. "Computational analysis of kilohertz frequency spinal cord stimulation for chronic pain management". In: Anesthesiology: The Journal of the American Society of Anesthesiologists 122.6 (2015), pp. 13621376.

[80] Scott F Lempka and Parag G Patil. "Innovations in spinal cord stimulation for pain". In: Current opinion in biomedical engineering 8 (2018), pp. 5160 .

[81] Scott F Lempka, Hans J Zander, Carlos J Anaya, Alexandria Wyant, John G Ozinga IV, and Andre G Machado. "Patient-Specific Analysis of Neural Activation During Spinal Cord Stimulation for Pain". In: Neuromodulation: Technology at the Neural Interface (2019).

[82] Scott F Lempka, Hans J Zander, Carlos J Anaya, Alexandria Wyant, John G Ozinga IV, and Andre G Machado. "Patient-specific analysis of neural activation during spinal cord stimulation for pain". In: Neuromodulation: Technology at the Neural Interface 23.5 (2020), pp. 572-581.

[83] Robert M Levy. "Anatomic considerations for spinal cord stimulation". In: Neuromodulation: Technology at the Neural Interface 17 (2014), pp. 2-11. 
[84] Jaquette Liljencrantz and Håkan Olausson. "Tactile C fibers and their contributions to pleasant sensations and to tactile allodynia". In: Frontiers in behavioral neuroscience 8 (2014), p. 37.

[85] Cindy S-Y Lin, Ilona Mogyoros, and David Burke. "Recovery of excitability of cutaneous afferents in the median and sural nerves following activity". In: Muscle \& Nerve: Official Journal of the American Association of Electrodiagnostic Medicine 23.5 (2000), pp. 763-770.

[86] Cindy SY Lin, Ilona Mogyoros, Satoshi Kuwabara, Cecilia CappelenSmith, and David Burke. "Accommodation to depolarizing and hyperpolarizing currents in cutaneous afferents of the human median and sural nerves". In: The Journal of physiology 529.Pt 2 (2000), p. 483.

[87] Bengt Linderoth and Robert D Foreman. "Conventional and novel spinal stimulation algorithms: hypothetical mechanisms of action and comments on outcomes". In: Neuromodulation: Technology at the Neural Interface 20.6 (2017), pp. 525-533.

[88] Hailong Liu, James R Roppolo, William C de Groat, and Changfeng Tai. "The role of slow potassium current in nerve conduction block induced by high-frequency biphasic electrical current". In: IEEE Transactions on Biomedical Engineering 56.1 (2008), pp. 137-146.

[89] Mufti Mahmud and Stefano Vassanelli. "Differential modulation of excitatory and inhibitory neurons during periodic stimulation". In: Frontiers in neuroscience 10 (2016), p. 62.

[90] Mitsunori Makino, Kentaro Mimatsu, Haruhiko Saito, Nobuo Konishi, and Yoshio Hashizume. "Morphometric study of myelinated fibers in human cervical spinal cord white matter". In: Spine 21.9 (1996), pp. 10101016.

[91] Preet GS Makker, José M Matamala, Susanna B Park, Justin G Lees, Matthew C Kiernan, David Burke, Gila Moalem-Taylor, and James Howells. "A unified model of the excitability of mouse sensory and motor axons". In: Journal of the Peripheral Nervous System 23.3 (2018), pp. 159173. 
[92] Ljubomir Manola, Jan Holsheimer, and Peter Veltink. "Technical performance of percutaneous leads for spinal cord stimulation: a modeling study". In: Neuromodulation: Technology at the Neural Interface 8.2 (2005), pp. 88-99.

[93] Ljubomir Manola, Jan Holsheimer, Peter H Veltink, Kerry Bradley, and David Peterson. "Theoretical investigation into longitudinal cathodal field steering in spinal cord stimulation". In: Neuromodulation: Technology at the Neural Interface 10.2 (2007), pp. 120-132.

[94] Hannah McCann, Giampaolo Pisano, and Leandro Beltrachini. "Variation in reported human head tissue electrical conductivity values". In: Brain topography 32.5 (2019), pp. 825-858.

[95] Cameron C McIntyre, Susumu Mori, David L Sherman, Nitish V Thakor, and Jerrold L Vitek. "Electric field and stimulating influence generated by deep brain stimulation of the subthalamic nucleus". In: Clinical neurophysiology 115.3 (2004), pp. 589-595.

[96] Cameron C McIntyre, Andrew G Richardson, and Warren M Grill. "Modeling the excitability of mammalian nerve fibers: influence of afterpotentials on the recovery cycle". In: Journal of neurophysiology 87.2 (2002), pp. 995-1006.

[97] Donald R McNeal. "Analysis of a model for excitation of myelinated nerve". In: IEEE Transactions on Biomedical Engineering 4 (1976), pp. 329-337.

[98] Medtronic. Vectris SureScan MRI 1x8 Compact. Implant manual. Available on: http: / / manuals . medtronic. com/ content / dam / emanuals/neuro/M939859A009A_view.pdf. Minneapolis, MN 55432-5604, USA, 2013. URL: http : / / manuals . medtronic . com / content / dam / emanuals / neuro / CONTRIB $\div$ 7B $\%$ 5C_ ㄱD220954.pdf.

[99] Medtronic. Vectris SureScan MRI 1x8 Compact. Implant manual. Available on: http: / / manuals . medtronic.com/ content / dam / emanuals/neuro/CONTRIB_220954.pdf. 2013. 
[100] Ronald Melzack, Patrick D Wall, et al. "Pain mechanisms: a new theory". In: Science 150.3699 (1965), pp. 971-979.

[101] Michelson Medical. Spinal Cord - Anatomy | Michelson Medical Research Foundation. url: https://michelsonmedical.org/2014/11/ 21/spinal-cord-injury-critical-research-pva/pvaspinal-cord-1-anatomy/. Accessed September 27, 2019. 2014.

[102] Damijan Miklavčič, Nataša Pavšelj, and Francis X Hart. "Electric properties of tissues". In: Wiley encyclopedia of biomedical engineering (2006).

[103] Jonathan P Miller, Sam Eldabe, Eric Buchser, Lisa M Johanek, Yun Guan, and Bengt Linderoth. "Parameters of spinal cord stimulation and their role in electrical charge delivery: a review". In: Neuromodulation: Technology at the Neural Interface 19.4 (2016), pp. 373-384.

[104] Xiaoyi Min, Alexander R Kent, Stuart P Rosenberg, and Timothy A Fayram. "Modeling dermatome selectivity of single-and multiple-current source spinal cord stimulation systems". In: 2014 36th Annual International Conference of the IEEE Engineering in Medicine and Biology Society. IEEE. 2014, pp. 6246-6249.

[105] Ilona Mogyoros, Matthew C Kiernan, and David Burke. "Strengthduration properties of human peripheral nerve". In: Brain 119.2 (1996), pp. 439-447.

[106] Gabriela Molnar and Giancarlo Barolat. "Principles of cord activation during spinal cord stimulation". In: Neuromodulation: Technology at the Neural Interface 17 (2014), pp. 12-21.

[107] G Morita, YX Tu, Y Okajima, S Honda, and Y Tomita. "Estimation of the conduction velocity distribution of human sensory nerve fibers". In: Journal of Electromyography and kinesiology 12.1 (2002), pp. 37-43.

[108] Musculoskeletal Key. Spinal Cord and Related Injuries. url: https : / / musculoskeletalkey . com / spinal - cord - and related-injuries/. Accessed September 27, 2019. 2016. (Visited on 09/27/2019). 
[109] Richard B North, David H Kidd, John Olin, Jeffrey M Sieracki, and Marc Boulay. "Spinal cord stimulation with interleaved pulses: a randomized, controlled trial". In: Neuromodulation: Technology at the Neural Interface 10.4 (2007), pp. 349-357.

[110] LG Nowak and J Bullier. "Axons, but not cell bodies, are activated by electrical stimulation in cortical gray matter I. Evidence from chronaxie measurements". In: Experimental brain research 118.4 (1998), pp. 477488.

[111] John C Oakley and Joshua P Prager. "Spinal cord stimulation: mechanisms of action”. In: Spine 27.22 (2002), pp. 2574-2583.

[112] Oxford Functional Neurosurgery. SCS-Functional Neurosurgery. url: http: / / www. oxfordfunctionalneurosurgery.org/scs . shtml. Accessed September 25, 2019. 2015. (Visited on 09/25/2019).

[113] John L Parker, Dean M Karantonis, Peter S Single, Milan Obradovic, and Michael J Cousins. "Compound action potentials recorded in the human spinal cord during neurostimulation for pain relief". In: Pain 153.3 (2012), pp. 593-601.

[114] Jason E Pope, Steven Falowski, and Tim R Deer. "Advanced waveforms and frequency with spinal cord stimulation: burst and high-frequency energy delivery". In: Expert review of medical devices 12.4 (2015), pp. 431437.

[115] James B Ranck Jr. "Which elements are excited in electrical stimulation of mammalian central nervous system: a review". In: Brain research 98.3 (1975), pp. 417-440.

[116] "Overview of Finite Element Method". In: The Finite Element Method in Engineering (Fourth Edition). Ed. by Singiresu S. Rao. Fourth Edition. Burlington: Butterworth-Heinemann, 2005, pp. 659-663. ISBN: 978-07506-7828-5. URL: https : / / doi . org/10 . 1016/B978$0750678-5 / 50025-1$. 
[117] Frank Rattay. "Current distance relations for fiber stimulation with pointsources". In: IEEE Transactions on Biomedical Engineering 55.3 (2008), pp. 1122-1127.

[118] Kim J Reid, Julie Harker, Malgorzata M Bala, Carla Truyers, Eliane Kellen, Geertruida Elsiena Bekkering, and Jos Kleijnen. "Epidemiology of chronic non-cancer pain in Europe: narrative review of prevalence, pain treatments and pain impact". In: Current medical research and opinion 27.2 (2011), pp. 449-462.

[119] MA Reina, CD Franco, A López, JA Dé Andrés, and Adrien Van Zundert. "Clinical implications of epidural fat in the spinal canal. A scanning electron microscopic study". In: Acta anaesthesiologica belgica 60.1 (2009), p. 7.

[120] MA Reina, A Lopez-Garcia, M Dittmann, and JA De Andrés. "Structural analysis of the thickness of human dura mater with scanning electron microscopy". In: Revista espanola de anestesiologia y reanimacion 43.4 (1996), pp. 135-137.

[121] AG Richardson, CC McIntyre, and WM Grill. "Modelling the effects of electric fields on nerve fibres: influence of the myelin sheath". In: Medical and Biological Engineering and Computing 38.4 (2000), pp. 438-446.

[122] JT Rubinstein. "Analytical theory for extracellular electrical stimulation of nerve with focal electrodes. II. Passive myelinated axon". In: Biophysical journal 60.3 (1991), pp. 538-555.

[123] Marc Russo and Jean-Pierre Van Buyten. "10-kHz high-frequency SCS therapy: a clinical summary". In: Pain Medicine 16.5 (2015), pp. 934942.

[124] Saboohi Saeed and M Akram. "Impact of anthropometric measures on sural nerve conduction in healthy subjects". In: J Ayub Med Coll Abbottabad 20.4 (2008), p. 112.

[125] Vishwanath Sankarasubramanian. Model-based stimulation optimization for chronic pain suppression using percutaneous and surgical. 2013. 
[126] G Schalow, GA Zäch, and R Warzok. "Classification of human peripheral nerve fibre groups by conduction velocity and nerve fibre diameter is preserved following spinal cord lesion". In: Journal of the autonomic nervous system 52.2-3 (1995), pp. 125-150.

[127] Jürgen R Schwarz, Gordon Reid, and Hugh Bostock. "Action potentials and membrane currents in the human node of Ranvier". In: Pflügers Archiv 430.2 (1995), pp. 283-292.

[128] C Norman Shealy, J Thomas Mortimer, and James B Reswick. "Electrical inhibition of pain by stimulation of the dorsal columns: preliminary clinical report”. In: Anesthesia \& Analgesia 46.4 (1967), pp. 489-491.

[129] K Shimoji, M Matsuki, H Shimizu, T Iwane, R Takahashi, M Maruyama, and K Masuko. "Low-frequency, weak extradural stimulation in the management of intractable pain". In: BJA: British Journal of Anaesthesia 49.11 (1977), pp. 1081-1086.

[130] Eellan Sivanesan, Dermot P Maher, Srinivasa N Raja, Bengt Linderoth, and Yun Guan. "Supraspinal mechanisms of spinal cord stimulation for modulation of pain". In: Anesthesiology (2018), pp. 1-1.

[131] H Smits, M Van Kleef, and EA Joosten. "Spinal cord stimulation of dorsal columns in a rat model of neuropathic pain: evidence for a segmental spinal mechanism of pain relief”. In: Pain 153.1 (2012), pp. 177-183.

[132] C Solanes, JL Durá, MA Canós, J De Andrés, L Martí-Bonmatí, and J Saiz. "Predicción de la activación neuronal en estimulación tónica en la terapia de EME: uso de modelos 3D de médula espinal personalizados al paciente frente a modelos generalizados". In: XXXVIII Congreso Anual de la Sociedad Espa nola de Ingeniería Biomédica. Valladolid, Spain, Nov. 2020, pp. 306-309.

[133] C Solanes, JL Durá, J De Andrés, and J Saiz. "A human A $\beta$ sensory nerve fiber model for accurate neural activation prediction in tonic spinal cord stimulation modeling". In: 15th International Conference in Advanced Biomedical Engineering and Biomechanics Conference Proceedings. Madrid, Spain, Mar. 2021, p. 815. 
[134] C Solanes, JL Durá, J De Andrés, and J Saiz. "Effect of electrode polarity on paresthesia coverage in spinal cord stimulation". In: World Congress on Medical Physics \& Biomedical Engineering Book of Abstracts. Prague, Czech Republic, June 2018, p. 389.

[135] C Solanes, JL Durá, J De Andrés, and J Saiz. "Estudio del efecto de la posición, polaridad y número de electrodos sobre el área de parestesia en la terapia de EME mediante el uso de un modelo 3D de médula espinal". In: XXXV Congreso Anual de la Sociedad Espa nola de Ingeniería Biomédica. Bilbao, Spain, 29th November-1st December 2017, pp. 353356.

[136] Carmen Solanes, Jose L Durá, M Ángeles Canós, Jose De Andrés, Luis Martí-Bonmatí, and Javier Saiz. "3D patient-specific spinal cord computational model for SCS management: potential clinical applications". In: Journal of Neural Engineering 18.3 (2021), p. 036017.

[137] Carmen Solanes Galbis. Diseño, desarrollo y validación de un software para la simulación del efecto del campo eléctrico sobre la activación neuronal. 2016.

[138] Martin J Stebbing, Sebastian Eschenfelder, Heinz-Joachim Häbler, M Carmen Acosta, Wilfrid Jänig, and Elspeth M McLachlan. "Changes in the action potential in sensory neurones after peripheral axotomy in vivo". In: Neuroreport 10.2 (1999), pp. 201-206.

[139] Johannes J Struijk, Jan Holsheimer, Giancarlo Barolat, Jiping He, and Herman BK Boom. "Paresthesia thresholds in spinal cord stimulation: a comparison of theoretical results with clinical data". In: IEEE Transactions on Rehabilitation Engineering 1.2 (1993), pp. 101-108.

[140] Johannes J Struijk, Jan Holsheimer, and Herman BK Boom. "Excitation of dorsal root fibers in spinal cord stimulation: a theoretical study". In: IEEE transactions on biomedical engineering 40.7 (1993), pp. 632-639.

[141] Johannes J Struijk, Jan Holsheimer, Gerlof G van der Heide, and Herman BK Boom. "Recruitment of dorsal column fibers in spinal cord stimulation: influence of collateral branching". In: IEEE Transactions on Biomedical Engineering 39.9 (1992), pp. 903-912. 
[142] Johannes J Struijk, Jan Holsheimer, Benno K van Veen, and Herman BK Boom. "Epidural spinal cord stimulation: calculation of field potentials with special reference to dorsal column nerve fibers". In: IEEE transactions on biomedical engineering 38.1 (1991), pp. 104-110.

[143] JD Sweeney, JT Mortimer, and D Durand. "Modeling of mammalian myelinated nerve for functional neuromuscular stimulation". In: IEEE 9th Annual Conference of the Engineering in Medicine and Biology Society. Vol. 3. 1987, pp. 1577-1578.

[144] W Tackmann and HJ Lehmann. "Refractory period in human sensory nerve fibres". In: European neurology 12.5-6 (1974), pp. 277-292.

[145] Alexander Taghva, Edward Karst, and Paul Underwood. "Clinical paresthesia atlas illustrates likelihood of coverage based on spinal cord stimulator electrode location". In: Neuromodulation: Technology at the Neural Interface 20.6 (2017), pp. 582-588.

[146] Rurong Tang, Marte Martinez, Melanie Goodman-Keiser, Jay P Farber, Chao Qin, and Robert D Foreman. "Comparison of burst and tonic spinal cord stimulation on spinal neural processing in an animal model". In: $\mathrm{Neu}$ romodulation: Technology at the Neural Interface 17.2 (2014), pp. 143151.

[147] T Tateno, A Harsch, and HPC Robinson. "Threshold firing frequencycurrent relationships of neurons in rat somatosensory cortex: type 1 and type 2 dynamics". In: Journal of neurophysiology 92.4 (2004), pp. 22832294.

[148] Jeffrey Tiede, Lora Brown, Gennady Gekht, Ricardo Vallejo, Thomas Yearwood, and Donna Morgan. "Novel spinal cord stimulation parameters in patients with predominant back pain". In: Neuromodulation: Technology at the Neural Interface 16.4 (2013), pp. 370-375.

[149] A Torralba, A Miquel, and J Darba. "Situación actual del dolor crónico en España: iniciativa" Pain Proposal"', In: Revista de la Sociedad Española del Dolor 21.1 (2014), pp. 16-22. 
[150] Rolf-Detlef Treede, Winfried Rief, Antonia Barke, Qasim Aziz, Michael I Bennett, Rafael Benoliel, Milton Cohen, Stefan Evers, Nanna B Finnerup, Michael B First, et al. "A classification of chronic pain for ICD-11". In: Pain 156.6 (2015), p. 1003.

[151] Ricardo Vallejo, Kerry Bradley, and Leonardo Kapural. "Spinal cord stimulation in chronic pain". In: Spine 42.1 (2017), S53-S60.

[152] O Van Hecke, N Torrance, and BH Smith. "Chronic pain epidemiology and its clinical relevance". In: British journal of anaesthesia 111.1 (2013), pp. 13-18.

[153] Benno K van Veen, Ronald LLA Schellens, Dick F Stegeman, Ruurd Schoonhoven, and Anneke AWM Gabreëls-Festen. "Conduction velocity distributions compared to fiber size distributions in normal human sural nerve". In: Muscle \& Nerve: Official Journal of the American Association of Electrodiagnostic Medicine 18.10 (1995), pp. 1121-1127.

[154] Elias Veizi, Salim M Hayek, James North, T Brent Chafin, Thomas L Yearwood, Louis Raso, Robert Frey, Kevin Cairns, Anthony Berg, John Brendel, et al. "Spinal cord stimulation (SCS) with anatomically guided (3D) neural targeting shows superior chronic axial low back pain relief compared to traditional SCS-LUMINA study". In: Pain Medicine 18.8 (2017), pp. 1534-1548.

[155] Paul Verrills, Chantelle Sinclair, and Adele Barnard. "A review of spinal cord stimulation systems for chronic pain”. In: Journal of pain research 9 (2016), p. 481.

[156] Stephanus Viljoen, Brian D Dalm, Chandan G Reddy, Saul Wilson, Charles Smittkamp, George T Gillies, and Matthew A Howard III. "Optimization of intradural spinal cord stimulator designs via analysis of thoracic spine imaging data". In: Journal of Medical and Biological Engineering 33.2 (2013), pp. 193-198.

[157] Viva Differences. Myelinated Vs. Unmyelinated Neurons (Nerve Fiber): Basic Differences \& Examples. url: https: / / vivadifferences .

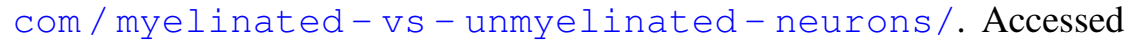
October 1, 2019. 2019. (Visited on 10/01/2019). 
[158] Eduardo N Warman, Warren M Grill, and Dominique Durand. "Modeling the effects of electric fields on nerve fibers: determination of excitation thresholds". In: IEEE Transactions on Biomedical Engineering 39.12 (1992), pp. 1244-1254.

[159] WA Wesselink, J Holsheimer, and HBK Boom. "A model of the electrical behaviour of myelinated sensory nerve fibres based on human data". In: Medical \& biological engineering \& computing 37.2 (1999), pp. 228-235.

[160] Wilbert A Wesselink, Jan Holsheimer, Bart Nuttin, Herman BK Boom, Gary W King, Jan M Gybels, and Paul de Sutter. "Estimation of fiber diameters in the spinal dorsal columns from clinical data". In: IEEE transactions on biomedical engineering 45.11 (1998), pp. 1355-1362.

[161] JL Westbrook, SA Renowden, and LES Carrie. "Study of the anatomy of the extradural region using magnetic resonance imaging". In: British Journal of Anaesthesia 71.4 (1993), pp. 495-498.

[162] Hans Zander, Robert Graham, Carlos J Anaya, and Scott Lempka. "Anatomical and technical factors affecting the neural response to epidural spinal cord stimulation". In: Journal of Neural Engineering (2020).

[163] Kaihua Zhu, Liming Li, Xuyong Wei, and Xiaohong Sui. "A 3D computational model of transcutaneous electrical nerve stimulation for estimating $\mathrm{A} \beta$ tactile nerve fiber excitability". In: Frontiers in neuroscience 11 (2017), p. 250. 
“Lograr aquello que has soñado te hace feliz, pero sobre todo, te hace feliz recordar el esfuerzo empleado para lograrlo."

"Achieving what you dreamed of makes you happy, but mostly, it makes you happy to remember the effort used to achieve it."

Rafa Nadal 
